\title{
Assessment of genetic variation as a predictor of smoking cessation success : a promising preventive and intervention tool?
}

Citation for published version (APA):

Quaak, M. (2012). Assessment of genetic variation as a predictor of smoking cessation success : a promising preventive and intervention tool? [Doctoral Thesis, Maastricht University]. Maastricht University. https://doi.org/10.26481/dis.20120419mq

Document status and date:

Published: 01/01/2012

DOI:

10.26481/dis.20120419mq

Document Version:

Publisher's PDF, also known as Version of record

\section{Please check the document version of this publication:}

- A submitted manuscript is the version of the article upon submission and before peer-review. There can be important differences between the submitted version and the official published version of record.

People interested in the research are advised to contact the author for the final version of the publication, or visit the DOI to the publisher's website.

- The final author version and the galley proof are versions of the publication after peer review.

- The final published version features the final layout of the paper including the volume, issue and page numbers.

Link to publication

\footnotetext{
General rights rights.

- You may freely distribute the URL identifying the publication in the public portal. please follow below link for the End User Agreement:

www.umlib.nl/taverne-license

Take down policy

If you believe that this document breaches copyright please contact us at:

repository@maastrichtuniversity.nl

providing details and we will investigate your claim.
}

Copyright and moral rights for the publications made accessible in the public portal are retained by the authors and/or other copyright owners and it is a condition of accessing publications that users recognise and abide by the legal requirements associated with these

- Users may download and print one copy of any publication from the public portal for the purpose of private study or research.

- You may not further distribute the material or use it for any profit-making activity or commercial gain

If the publication is distributed under the terms of Article $25 \mathrm{fa}$ of the Dutch Copyright Act, indicated by the "Taverne" license above, 


\section{Assessment of genetic variation as a predictor of smoking cessation success.}

A promising preventive and intervention tool?

Marieke Quaak 
(C) Marieke Quaak, Maastricht 2012

ISBN: 978-90-5681-383-3

Coverdesign: Niels Zwirs

Lay-out: Marieke Quaak

Production: Océ Business Services, Maastricht

The research presented in this thesis was conducted at the School for Public Health and Primary Care (CAPHRI), Department of General Practice, and the School for Nutrition, Toxicology and Metabolism (NUTRIM), Department of Toxicology (formerly Health Risk Analysis and Toxicology), of Maastricht University. CAPHRI participates in the Netherlands School of Primary Care Research (CaRe). CAPHRI was classified as 'excellent' by the external evaluation committee of leading international experts that reviewed CAPHRI in December 2010. NUTRIM participates in the Graduate School VLAG (Food Technology, Agrobiotechnology, Nutrition, and Health Sciences), accredited by the Royal Netherlands Academy of Arts and Sciences (KNAW).

Financial support by Sequenom ${ }^{\circledR} \mathrm{GmBH}$ for the printing of this thesis is gratefully acknowledged.

\section{SEQUENOM}




\section{Assessment of genetic variation as a predictor of smoking cessation success.}

A promising preventive and intervention tool?

\section{PROEFSCHRIFT}

ter verkrijging van de graad van doctor aan de Universiteit Maastricht, op gezag van Rector Magnificus, Prof. Mr. G.P.M.F. Mols, volgens het besluit van het College van Decanen, in het openbaar te verdedigen op donderdag 19 april 2012 om 14.00 uur

door

Marieke Quaak 


\section{Promotores}

Prof. Dr. C.P. van Schayck

Prof. Dr. F.J. van Schooten

\section{Beoordelingscommissie:}

Prof. Dr. J.P.M. Geraedts (voorzitter)

Dr. D. Kotz

Prof. Dr. M.P. Zeegers (University of Birmingham, UK) 
CONTENTS

$\begin{array}{lll}\text { Chapter } 1 & \text { General Introduction } & 6\end{array}$

Chapter $2 \quad$ Candidate genes for the variation in smoking behaviour $\quad 30$

Chapter $3 \quad$ Multiple genetic variants influence nicotine dependence 44

Chapter 4 Different aspects of nicotine dependence are influenced by $\quad \mathbf{6 2}$ genetic variants in distinct pathways

Chapter $5 \quad$ Candidate genes influencing the efficacy of smoking cessation $\quad 76$ therapy

Chapter $6 \quad$ Genetic variants in the serotonin transporter influence the $\quad 98$ efficacy of bupropion and nortriptyline in smoking cessation

Chapter 7 Influence of genetic variants in multiple pathways on antidepressant therapy

Chapter 8 Knowledge, attitudes, and preferences regarding genetic 134 testing for smoking cessation. A cross-sectional survey among Dutch smokers.

Chapter 9 GPs' knowledge, attitudes and preferences regarding genetic 150 testing for smoking.

Chapter 10 General discussion

Summary

Nederlandse samenvatting

Supplementary Data 



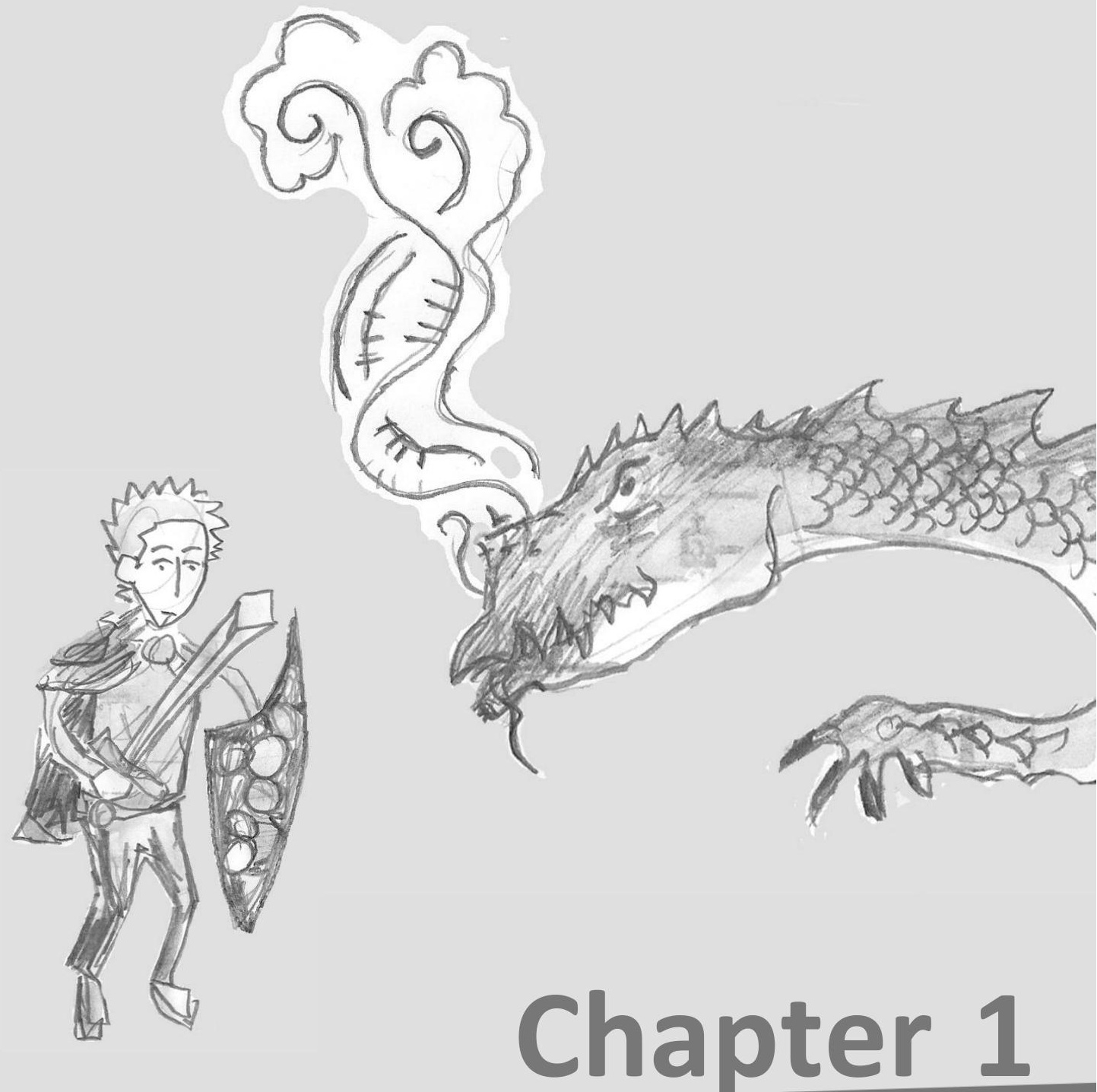

GENERAL INTRODUCTION 


\section{SMOKING PREVALENCE}

Although the risk of smoking is well documented, tobacco smoking continues to be the largest preventable cause of disease and premature death throughout the world.

It is estimated that there are currently still over 1.5 billion smokers world-wide and this is expected to reach about 2 billion by 2025, eventhough numbers are leveling or even decreasing in some countries [1-4]. The number of smokers will increase mainly due to an increase in the (adult) population [1-4]. By 2030 there will be at least 2 billion people more in the world. Therefore, the absolute number of smokers will increase, even if the prevalence rates decrease. Furthermore, consumption in the low- and middle-income countries and among teenagers and women in highincome countries is increasing [1-4]. On the other hand, smoking prevalence among men in the high-income countries is declining [1-4]. Currently, about $50 \%$ of men and $9 \%$ of women in developing countries smoke, as compared with $35 \%$ of men and $22 \%$ of women in developed countries $[1,2]$.

It has been proposed that the current smoking prevalence in different regions of the world can be divided into four stages [5]:

- Stage I:

This stage is characterized by a low prevalence of smoking. Less than $15 \%$ of the men and a considerably lower percentage of women smoke. Smoking-related morbidity and mortality is not yet evident. Many countries in sub-Saharan Africa fall into this category.

- Stage II:

The number of male smokers increases rapidly until it reaches a peak of about $50-80 \%$ and there is an increasing percentage of female smokers. This category includes countries such as China and Japan and some countries in northern Africa and Latin-America.

\section{- Stage III:}

In this stage there is a noticeable decrease in smoking prevalence among men to about $40 \%$ by the end of this stage. Prevalence among women will peak at $35-45 \%$ followed by a short decline at the end. The most important characteristic of this stage, however, is the rapid increase in the prevalence of mortality from smoking-related diseases, although female deaths are still relatively low. Some countries in Latin-America and Eastern- and Southern-Europe fall into this category.

- Stage IV:

Smoking prevalence continues to decline for both sexes, but only slowly. Female prevalence will typically have fallen back to about $30 \%$ and male prevalence will be slightly higher (around 33-35\%). During this period mortality from smoking-related disease will start to decline among men, but will still rise rapidly among women. This is currently the case in Autralia, Canada, the USA, and Western-Europe. 


\section{HEALTH CONSEQUENCES OF SMOKING}

Smoking harms nearly every organ of the body and compromises health of smokers in general, resulting in many of the most common diseases: cancers, cardiovascular diseases, and chronic lung diseases such as chronic obstructive pulmonary disease [COPD] and asthma) [1].

Smoking raises the risk of disease even at low levels of intensity $(\leq 20-24$ cigarettes a day) to about 3-times that of non-smokers [6-7]. And risks increase significantly with increased number of cigarettes smoked per day, decreased age of initiation, and with increasing pack-years [6-7].

Moreover, about half of all smokers who continue to smoke will eventually die from a smoking-related disease, resulting in over 6 million deaths world-wide per year [1,4,6,8-9]. And if current trends continue, tobacco smoking will kill about 10 million people worldwide each year by 2030 , and even somewhat more in later decades $[1,6,10]$. This means that about 1 in 10 deaths is currently related to a smoking-related disease, but this figure could rise to 1 in 6 by $2030[1,6,10]$.

About half of the smoking-related deaths will be in people of middle age (35-69) rather than old age, which results in a loss of, on average, more than 20 years of life expectancy compared to non-smokers [10].

Currently, 35\% of all smoking-related deaths can be attributed to cardiovascular diseases, making it the most common cause of death from smoking [8-9]. On the other hand, by 2015 about one-third of the smoking-related deaths will probably be caused by cancers, but will be closely followed by cardiovascular diseases and chronic respiratory diseases (both about 30\%) [8-9].

\section{Cancers}

Tobacco smoking is the single greatest avoidable risk factor for cancer mortality worldwide; it causes more cancer deaths than all other known causes of cancer [10-12]. Worldwide, tobacco currently causes about $20 \%$ of the cancer deaths per year [10-12].

Lung cancer is the most prevalent smoking-related cancer for two reasons. First, it is the most common cause of death from cancer in the world, with a total of 1.2 million cases annually, and this number is still increasing [11]. Secondly, tobacco smoking is the major cause of lung cancer. About $70 \%$ of the lung cancer burden can be attributed to smoking alone. And in populations with prolonged cigarette use, e.g. the developed countries, the proportion of lung cancer cases attributable to cigarette smoking can even reach about $90 \%$ [10].

There is also strong evidence supporting a role for tobacco use in the causation of cancers in other parts of the respiratory tract, including the oral cavity (mouth), pharynx, and larynx, as well as the urinary bladder [12-13]. Moreover tobacco use contributes to cancer of the pancreas, kidney and renal pelvis [12-13]. The association between cancers of the digestive tract and tobacco use diminishes as one passes down the alimentary canal; there is strong evidence for a link with esophageal cancer 
and stomach cancer, but the evidence for colon and rectal cancer and cancers of the small intestines is weaker [12-13]. An association between leukemia, gallbladder cancer, cervical cancer, sinonasal cancer, childhood cancers and cancers of the adrenal gland and tobacco use is possible, but remains to be established [12-13]. It is unlikely that an association exists between tobacco use and cancer of the breast, prostate, brain, skin, and testicles, or with soft tissue sarcoma, lymphoma or melanoma [12-13]. Overall, it can be concluded that for those cancers that were already linked to smoking in early reports (e.g. oral cavity, pharynx, larynx, oesophagus, pancreas, urinary bladder and renal pelvis) observed relative risks are generally higher than for those linked in later studies (e.g. nasal cavities and sinuses, stomach, liver, kidney, uterine cervix and myeloid leukemia) [12]. For the first group relative risks vary between 3 - and 20 -fold, while for the second group generally two- to three-fold increased risks are observed [12]. Furthermore, for all these forms of cancer a dose-respons relationship has been detected with duration and amount of smoking, and for some also with decreasing age at start of smoking [12].

Several sources of evidence suggest that passive smoking (environmental tobacco exposure) increases the risk of cancer as well. Epidemiological studies have repeatedly shown an association between exposure to passive smoke and lung cancer risk in non-smokers, resulting in an about $20 \%$ increased risk amongst those exposed [12,14-17].

Moreover, continued smoking after cancer diagnosis has been shown to inhibit response to treatment, decrease quality of life, increase risk of recurrence, and reduce survival time [18]. However, a substantial proportion (30-40\%) of cancer patients continue to smoke [18].

\section{Cardiovascular diseases}

An estimated 17.1 million people die of cardiovascular disease (CVD) each year and a substantial number of these deaths can be attributed to tobacco smoking [19-20]. In the year 2000, 1.62 million deaths - about one in every ten cardiovascular deaths in the world - were attributable to tobacco smoking [21]. In developed countries, cardiovascular disease is even the most common smoking-related cause of death [22]. Coronary heart disease accounted for $54 \%$ of smoking-attributable cardiovascular mortality, followed by cerebrovascular disease $(25 \%)$, however, there is a regional variation [21-22].

The exact toxic components of cigarette smoke and the mechanisms involved in cardiovascular dysfunction are largely unknown. However, smoking has been shown to increase inflammation, and oxidation of low-density lipoprotein cholesterol and to result in injury and dysfunction of the endothelium in both peripheral and coronary arteries, predisposing individuals to vasomotor dysfunction, thrombosis and several different atherosclerotic syndromes, including coronary artery disease (CAD), cerebrovascular disease (stroke), abdominal aortic aneurysms, intermittent claudication, impotence and hypertension [23-24]. 
Smoking increases the risk of CAD with about $80 \%$ [19,24-25]. Risks vary depending on the form of CAD. The attributable risk for myocardial infarction is well over 0.5 , while the relative risk for coronary heart disease is $70 \%$ higher for smokers and even $200 \%$ higher in heavy smokers [19,24-25]. The relative risk for sudden death is 2-4 times greater for a smoker [19,24-25]. Risks are greatest in smokers with heavier smoking levels and with longer durations of smoking behavior [19,24-25].

Smoking has been shown to be associated with an increase in incidence and mortality from both main subtypes of stroke, ischemic stroke and subarachnoid hemorrhage, as well. An estimated overall relative risk of stroke of 1.5 has been found in smokers versus non-smokers [19,24-25].

Also, smokers have more atherosclerosis in the abdominal aorta, leading to an increased relative risk for abdominal aortic aneurysms, varying from an odds ratio of 2.75 for 1-19 pack years up to an odds ratio of 9.55 for 50 or more pack years [19,24-25]. Cigarette smoking approximately doubles the risk of intermittent claudication for both men and women and increases to up to nine times that of non-smokers in smokers over the age of 45 smoking $>15$ cigarettes/day [19,24-25].

Furthermore smoking has been shown to increase cardiovascular morbidity and mortality even among patients using medications known to reduce cardiovascular events [26]. After adjusting for confounding variables, including medications to reduce cardiovascular mortality and morbidity, smokers had relative risks compared to never smokers for cardiovascular death of 1.65 [95\% Cl, 1.28-2.14], for myocardial infarction of $1.26(95 \% \mathrm{Cl}, 1.01-1.58)$, for stroke of $1.42(95 \% \mathrm{Cl}, 1.00-2.04)$, and for total mortality of $1.99(95 \% \mathrm{Cl}, 1.63-2.44)$ [23]. On the other hand, the rates of these events among former smokers were not different from those of never smokers [23].

Passive smoking has been shown to promote vasomotor dysfunction, artherogenesis and thrombosis in multiple vascular beds and has been shown to be associated with an about $30 \%$ increased risk of CAD [27].

\section{Chronic lung diseases}

Inhalation of (cigarette) smoke has several deleterious effects on the airways, leading to and/or influencing chronic respiratory diseases such as asthma and COPD). According to the latest World Health Organization (WHO) estimates (2007), currently 300 million people have asthma and 210 million people have COPD. In contrast to other common smoking-related diseases, such as cardiovascular disease and cancer, chronic respiratory diseases are the only causes of death that are still increasing. By 2015 about 30\% of the smoking-related deaths will probably be caused by chronic respiratory diseases [28].

\section{Chronic obstructive pulmonary disease (COPD)}

COPD is a leading cause of morbidity and mortality world-wide and results in an economic and social burden that is both substantial and increasing [29-31]. World- 
wide, COPD is the 12th most prevalent disease and the 6th most common cause of death and one of the few common causes of death increasing in incidence [29-31]. COPD is predicted to rise to the 4th most prevalent disease and the 4th most common cause of death by 2035 [28].

Smoking accounts for $75-90 \%$ of COPD cases in the developed world, and exposure to tobacco smoke leads to a higher risk of developing COPD and a higher rate of disease progression [32-33]. The rate of mortality from COPD in non-smokers is less than $10 \%$ of that of lifetime smokers [34], and the number of deaths from COPD increases depending on the number of cigarettes smoked [34]. Even modest smoking (1-14 cigarettes/day) increases the rate of mortality from COPD by at least 8 times compared with that of non-smokers [34].

Furthermore, a pooled meta-analysis has shown that steroid treatment is probably less effective in COPD patients who continue to smoke [35].

\section{Asthma}

The prevalence of asthma has increased world-wide during the last quarter of the 20th century, particularly among children and adolescents, making it the most common chronic illness of childhood, with a prevalence varying from $0-30 \%$ in different geographical areas, and in many countries a gradual increase in asthma mortality is seen over the last 50 years [36-38].

The health effects associated with exposure to passive smoking have been widely studied and reviewed [39-46]. Passive smoking, especially maternal smoking, in early childhood is reported to be associated with an increased risk for the development of asthma and more severe asthma symptoms, by impairing pulmonary function, enhancing airway reactivity, and increasing pulmonary morbidity, leading to increased emergency department visits, hospitalization rates, medication usage, and longer recovery periods after hospitalization [39-46].

The health effects associated with active smoking have received less attention, since asthmatics are generally believed to be non-smokers. However, the prevalence of smoking among adolescents with asthma has consistently been demonstrated to be equivalent to or even higher than rates among adolescents without asthma [43-44,47-48], which means that about $15-35 \%$ of adult asthmatics are currentsmokers. Only a few reviews on the association of active smoking and asthma have been published [41-44]. Smoking asthmatics have been shown to have worse symptom control than non-smoking asthmatics, about 4 times more asthma attacks, an accelerated decline in lung function $\left(\mathrm{FEV}_{1}\right)$, and increased pulmonary problems such as a higher chance of respiratory failure and arrest, increased airway inflammation, more exacerbations, an exaggerated bronchoconstrictor response, a higher mortality rate after admission with a near fatal asthma attack, and a higher chance of hospi-talization for intubation. The severity of these complications is positively related to the number of cigarettes smoked [41-44].

In addition, several studies have found that the efficacy of inhaled or oral corticosteroid treatment is also impaired in smokers with chronic asthma [48-49]. 


\section{SMOKING CESSATION}

Smoking cessation has well-documented health benefits. Research has shown that it reverses many of the adverse effects of smoking. [50-52].

Overall life expectancy has been shown to increase after cessation independent of age at which cessation occurs. However, smokers who quit at younger ages realize greater life extensions [34,51]. One study showed that even those who quit at age 65 gain 1.4-2.0 years of life for men and 2.7-3.7 years for women, while quitting at age 35 results in a gain of 6.9-8.5 years for men and 6.1-7.7 years for women [51]. A previous study had already shown as well that the survival pattern among those who stopped before age 35 (average age 29) did not differ significantly from that of non-smokers [34]. The survival for those who stopped later was found to be intermediate between that of non-smokers and continuing-smokers, but even those who stopped at 65-74 years of age (mean 71 years) had appreciably lower age specific mortality rates than those who continued (see Figure 1) [34].

Furthermore, it has been shown that smoking cessation at any age avoids a further increase in lung cancer risk [53]. The earlier a person gives up smoking, the more the risk of cancer is reduced [53]. Even people who stop smoking at 50-60 years of age avoid most of their subsequent risk of developing lung cancer, and those who stop at 30 years of age avoid more than $90 \%$ of the risk attributable to tobacco [53]. And also for cancers of the urinary tract, oral cavity, oropharynx and hypopharynx, oesophagus larynx, pancreas, and stomach a decreased risk with increasing number of years since quitting have been observed [12]. However risk for oesophageal cancer remains elevated many years after cessation [12].



Figure 1: Influence of smoking cessation on life expectancy.

Adapted from Doll et al, 1994 [34] 
Smoking cessation has also been associated with a risk reduction of cardiovascular disease within 2 years and the risk even reaches the level of non-smokers within about 5 years [54]. Patients with coronary heart disease, who continue to smoke, are at higher risk of sudden death and myocardial infarction than patients who stopped smoking, and the risk for cardiac events falls about $50 \%$ in people who stop smoking [55-56]. Smokers with coronary venous grafts have an increased risk of coronary events [57], and of progression of atherosclerosis in the bypass graft and native vessels [58]. Furthermore, patients with peripheral artery disease or previous stroke, who continue to smoke, also have a much higher risk of future vascular complications and coronary events compared to non-smokers [59-60].

The impact of smoking cessation on respiratory symptoms, lung function, airway hyperresponsiveness and inflammation has been reviewed multiple times [61-64]. It has been shown that when a smoker with a declined lung function stops smoking, he/she will not regain already lost lung function, but it is the only intervention proven to rapidly revert the rate of decline in $\mathrm{FEV}_{1}$ to the usual age-related decline for both males and females at all stages of COPD. Smoking cessation improves long-term prognosis, and reduces respiratory symptoms such as cough and sputum production, as well. Furthermore, airway reactivity seemed to improve in a 5 -year follow-up study, but several cross-sectional studies showed no reduction in airway reactivity to direct stimuli in ex-smokers compared to current-smokers. And although some indirect markers of airway inflammation suggest a reduction in inflammation after smoking cessation, ex-smokers seem to have persistent airway wall inflammation and often remain symptomatic and experience frequent exacerbations of their disease.

The health benefits experienced after smoking cessation thus seem to increase in proportion to the number of years since cessation. Therefore, smoking cessation as early as possible is important, but cessation at any age results in significant health benefits. If the global cigarette consumption per adult is halved by the year 2020, this would prevent about one-third of the tobacco-related deaths in 2020. Furthermore, this would almost halve tobacco-related deaths in the second quarter of the century. Hereby about 20-30 million tobacco-related deaths could be avoided in the first quarter of the century and about 100-150 million in the second quarter.

Epidemiologic studies have shown that more than $70 \%$ of smokers want to quit smoking [65]. And although the majority of these smokers are highly motivated to quit, both smokers and healthcare practitioners are confronted with high relapse rates after initial successful smoking cessation attempts. Despite progress made in the (pharmacological) treatment of nicotine dependence, the efficacy of available treatments is limited. As shown in Table 1, only $15-30 \%$ of the smokers continue to abstain from smoking [66-74]. Therefore, often multiple quit attempts are required. 


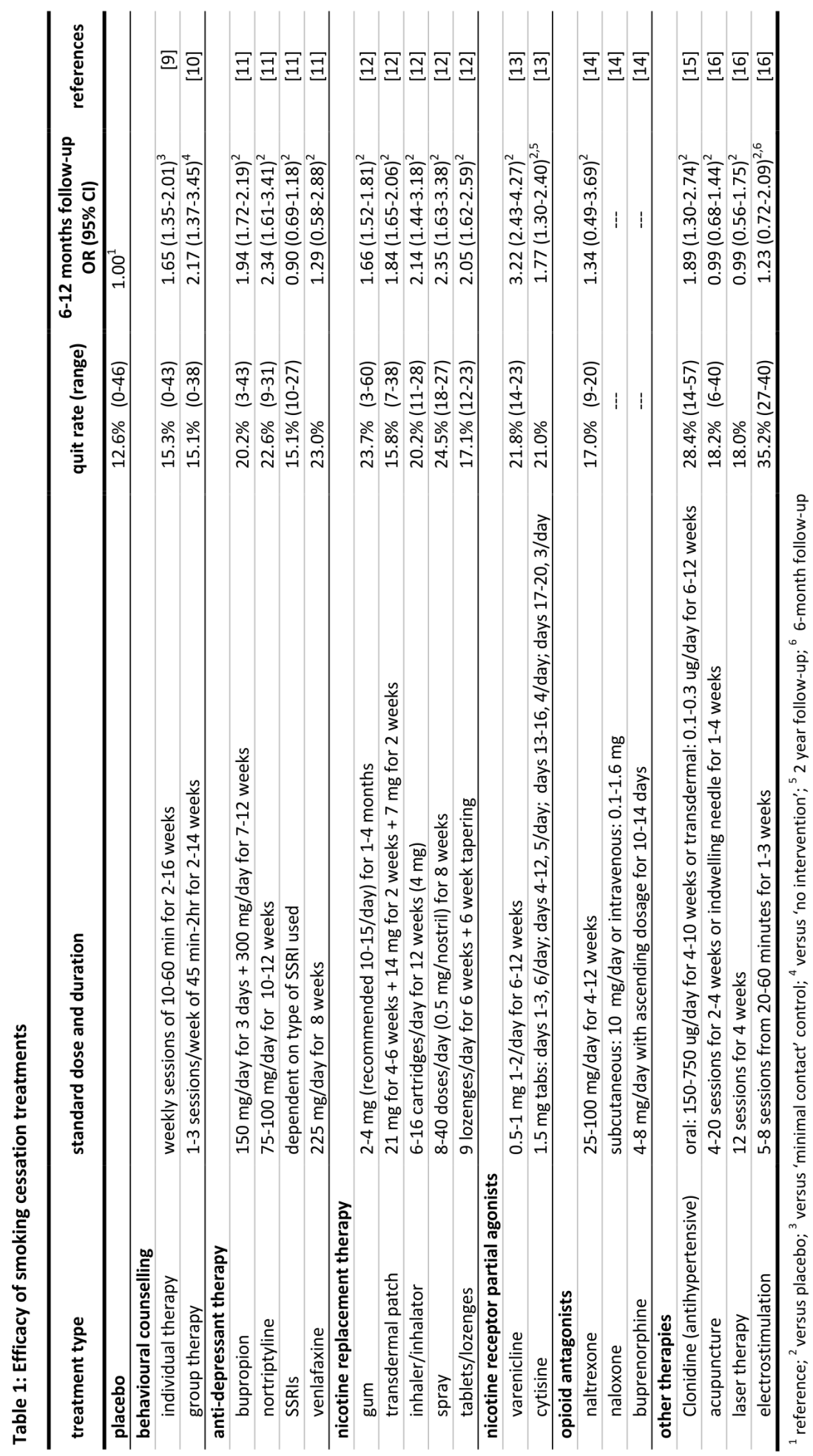




\section{BIOLOGICAL PATHWAYS ASSOCIATED WITH SMOKING}

Nicotine in cigarette smoke is the primary reward component which is associated with the addictive effects of smoking. The level of nicotine addiction has been shown to depend on 1) the amount of nicotine that is delivered and 2) the way in which it is delivered [75-76].

The amount and the duration of nicotine in the body is determined by the rate the nicotine is metabolized. The average half-life of nicotine is approximately 2 hours, but differs depending on the rate of nicotine metabolism. The major genes responsible for the metabolism of nicotine are the hepatic enzymes cytochrome P450 2A6 (CYP2A6) and cytochrome P450 2D6 (CYP2D6). Of these, CYP2A6 is believed to be the most important predictor of the rate of nicotine metabolism, because it is responsible for roughly $90 \%$ of the metabolic inactivation of nicotine to cotinine [77-78].

Nicotine can be rapidly absorbed by the lungs, but also by the oral mucosa and nose, and through the skin [79]. When nicotine enters the lungs it is rapidly absorbed into the pulmonary venous circulation via which it quickly moves to the brain [80]. This will lead to a peak concentration of nicotine in the brain within 10 to 19 seconds after inhalation.

Upon entering the brain, nicotine binds to nicotinic acetylcholine receptors (nAChRs). Each nicotinic receptor is build up from five subunits [81]. The mammalian brain expresses nine types of $\alpha$-subunits $\left(\alpha_{2}\right.$ through $\left.\alpha_{10}\right)$ and three $\beta$-subunits $\left(\beta_{2}\right.$ through $\beta_{4}$ ). The most abundant receptors are $\alpha_{4} \beta_{2}, \alpha_{3} \beta_{4}$, and $\alpha_{7}$. High affinity nicotinic receptors mainly contain the $\alpha 4$ (CHRNA4) and $\beta 2$ (CHRNB2) subunits, and $\alpha 4 \beta 2 *$ (* indicates that another subunit may be included) is the most frequently encountered nicotinic receptor subtype [82].

Binding of nicotine activates the nicotinic receptors, which are mainly located in presynaptic terminals, thereby resulting in the release of several types of neurotransmitters and hormones in the brain [80,82-83]. Release of these neurochemicals induces the behavioural effects associated with smoking such as pleasure, arousal, increased attention and concentration, enhancement of memory, reduction of anxiety and tension, and suppression of appetite (see Figure 2).

Dopamine is the most important neurotransmitter released by nicotine. Dopamine is responsible for the pleasurable (rewarding) effects of nicotine and is ther efore critical for the reinforcing effects of nicotine [84-88]. Further, dopamine is responsible for compelling drives such as eating [88].

Nicotine also seems to play a role in modulating fast synaptic transmission, mediated by the release of glutamate, which is believed to play a role in learning and memory [89], and stimulates the release of $y$-aminobutyric acid (GABA), associated with a reduction in anxiety and tension [89]. Furthermore, glutamate has been shown to facilitate the release of dopamine while GABA inhibits dopamine release [90-91]. With long-term exposure to nicotine, some nicotinic cholinergic receptors become desensitized but some do not. As a result, GABA-mediated inhibitory tone diminishes while glutamate- 


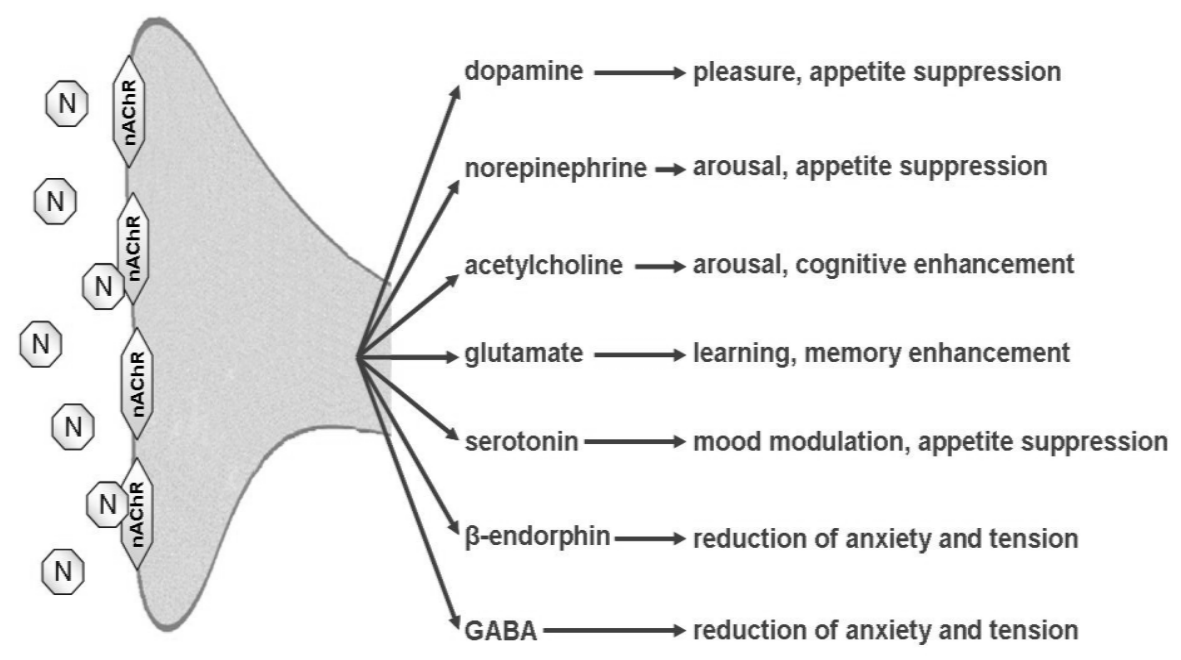

Figure 2: Neurochemical and related psychological effects of nicotine's binding to nAChRs

Adapted from: Benowitz, 1999 [89]

$\mathrm{N}$ : nicotine; nAChR: nicotinic acetylcholinic receptor; GABA: $\gamma$-aminobutyric acid

mediated excitation persists, thereby increasing excitation of dopaminergic neurons and enhancing responsiveness to nicotine [90-91].

Nicotine has also been shown to increase the secretion of serotonin in the brain [92-93], which is involved in mood regulation, impulse control, appetite and aggression [94]. Increased serotonin levels have been associated with decreased food intake and weight gain, and have been shown to have an anti-depressant effect [92]. On the other hand, lower serotonin re-uptake has been associated with several behavioural traits (e.g. neuroticism, novelty seeking, and anxiety-related personality traits) that are related to an increased incidence of smoking, increased nicotine dependence, and difficulty in quitting smoking [95-96].

Release of acetylcholine (ACh) in the cerebral cortex, has been suggested to result in cerebral arousal and thereby cognitive enhancement, but not behavioral stimulation $[89,97]$.

In the hypothalamus, nicotine results in the release of norepinephrine (NE) [97]. This appears to result in arousal and cognitive enhancement $[89,97]$.

Finally, cholinergic stimulation results in the release of the hormone $\beta$-endorphin, which is also responsible for a reduction of anxiety and tension $[89,97]$.

With chronic exposure to nicotine, tolerance develops to the release of many of these neurochemicals. In the absence of nicotine, this results in a relative deficiency state, which is generally characterized by symptoms that are the opposite to the acute effects of nicotine [89]. 


\section{Box 1: Basic genetics}

DNA: (deoxyribonucleic acid) consists of two long polynucleotide chains composed of four types of nucleotide subunits.

Nucleotide: nucleotides consist of a sugar-phosphate molecule with a base attached to it. The bases are of four types (adenine, guanine, cytosine, and thymine), corresponding to four distinct nucleotides, labeled A, G, C, and T. This forms the four-letter alphabet that encodes the genetic information.

Chromosome: human DNA is divided over 23 sets of chromosomes, one set inherited from the father and one from the mother, resulting in a total of 48 chromosomes.

Gene: chromosomes contain numerous genes; sections of DNA containing the information for one protein or set of proteins.

Allele: alternative versions of the same gene are called alleles. An individul with identical alleles at a genetic locus is a homozygote; one with non-identical alleles is a heterozygote. In a case in which one allele leads to an observable gene product and the other has no phenotype, the functional allele is said to be dominant and the non-functional allele recessive.

\section{GENETIC VARIATION}

DNA from individuals is almost completely the same, however, about $0,1 \%$ will differ due the presence of genetic variants. Many of these variants will not have any effect, however, some will. This is what makes every human unique. It leads to differences in physical traits (e.g. hair color, eye color, height), and behavioural traits (e.g. the way one acts). Furthermore, it can also influence the chance of getting a certain disease or disorder (this is called a genetic predisposition).

Several types of genetic variants (or polymorphisms) are present in the human genome. The most common types are:

Single Nucleotide Polymorphisms (SNPs), differences in a single nucleotide, are the most common type of genetic variation among people. SNPs make up about $90 \%$ of all human genetic variation. They occur throughout a person's DNA, about every 100 to 200 bases.

Variable Number of Tandem Repeats (VNTRs) are locations in the genome where a short nucleotide sequence is repeated adjacent to each other. They can be found on many chromosomes and show variations in length (e.g. the number of copies) between individuals.

Copy Number Variants (CNVs) are a form of structural variation, in which a cel has an abnormal number of copies of one or more sections of the DNA. This can be an entire gene, but also just part of a gene. It can lead to a higher number of copies, but also to a lower number of copies. 
Furthermore, epigenetic changes, changes other than changes in the underlying DNA sequence, are present. Several types of epigenetic changes are known. The most common types are DNA methylation and chromatin remodeling.

Several approaches can be used to investigate the effect of genetic variation on a certain phenotype and/or trait.

Family, twin and adoption studies are used to determine whether or not there is a genetic contribution. Twin and adoption studies also help to dissociate environmental factors from genetic factors.

Twin studies are commonly used, although it may confound genetic and environmental influences on the phenotype of interest. In twin studies, the agreement in the behavior of monozygotic (MZ) twins, who share the same genetic make-up, with that of dizygotic (DZ) twins, who share on average $50 \%$ of their genetic make-up, is compared. When the twins are raised together, they share similar environments and therefore when a higher rate of concordant behavior (e.g. both engage in the same behaviour) is observed in $\mathrm{MZ}$ than in $\mathrm{DZ}$ twins, the behavior is considered to be significantly influenced by genetic factors.

Adoption studies are another form in which individuals who share genes are compared. Compared with twin studies, adoption studies can minimize the confounding influences of genetic and environmental effects on smoking behavior. However, it has become increasingly difficult to conduct adoption studies because few children are available for adoption in developed countries.

Linkage analysis is the study of the inheritance pattern of phenotypes and genotypes in related individuals (e.g. pedigrees). This type of research is used to identify regions of DNA that may be involved in the expression of the phenotype of interest. The concept of linkage analysis is based on the fact that genes located close to one another on a chromosome are more likely to be inherited together from one parent than two genes located further apart and are therefore said to be 'linked'.

Association studies, or case-control studies, are based on a comparison of unrelated affected and unaffected individuals in a population. They are also used to identify DNA regions that may be involved in the expression of the trait of interest. A certain allele from a gene is said to be associated with the trait if it occurs at a significantly higher frequency among affected individuals compared to control subjects. Association studies are performed at a genome-wide level but also with just a few candidate genes (e.g. selection in advance of genes which may have relevance to the phenotype in question).

And finaly, animal studies, such as the analysis of inbred, transgenic and gene knock-out animals. Animal studies offer the advantage of studying large numbers of genetically identical animals under controlled conditions. Transgenic animals are created by the injection of a foreign gene (transgene) into fertilized egg and the use of these to breed animals which have thise transgene integrated in their genome. The gene knock-out methodology allows the deletion of a gene - or a fragment of a gene from the animal chromosome. 


\section{INFLUENCE OF GENETIC VARIATION ON SMOKING AND SMOKING CESSATION}

Tobacco smoking is believed to be a complex, multi-factorial behaviour with both genetic and environmental determinants. While early reports suggested that the influence of heredity on smoking was modest, more recent twin studies have found significant genetic influences on several aspects of smoking behaviour [98-106]. It has been demonstrated that genetic factors account for approximately $40-75 \%$ of the variation in the probability that a individual will become a smoker (initiation), $70-80 \%$ of the variation in continuation of the smoking habit once smoking has started (persistence/ maintenance), approximately $45-85 \%$ of the variation in cigarette consumption, about $50 \%$ of the variance in cessation success, $30-50 \%$ of the variance in risk of withdrawal symptoms and 30-75\% of the variance in nicotine dependence (ND) [98-106].

Variations in several genes have been suggested to contribute to smoking behaviour, and research has been focused on two broad classes of candidate genes (for extended reviews see [104,107-110]):

1) Genes that may influence the response to nicotine (e.g. nicotine metabolism, nicotinic receptors).

2) Genes that may predispose to addictive behaviour due to their effects on key neurotransmitter pathways (e.g. dopamine and serotonin).

Since pharmacological therapies used for smoking cessation are often directed to the pathways related to tobacco dependence, these genetic variants might also influence the response to smoking cessation therapies. And furthermore, genetic variations in pathways involved in the metabolism and/or secretion of the pharmacotherapies might also influence the medication levels available in the blood and thereby the efficacy of the medication.

Nicotine replacement therapy (NRT), like nicotine itself, is metabolized in the liver by CYP2A6 and CYP2D6. The antidepressant bupropion (Zyban ${ }^{\circledR}$ ) is metabolized in the liver by CYP2B6, while the antidepressant nortriptyline (Nortrilen ${ }^{\circledR}$ ) is broken down by the liver enzyme CYP2D6. The partial nicotinic agonist Varenicline (Champix ${ }^{\circledR}$ ), on the other hand, is hardly being metabolized, but is secreted in its original form by the kidneys via a transporter called the organic cation transporter 2 (OCT2).

The effects of smoking cessation therapy might thus differ considerably in subgroups of smokers carrying certain genetic variants. This makes it likely that no single medication will be effective in facilitating smoking cessation for all smokers.

\section{(PHARMACO)GENETIC TESTING}

A genetic test investigates whether there are changes or defects in a specific part or parts of the DNA, which are known to have an effect on the trait or disorder that is being investigated. A pharmacogenetic test is a subtype of a genetic test in which variants are investigated that are known to influence the response to a certain drug.

To perform a genetic test DNA is needed, which can be extracted from all kinds of cells, such as cells from blood, saliva, buccal swaps, hairs, skin or from the amniotic 
fluid of a pregnant woman to investigate the DNA of an unborn child. Next, different techniques can be used to make the change in the DNA 'visible'. Which technique is used will depend on the kind of change in the DNA that is being investigated. This will, at least for the present, take place in a laboratory, after which the results can be returned to the applicant.

Genetic tests have quite a few advantages, but also some disadvantages and risks.

The physical risks associated with most genetic tests are very small, since usually only a small amount of DNA is needed, which can be taken from cells that are easily accessable (e.g. blood, saliva, buccal cells, hair).

An important advantage of a genetic test is that it can give certainty about someones genetic material, which can be a big relieve, especially when it provides good news, but often also when it provides bad news, because it provides more clarity. Furthermore, it can help to determine whether someone has a genetic predisposition or genetic disorder. When a correct diagnosis has been established, the correct treatment or counselling can be initiated. And when a genetic test shows that someone has an increased risk to develop a certain disease, a regular check-up can be done or exposure to risk factors can be minimized to decrease the chance to get the disease. Finally, because family members have most of their DNA in common, this information can also be usefull for other family members. When it is known that a certain heriditairy trait runs in the family, this can also help to set a diagnosis for other family members.

Many of the disadvantages associated with genetic testing involve the emotional, social, or financial consequences of the test results. People may feel angry, depressed, anxious, or guilty about their results. In some cases, genetic testing creates tension within a family because the results can reveal information about other family members in addition to the person who is tested. The possibility of genetic discrimination in employment or insurance is also a concern. Some individuals avoid genetic testing out of fear that it will affect their ability to purchase insurance or find a job.

The use of (pharmaco)genetic testing for smoking in clinical practice for increasing quit rates by genetically-tailored smoking cessation treatment seems to be on the horizon. A profile of genetic variants in smoking-related pathways and pathways involved in the metabolism and/or secretion of medication could possibly be used to predict in advance which smoking cessation therapy is likely to be most effective for an individual smoker. This could lead to a more effective use of smoking cessation therapies, resulting in less side-effects and increased cessation rates, and ultimately in reduced morbidity and mortality from smoking-related diseases.

However, the genetic variants that are likely to predict the effectiveness of smoking cessation therapy, also predict the risk for smoking addiction and addiction in general. This could lead to stigmatisation and might also have consequences for the purchase of a health-insurance, mortgage or life-insurance, and when looking for job.

Furthermore, future implementation of (pharmaco)genetic testing for smoking in daily medical practice, will ultimately depend upon acceptance of these tests by patients and health care providers. At present there is relatively little knowledge 
about the willingness and preferences of patients and health care providers concerning genetic testing for smoking addiction and cessation, and about individuals' knowledge and attitudes on this subject.

\section{AIMS AND OUTLINE OF THE THESIS}

Smoking continues to be a major public health problem. Because smoking is a modifiable risk factor, treatment and prevention represents a huge opportunity for public health promotion. However, many smokers find it extremely difficult to stop smoking, even though several anti-smoking therapies are available to aid smokers during their quit attempts, such as NRT, antidepressants and behavioural therapies. Even with a combination of pharmacotherapeutic and behavioural therapy only $5-30 \%$ of the smokers are actually successful to quit smoking permanently and without this intensive treatment only $5 \%$ will succeed to quit smoking.

Recent research strongly suggests that a specific genetic background influences smoking behaviour and might also influence the efficacy of pharmacotherapies used for smoking cessation. However, so far most studies only investigated single genes or single genetic variants. Regarding the number of genes that are implicated in smoking addiction, and the large number of polymorphisms present, approaches analysing single variants or single genes will probably fail to fully determine the role of genetic variation in the individual susceptibility towards smoking addiction. Also, the effect of genetics on only a couple of smoking cessation therapies has been investigated. Therefore, the effect of multiple susceptibility genes as well as their mutual interactions on several smoking cessation therapies will have to be investigated to make genetically based personalized treatments in the near future possible.

Therefore, the objective of the present study is to find out if and to which extent a number of genetic variants in the established smoking-addiction related genes and treatment-realted genes can predict the response to smoking cessation therapy in smokers. Ultimately this reseach could lead to the development of a genetic test that can be implemented in general practice to predict in advance which smoking cessation therapy can be used best for an individual smoker to guide a personalized treatment programme. To reach this objective, a combination of literature studies, genotyping studies and surveys has been performed.

The first part of this thesis focuses on the role of genetic variants on smoking behaviour. To determine which genetic variants influence smoking behaviour the available literature was reviewed. The data from this review are presented in Chapter $\mathbf{2}$. A number of genetic variants in the candidate genes for smoking behaviour were selected for further research. A total number of 35 genetic variants in 19 candidate genes were selected and 772 smokers participating in four smoking and smoking cessation studies were genotyped for these variants. Next we determined which of these genetic variants influenced nicotine dependence (ND) level, as determined by the Fagerström Test for Nicotine Dependence (FTND). The data from this study are presented in Chapter 3. Furthermore, since it has been suggested that the FTND 
questionnaire has a multi-factor structure, the effect of these genetic variants on the different items of the FNTD was assessed in Chapter 4.

The second part of this thesis focuses on the influence of genetic variants on smoking cessation therapy. In Chapter $\mathbf{5}$ the literature on this subject is reviewed. Most research has been focused on the two most widely accepted and licensed forms of smoking cessation therapy (NRT and bupropion). Only a low number of genetic studies for other smoking cessation therapies is available and these therapies are not used very frequently. Therefore, this review focuses on the pharmacogenetic studies of NRT and bupropion only. From this review it was noticed that eventhough genetic variants in the serotonin transporter were expected to influence smoking cessation rates using antidepresant therapy, this had not yet been investigated. Because of this, in Chapter 6, we investigated the influence of genetic variants in the serotonin transporter on the efficacy of two antidepressants, bupropion and nortriptyline, for smoking cessation. A second, more extensive study, as described in Chapter 7, focuses on the influence of multiple genetic variants in multiple candidate genes on the efficacy of anti-depressant therapy used for smoking cessation.

The third part of this thesis focuses on the possibilities and barriers for future implementation of (pharmaco)genetic testing for smoking in daily medical practice. This will ultimately depend upon patients' and health care providers' acceptance of these tests. At present there is relatively little knowledge about their willingness and preferences concerning genetic testing for smoking cessation, and about individuals' knowledge and attitudes on this subject. Therefore, the first of these studies, presented in Chapter 8, focuses on smokers' attitudes, beliefs and preferences regarding genetic testing for smoking cessation using an online survey. Since this study showed that smokers allocate their GPs a crucial role in the provision of information on this subject and the delivery of a genetic test for smoking cessation, a comparable survey was send to GPs, as described in Chapter 9, to assess their attitudes, beliefs and preferences concerning genetic testing for smoking and their willingness to offer a genetic test for smoking.

Chapter 10 presents a general discussion of the major findings of all the studies in this thesis and focuses on the implications of this research and possibilities for future research.

\section{REFERENCES}

1. The World Bank. Curbing the epidemic: governments and the economics of tobacco control. Tob Control. 1999; 8(2): 196-201.

2. Mackay J, Eriksen M. The tobacco Atlas. Geneva, World Health Organization. 2002.

3. Guindon GE, Boisclair D. Past, current and future trends in tobacco use. HNP discussion paper no.6. Econcomics of tobacco control paper no. 6. 2003.

4. World Health Organization. The world health report 2003 - shaping the future; 2003.

5. Lopez AD, Collishaw N, Piha ET. A descriptive model of the cigarette epidemic in developed countries. Tob Control. 1994; 3(3): 242-247. 
6. Mucha L, Stephenson J, Morandi N, Dirani R. Meta-analysis of disease risk associated with smoking, by gender and intensity of smoking. Gend Med. 2006; 3(4): 279-291.

7. Kenfield SA, Stampfer MJ, Rosner BA, Colditz GA. Smoking and smoking cessation in relation to mortality in women. Jama. 2008; 299(17): 2037-2047.

8. Ezzati M, Lopez AD. Estimates of global mortality attributable to smoking in 2000. Lancet. 2003; 362(9387): 847-852.

9. Mathers CD, Loncar D. Evidence and information for policy: World Health Organization; 2005.

10. Peto R, Lopez AD, Boreham J, Thun M, Heath CJ. Mortality from Smoking in Developed Countries 19502000. Indirect Estimates from National Vital Statistics. New York: Oxford University Press; 1994.

11. Parkin DM, Pisani P, Masuyer E. Tobacco-attributable cancer burden: A global review. In: Lu R, Mackay J, Niu S, Peto R, editors. Tobacco: The Growing Epidemic. London: Springer-Verlag; 2000. p. 81-84.

12. World Health Organization. IARC Monographs on the Evaluation of Carcinogenic Risks to Humans. Volume 83. Tobacco Smoke and Involuntary Smoking. 2004; Available from: http://monographs.iarc.fr/ENG/ Monographs/ vol83/mono83.pdf; accessed on 16/07/2011

13. Kuper H, Adami HO, Boffetta P. Tobacco use, cancer causation and public health impact. J Intern Med. 2002; 251(6): 455-466.

14. Trichopoulos D, Kalandidi A, Sparros L, MacMahon B. Lung cancer and passive smoking. Int J Cancer. 1981; 27(1): 1-4.

15. Pershagen G. Passive smoking and lung cancer. In: Samet JM, editor. Epidemiology of lung cancer (Lung Biology in Health and Disease, vol 74). New York: Marcel Dekker; 1994. p. 109-130.

16. Hackshaw AK, Law MR, Wald NJ. The accumulated evidence on lung cancer and environmental tobacco smoke. BMJ. 1997; 315(7114): 980-988.

17. Boffetta P, Agudo A, Ahrens W, Benhamou E, Benhamou S, Darby SC, Ferro G, Fortes C, Gonzalez CA, Jockel KH, Krauss M, Kreienbrock L, Kreuzer M, Mendes A, Merletti F, Nyberg F, Pershagen G, Pohlabeln H, Riboli E, Schmid G, Simonato L, Tredaniel J, Whitley E, Wichmann HE, Winck C, Zambon P, Saracci R. Multicenter case-control study of exposure to environmental tobacco smoke and lung cancer in Europe. J Natl Cancer Inst. 1998; 90(19): 1440-1450.

18. Lerman C, Patterson F, Berrettini W. Treating tobacco dependence: state of the science and new directions. J Clin Oncol. 2005; 23(2): 311-323.

19. Lakier JB. Smoking and cardiovascular disease. Am J Med. 1992; 93(1A): 8S-12S.

20. Burns DM. Epidemiology of smoking-induced cardiovascular disease. Progress in Cardiovascular Diseases. 2003; 46(1): 11-29.

21. Ezzati M, Lopez AD. Regional, disease specific patterns of smoking-attributable mortality in 2000. Tob Control. 2004; 13(4): 388-395.

22. Jha P, Chaloupka FJ, Moore J, al. e. Tobacco Addiction. In: Jamison DT, Bregman JG, Measham A, editors. Disease Control Priorities in Developing Countries. NY, USA: Oxford University Press, World Bank; 2006. p. 869-885.

23. Ambrose JA, Barua RS. The pathophysiology of cigarette smoking and cardiovascular disease: an update. J Am Coll Cardiol. 2004; 43(10): 1731-1737.

24. Tonstad S, Andrew Johnston J. Cardiovascular risks associated with smoking: a review for clinicians. Eur J Cardiovasc Prev Rehabil. 2006; 13(4): 507-514.

25. Bullen C. Impact of tobacco smoking and smoking cessation on cardiovascular risk and disease. Expert Rev Cardiovasc Ther. 2008; 6(6): 883-895.

26. Dagenais GR, Yi Q, Lonn E, Sleight $P$, Ostergren J, Yusuf S. Impact of cigarette smoking in high-risk patients participating in a clinical trial. A substudy from the Heart Outcomes Prevention Evaluation (HOPE) trial. Eur J Cardiovasc Prev Rehabil. 2005; 12(1): 75-81. 
27. Ambrose JA, Barua RS. The pathophysiology of cigarette smoking and cardiovascular disease. J Am Coll Cardiol. 2004; 43(10): 1731-1737.

28. Mathers CD, Loncar D. Projections of global mortality and burden of disease from 2002 to 2030. PLoS Med. 2006; 3(11): e442.

29. Murray CJ, Lopez AD. Mortality by cause for eight regions of the world: Global Burden of Disease Study. Lancet. 1997; 349(9061): 1269-1276.

30. Barnes PJ. Chronic obstructive pulmonary disease. N Engl J Med. 2000; 343(4): 269-280.

31. Pauwels RA, Buist AS, Calverley PM, Jenkins CR, Hurd SS. Global strategy for the diagnosis, management, and prevention of chronic obstructive pulmonary disease. NHLBI/WHO Global Initiative for Chronic Obstructive Lung Disease (GOLD) Workshop summary. Am J Respir Crit Care Med. 2001; 163(5): 1256-1276.

32. Siafakas NM, Vermeire P, Pride NB, Paoletti P, Gibson J, Howard P, Yernault JC, Decramer M, Higenbottam T, Postma DS, Rees J, on behalf of the Task Force. Optimal assessment and management of chronic obstructive pulmonary disease (COPD). ERS - consensus statement. Eur Respir J. 1995; 8: 1398-1420.

33. Office of the Surgeon General; Office on Smoking and Health; Centers for Disease Control and Prevention; Atlanta (GA, USA). The Health Consequences of Smoking: A Report of the Surgeon General. 2004: Available from: http://www.cdc.gov/tobacco/data_statistics/sgr/sgr_2004/index.htm.

34. Doll R, Peto R, Wheatley K, Gray R, Sutherland I. Mortality in relation to smoking: 40 years' observations on male British doctors. BMJ. 1994; 309(6959): 901-911.

35. Sin DD, Wu L, Anderson JA, Anthonisen NR, Buist AS, Burge PS, Calverley PM, Connett JE, Lindmark B, Pauwels RA, Postma DS, Soriano JB, Szafranski W, Vestbo J. Inhaled corticosteroids and mortality in chronic obstructive pulmonary disease. Thorax. 2005; 60(12): 992-997.

36. Variations in the prevalence of respiratory symptoms, self-reported asthma attacks, and use of asthma medication in the European Community Respiratory Health Survey (ECRHS). Eur Respir J. 1996; 9(4): 687-695.

37. Beasley R, Pearce N, Crane J. International trends in asthma mortality. Ciba Found Symp. 1997; 206: 140-150; discussion 150-146, 157-149.

38. Sunyer J, Anto JM, Tobias A, Burney P. Generational increase of self-reported first attack of asthma in fifteen industrialized countries. European Community Respiratory Health Study (ECRHS). Eur Respir J. 1999; 14(4): 885-891.

39. Beeber SJ. Parental smoking and childhood asthma. J Pediatr Health Care. 1996; 10(2): 58-62.

40. Cook DG, Strachan DP. Health effects of passive smoking-10: Summary of effects of parental smoking on the respiratory health of children and implications for research. Thorax. 1999; 54(4): 357-366.

41. Ulrik CS, Lange P. Cigarette smoking and asthma. Monaldi Arch Chest Dis. 2001; 56(4): 349-353.

42. Jindal SK, Gupta D. The relationship between tobacco smoke \& bronchial asthma. Review article. Indian J Med Res. 2004; 120: 443-453.

43. Thomson NC, Chaudhuri R, Livingston E. Asthma and cigarette smoking. Eur Respir J. 2004; 24(5): 822-833.

44. Tyc VL, Throckmorton-Belzer L. Smoking rates and the state of smoking interventions for children and adolescents with chronic illness. Pediatrics. 2006; 118(2): e471-487.

45. Tager IB. The effects of second-hand and direct exposure to tobacco smoke on asthma and lung function in adolescence. Paediatr Respir Rev. 2008; 9(1): 29-37; quiz 37-28.

46. Wang L, Pinkerton KE. Detrimental effects of tobacco smoke exposure during development on postnatal lung function and asthma. Birth Defects Res C Embryo Today. 2008; 84(1): 54-60.

47. Lemiere C, Boulet LP. Cigarette smoking and asthma: a dangerous mix. Can Respir J. 2005; 12(2): 79-80. 
48. Thomson NC, Spears M. The influence of smoking on the treatment response in patients with asthma. Curr Opin Allergy Clin immunol. 2005; 5: 57-63.

49. Livingston E, Thomson NC, Chalmers GW. Impact of smoking on asthma therapy: a critical review of clinical evidence. Drugs. 2005; 65(11): 1521-1536.

50. U.S. Department of Health and Human Services. The health benefits of smoking cessation. US Department of Health and Human Services, Public Health Service, Centers for Disease Control, Center for Chronic Disease Prevention and Health Promotion, Office on Smoking and Health. 1990; DHHS Publication No. (CDC) 90-8416.

51. Taylor DH, Jr., Hasselblad V, Henley SJ, Thun MJ, Sloan FA. Benefits of smoking cessation for longevity. Am J Public Health. 2002; 92(6): 990-996.

52. Doll R, Peto R, Boreham J, Sutherland I. Mortality from cancer in relation to smoking: 50 years observations on British doctors. Br J Cancer. 2005; 92(3): 426-429.

53. Peto R, Darby S, Deo H, Silcocks $P$, Whitley E, Doll R. Smoking, smoking cessation, and lung cancer in the UK since 1950: combination of national statistics with two case-control studies. BMJ. 2000; 321(7257): 323-329.

54. Becker DM. Clinical approaches to cardiovascular risk factors: smoking. In: Pearson TA, Criqui $\mathrm{MH}$, Luepker RV, Oberman A, Winston M, editors. Primer in preventive cardiology: American Heart Association; 1994. p. 143-157.

55. Cavender JB, Rogers WJ, Fisher LD, Gersh BJ, Coggin CJ, Myers WO, al. e. Effects of smoking on survival and morbidity in patients randomized to medical or surgical therapy in the Coronary Artery Surgery Study (CASS): 10-year follow-up. CASS investigators. J Am Coll Cardiol. 1992; 20: 287-294.

56. Goldenberg I, M. J, Tenenbaum A, Boyko V, Mateztzky S, Shotan A, al. e. Current smoking, smoking cessation, and the risk of sudden death in patients with coronary artery disease. Arch Intern Med. 2003; 163: 2301-2305.

57. Voors AA, van Brussel BL, Plokker HW, Ernst SMPG, Ernst NM, Koomen EM, et al. Smoking and cardiac events after venous coronary bypass surgery. A 15-year follow-up study. Circulation. 1996; 93: 42-47.

58. Campeau L, Enjalbert M, Lespérance J, Bourassa MG, Kwiterovich P, Wacholder S, al. e. THe realion of risk factors to the development of atherosclerosis in saphenous-vein bypass grafts and the progression of disease in the native circulation. A study 10 years after aortocoronary bypass surgery. N Engl J Med. 1984; 311: 1329-1332.

59. Jonason T, Bergstrom R. Cessation of smoking in patients with intermittent claudication. Effects on the risk of peripheral vascular complications, myocardial infarction and mortality. Acta Med Scand. 1987; 221: 253-260.

60. Burn J, Dennis M, Barnford J, Sandercock P, D. W, Warlow C. Long-term risk of recurrent stroke after a first-ever stroke. Stroke. 1994; 25: 333-337.

61. Sethi JM, Rochester CL. Smoking and chronic obstructive pulmonary disease. Clin Chest Med. 2000; 21(1): 67-86.

62. Willemse BWM, Postma DS, Timens W, Ten Hacken NHT. The impact of smoking cessation on respiratory symptoms, lung function, airway hyperresponsiveness and inflammation. Review. Eur Respir J. 2004; 23: 464-476.

63. Bartal M. COPD and tobacco smoke. Monaldi Arch Chest Dis. 2005; 63(4): 213-225.

64. Hylkema MN, Sterk PJ, de Boer WI, Postma DS. Tobacco use in relation to COPD and asthma. Eur Respir J. 2007; 29: 438-445.

65. Khurana S, Batra V, Patkar AA, Leone FT. Twenty-first century tobacco use: it is not just a risk factor anymore. Respir Med. 2003; 97(4): 295-301. 
66. Lancaster T, Stead L, Silagy C, Sowden A. Effectiveness of interventions to help people stop smoking: findings from the Cochrane Library. BMJ. 2000; 321(7257): 355-358.

67. Lancaster T, Stead LF. Individual behavioural counselling for smoking cessation. Cochrane Database Syst Rev. 2002; (3): CD001292.

68. Stead LF, Lancaster T. Group behaviour therapy programmes for smoking cessation. Cochrane Database Syst Rev. 2005; (2): CD001007.

69. Hughes JR, Stead LF, Lancaster T. Antidepressants for smoking cessation. Cochrane Database Syst Rev. 2007; (1): CD000031.

70. Silagy C, Lancaster T, Stead L, Mant D, Fowler G. Nicotine replacement therapy for smoking cessation. Cochrane Database Syst Rev. 2004; (3): CD000146.

71. Cahill K, Stead LF, Lancaster T. Nicotine receptor partial agonists for smoking cessation. Cochrane Database Syst Rev. 2007; (1): CD006103.

72. David S, Lancaster T, Stead LF, Evins AE. Opioid antagonists for smoking cessation. Cochrane Database Syst Rev. 2006; (4): CD003086.

73. Gourlay SG, Stead LF, Benowitz NL. Clonidine for smoking cessation. Cochrane Database Syst Rev. 2004; (3): CD000058.

74. White AR, Rampes H, Campbell JL. Acupuncture and related interventions for smoking cessation. Cochrane Database Syst Rev. 2006; (1): CD000009.

75. Henningfield JE, Keenan RM. Nicotine delivery kinetics and abuse liability. J Consult Clin Psychol. 1993; 61(5): 743-750.

76. U.S. Department of Health and Human Services. How Tobacco Smoke Causes Disease: The Biology and Behavioral Basis for Smoking-Attributable Disease: A Report of the Surgeon General. Atlanta, GA: US Department of Health and Human Services, Centers for Disease Control and Prevention, National Center for Chronic Disease Prevention and Health Promotion, Office on Smoking and Health Pschology. 2010.

77. Nakajima M, Yamamoto T, Nunoya K, Yokoi T, Nagashima K, Inoue K, Funae Y, Shimada N, Kamataki T, Kuroiwa Y. Role of human cytochrome P4502A6 in C-oxidation of nicotine. Drug Metab Dispos. 1996; 24(11): 1212-1217.

78. Messina ES, Tyndale RF, Sellers EM. A major role for CYP2A6 in nicotine C-oxidation by human liver microsomes. J Pharmacol Exp Ther. 1997; 282(3): 1608-1614.

79. Benowitz N, Porchet $\mathrm{H}$, Sheiner L, Jacob Pr. Nicotine absorption and cardiovascular effects with smokeless tobacco use: comparison with cigarettes and nicotine gum. Clin Pharmacol Ther. 1988; 44(1): 23-28.

80. Benowitz NL. Nicotine addiction. N Engl J Med. 2010; 362(24): 2295-2303.

81. Dajas-Bailador F, Wonnacott S. Nicotinic acetylcholine receptors and the regulation of neuronal signalling. Trends Pharmacol Sci 2004; 25: 317-324.

82. Dani JÁ, De Biasi M. Cellular mechanisms of nicotine addiction. Pharmacol Biochem Behav. 2001; 70: 439-446.

83. Kenny PJ, Markou A. Neurobiology of the nicotine withdrawal syndrome. Pharmacol Biochem Behav. 2001; 70: 531-549.

84. Di Chiara G, Imperato A. Drugs abused by humans preferentially increase synaptic dopamine concentrations in the mesolimbic system of freely moving rats. Proc Natl Acad Sci U S A. 1988; 5(14): 5274-5278.

85. Pontieri FE, Tanda G, Orzi F, Di Chiara G. Effects of nicotine on the nucleus accumbens and similarity to those of addictive drugs. Nature. 1996; 382(6588): 255-257.

86. Zoli M, Moretti M, Zanardi A, McIntosh JM, Clementi F, Gotti C. Identification of the nicotinic receptor 
subtypes expressed on dopaminergic terminals in the rat striatum. J Neurosci. 2002; 22(20): 8785-8789.

87. Balfour DJ. The neurobiology of tobacco dependence: a preclinical perspective on the role of the dopamine projections to the nucleus accumbens [corrected]. Nicotine Tob Res. 2004; 6(6): 899-912.

88. Nestler EJ. Is there a common molecular pathway for addiction? . Nat Neurosci 2005; 8: 1445-1449.

89. Benowitz NL. The biology of nicotine dependence: from the 1988 Surgeon General's Report to the present and into the future. Nicotine Tob Res. 1999; 1 Suppl 2: S159-163.

90. Mansvelder HD, McGehee DS. Long-term potentiation of excitatory inputs to brain reward areas by nicotine. Neuron 2000; 27: 349-357.

91. Mansvelder HD, McGehee DS. Cellular and synaptic mechanisms of nicotine addiction. J Neurobiol 2002; 53: 606-617.

92. Ribeiro EB, Bettiker RL, Bogdanov M, Wurtman RJ. Effects of systemic nicotine on serotonin release in rat brain. Brain Res. 1993; 621(2): 311-318.

93. Mihailescu S, Palomero-Rivero M, Meade-Huerta P, Maza-Flores A, Drucker-Colin R. Effects of nicotine and mecamylamine on rat dorsal raphe neurons. Eur J Pharmacol. 1998; 360(1): 31-36.

94. Veenstra-van der Weele J, Anderson GM, Cook Jr EH. Pharmacogenetics and the serotonin system: initial studies and future directions. Eur J Pharmacol. 2000; 410: 165-181.

95. Hu S, Brody CL, Fisher C, Gunzerath L, Nelson ML, Sabol SZ, Sirota LA, Marcus SE, Greenberg BD, Murphy DL, Hamer DH. Interaction between the serotonin transporter gene and neuroticism in cigarette smoking behavior. Mol Psychiatry. 2000; 5(2): 181-188.

96. Lerman C, Caporaso NE, Audrain J, Main D, Boyd NR, Shields PG. Interacting effects of the serotonin transporter gene and neuroticism in smoking practices and nicotine dependence. Mol Psychiatry. 2000; 5(2): 189-192.

97. U.S. Department of Health and Human Services. The health consequences of smoking. Nicotine addiction. A report of the Surgeon General. US Department of Health and Human Services, Public Health Service, Centers for Disease Control, Center for Chronic Disease Prevention and Health Promotion, Office on Smoking and Health. 1988.

98. Kaprio J, Hammar N, Koskenvuo M, Floderus-Myrhed B, Langinvainio H, Sarna S. Cigarette smoking and alcohol use in Finland and Sweden: a cross-national twin study. Int J Epidemiol. 1982; 11(4): 378-386.

99. Heath AC, Cates R, Martin NG, Meyer J, Hewitt JK, Neale MC, Eaves LJ. Genetic contribution to risk of smoking initiation: comparisons across birth cohorts and across cultures. J Subst Abuse. 1993; 5(3): 221-246.

100. Heath AC, Martin NG. Genetic models for the natural history of smoking: evidence for a genetic influence on smoking persistence. Addict Behav. 1993; 18(1): 19-34.

101. True WR, Heath AC, Scherrer JF, Waterman B, Goldberg J, Lin N, Eisen SA, Lyons MJ, Tsuang MT. Genetic and environmental contributions to smoking. Addiction. 1997; 92(10): 1277-1287.

102. Kendler KS, Neale MC, Sullivan P, Corey LA, Gardner CO, Prescott CA. A population-based twin study in women of smoking initiation and nicotine dependence. Psychol Med. 1999; 29(2): 299-308.

103. Sullivan PM, Kendler K. The genetic epidemiology of smoking.. Nicotine Tob Res. 1999; 1(Suppl 2): S51-S57.

104. Batra V, Patkar AA, Berrettini WH, Weinstein SP, Leone FT. The Genetic Determinants of Smoking. Chest. 2003; 123: 1730-1739.

105. Xian H, Scherrer JF, Madden PA, Lyons MJ, Tsuang M, True WR, Eisen SA. The heritability of failed smoking cessation and nicotine withdrawal in twins who smoked and attempted to quit. Nicotine Tob Res. 2003; 5(2): 245-254.

106. Pergadia ML, Heath AC, Martin NG, Madden PA. Genetic analyses of DSM-IV nicotine withdrawal in adult twins. Psychol Med. 2006; 36(7): 963-972. 
107. Rossing MA. Genetic influences on smoking: candidate genes. Environ Health Perspect. 1998; 106: 231-238.

108. Arinami T, Ishiguro H, Onaivi ES. Polymorphisms in genes involved in neurotransmission in relation to smoking. European Journal of Pharmacology. 2000; 410: 215-226.

109. Al Koudsi N, Tyndale RF. Genetic influences on smoking: a brief review. Ther Drug Monit. 2005; 27(6): 704-709.

110. MacLeod SL, Chowdhury P. The genetics of nicotine dependence: relationship to pancreatic cancer. World J Gastroenterol. 2006; 12(46): 7433-7439. 
Health promotion and health education regarding tobacco use has made the public aware of the dangers of smoking and has resulted in increased cessation rates, but many smokers still continue to smoke, leading to high morbidity and mortality rates, especially from chronic respiratory diseases such as COPD and asthma. Although many of these smokers are highly motivated to quit, only a small proportion of individuals respond to the various treatments that are currently available to aid long-term smoking cessation.

Recent research has shown that genetic factors contribute significantly to the variance in smoking behaviour. Variations in two broad classes of candidate genes have been suggested to contribute to smoking behaviour: 1) genes that may influence the response to nicotine (e.g. nicotine metabolism, nicotinic receptors); and 2) genes that may predispose to addictive behaviour due to their effects on key neurotransmitter pathways (e.g. dopamine and serotonin).

Overall, it seems that smokers with a reduced nicotine metabolism and increased dopamine levels are less addicted to smoking, while smokers with an increased nicotine metabolism and reduced dopamine levels seem to be more addicted. There also seems to be a relationship with variations in the nicotinic acetylcholinic receptors and the serotonin pathway, but the nature of this relationship is not yet clear. 


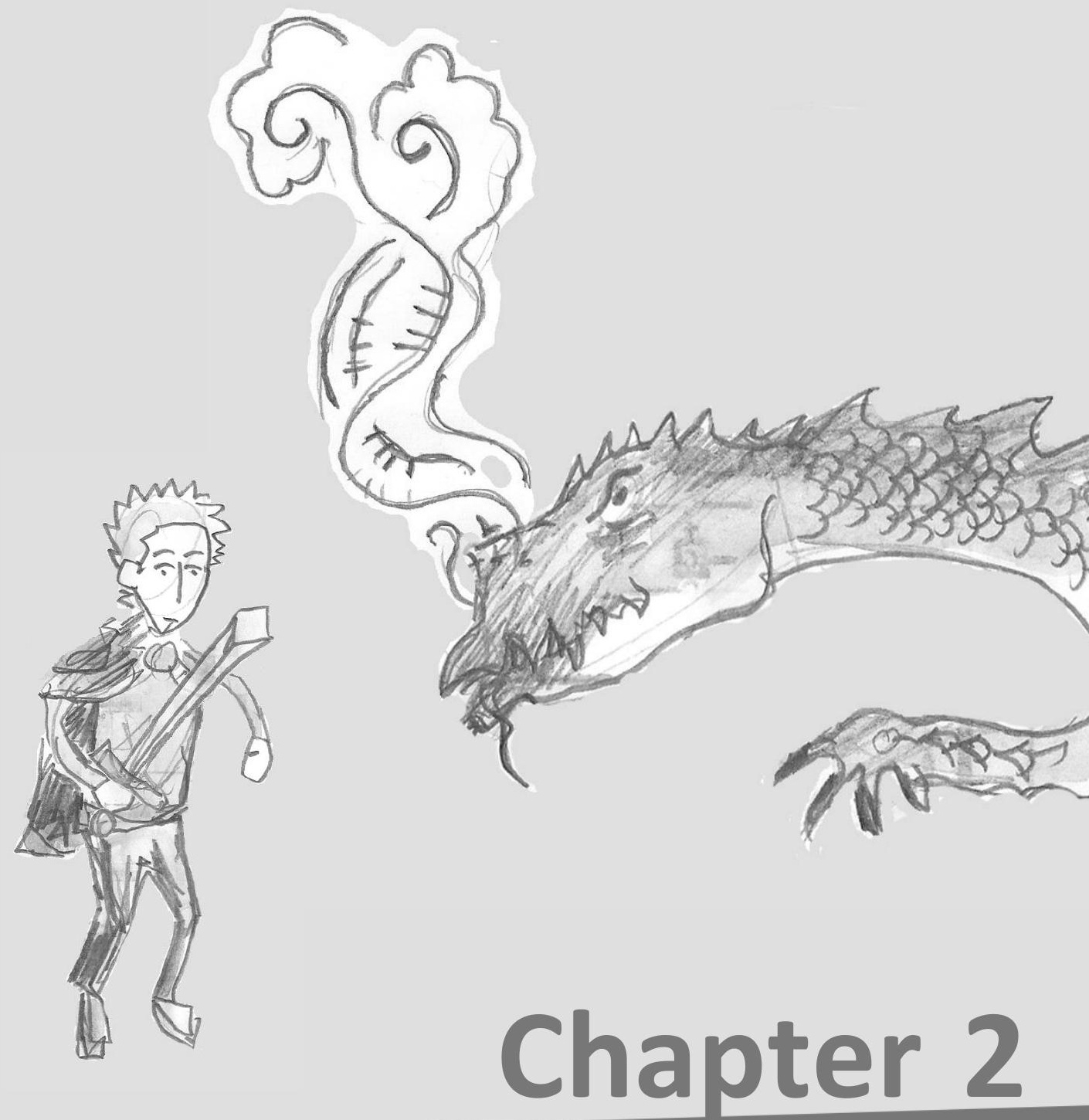

CANDIDATE GENES FOR THE VARIATION IN SMOKING BEHAVIOUR

Marieke Quaak, Constant P. van Schayck, Ad M. Knaapen, Frederik J. van Schooten. Based on: ERJ 2009; 33(3): 460-480; Mutat Res. 2009; 667(1-2):44-57 


\section{INTRODUCTION}

Although the risk of cigarette smoking is well documented, tobacco smoking continues to be the largest preventable cause of disease and premature death throughout the world. It is estimated that there are currently still over 1.5 billion smokers world-wide and this is expected to reach about 2 billion by 2025 [1-4]. Smoking harms nearly every organ of the body and compromises health of smokers in general, resulting in many common diseases (e.g. cancers, cardiovascular diseases, and chronic lung diseaseas such as chronic obstructive pulmonary disease [COPD] and asthma) [1]. Smoking raises the risk of disease even at low levels of intensity to about 3 times that of non-smokers and even more at a higher intensity of smoking [5]. Moreover, about half of all smokers who continue to smoke will die from a smoking-related disease, resulting in 3-6 million deaths world-wide per year [1,4-8]. This means that about 1 in 10 deaths is related to a smoking-induced disease, but this figure could rise to 1 in 6 by 2030 [1,5]. Currently, $35 \%$ of all smoking-related deaths can be attributed to cardiovascular diseases, making it the most common cause of death from smoking [7,8]. On the other hand, by 2015, about one-third of the smoking-related deaths will proably be caused by cancers, but will be closely followed by cardiovascular diseases and chronic respiratory diseases (both 30\%) [7,8].

Cessation reverses most adverse effects of smoking $[9,10]$. Smoking cessation as early as possible is important, but cessation at any age results in significant life extensions $[9,10]$. Although the majority of smokers are highly motivated to quit, both smokers and healthcare practitioners are confronted with high relapse rates after initial successful smoking cessation attempts. Despite progress made in the (pharmacological) treatment of nicotine dependence, the efficacy of available treatments is limited; only $15-30 \%$ of the smokers continue to abstain from smoking [11-19]. Therefore, often multiple quit attempts are required.

Both genetic and environmental determinants are believed to contribute to smoking. While early reports suggested that the influence of heredity on smoking was modest, more recent twin and adoption studies have found significant genetic influences on several aspects of smoking behaviour [20-28]. It has been demonstrated that genetic factors account for approximately $40-75 \%$ of the variation in smoking initiation, $70-80 \%$ of the variation in smoking maintenance, about $50 \%$ of the variance in cessation success and $30-50 \%$ of the variance in risk of withdrawal symptoms [20-28]. Variations in several genes have been suggested to contribute to smoking behaviour, and has been focused on two broad classes of candidate genes (for extended reviews see [26,29-32]):

1) Genes that may influence the response to nicotine (e.g. nicotine metabolism, nicotinic receptors).

2) Genes that may predispose to addictive behaviour due to their effects on key neurotransmitter pathways (e.g. dopamine and serotonin).

In the next section the most important candidate genes for the variation in smoking behaviour and the effect of variants in these genes on smoking behaviour will be discussed (for a summary see Table 1). 


\section{GENES INFLUENCING THE RESPONSE TO NICOTINE}

Nicotine is the primary reward component in tobacco products. Therefore genes involved in the metabolism of nicotine are biologically plausible candidates for genetic studies of smoking behaviour, because they determine the levels and duration of nicotine in the body. It is hypothesized that individuals with a high nicotine metabolism may experience fewer adverse reactions to their first encounter with nicotine, and therefore may have a greater chance to continue smoking and become addicted. Conversely, slow nicotine metabolizers may be less prone to initiate smoking because they may experience more adverse effects and would require fewer cigarettes to maintain nicotine titres at an optimal level once smoking is initiated [33].

The major genes responsible for the metabolism of nicotine are the hepatic enzymes cytochrome P450 2A6 (CYP2A6) and cytochrome P450 2D6 (CYP2D6) (see Figure 1). Of these, CYP2A6 is believed to be the most important predictor of the rate of nicotine metabolism, because it is responsible for roughly $90 \%$ of the metabolic inactivation of nicotine to cotinine $[34,35]$. A number of studies have shown that individuals carrying CYP2A6 variants that reduce the enzyme activity, determined in vivo via the measurement of the cotinine/nicotine (COT/NIC) or trans-3'-hydroxycotinine/cotinine (3HC/COT) ratio in blood or urine, are less tobacco-dependent, smoke significantly fewer cigarettes per day and have an increased likelihood of quitting smoking [33, 36-40]. Other studies have failed to detect these associations [41,42] and a meta-analysis reviewing several studies on CYP2A6 genotype and smoking found no association with smoking status and number of cigarettes smoked as well [43].

In addition, several studies have investigated the effects of CYP2D6 polymorphisms. Polymorphisms in CYP2D6 do not seem to be major determinants of nicotine metabolism in smokers except in ultrametabolizers (gene duplication) [44]. This is probably because its catalytic activity towards nicotine is negligible in the presence of functional CYP2A6. Ultrametabolizers were found to be more likely to be heavy smokers [45]. No relation has been found for individuals with a poor CYP2D6 metabolism $[45,46]$, although one study did find a trend towards more poor metabolizers among men in the non-smoking group [47], and another study reported that a poor CYP2D6 metabolism may reinforce smoking behaviour in committed smokers [48].

The pharmacological effects of nicotine are mediated by the activation of nicotinic acetylcholine receptors ( $\mathrm{nAChRs)}$. High affinity nicotinic receptors mainly contain the $\alpha 4$ (CHRNA4) and $\beta 2$ (CHRNB2) subunits, and $\alpha 4 \beta 2 *$ (* indicates that another subunit may be included) is the most frequently encountered nicotinic receptor subtype. Several nicotinic acetylcholine receptor subunit genes have been examined for associations with smoking status (e.g. CHRNA4, CHRNA5, CHRNA7, CHRNB1, CHRNB2 and CHRNB3), but the functional relevance of the investigated variants in these genes is not yet known. Some evidence for an association with tobacco dependence and smoking status for variants in CHRNA5, CHRNA7, CHRNB1 and CHRNB3 [49-51] has been provided. Evidence on the association of variants in the CHRNB2 and CHRNA4 genes is inconclusive [52-57]. 


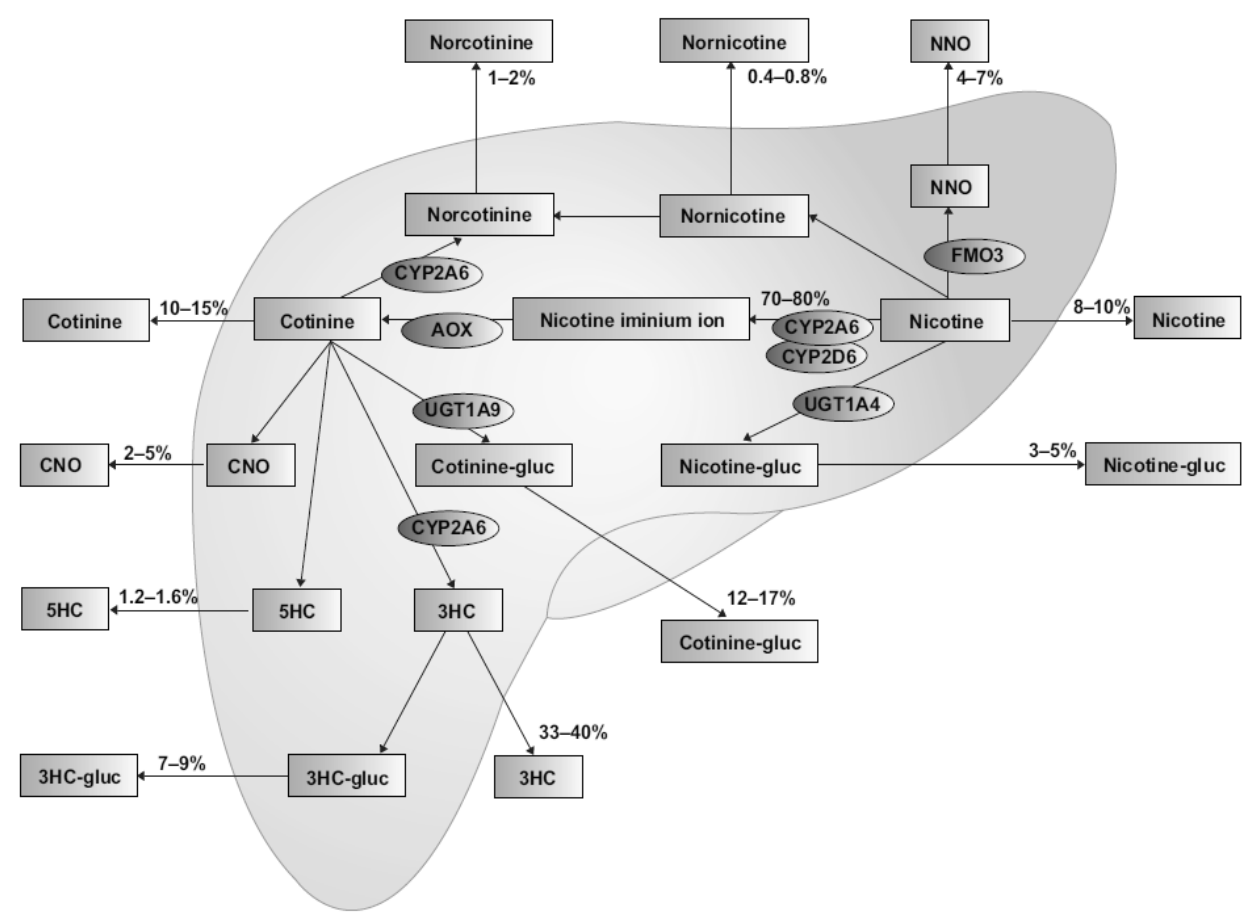

Figure 1: Nicotine metabolism in the human liver.

NNO: nicotine-19-N-oxidase; CYP2A6: cytochrome P450 2A6; FMO3: flavin-containing monooxygenase 3; AOX: aldehyde-oxidase; CYP2D6: cytochrome P450 2D6; CNO: cotinine-N-oxide; UGT: uridine diphosphateglucuronosyltransferase; cotinine-gluc: cotinine-glucuronide; nicotinegluc: (S)-nicotine-glucuronide; 5HC: 59-hydroxycotinine; 3HC: 39-hydroxycotinine; 3HC-gluc: 39-hydroxycotinine-glucuronide.

\section{GENES INVOLVED IN THE DOPAMINE PATHWAY}

The mesolimbic dopamine system has been proven to play an important role in nicotine's rewarding effects [58-61]. Therefore, investigators have examined the association between smoking behaviour and variations in several genes involved in the dopamine pathway, such as dopamine receptors, the dopamine transporter and enzymes involved in dopamine synthesis and metabolism (see Figure 2).

Variants in several dopamine receptor genes (e.g. DRD1, DRD2, DRD4 and DRD5) have been detected and studied in relation to smoking behaviour. Overall, genotypes associated with reduced dopamine receptor expression or function seem to predict a higher chance of becoming a smoker, a younger age of onset, and fewer and less successful quit attempts [62-71]. This is probably because subjects with reduced numbers of dopamine receptors may compensate for this deficiency by using nicotine to increase brain dopamine levels. However, the evidence concerning above results is still inconclusive $[30,72-74]$. 


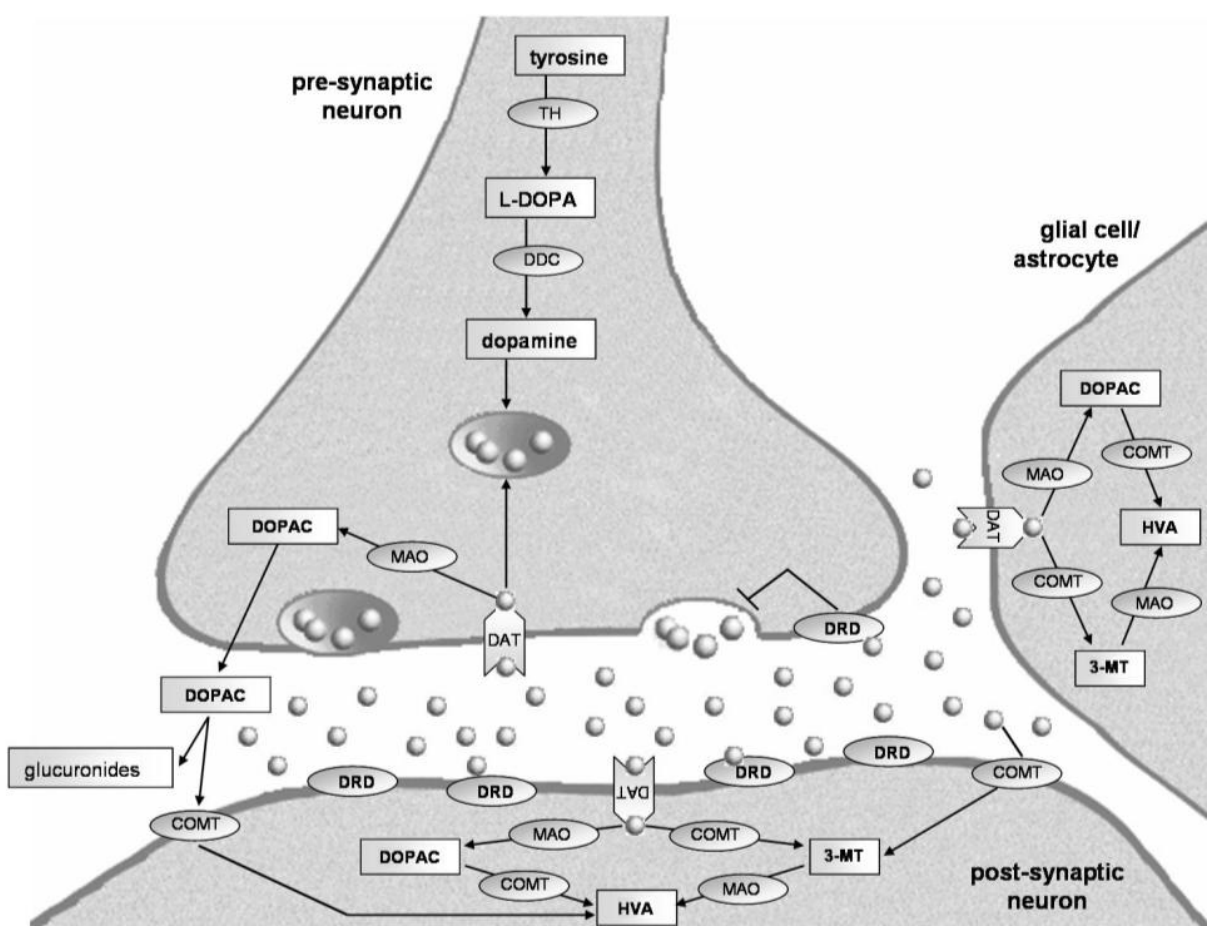

Figure 2: The dopamine pathway.

TH: tyrosine hydroxylase; L-DOPA: L-3,4-di-hydroxy-phenylalanine; DDC: 3,4-dihydroxyphenylacetic acid (DOPAC) decarboxylase; MAO: monoamine oxidase; DAT: dopamine transporter; DRD: dopamine receptor; COMT: catechol-O-methyltransferase; HVA: homovanillic acid; 3-MT: 3-methoxytyramine. Circles: dopamine.

The dopamine transporter (DAT-1, encoded by SLC6A3 gene) moves the dopamine released in the synapse into a neuron, glial cell or astrocyte to terminate the dopamine signal. A reduction in dopamine transporter levels, resulting in less clearance and greater bio-availability of dopamine, has been shown to be related to a lower chance to become a smoker, a lower nicotine intake, and longer periods of smoking cessation $[75,76]$, but also to increased craving among African American smokers [77]. Several other studies failed to replicate these results [78,79].

Several enzymes, such as tyrosine hydroxylase (TH), DOPA decarboxylase (DDC), dopamine beta-hydroxylase (DBH), catechol-O-methyl-transferase (COMT) and monoamine oxidase (MAO)-A and $-B$, are involved in the synthesis and metabolism of dopamine. Only limited data on the effects of variations in these enzymes on smoking behaviour is available. Associations between smoking and variations in genes for MAO-A, MAO-B, DBH and DDC have been found [80-86]. No associations for most variants in $T H$ have been reported, however one variant seems to protect against smoking [80, 87-89]. Contradicting results have been found for an increased activity COMT variant; some studies have found a positive association between the variant and nicotine dependence, and smoking cessation [90-93], while others did not find an association $[80,91]$. 


\section{GENES INVOLVED IN THE SEROTONIN PATHWAY}

The serotonin pathway is also under investigation in genetic studies of smoking for several reasons. Firstly, nicotine has been shown to increase the secretion of serotonin in the brain [94,95]. Secondly, increased serotonin levels have been associated with decreased food intake and weight gain, and have been shown to have an antidepressant effect [94]. Furthermore lower serotonin re-uptake has been associated with several behavioural traits (e.g. neuroticism, novelty seeking, and anxiety-related personality traits) that are related to an increased incidence of smoking, increased nicotine dependence, and difficulty in quitting smoking [96,97].

Candidate polymorphisms include those involved in serotonin biosynthesis (e.g. tryptophan hydroxylase, TPH) and serotonin re-uptake (e.g. serotonin transporter [SERT/5-HTT], SLC6A4). Individuals homozygous for a variant of TPH, with unknown effect, have been shown to be more prone to initiate smoking and to start smoking at an earlier age [98-100], but no effect on progression to nicotine dependence and smoking status has been found [98-100]. Other studies have found that lower serotonin transporter levels are associated with increased neuroticism in nicotine dependence [96, 97]. Another study was unable to detect an association [101]. Conversely, in a Japanese population increased serotonin transporter levels appeared to be associated with smoking [102].

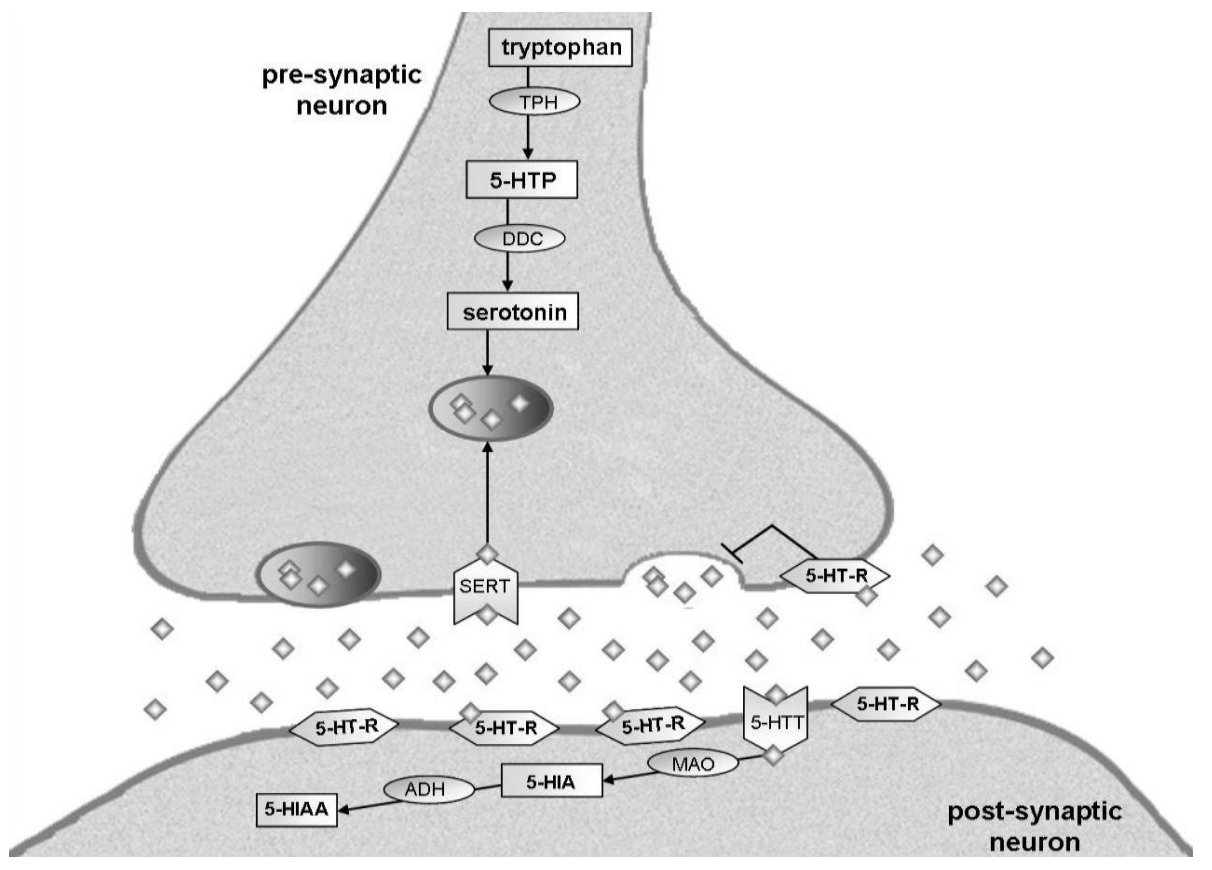

Figure 3: The serotonin pathway.

TPH: tryptophan hydroxylase; 5-HTP: 5-hydroxytryptophan; DDC: amino acid decarboxylase; SERT: serotonin transporter (pre-synaptic); 5-HT-R: serotonin transporter; 5-HTT: serotonin transporter (post-synaptic); MAO: monoamine oxidase; 5-HIA: 5-hydroxyindole acid ADH: aldehyde dehydrogenase; 5-HIAA: 5-hydroxyindoleacetic acid. Diamonds: serotonin 
Table 1: Candidate genes for the variation in nicotine dependence and smoking cessation

\begin{tabular}{|c|c|c|c|c|}
\hline function & gene & variant phenotype & effect on smoking & references \\
\hline \multicolumn{5}{|c|}{ Genes influencing the response to nicotine } \\
\hline \multirow{5}{*}{$\begin{array}{l}\text { nicotine } \\
\text { metabolism }\end{array}$} & \multirow[t]{2}{*}{ CYP2A6 } & \multirow[t]{2}{*}{ reduced activity } & $\begin{array}{l}\text { lower ND; smoke fewer cigarettes; } \\
\text { increased likelihood of quitting }\end{array}$ & {$[33,36-40]$} \\
\hline & & & no association & [41-43] \\
\hline & \multirow{3}{*}{ CYP2D6 } & $\begin{array}{l}\text { higher nicotine metabolism } \\
\text { (ultrametabolizers) }\end{array}$ & more likely to be heavy smokers & [45] \\
\hline & & \multirow{2}{*}{$\begin{array}{c}\text { reduced activity } \\
\text { no effect on nicotine } \\
\text { metabolism (in presence } \\
\text { functional CYP2A6?) }\end{array}$} & no relation with smoking & {$[45,46]$} \\
\hline & & & $\begin{array}{l}\text { trend towards non-smoking in men; } \\
\text { no effect on initiation, but possibly } \\
\text { on subsequent smoking behaviour }\end{array}$ & {$[47,48]$} \\
\hline \multirow{6}{*}{$\begin{array}{l}\text { nicotinic } \\
\text { acetylcholinic } \\
\text { receptors } \\
\text { (nAchRs) }\end{array}$} & CHRNA4 & unknown & inconclusive & {$[53,56,57,103]$} \\
\hline & CHRNA5 & unknown & associated with ND and smoking status & {$[51]$} \\
\hline & CHRNA7 & unknown & associated with ND and smoking status & [49] \\
\hline & CHRNB1 & unknown & associated with ND and smoking status & {$[50]$} \\
\hline & CHRNB2 & unknown & inconclusive & {$[52,55,57]$} \\
\hline & CHRNB3 & unknown & associated with ND and smoking status & {$[51]$} \\
\hline \multicolumn{5}{|c|}{ Genes influencing key neurotransmitter pathways - Dopamine pathway } \\
\hline \multirow{3}{*}{$\begin{array}{l}\text { dopamine } \\
\text { receptors }\end{array}$} & DRD1 & \multirow{2}{*}{$\begin{array}{l}\text { reduced receptor } \\
\text { expression or function }\end{array}$} & \multirow{2}{*}{$\begin{array}{l}\text { higher chance of becoming a smoker; } \\
\text { younger age of onset; fewer and } \\
\text { less successful quit attempts }\end{array}$} & \multirow{2}{*}{ [62-71] } \\
\hline & DRD2 & & & \\
\hline & DRD4 & $\begin{array}{l}\text { reduced receptor } \\
\text { expression or function }\end{array}$ & no association & {$[30,72-74]$} \\
\hline \multirow{3}{*}{$\begin{array}{l}\text { dopamine } \\
\text { transporter-1 } \\
\text { (DAT-1) }\end{array}$} & \multirow{3}{*}{ SLC6A3 } & \multirow{3}{*}{$\begin{array}{l}\text { lower transporter } \\
\text { levels } \rightarrow \text { less clearance } \\
\rightarrow \text { higher bioavailability } \\
\text { dopamine }\end{array}$} & $\begin{array}{l}\text { lower chance to be a smoker; } \\
\text { lower nicotine intake; greater } \\
\text { periods of smoking cessation }\end{array}$ & {$[75,76]$} \\
\hline & & & $\begin{array}{l}\text { increased craving among } \\
\text { African-American smokers }\end{array}$ & [77] \\
\hline & & & no association & {$[78,79]$} \\
\hline \multirow{2}{*}{$\begin{array}{l}\text { dopamine } \\
\text { synthesis }\end{array}$} & $T H$ & $\begin{array}{l}\text { unknown; suggested to } \\
\text { have lower activity }\end{array}$ & $\begin{array}{l}\text { earlier age of onset; no association } \\
\text { with progression to ND }\end{array}$ & {$[80,87-89]$} \\
\hline & $D D C$ & unknown & increased ND & {$[80,83,85,86]$} \\
\hline \multirow{5}{*}{$\begin{array}{l}\text { dopamine } \\
\text { metabolism }\end{array}$} & $D B H$ & lower activity & more heavy smokers & {$[80,84]$} \\
\hline & \multirow[t]{2}{*}{ COMT } & \multirow[t]{2}{*}{ increased activity } & $\begin{array}{l}\text { positive association with ND } \\
\text { and smoking cessation }\end{array}$ & [90-93] \\
\hline & & & no association & {$[80,91]$} \\
\hline & MAO-A & increased activity & more heavy smokers & {$[80-82,84]$} \\
\hline & $M A O-B$ & lower activity & no association & {$[80-82,84]$} \\
\hline \multicolumn{5}{|c|}{ Genes influencing key neurotransmitter pathways - Serotonin pathway } \\
\hline $\begin{array}{l}\text { serotonin } \\
\text { biosynthesis }\end{array}$ & $\mathrm{TPH}$ & unknown & $\begin{array}{l}\text { more prone to initiate smoking; } \\
\text { start at an earlier age; no effect on } \\
\text { progression to ND and smoking status }\end{array}$ & [98-100] \\
\hline \multirow{3}{*}{$\begin{array}{l}\text { serotonin } \\
\text { transporter }\end{array}$} & \multirow{3}{*}{$5-H T T$} & \multirow{2}{*}{ lower transporter levels } & increased neuroticism & {$[96,97]$} \\
\hline & & & no association & {$[101]$} \\
\hline & & higher transporter levels & Increased smoking (Japanese) & [102] \\
\hline
\end{tabular}




\section{CONCLUSIONS}

Health promotion and health education regarding tobacco use has made the public more aware of the dangers of smoking and has resulted in increased cessation rates, but many smokers still continue to smoke, leading to high morbidity and mortality rates. Although many of these smokers are highly motivated to quit, only a small proportion of individuals respond to the various treatments that are currently available to aid long-term smoking cessation.

Recent research has shown that genetic factors contribute to the variance in smoking behaviour (see Table 1). Overall, it seemed that smokers with a reduced nicotine metabolism and increased dopamine levels were less addicted to smoking, smoke fewer cigarettes, had an increased likelihood of quitting and stopped for a longer period of time. In contrast, smokers with an increased nicotine metabolism and reduced dopamine levels seemed to be more addicted, had a higher chance of becoming a smoker, a younger age of onset, smoked more cigarettes, and underwent fewer and less succesfull quit attempts. There also seemed to be a relationship with variants in the nicotinic acetylcholinic receptors and the serotonin pathway, but the nature of this relationship was not yet clear.

Since the genetic background of mechanisms influencing smoking behaviour and addiction varies between smokers, and the available smoking cessation therapies are directed at the pathways involved in smoking, it is a logical step to assess whether this genetic variation also determines the efficacy of smoking cessation treatment. Research on the role of such inherited genetic variation in the response to pharmacotherapy for smoking cessation opens avenues for individually tailored smoking cessation treatment based on genetic background. This might improve efficacy and minimize toxicity and side-effects of the treatments.

\section{REFERENCES}

1. The World Bank. Curbing the epidemic: governments and the economics of tobacco control. Tob Control. 1999; 8(2): 196-201.

2. Mackay J, Eriksen M. The tobacco Atlas. Geneva, World Health Organization. 2002.

3. Guindon GE, Boisclair D. Past, current and future trends in tobacco use. HNP discussion paper no.6. Econcomics of tobacco control paper no. 6. 2003.

4. World Health Organization. The world health report 2003 - shaping the future; 2003.

5. Mucha L, Stephenson J, Morandi N, Dirani R. Meta-analysis of disease risk associated with smoking, by gender and intensity of smoking. Gend Med. 2006; 3(4): 279-291.

6. Steptoe A, Wardle J, Cui W, Baban A, Glass K, Tsuda A, Vinck J. An international comparison of tobacco smoking, beliefs and risk awareness in university students from 23 countries. Addiction. 2002; 97(12): 1561-1571.

7. Ezzati M, Lopez AD. Estimates of global mortality attributable to smoking in 2000. Lancet. 2003; 362(9387): 847-852.

8. Mathers CD, Loncar D. Projections of global mortality and burden of disease from 2002 to 2030. PLoS Med. 2006; 3(11): e442. 
9. Taylor DH, Jr., Hasselblad V, Henley SJ, Thun MJ, Sloan FA. Benefits of smoking cessation for longevity. Am J Public Health. 2002; 92(6): 990-996.

10. Doll R, Peto R, Boreham J, Sutherland I. Mortality from cancer in relation to smoking: 50 years observations on British doctors. Br J Cancer. 2005; 92(3): 426-429.

11. Lancaster T, Stead L, Silagy C, Sowden A. Effectiveness of interventions to help people stop smoking: findings from the Cochrane Library. BMJ. 2000; 321(7257): 355-358.

12. Lancaster T, Stead LF. Individual behavioural counselling for smoking cessation. Cochrane Database Syst Rev. 2002; (3): CD001292.

13. Stead LF, Lancaster T. Group behaviour therapy programmes for smoking cessation. Cochrane Database Syst Rev. 2005; (2): CD001007.

14. Hughes JR, Stead LF, Lancaster T. Antidepressants for smoking cessation. Cochrane Database Syst Rev. 2007; (1): CD000031.

15. Silagy C, Lancaster T, Stead L, Mant D, Fowler G. Nicotine replacement therapy for smoking cessation. Cochrane Database Syst Rev. 2004; (3): CD000146.

16. Cahill K, Stead LF, Lancaster T. Nicotine receptor partial agonists for smoking cessation. Cochrane Database Syst Rev. 2007; (1): CD006103.

17. David S, Lancaster T, Stead LF, Evins AE. Opioid antagonists for smoking cessation. Cochrane Database Syst Rev. 2006; (4): CD003086.

18. Gourlay SG, Stead LF, Benowitz NL. Clonidine for smoking cessation. Cochrane Database Syst Rev. 2004; (3): CD000058.

19. White AR, Rampes H, Campbell JL. Acupuncture and related interventions for smoking cessation. Cochrane Database Syst Rev. 2006; (1): CD000009.

20. Kaprio J, Hammar N, Koskenvuo M, Floderus-Myrhed B, Langinvainio H, Sarna S. Cigarette smoking and alcohol use in Finland and Sweden: a cross-national twin study. Int J Epidemiol. 1982; 11(4): 378-386.

21. Heath AC, Cates R, Martin NG, Meyer J, Hewitt JK, Neale MC, Eaves L. Genetic contribution to risk of smoking initiation: comparisons across birth cohorts and across cultures. J Subst Abuse. 1993; 5(3): 221-246.

22. Heath AC, Martin NG. Genetic models for the natural history of smoking: evidence for a genetic influence on smoking persistence. Addict Behav. 1993; 18(1): 19-34.

23. True WR, Heath AC, Scherrer JF, Waterman B, Goldberg J, Lin N, Eisen SA, Lyons MJ, Tsuang MT. Genetic and environmental contributions to smoking. Addiction. 1997; 92(10): 1277-1287.

24. Kendler KS, Neale MC, Sullivan P, Corey LA, Gardner CO, Prescott CA. A population-based twin study in women of smoking initiation and nicotine dependence. Psychol Med. 1999; 29(2): 299-308.

25. Sullivan PM, Kendler K. The genetic epidemiology of smoking. . Nicotine and Tobacco Research. 1999; 1(Suppl 2): S51-S57.

26. Batra V, Patkar AA, Berrettini WH, Weinstein SP, Leone FT. The Genetic Determinants of Smoking. Chest. 2003; 123: 1730-1739.

27. Xian H, Scherrer JF, Madden PA, Lyons MJ, Tsuang M, True WR, Eisen SA. The heritability of failed smoking cessation and nicotine withdrawal in twins who smoked and attempted to quit. Nicotine Tob Res. 2003; 5(2): 245-254.

28. Pergadia ML, Heath AC, Martin NG, Madden PA. Genetic analyses of DSM-IV nicotine withdrawal in adult twins. Psychol Med. 2006; 36(7): 963-972.

29. Rossing MA. Genetic influences on smoking: candidate genes. Environ Health Perspect. 1998; 106: 231-238.

30. Arinami T, Ishiguro $\mathrm{H}$, Onaivi ES. Polymorphisms in genes involved in neurotransmission in relation to smoking. European Journal of Pharmacology. 2000; 410: 215-226.

31. Al Koudsi N, Tyndale RF. Genetic influences on smoking: a brief review. Ther Drug Monit. 2005; 27(6): 704-709.

32. MacLeod SL, Chowdhury P. The genetics of nicotine dependence: relationship to pancreatic cancer. World 
J Gastroenterol. 2006; 12(46): 7433-7439.

33. Pianezza ML, Sellers EM, Tyndale RF. Nicotine metabolism defect reduces smoking. Nature. 1998; 393(750).

34. Nakajima M, Yamamoto T, Nunoya K, Yokoi T, Nagashima K, Inoue K, Funae Y, Shimada N, Kamataki T, Kuroiwa Y. Role of human cytochrome P4502A6 in C-oxidation of nicotine. Drug Metab Dispos. 1996; 24(11): 1212-1217.

35. Messina ES, Tyndale RF, Sellers EM. A major role for CYP2A6 in nicotine C-oxidation by human liver microsomes. J Pharmacol Exp Ther. 1997; 282(3): 1608-1614.

36. Rao Y, Hoffmann E, Zia M, Bodin L, Zeman M, Sellers EM, Tyndale RF. Duplications and defects in the CYP2A6 gene: identification, genotyping and in vivo effects on smoking. Molecular pharmacology. 2000; 58: 747-755.

37. Tyndale RF, Sellers EM. Variable CYP2A6-mediated nicotine metabolism alters smoking behavior and risk. Drug metabolism and disposition. 2001; 29(4): 548-552.

38. Ando M, Hamajima N, Ariyoshi N, Kamataki T, Matsuo K, Ohno Y. Association of CYP2A6 gene deletion with cigarette smoking status in Japanese adults. J Epidemiol. 2003; 13(3): 176-181.

39. Fujieda M, Yamazaki H, Saito T, Kiyotani K, Gyamfi MA, Sakurai M, Dosaka-Akita H, Sawamura Y, Yokota J, Kunitoh H, Kamataki T. Evaluation of CYP2A6 genetic polymorphisms as determinants of smoking behavior and tobacco-related lung cancer risk in male Japanese smokers. Carcinogenesis. 2004; 25(12): 2451-2458.

40. Schoedel KA, Hoffmann EB, Rao Y, Sellers EM, Tyndale RF. Ethnic variation in CYP2A6 and association of genetically slow nicotine metabolism and smokng in adult Caucasians. Pharmacogenetics. 2004; 14: 615-626.

41. London SJ, Idle JR, Daly AK, Coetzee GA. Genetic variation of CYP2A6, smoking, and risk of cancer. Lancet. 1999; 353(9156): 898-899.

42. Loriot MA, Rebuissou S, Oscarson M, Cenee S, Miyamoto M, Ariyoshi N, Kamataki T, Hemon D, Beaune P, Stucker I. Genetic polymorphisms of cytochrome P450 2A6 in a case-control study on lung cancer in a French population. Pharmacogenetics. 2001; 11(1): 39-44.

43. Carter B, Long T, Cinciripini P. A meta-analytic review of the CYP2A6 genotype and smoking behavior. Nicotine Tob Res. 2004; 6(2): 221-227.

44. Caporaso NE, Lerman C, Audrain J, Boyd NR, Main D, Issaq HJ, Utermahlan B, Falk RT, Shields P. Nicotine metabolism and CYP2D6 phenotype in smokers. Cancer Epidemiology, Biomarkers \& Prevention. 2001; 10: 261-263.

45. Saarikoski ST, Sata F, Husgafvel-Pursiainen K, Rautalahti M, Haukka J, Impivaara O, Jarvisalo J, Vainio $\mathrm{H}$, Hirvonen A. CYP2D6 ultrarapid metabolizer genotype as a potential modifier of smoking behaviour. Pharmacogenetics. 2000; 10(1)(1): 5-10.

46. Cholerton S, Boustead C, Taber H, Arpanahi A, Idle JR. CYP2D6 genotypes in cigarette smokers and nontobacco users. Pharmacogenetics. 1996; 6(3): 261-263.

47. Saarikoski ST, Sata F, Husgafvel-Pursiainen K, Rautalahti M, Haukka J, Impivaara O, Jarvisalo J, Vainio H, Hirvonen A. CYP2D6 ultrarapid metabolizer genotype as a potential modifier of smoking behaviour. Pharmacogenetics. 2000; 10(1): 5-10.

48. Boustead C, Taber H, Idle JR, Cholerton S. CYP2D6 genotype and smoking behaviour in cigarette smokers. Pharmacogenetics. 1997; 7(5): 411-414.

49. De Luca V, Wang H, Squassina A, Wong GW, Yeomans J, Kennedy JL. Linkage of M5 muscarinic and alpha7nicotinic receptor genes on 15q13 to schizophrenia. Neuropsychobiology. 2004; 50(2): 124-127.

50. Lou XY, Ma JZ, Payne TJ, Beuten J, Crew KM, Li MD. Gene-based analysis suggests association of the nicotinic acetylcholine receptor beta1 subunit (CHRNB1) and M1 muscarinic acetylcholine receptor (CHRM1) with vulnerability for nicotine dependence. Hum Genet. 2006; 120(3): 381-389.

51. Saccone SF, Hinrichs AL, Saccone NL, Chase GA, Konvicka K, Madden PA, Breslau N, Johnson EO, Hatsukami D, Pomerleau O, Swan GE, Goate AM, Rutter J, Bertelsen S, Fox L, Fugman D, Martin NG, Montgomery GW, Wang JC, Ballinger DG, Rice JP, Bierut LJ. Cholinergic nicotinic receptor genes implicated in a nicotine dependence association study targeting 348 candidate genes with 3713 SNPs. Hum Mol Genet. 2007; 
16(1): 36-49.

52. Silverman MA, Neale MC, Sullivan PF, Harris-Kerr C, Wormley B, Sadek H, Ma Y, Kendler KS, Straub RE. Haplotypes of four novel single nucleotide polymorphisms in the nicotinic acetylcholine receptor beta2subunit (CHRNB2) gene show no association with smoking initiation or nicotine dependence. Am J Med Genet. 2000; 96(5): 646-653.

53. Feng $\mathrm{Y}$, Niu T, Xing H, Xu X, Chen C, Peng S, Wang L, Laird N, Xu X. A common haplotype of the nicotine acetylcholine receptor alpha 4 subunit gene is associated with vulnerability to nicotine addiction in men. Am J Hum Genet. 2004; 75(1): 112-121.

54. Li MD, Beuten J, Ma JZ, Payne TJ, Lou XY, Garcia V, Duenes AS, Crews KM, Elston RC. Ethnic- and genderspecific association of the nicotinic acetylcholine receptor alpha4 subunit gene (CHRNA4) with nicotine dependence. Hum Mol Genet. 2005; 14(9): 1211-1219.

55. Staley JK, Krishnan-Sarin S, Cosgrove KP, Krantzler E, Frohlich E, Perry E, Dubin JA, Estok K, Brenner E, Baldwin RM, Tamagnan GD, Seibyl JP, Jatlow P, Picciotto MR, London ED, O'Malley S, van Dyck CH. Human tobacco smokers in early abstinence have higher levels of beta2 nicotinic acetylcholine receptors than nonsmokers. J Neurosci. 2006; 26(34): 8707-8714.

56. Ehringer MA, Clegg HV, Collins AC, Corley RP, Crowley T, Hewitt JK, Hopfer CJ, Krauter K, Lessem J, Rhee SH, Schlaepfer I, Smolen A, Stallings MC, Young SE, Zeiger JS. Association of the neuronal nicotinic receptor beta2 subunit gene (CHRNB2) with subjective responses to alcohol and nicotine. Am J Med Genet B Neuropsychiatr Genet. 2007; 144B(5): 596-604.

57. Voineskos S, De Luca V, Mensah A, Vincent JB, Potapova N, Kennedy JL. Association of alpha4beta2 nicotinic receptor and heavy smoking in schizophrenia. J Psychiatry Neurosci. 2007; 32(6): 412-416.

58. Di Chiara G, Imperato A. Drugs abused by humans preferentially increase synaptic dopamine concentrations in the mesolimbic system of freely moving rats. Proc Natl Acad Sci U SA. 1988; 85(14): 5274-5278.

59. Pontieri FE, Tanda G, Orzi F, Di Chiara G. Effects of nicotine on the nucleus accumbens and similarity to those of addictive drugs. Nature. 1996; 382(6588): 255-257.

60. Zoli M, Moretti M, Zanardi A, McIntosh JM, Clementi F, Gotti C. Identification of the nicotinic receptor subtypes expressed on dopaminergic terminals in the rat striatum. $J$ Neurosci. 2002; 22(20): 8785-8789.

61. Balfour DJ. The neurobiology of tobacco dependence: a preclinical perspective on the role of the dopamine projections to the nucleus accumbens [corrected]. Nicotine Tob Res. 2004; 6(6): 899-912.

62. Noble EP, St. Jeor ST, Ritchie T, Syndulko K, St. Jeor SC, Fitch RJ, Brunner RL, Sparkes RS. D2 dopamine receptor gene and cigarette smoking: a reward gene? Medical Hypotheses. 1994; 42: 257-260.

63. Comings DE, Ferry L, Bradshaw-Robinson S, Burchette R, Chiu C, Muhleman D. The dopamine D2 receptor (DRD2) gene: a genetic risk factor in smoking. Pharmacogenetics. 1996; 6(1): 73-79.

64. Comings DE, Gade R, Wu S, Chiu C, Dietz G, Muhleman D, Saucier G, Ferry L, Rosenthal RJ, Lesieur HR,

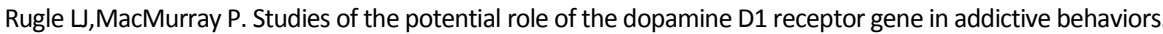
Mol Psychiatry. 1997; 2(1): 44-56.

65. Shields PG, Lerman C, Audrain JB, E.D., Main D, Boyd NR, Caporaso N. Dopamine D4 receptors and the risk of cigarette smoking in African-Americans and Caucasians. Cancer Epidemiology, Biomarkers \& Prevention. 1998; 7: 453-458.

66. Spitz MR, Shi H, Yang F, Hudmon KS, Jiang H, Chamberlain RM, Amos Cl, Wan Y, Cinciripini P, Hong WK, Wu X. Case-control study of the D2 dopamine receptor gene and smoking status in lung cancer patients. $J$ Natl Cancer Inst. 1998; 90(5): 358-363.

67. Wu X, Hudmon KS, Detry MA, Chamberlain RM, Spitz MR. D2 dopamine receptor gene polymorphisms among African-Americans and Mexican-Americans: a lung cancer case-control study. Cancer Epidemiology, Biomarkers \& Prevention. 2000; 9: 1021-1026.

68. Sullivan PF, Neale MC, Silverman MA, Harris-Kerr C, Myakishev MV, Wormley B, Webb BT, Ma Y, Kendler KS, 
Straub RE. An association study of DRD5 with smoking initiation and progression to nicotine dependence. Am J Med Genet. 2001; 105(3): 259-265.

69. Yoshida K, Hamajima N, Kozaki K, Saito H, Maeno K, Sugiara T, Ookuma K, Takahashi K. Association between the dopamine D2 receptor A2/A2 genotype and smoking behavior in the Japenese. Cancer Epidemiology, Biomarkers \& Prevention. 2001; 10: 403-405.

70. Munafo M, Clark T, Johnstone $\mathrm{E}$, Murphy M, Walton R. The genetic basis for smoking behavior: a systematic review and meta-analysis. Nicotine Tob Res. 2004; 6(4): 583-597.

71. Laucht M, Becker K, El-Faddagh M, Hohm E, Schmidt MH. Association of the DRD4 exon III polymorphism with smoking in fifteen-year-olds: a mediating role for novelty seeking? J Am Acad Child Adolesc Psychiatry. 2005; 44(5): 477-484.

72. Bierut L, Rice JP, Edenberg HJ, Goate A, Foroud T, Cloninger CR, Begleiter H, Conneally PM, Crowe RR, Hesselbrock V, Li T-K, Nurnberger Jr Jl, Porjesz B, Schuckit MA, Reich T. Family-based study of the association of the dopamine D2 receptor gene (DRD2) with habitual smoking. Am J Med Genet 2000; 90: 299-302.

73. Singleton AB, Thomson JH, Morris CM, Court JA, Lloyd S, Cholerton S. Lack of association between the dopamine D2 receptor gene allele DRD2*A1 and cigarette smoking in a United Kingdom population. Pharmacogenetics. 1998; 8(2): 125-128.

74. Johnstone EC, Yudkin P, Griffiths SE, Fuller A, Murphy M, Walton R. The dopamine D2 receptor C32806T polymorphism (DRD2 Taq1A RFLP) exhibits nog association with smoking behaviour in a healthy UK population. Addict Biol. 2004; 9(3-4): 221-226.

75. Lerman C, Caporaso N, Main D, Audrain J, Boyd NR, Bowman ED, Shields PG. Evidence suggesting the role of specific genetic factors in cigarette smoking. Health Pschology. 1999; 18(1): 14-20.

76. Sabol SZ, Nelson ML, Fisher LG, Brody CL, Hu S, Sirota LA, Marcus SE, Greenberg BD, Lucas IV FR, Benjamin J, Murphy DL, Hamer D. A genetic association for cigarette smoknb behavior. Health Pschology. 1999; 18(1): 7-13.

77. Erblich J, Lerman C, Self DW, Diaz GA, Bovbjerg DH. Stress-induced cigarette craving effects of the DRD2 Taql RFLP and SLC6A3 VNTR polymorphisms. Pharmacogenomics. 2004; 4(2): 102-109.

78. Jorm AF, Henderson AS, Jacomb PA, Cristensen H, Korten AE, Rodgers B, Tan X, Easteal S. Association of smoking and personality with a polymorphism of the dopamine transporter gene: results from a community survey. $A m J$ Med Genet B Neurophsychiatr Genet. 2000; 96: 331-334.

79. Vandenbergh DJ, Bennet DJ, Grant MD, Strasser AA, O'Connor R, Stauffer RL, Vogler GP, Kozlowski LT. Smoking status and the human dopamine transporter variable number of tandem repeats (VNTR) polymorphism: failrure to replicate and finding that never-smokers may be different. Nicotine Tob Res. 2002; 4(3): 333-340.

80. McKinney EF, Walton RT, Yudkin P, Fuller A, Haldar NA, Mant D, Murphy M, Welsh KI, Marshal SE. Association between polymorphisms in dopamine metabolic enzymes and tobacco consumption in smokers. Pharmacogenetics. 2000; 10(6)(6): 483-491.

81. Ito H, Hamajima N, Matsuo K, Okuma K, Sato S, Ueda R, Tajima K. Monoamine oxidase polymorphisms and smoking behaviour in Japanese. Pharmacogenetics. 2003; 13(2): 73-79.

82. Costa-Mallen P, Costa LG, Checkoway H. Genotype combinations for monoamine oxidase-B intron 13 polymorphism and dopamine D2 receptor TaqIB polymorphism are associated with ever-smoking status among men. Neurosci Lett. 2005; 385: 158-162.

83. Ma JZ, Beuten J, Payne TJD, R.T., Elston RC, Li MD. Haplotype analysis indicates an association between the DOPA decarboxylase (DDC) gene and nicotine dependence. Hum Mol Genet. 2005; 14(12): 1691-1698.

84. Freire MT, Marques FZ, Hutz MH, Bau CH. Polymorphisms in the DBH and DRD2 gene regions and smoking behavior. Eur Arch Psychiatry Clin Neurosci. 2006; 256(2): 93-97.

85. Yu Y, Panhuysen C, Kranzler HR, Hesselbrock V, Rounsaville B, Weiss R, Brady K, Farrer LA, Gelernter J. Intronic variants in the dopa decarboxylase (DDC) gene are associated with smoking behavior in European-Americans and African-Americans. Hum Mol Genet. 2006; 15(14): 2192-2199. 
86. Zhang $H$, Ye Y, Wang X, Gelernter J, Ma JZ, Li MD. DOPA decarboxylase gene is associated with nicotine dependence. Pharmacogenomics. 2006; 7(8): 1159-1166.

87. Lerman C, Shields PG, Main D, Audrain J, Roth J, Boyd NR, Caporaso NE. Lack of association of tyrosine hydroxylase genetic polymorphism with cigarette smoking. Pharmacogenetics. 1997; 7(6): 521-524.

88. Anney RJ, Olsson CA, Lotfi-Miri M, Patton GC, Williamson R. Nicotine dependence in a prospective populationbased study of adolescents: the protective role of a functional tyrosine hydroxylase polymorphism. Pharmacogenetics. 2004; 14(2): 73-81.

89. Olsson C, Anney R, Forrest S, Patton G, Coffey C, Cameron T, Hassett A, Williamson R. Association between dependent smoking and a polymorphism in the tyrosine hydroxylase gene in a prospective populationbased study of adolescent health. Behav Genet. 2004; 34(1): 85-91.

90. Colilla S, Lerman C, Shields PG, Jepson C, Rukstalis M, Berlin J, DeMichele A, Bunin G, Strom BL, Rebbeck TR. Association of catechol-O-methyltransferase with smoking cessation in two independent studies of women. Pharmacogenet Genomics. 2005; 15(6): 393-398.

91. Redden DT, Shields PG, Epstein L, Wileyto EP, Zahkarkin SO, Allison DB, Lerman C. Catechol-O-methyltransferase functional polymorphism and nicotine dependence: an evaluation of nonreplicated results. Cancer Epidemiology, Biomarkers \& Prevention. 2005; 14(6): 1384-1389.

92. Beuten J, Payne TJ, Ma JZ, Li MD. Significant association of catechol-O-methyltransferase (COMT) haplotypes with nicotine dependence in male and female smokers of two ethnic populations. Neuropsychopharmacology. 2006; 31(3): 675-684.

93. Guo S, Chen da F, Zhou DF, Sun HQ, Wu GY, Haile CN, Kosten TA, Kosten TR, Zhang XY. Association of functional catechol O-methyl transferase (COMT) Val108Met polymorphism with smoking severity and age of smoking initiation in Chinese male smokers. Psychopharmacology (Berl). 2007; 190(4): 449-456.

94. Ribeiro EB, Bettiker RL, Bogdanov M, Wurtman RJ. Effects of systemic nicotine on serotonin release in rat brain. Brain Res. 1993; 621(2): 311-318.

95. Mihailescu S, Palomero-Rivero M, Meade-Huerta P, Maza-Flores A, Drucker-Colin R. Effects of nicotine and mecamylamine on rat dorsal raphe neurons. Eur J Pharmacol. 1998; 360(1): 31-36.

96. Hu S, Brody CL, Fisher C, Gunzerath L, Nelson ML, Sabol SZ, Sirota LA, Marcus SE, Greenberg BD, Murphy DL, Hamer DH. Interaction between the serotonin transporter gene and neuroticism in cigarette smoking behavior. Mol Psychiatry. 2000; 5(2): 181-188.

97. Lerman C, Caporaso NE, Audrain J, Main D, Boyd NR, Shields PG. Interacting effects of the serotonin transporter gene and neuroticism in smoking practices and nicotine dependence. Mol Psychiatry. 2000; 5(2): 189-192.

98. Lerman C, Caporaso NE, Bush A, Zheng YL, Audrain J, Main D, Shields PG. Tryptophan hydroxylase gene variant and smoking behavior. Am J Med Genet. 2001; 105(6): 518-520.

99. Sullivan PF, Jiang Y, Neale MC, Kendler KS, Straub RE. Association of the tryptophan hydroxylase gene with smoking initiation but not progression to nicotine dependence. Am J Med Genet. 2001; 105(5): 479-484.

100. Mizuno S, Ito H, Hamajima N, Tamakoshi A, Hirose K, Tajima K. Association between smoking habits and tryptophan hydroxylase gene C218A polymorphism among the Japanese population. J Epidemiol. 2004; 14(3): 94-99.

101. Lerman C, Shields PG, Audrain J, Main D, Cobb B, Boyd NR, Caporaso N. The role of the serotonin transporter gene in cigarette smoking. Cancer Epidemiol Biomarkers Prev. 1998; 7(3): 253-255.

102. Ishikawa H, Ohtsuki T, Ishiguro H, Yamakawa-Kobayashi K, Endo K, Lin YL, Yanagi H, Tsuchiya S, Kawata K, Hamaguchi $\mathrm{H}$, Arinami T. Association between serotonin transporter gene polymorphism and smoking among Japanese males. Cancer Epidemiol Biomarkers Prev. 1999; 8(9): 831-833.

103. Li MD, Beuten J, Ma JZ, Payne TJ, Lou XY, Garcia V, Duenes AS, Crews KM, Elston RC. Ethnic- and genderspecific association of the nicotinic acetylcholine receptor alpha4 subunit gene (CHRNA4) with nicotine dependence. Hum Mol Genet. 2005; 14(9): 1211-1219. 
Background: Both genetic and environmental determinants are believed to contribute to nicotine dependence (ND). However, so far most (candidate) gene studies investigated only single genes.

Aim: Investigate the influence of multiple genetic variants in candidate genes in smokingrelated pathways on ND.

Methods: Smokers were recruited via four smoking and smoking cessation trials ( $\mathrm{N}=1502)$, and 783 (52\%) provided a DNA sample. Participants were genotyped for 35 genetic variants in 19 candidate genes in smoking-related pathways. The primary outcome measure was level of ND assessed at baseline with the Fagerström Test of Nicotine Dependence (FTND). The secondary outcome measure was level of addiction (low: FTND<6 vs. high: FTND $\geq 6$ ).

Results: The FTND-score was significantly lower among smokers with a decreased nicotine metabolism (CYP2B6 rs3211371 T-allele; ratio $=0.73,95 \% \mathrm{Cl}=0.60-0.95)$, while it was increased among smokers with a low number of dopamine receptors (DRD2 rs1800497 T-allele; ratio=1.06, $95 \% \mathrm{Cl}=1.00-1.12$ ) or increased binding activity $\mu$-opioid receptor (OPRM1 rs1799971 G-allele; ratio=1.29, 95\%Cl=1.11-1.47). Furthermore, smokers with the nicotinic acetylcholinic receptor (nAChR) a4-subunit (CHRNA4) G-C haplotype or the serotonin transporter (SLC6A4) 12-L-G haplotype had a significantly higher FNTD scores (difference $=0.22$ and dif $=0.91$, respectively), while the $S L C 6 A 4{ }^{*}$-S-G haplotype resulted in a lower FTND-score (difference=-2.06). Finally, MDR analysis revealed two genetic interactions. Firstly, a combination of a variant in the dopamine pathway (DRD2 rs6277) with one in the opioid pathway (ARRB2 rs3786047) resulted in increased FTND-scores among smokers homozygous wildtype for rs378647 and heterozygous for rs6277. Secondly, a combination of three variants in the dopamine pathway (e.g. SLC6A3 VNTR, COMT rs737865, and DBH rs77905) was found to have an effect on FTND-score. Most of the associations found for FTND-score, were also found in the analysis on level of addiction. Conclusions: Several variants in genes in smoking-related pathways influenced FTND and level of addiction. Moreover, combinations of genetic variants had significant effects, even if they did not have an effect on their own. Thus it is important to investigate the effect of combinations of genetic variants on ND. 




MULTIPLE GENETIC VARIANTS INFLUENCE NICOTINE ADDICTION

Marieke Quaak, Constant P. van Schayck, Dirkje S. Postma, Philippe H.J. Hoogsteder, Edwin J. Wagena, Daniel Kotz, Frederik J. van Schooten.

Submitted. 


\section{INTRODUCTION}

Both genetic and environmental determinants are thought to contribute to cigarette smoking. While early reports suggested that the influence of heredity on smoking was modest, more recent twin and adoption studies have found significant genetic influences on several aspects of smoking behaviour [1-9]. It has been demonstrated that genetic factors account for approximately $40-75 \%$ of the variation in the probability that a individual will become a smoker (initiation), $70-80 \%$ of the variation in continuation of the smoking habit once smoking has started (persistence/ maintenance), and about $50 \%$ of the variance in cessation success [1-9]. Significant genetic influences on more clinically relevant phenotypes, such as indicators of nicotine dependence (ND) (30-75\%) and nicotine withdrawal (30-50\%), have been found more recently $[5,8,10]$.

Variations in several genes have been suggested to contribute to smoking behaviour, and research has been focused on two broad classes of candidate genes (for extended reviews see $[7,11-14]$ ): 1) Genes that may influence the response to nicotine (e.g. nicotine metabolism, nicotinic receptors) and 2) Genes that may predispose to addictive behaviour due to their effects on key neurotransmitter pathways (e.g. dopamine, serotonin, mu-opioid, acetylcholine). However, so far most (candidate) gene studies investigated only single genes. Since a large number of genes and several variants in these genes are likely to contribute to the individual susceptibility towards ND this approach will probably fail to fully determine the role of genetic variation in ND. Therefore, studies should focus on multiple functional variants and multiple genes operating within a single pathway.

Several self-administered tests are available to assess ND. The Fagerström Test for Nicotine Dependence (FTND) is the most widely used and studied test [15]. It has been found to correlate with several aspects of smoking, such as ability to stop smoking, biochemical measures of smoke exposure, and withdrawal symptoms [15-17].

In this study we therefore investigated the influence of 35 genetic variants in 19 candidate genes in smoking-related pathways (Table S1) on FTND-score.

\section{MATERIALS AND METHODS}

\section{Subjects and procedures}

Smokers for this study were recruited via four smoking and smoking cessation trials from the School for Public Health and Primary Care (Caphri) from Maastricht University: 1) a cessation trial on the efficacy of antidepressant therapy for smokers with and without COPD $[18,19], 2)$ a cessation trial on the efficacy of confronting smokers with airflow limitation for smoking cessation [20], 3) a study on smoking cessation and development of respiratory health in smokers screened with normal spirometry [21], and 4) a phase 2B trial to assess efficacy and safety of nicotine vaccine $\left(\mathrm{NicVAX}^{\circledR}\right)$ in combination with Varenicline (registred at ClinalTrials.gov; 
NCT0099503). These studies consisted of a total of 1502 smokers. All participants were aged $\geq 18$ years, had a smoking history of $\geq 5$ years, and smoked on average $\geq 10$ cigarettes/day during the last year.

During one of the follow-up visits, a $10-\mathrm{ml}$ blood sample $(\mathrm{N}=188,12 \%)$, buccal sample $(N=225,15 \%)$, or saliva sample $(N=343,23 \%)$ was collected, or participants were invited to provide a buccal sample by postal mail $(\mathrm{N}=27,2 \%)$, resulting in a total of 783 samples for genotyping (52\%).

Ethical approval was obtained from the medical ethics committee of the Maastricht University Medical Centre. Participants provided written informed consent for genotyping.

\section{Measures}

\section{Outcomes}

The primary outcome for the current study was level of ND assessed at bas eline with the Fagerström Test for Nicotine Dependence (FTND) (Table 1) [15]. This is a 6 item test developed with the aim to diagnose the degree of dependence among smokers coming to a clinic seeking for help with stopping. It can be filled out either by the provider or by the smoker. It contains a four answering category for the items regarding time until first cigarette and number of cigarettes smoked. The remaining 4 items (e.g. forbidden-cigarettes, hate-most-to-give-up, smoke-more-first-hours-awakening, and smoke-if-ill) have two answering categories. This results in a total possible score of 10 [15].

The secondary outcome was level of addiction (low [FTND-scores<6] versus high [FTND-scores $\geq 6]$ ).

Table 1: Fagerström Test for Nicotine Dependence (FTND)

\begin{tabular}{|c|c|c|}
\hline Question & Answering categories & Score \\
\hline \multirow[t]{4}{*}{ 1. How soon after you wake up do you have your first cigarette? } & $\leq 5$ minutes & 3 \\
\hline & 6-30 minutes & 2 \\
\hline & $31-60$ minutes & 1 \\
\hline & $\geq 60$ minutes & 0 \\
\hline \multirow{2}{*}{$\begin{array}{l}\text { 2. Do you find it difficult to refrain from smoking in places where it is } \\
\text { forbidden? }\end{array}$} & Yes & 1 \\
\hline & No & 0 \\
\hline \multirow[t]{2}{*}{ 3. Which cigarette would you hate most to give up? } & The first one in the morning. & 1 \\
\hline & Any other. & 0 \\
\hline \multirow[t]{4}{*}{ 4. How many cigarettes do you smoke per day? } & 10 or fewer & 0 \\
\hline & $11-20$ & 1 \\
\hline & $21-30$ & 2 \\
\hline & 31 or more & 3 \\
\hline \multirow{2}{*}{$\begin{array}{l}\text { 5. Do you smoke more often during the first hours after waking than } \\
\text { during the rest of the day? }\end{array}$} & Yes & 1 \\
\hline & No & 0 \\
\hline \multirow[t]{2}{*}{ 6. Do you smoke even if you are so ill that you are in bed most of the day? } & Yes & 1 \\
\hline & No & 0 \\
\hline TOTAL & & $0-10$ \\
\hline
\end{tabular}




\section{Participant characteristics}

Ethnicity was not assessed, however based on the make-up of the region where the participants were recruited (e.g. Dutch- and Belgian-Limburg), it is expected that virtually all participants are Caucasians. Other characteristics that were assessed included age, gender, the number of cigarettes per day and the severity of COPD, according to the definition of the Global Initiative for Chronic Obstructive Lung Disease (GOLD) [22].

\section{Genotyping}

Participants were genotyped for 35 genetic variants in 19 candidate genes (Table S1) using the mass-spectroscopy based, high-throughput MassARRAY ${ }^{\circledR}$ iPLEX $^{\text {TM }}$ platform (Sequenom ${ }^{\circledR}$, Hamburg, Germany) or traditional PCR, if applicable. Details of primers and genotyping assays are available on request.

Genotype calls were then evaluated for 7 criteria:

1) First it was checked if genetic variants were determined in all of the studies. Genotyping for two variants was not performed in one of the studies (rs3892097 and rs5030655), and one completely failed in one of the studies and performed badly in the other studies (rs165599). These variants were therefore excluded from further analyses.

2) Chi-square analysis was used to test whether the distribution of genotypes was in accordance with Hardy-Weinberg equilibrium (HWE). One SNP (rs1917810) was excluded because it showed a significant deviation $(p<0.001)$ from HWE.

3) The minor allele frequency (MAF) was calculated. Two SNPs (rs1799835 and rs1801028) with an observed MAF $<0.01$ were excluded.

4) SNP call rates were calculated, and SNPs with a call rate $\leq 80 \%$ were excluded. No SNPs were removed and most of the remaining SNPs (28) had a call rate of $\geq 95 \%, 3$ SNPs had a call rate between $90 \%$ and $95 \%$, and the lowest call rate was $88.3 \%$ (1 SNP).

5) Individual call rates were calculated, and individuals with a call rate $\leq 75 \%$ were removed from the analysis $(\mathrm{N}=11)$. Of the remaining individuals $74.4 \%$ had a call rate $\geq 95 \%$, and $95.7 \%$ a call rate $\geq 85 \%$.

6) Data from men with a heterozygous genotype for the MAO-A uVNTR located on the $\mathrm{X}$-chromosome was removed $(\mathrm{N}=5)$.

7) Linkage disequilibrium (LD) was calculated (Haploview version 4.2). To avoid redundant analyses, only one SNP was evaluated when SNPs were in strong linkage with other SNPs using a cut-off value of $r^{2}>0.85$. As a result 1 SNP ( $r$ 2292975) was removed from the analysis because it was in complete LD with another SNP (rs2292974) (see Figure S1).

Final analyses were performed with a total of 772 smokers and 29 genetic variants.

\section{Statistical analysis}

Univariate associations between genotypes and FTND-score were assessed by analysis of variance (ANOVA). When associations reached $p$-values $<0.10$, we further determined the best fitting genetic model (additive, dominant, recessive or co-dominant) in linear regression. Since gender has been shown to influence ND, all regression models were adjusted for gender. To control for multiple testing, we calculated the false discovery rate (FDR) according to Benjamini and Hochberg [23]. 
In addition we assessed the distribution of alleles and genotypes for the level of addiction (high versus low) using Pearson's chi-square tests, and determined the best fitting genetic model using logistic regression. Regression models were corrected for gender.

PHASE (version2.1), a program for reconstructing haplotypes from population genotype data, was used to generate haplotypes for candidate genes with more than one variant. Then the effect of haplotypes on FTND-score was assessed using linear regression.

Gene-gene interactions were studied using Multifactor Dimensionality Reduction (MDR version 1.0.0) as described in detail by Ritchie et al [24]. Missing SNPs were imputed using the haplotype data. We performed MDR analysis for individuals with the $~ 15 \%$ highest FTND-scores (scores of 8-10) compared to individuals with the $15 \%$ lowest FTND-scores (scores of 0-3). The model with the lowest average prediction error and highest average cross validation consistency was selected as "best model".

All analyses were performed using PASW statistics (v17.02) for windows (Chicago, Illinois, USA) and all tests were two-sided, unless otherwise specified.

\section{RESULTS}

\section{Participant characteristics}

Table 2 presents the baseline characteristics of the total group of smokers from the various smoking trials and for the participants of this study.

The average age of the participants was 51.4 years $(S D=8.3)$, and $42.3 \%$ were women. Participants smoked on average 22.2 cigarettes/day ( $S D=9.0)$, had an average FTNDscore of $5.3(S D=2.0)$, and $46.5 \%$ had a high level of ND (FTND-score $\geq 6)$. When using the GOLD guideline [22] to classify participants, 377 (55.8\%) had no COPD, 148 (21.9\%) had mild COPD (Stage 1) and 151 (22.3\%) had moderate or severe COPD (Stage 2 or 3).

There were no differences in gender, number of cigarettes smoked, and level of ND between the participants and the total group of smokers. Participants' had a somewhat higher age and had more frequently COPD (stage 1 and stage $2 \& 3$ ).

Table 2: Baseline characteristics of the participants

\begin{tabular}{|c|c|c|c|}
\hline & $\begin{array}{c}\text { total } \\
(\mathrm{N}=1502)\end{array}$ & $\begin{array}{l}\text { genotyping study } \\
(\mathrm{N}=783)\end{array}$ & p-value \\
\hline Age (years), mean (SD) & $49.9(8.6)$ & $51.4(8.3)$ & $<0.01$ \\
\hline Women, No. (\%) & $660(44.0)$ & $452(42.3)$ & NS \\
\hline No. of cigarettes smoked per day, mean $(S D)^{b}$ & $22.6(9.0)$ & $22.2(9.0)$ & NS \\
\hline COPD classification, No. (\%) & & & $<0.01$ \\
\hline No COPD (previously Stage 0: at risk for COPD) & $767(63.5)$ & $377(55.8)$ & \\
\hline Stage 1: mild COPD & $214(17.7)$ & $148(21.9)$ & \\
\hline Stage 2 \& 3: moderate \& severe COPD & $226(18.7)$ & $151(22.3)$ & \\
\hline
\end{tabular}

\footnotetext{
${ }^{a}$ For two participants gender was not known

${ }^{\mathrm{b}}$ For 20 participants ( 6 in genotyping study) the number of cigarettes was not known

${ }^{c}$ For 103 participants (44 in genotyping study) the total FTND-score could not be calculated

${ }^{d}$ For 52 participants ( 21 in genotyping study) the FTND cut-of value could not be calculated

${ }^{\text {e }}$ For participants of the NicVAX study (295 in total and 107 in genotyping study) COPD stage was not known
} 


\section{Single gene associations}

In total, 6 genetic variants in smoking-related genes were found to be associated $(p<0.10)$ with FTND-score and/or level of addiction (Table 3). Of these variants, 2 were in genes influencing the response to nicotine, and 4 in genes in key neurotransmitter pathways involved in addiction ( 2 in dopamine pathway, and 2 in mu-opioid pathway). P-values in this table were calculated without prior assumption of the mode of inheritance. Subsequently the $\mathrm{p}$-value for the best fitting genetic model was calculated.

Table 4 gives the ratios and the 95\% confidence intervals for the FTND-score belonging to the best genetic model (adjusted for gender). This confirms the association between FTND-score and CYP2B6 rs3211371, DRD2 rs1800497, and OPRM1 rs1799971. The association with the SLC6A4 rs25531 approached significance $(p=0.06)$. The presence of two T-alleles of the CYP2B6 rs3211371 SNP was associated with lower FTND-scores (ratio=0.73; $95 \% \mathrm{Cl}=0.60-0.95$ ), while the presence of one T-allele of the DRD2 rs 1800497 SNP was associated with a slightly increased FTND-score (ratio=1.06; 95\% Cl=1.00-1.12) and two G-alleles of the OPRM1 rs1799971 SNP with an approximately $30 \%$ increase in the FTND-score (ratio=1.29; $95 \% \mathrm{Cl}=1.11-1.47$ ). None of these associations remained significant after adjustment for multiple testing.

Table 3: Genetic variants in smoking-related genes significantly associated with FTND-score or level of addiction

\begin{tabular}{lllll}
\hline gene & variant & MAF & FTND-score & level of addiction \\
\hline CHRNA4 & rs2236196 & 0.31 & 0.20 & $\mathbf{0 . 0 4}$ \\
\hline CYP2B6 & rs3211371 & 0.13 & $\mathbf{0 . 0 2}$ & 0.29 \\
\hline DRD2 & rs1800497 & 0.20 & $\mathbf{0 . 0 7}$ & $\mathbf{0 . 0 3}$ \\
\hline COMT & rs737865 & 0.26 & 0.14 & 0.08 \\
\hline SLC6A4 & rs25531 & 0.06 & 0.08 & 0.30 \\
\hline OPRM1 & rs1799971 & 0.15 & $\mathbf{0 . 0 3}$ & 0.18 \\
\hline HINT-1 & rs3852209 & 0.21 & 0.22 & $\mathbf{0 . 0 8}$ \\
\hline
\end{tabular}

Bold $p$-values have a $p$-value $<0.05$ for the best fitting genetic model

${ }^{a}$ MAF: minor allele frequency

Table 4: Influence of genetic variants in smoking-related genes on FTND-score

\begin{tabular}{|c|c|c|c|c|c|c|c|}
\hline gene & variant & genotype & number & $\begin{array}{c}\text { mean FTND } \\
\text { score }(95 \% \mathrm{Cl})\end{array}$ & best model & $\begin{array}{c}\text { ratio FTND } \\
\text { score }(95 \% \mathrm{Cl})\end{array}$ & $p$-value ${ }^{a}$ \\
\hline \multirow[t]{3}{*}{ CYP2B6 } & rs3211371 & $\mathrm{C} / \mathrm{C}$ & 544 & $5.30(5.14 ; 5.46)$ & & & \\
\hline & & $\mathrm{C} / \mathrm{T}$ & 159 & $5.49(5.18 ; 5.80)$ & recessive & $0.73(0.60 ; 0.95)$ & 0.009 \\
\hline & & $\mathrm{T} / \mathrm{T}$ & 13 & $3.92(2.72 ; 5.13)$ & & & \\
\hline \multirow[t]{3}{*}{ DRD2 } & rs1800497 & $\mathrm{C} / \mathrm{C}$ & 471 & $5.22(5.04 ; 5.40)$ & & & \\
\hline & & $\mathrm{C} / \mathrm{T}$ & 226 & $5.56(5.32 ; 5.80)$ & dominant & $1.06(1.00 ; 1.12)$ & 0.04 \\
\hline & & $\mathrm{T} / \mathrm{T}$ & 29 & $5.24(4.45 ; 6.03)$ & & & \\
\hline \multirow[t]{3}{*}{ SLC6A4 } & rs25531 & $A / A$ & 643 & $5.30(5.15 ; 5.45)$ & & & \\
\hline & & $A / G$ & 78 & $5.06(5.20 ; 6.00)$ & recessive & $0.66(0.17 ; 1.15)$ & NS \\
\hline & & $\mathrm{G} / \mathrm{G}$ & 4 & $3.50(0.91 ; 6.09)$ & & & \\
\hline \multirow[t]{3}{*}{ OPRM1 } & rs1799971 & $A / A$ & 478 & $5.23(5.06 ; 5.40)$ & & & \\
\hline & & $A / G$ & 163 & $5.39(5.09 ; 5.69)$ & recessive & $1.29(1.11 ; 1.47)$ & 0.01 \\
\hline & & $\mathrm{G} / \mathrm{G}$ & 10 & $6.80(5.89 ; 7.72)$ & & & \\
\hline
\end{tabular}

\footnotetext{
${ }^{\mathrm{a}}$ Adjusted for gender
} 
Table 5: Influence of genetic variants in smoking-related genes on level of addiction

\begin{tabular}{|c|c|c|c|c|c|c|c|}
\hline gene & variant & genotype & \# low level (\%) & \# high level (\%) & best model & OR (95\%Cl) & p-value ${ }^{a}$ \\
\hline \multirow[t]{3}{*}{ CHRNA4 } & rs2236196 & $A / A$ & 208 (51.9) & $160(45.7)$ & & & \\
\hline & & $A / G$ & $158(39.4)$ & $141(40.3)$ & additive & $1.30(1.05 ; 1.60)$ & 0.02 \\
\hline & & $\mathrm{G} / \mathrm{G}$ & 35 (8.7) & $49(14.0)$ & & & \\
\hline \multirow[t]{3}{*}{ DRD2 } & rs1800497 & $\mathrm{G} / \mathrm{G}$ & 271 (67.8) & $212(60.6)$ & & & \\
\hline & & $\mathrm{G} / \mathrm{A}$ & $111(27.8)$ & $127(36.3)$ & dominant & $1.38(1.02 ; 1.86)$ & 0.04 \\
\hline & & $\mathrm{A} / \mathrm{A}$ & $18(4.5)$ & $11(3.1)$ & & & \\
\hline \multirow[t]{3}{*}{ COMT } & rs737865 & $\mathrm{T} / \mathrm{T}$ & $233(58.0)$ & $180(51.6)$ & & & \\
\hline & & $\mathrm{T} / \mathrm{C}$ & $140(34.8)$ & 148 (42.4) & co-dominant & $1.38(1.03 ; 1.85)$ & 0.03 \\
\hline & & $\mathrm{C} / \mathrm{C}$ & $29(7.2)$ & $42(6.0)$ & & & \\
\hline \multirow[t]{3}{*}{ HINT-1 } & rs3852209 & $\mathrm{C} / \mathrm{C}$ & $254(63.2)$ & $209(60.2)$ & & & \\
\hline & & $\mathrm{C} / \mathrm{T}$ & $136(33.8)$ & 117 (33.7) & recessive & $2.10(1.02 ; 4.32)$ & 0.05 \\
\hline & & $T / T$ & $12(3.0)$ & $21(6.1)$ & & & \\
\hline
\end{tabular}

${ }^{\mathrm{a}}$ Adjusted for gender

Table 6: FTND-score and haplotypes in smoking-related genes

\begin{tabular}{|c|c|c|c|c|}
\hline haplotype & $\mathbf{N}$ & FTND-score $( \pm S D)$ & difference $(95 \% \mathrm{Cl})^{a, b}$ & $p$-value ${ }^{a, b}$ \\
\hline \multicolumn{5}{|c|}{ CHRNA4 rs2236196, rs6122429 } \\
\hline$A-G$ & 934 & $5.27 \pm 1.93$ & $-0.04(-0.22 ; 0.13)$ & 0.64 \\
\hline$A-A$ & 72 & $5.18 \pm 2.09$ & $-0.14(-0.49 ; 0.21)$ & 0.44 \\
\hline G - G & 300 & $5.53 \pm 1.95$ & $0.22(0.00 ; 0.43)$ & 0.05 \\
\hline$G-A$ & 150 & $5.27 \pm 1.99$ & $-0.04(-0.30 ; 0.23)$ & 0.79 \\
\hline \multicolumn{5}{|c|}{ SLC6A4 STin2, 5-HTTLPR, rs25531 } \\
\hline$*-S-A^{c}$ & 532 & $5.28 \pm 2.01$ & $0.19(-0.19 ; 0.57)$ & 0.33 \\
\hline$*-L-A^{c}$ & 296 & $5.32 \pm 1.90$ & $0.23(-0.17 ; 0.63)$ & 0.25 \\
\hline $12-L-A$ & 450 & $5.34 \pm 1.92$ & $0.25(-0.14 ; 0.63)$ & 0.21 \\
\hline $12-L-G$ & 23 & $6.00 \pm 2.05$ & $0.91(0.15 ; 1.67)$ & 0.02 \\
\hline $12-\mathrm{S}-\mathrm{A}$ & 86 & $5.37 \pm 1.86$ & $0.28(-0.22 ; 0.77)$ & 0.27 \\
\hline$*-L-G^{c}$ & 60 & $5.30 \pm 1.87$ & $0.21(-0.34 ; 0.75)$ & 0.46 \\
\hline$*-\mathrm{S}-\mathrm{G}^{\mathrm{C}}$ & 3 & $3.00 \pm 1.00$ & $-2.06(-3.96 ;-0.17)$ & 0.03 \\
\hline
\end{tabular}

${ }^{a}$ Adjusted for gender

${ }^{\mathrm{b}}$ Compared to average FTND-score other haplotypes combined

${ }^{\mathrm{c} *}$ : every other possible allele than 12 -allele

Table 7: Results of gene-gene interactions analyzed by MDR

\begin{tabular}{|c|c|c|c|}
\hline gene and variant & $\begin{array}{l}\text { testing balanced } \\
\text { accuracy }^{\mathrm{a}}(\%)\end{array}$ & $\begin{array}{l}\text { cross validation } \\
\text { consistency }^{\text {b }}\end{array}$ & p-value ${ }^{c}$ \\
\hline COMT rs737865 & 57.9 & 8 & 0.30 \\
\hline$D R D 2$ rs6277 * ARRB2 rs3786047 & 62.6 & 7 & 0.06 \\
\hline SLC6A3 VNTR * COMT rs737865 * DBH rs77905 & 64.5 & 6 & 0.03 \\
\hline
\end{tabular}


Table 5 gives the odds ratios (ORs) belonging to the best fitting genetic model for the level of addiction (low versus high). These results confirmed the association between level of addiction and the CHRNA4 rs2236196, the DRD2 rs1800497, COMT rs737865 and the HINT-1 rs3852209 SNPs. All these SNPs increased the chance of having a high level of addiction. This association was the strongest for the HINT-1 rs3852209 SNP (OR=2.10,95\% Cl=1.02-4.32), slightly lower for DRD2 rs1800497 and COMT rs737865 (OR=1.38, 95\% $\mathrm{Cl}=1.02-1.86$ and $\mathrm{OR}=1.38,95 \% \mathrm{Cl}=1.03-1.85$, respectively) and lowest for the CHRNA4 rs2236196 SNP (OR=1.30, 95\%Cl=1.05-1.60). None of the associations remained significant after adjustment for multiple testing.

\section{Haplotype analysis}

For candidate genes with more than one variant haplotypes were generated to investigate the combined effect of the variants. Haplotypes in two candidate genes (CHRNA4 and SLC6A4) were identified that were significantly associated with FTND-score (Table 6).

Smokers with the G-C haplotype in CHRNA4 had a significantly higher FTND-score compared to smokers in the other three haplotype groups (difference $=0.22$; $95 \% \mathrm{Cl}=0.00-0.43 ; \mathrm{p}$-value $=0.05)$. For SLC6A4 the 12-L-G haplotype significantly increased FTND-score (difference $=0.91 ; 95 \% \mathrm{Cl}=0.15-1.67 ; \mathrm{p}$-value $=0.02$ ), while smokers with the *-S-G haplotype had significantly decreased FTND-scores (difference $=-2.06 ; 95 \% \mathrm{Cl}=-3.96$ $-0.17 ; p$-value $=0.03$ ).

\section{Gene-gene interactions}

MDR analyses revealed two genetic interactions for smokers with $15 \%$ highest FTNDscores (8-10) compared to smokers with 15\% lowest FNTD scores (0-3) (Table 7).

Firstly, a combination of a DRD2 SNP (rs6277) and ARRB2 SNP (rs3786047) had a strong synergistic effect on FTND-score which approached significance $(p=0.06$; average testing balanced accuracy $63 \%$ ). The interaction was confirmed by linear regression analysis for the FTND-score as the outcome ( $p$-value for interaction term $=0.025$ ), and in the logistic regression analysis for the highest and lowest FTND-scores ( $p$-value for interaction term $=0.009$ ). Especially smokers homozygous wildtype for rs378647 and heterozygous for rs6277 had a high chance of having a high FTND-score (Figure $1 A$ and Figure 2). The strong and significant interaction between the DRD2 (rs6277) and ARRB2 (rs3786047) SNPs was further indicated by a positive information gain based on measures of entropy.

Secondly, a combination of three variants in the dopamine pathway (e.g. SLC6A3 VNTR, COMT rs737865, and $D B H$ rs77905) was found to have a significant effect on FTND-score ( $p=0.03$; average testing balance 69\%). However, most of the effect seemed to come from the COMT rs737865 SNP. Mainly, smokers heterozygous for this variant had a higher chance on a high FTND-score (Figure 1B).

Of note is that the genetic variants found in this analysis were not associated with the FTND-score by themselves. Only one, COMT rs737865, was associated with level of ND. 


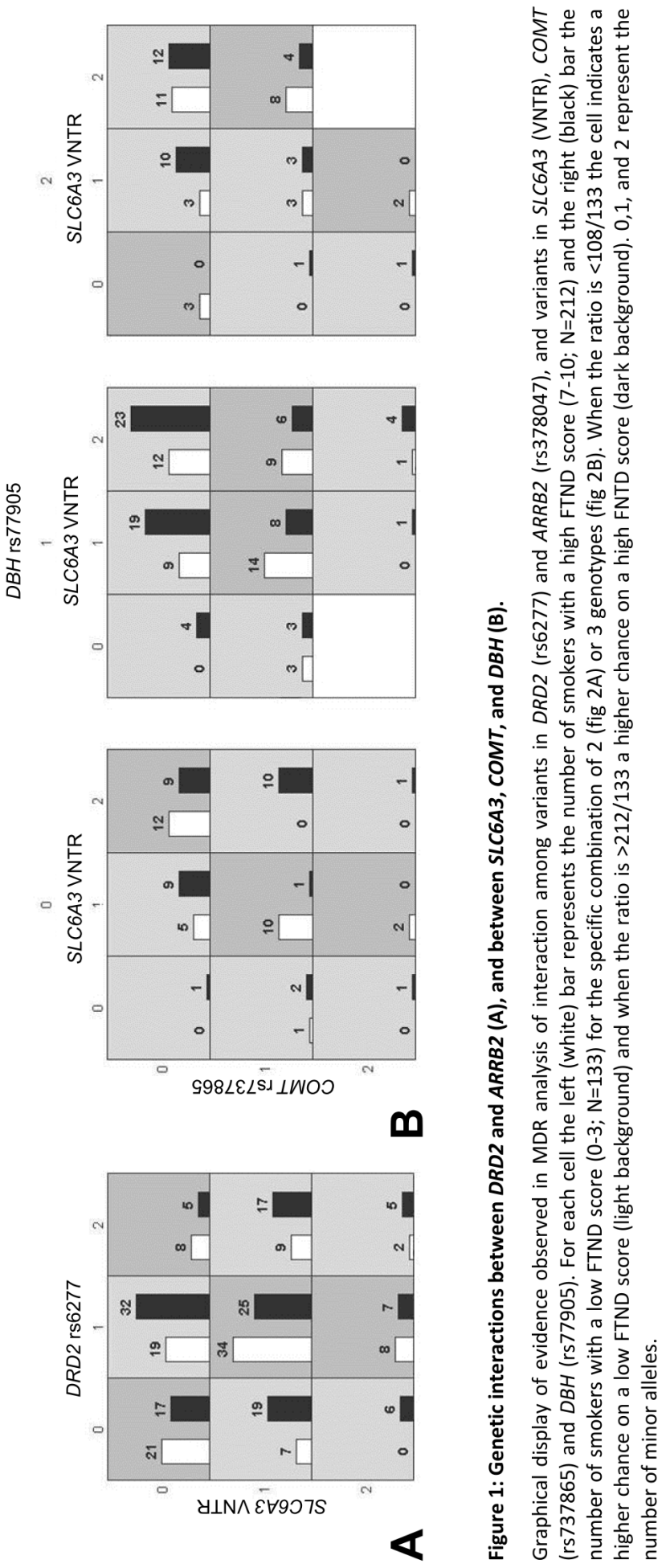




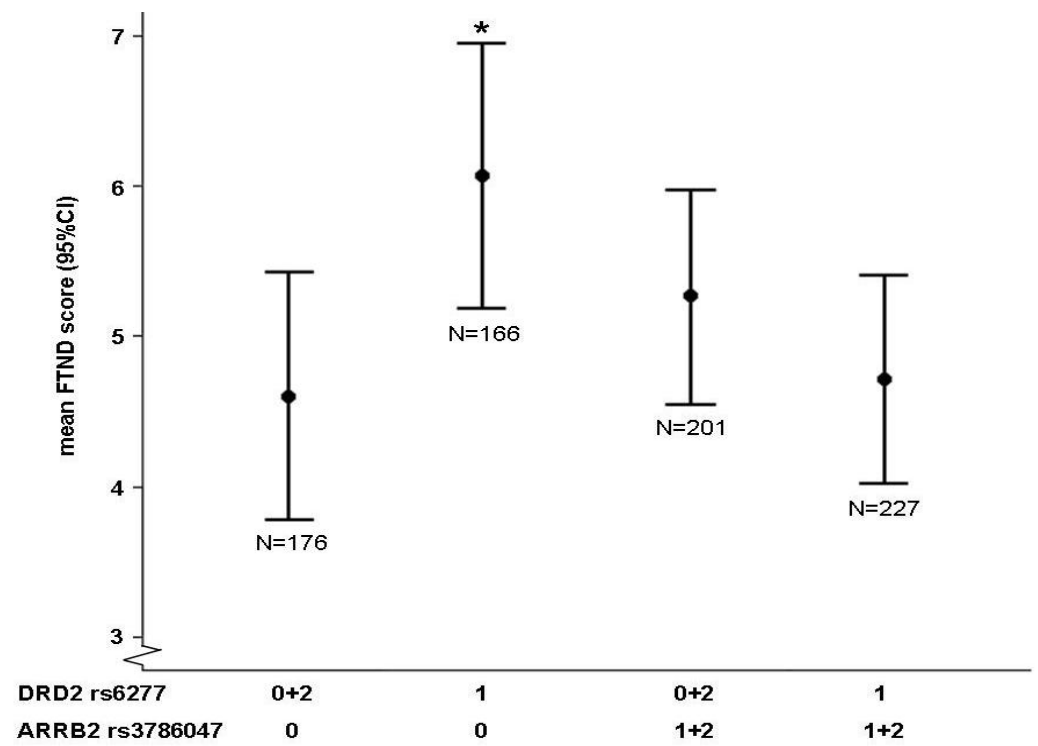

Figure 2: Influence of DRD2 rs6277 and ARRB2 rs37886047 and their interaction on FNTD score.

Influence of DRD2 rs6277 and ARRB2 rs37886047 and their interaction on FNTD score in a co-dominant model of inheritance for DRD2 and a dominant model for ARRB2. The presence of 1 minor allele of the DRD2 rs6277 SNP among smokers homozygous wildtype for the ARRB2 SNP, was associated with a significantly higher FTND-score ( $p=0.02$ ). 0,1,2 represent the number of minor alleles; $P$ interaction term $=0.009$.

\section{DISCUSSION}

Earlier studies have provided evidence that several genetic variants in genes associated with the effects of nicotine (e.g. nicotine metabolism and nicotinic receptors) and genes in key neurotransmitter pathways associated with addiction have an effect on ND levels. However, most (candidate gene) studies have only investigated one or a few genetic variants. Therefore, in this study the effect of multiple genetic variants in smokingrelated pathways on FTND-score and level of ND (high vs. low) was investigated.

Several genetic variants and combinations of genetic variants were found to influence FTND-score. Firstly, three genetic variants were identified that were significantly associated with FTND-score (CYP2B6 rs3211371, DRD2 rs1800497 and OPRM1 rs1799971).

In the presence of two T-alleles of CYP2B6 rs3211371 FNTD score was significantly decreased (ratio $=0.73$ ). The CYP2B6 enzyme has been reported to metabolize nicotine, but with a low affinity and probably mainly in individuals where CYP2A6 activity is decreased [25-27]. An impaired nicotine metabolism has been associated with decreased ND, smoking of fewer cigarettes a day and an increased likelihood of quitting smoking, because these smokers need less nicotine to reach sufficient levels, while an increased nicotine metabolism seems to result in increased smoking rates [28-33]. The T-allele of CYP2B6 rs3211371 has been associated with significantly reduced CYP2B6 
protein expression and S-mephenytoin $\mathrm{N}$-demethylase activity [34]. This variant might thus increase ND levels by lowering nicotine metabolism, thereby decreasing the need for the intake of high levels of nicotine, although no significant effects of this variant on nicotine metabolism were found in one study [27].

In contrast, the presence of one or two DRD2 rs1800497 T-alleles or two OPRM1 rs1799971 G-alleles resulted in significantly increased FTND-scores (ratio=1.06 and ratio $=1.29$, respectively). The association with $D R D 2$ rs1800497 (Taq1A) seems plausible, since individuals with the $A 1(T)$-allele have been found to have a lower number of dopamine receptors and lower receptor binding [35]. Therefore, they have a deficit in their reward system and experience enhanced reward when they are exposed to nicotine (reward hypothesis), and hence they are more vulnerable to nicotine addiction [36]. Two other studies also reported a significant association of FTND-score with the DRD2 Taq1A polymorphism [37,38].

The $\mu$-opioid receptor (MOR; encoded by the OPRM1 gene) is the primary site of action for the rewarding effects of $\beta$-endorphin [39], which is released by nicotine $[40,41]$. The Asp40 variant (G-allele) of the rs1799971 SNP has been found to result in a three-fold increased binding affinity of $\beta$-endorphin [42]. Therefore, nicotine intake will have a greater effect in smokers with the Asp40-allele, due to the potential for greater MOR occupancy by $\beta$-endorphin, leading to higher ND levels. This is in line with the results of this study.

Furthermore, we found haplotypes in two genes (CHRNA4 and SLC6A4) which were significantly associated with FTND-score. Firstly, a combination of the CHRNA4 rs2236196 G-variant with the rs6122429 G-allele was found to significantly increase the FTND-score, but not with a combination of both variants. The CHRNA4 rs2236196 alters an mRNA binding site for the iron-responsive element (IRE), leading to a substantial loss of binding affinity, decreasing mRNA stability, resulting in an approximately 2-fold less active subunit in the presence of the G-allele [43]. The CHRNA4 rs6122429 alters an specificity protein-1 (SP1) binding-site, resulting in a 5-fold greater expression with the G-allele [43]. Studies indicate that activation of receptors containing $\alpha 4$-subunits play an important role in nicotine-induced reward, tolerance, and sensitization $[44,45]$. Smokers with a high-expression genotype have been reported to be more sensitive to the acute effects of smoking and to experience a higher reward from smoking, and might therefore be more likely to be addicted [43]. However, in our study we found a higher FTND-score among individuals with a haplotype including the low-activity rs2236196 G-allele and also smokers carrying two G-alleles were found to be more likely to have a high level of addiction. These results are comparable to a previous study among male Chinese smokers, were the rs2236196 genotype also seemed to result in a higher FTND-score, which approached significance $(Z=1.828, p=0.067)$ [46]. On the other hand, in another study this SNP was found to significantly decrease FTND-score among African-American (female) smokers, but not among European-American smokers [47]. These differences might thus be explained by an ethnic- and/or gender-specific effect. However, we did not find a significant effect of gender in our study.

Secondly, a combination of three variants in the serotonin transporter (SLC6A4 STin2, 5-HTTLPR, rs25531) was found to significantly influence FTND-score. The 12-L-G haplotype significantly increased the FTND-score, while the *-S-G haplotype resulted in 
a significant decrease of the FTND-score. The serotonin transporter is responsible for regulating the magnitude and duration of the serotonergic neurotransmission. Nicotine has been shown to increase the release of serotonin in the brain and low serotonin levels have been shown to influence some aspects of smoking, such as mood variations, during nicotine withdrawal and to result in increased self-administration of nicotine [48-51]. Therefore carriers of high-activity variants (e.g. STin2 12-allele, 5HTTLPR L-allele and/or rs25531 G-allele) may have lower serotonin levels and therefore an increased sensitivity to the short-term serotonin releasing effects of smoking, resulting in an increase in ND. This is in line with the results of this study.

Finally, some interactions were found, for variants in genes that did not have a significant effect on FTND-score by themselves. The first interaction was between a SNP in the dopamine receptor (DRD2) and a SNP in a MOR-interacting protein (ARRB2). This interaction is plausible since several studies have reported that an interaction between dopamine and opioid pathways is involved in addiction, tolerance and withdrawal symptoms. It has been proposed that opioids hyperpolarize GABA-interneurons in the ventral tegmental area (VTA), which reduces the inhibition on dopaminergic neurons projecting to the noradrenalin. Consequently, dopaminergic neurons are overstimulated, which causes an increase in reinforcement associated with addiction [52].

The second interaction was between one variant in the dopamine transporter gene (SLC6A3) and two variants in genes involved in the dopamine metabolism (COMT and $D B H)$. Since these genes are all involved in the dopamine pathway, it is probable that they have a combined effect.

Overall, genetic variants that increase the sensitivity for smoking (e.g. reward deficit, or higher binding capacity) resulted in increased FTND-scores, while genetic variants that increase nicotine availability decreased FTND-scores. However, the only genotype associated with FTND-score common in the population ( $35 \%$ ) had only a small effect on FTND-score (6\% increase), while larger effects (about 30-40\% decrease or increase) were found only for genotypes that are relatively uncommon in the population $(<10 \%)$. Combining genetic variants seemed to result in larger effects, even for combinations of variants that are relatively common, for example about one-fifth of the population has the combination of the rs378647 and rs6277 SNP, resulting in an about $20 \%$ increased FTND-score.

Most of the associations found for FTND-score, were also observed in the analysis on level of addiction.

The presence of the DRD2 rs1800497 T-allele and CHRNA4 rs2236196 G-allele increased the chance of having a high level of addiction ( $O R=1.38$ and $O R=1.30)$, comparable to the increase in FTND-score found. We did not find an association with MOR for level of addiction, however we did find an association with a SNP in the MORinteracting protein HINT-1 (rs3852209), resulting in an increased chance of having a high level of addiction (OR=2.10). Furthermore, a positive association with the COMT rs737865 SNP was found (OR=1.38).

The histidine triad nucleotide binding protein 1 (HINT-1) has been shown to decrease MOR phosphorylation and desensitization upon binding to MOR [53] and a lack of HINT-1 seems to be associated with a dysregulation of postsynaptic dopamine transmission [54]. 
A recent study suggested that this gene is associated with increased risk of ND [55]. A genotype resulting in a significantly higher HINT-1 expression level was found to be associated with FTND-score [55]. Thus it is plausible that the HINT-1 rs3852209 SNP, or a related SNP, is associated with ND as well. However, we can not rule on the mechanism, since it is unknown which effect this SNP has on HINT-1 expression.

Catechol-O-methyltransferase (COMT) is involved in the inactivation of the catecholamine neurotransmitters (e.g. dopamine, epinephrine, and nor-epinephrine). It has been proposed that individuals with low-activity COMT variants might experience a longer-lasting and more effective dopamine release in the brain, thereby increasing the magnitude and duration of reward by dopamine release derived from smoking and the risk of becoming nicotine dependent [56]. Therefore, the higher chance of being heavily addicted found for the rs737865 SNP might have been caused by a lowered COMT activity, however, it is unknown which effect the rs737865 SNP has on COMT expression or activity.

All variants increased the chance of having a high level of smoking; the genotypes in CHRNA4 (rs2236196), DRD2 (rs1800497) and COMT (rs73786) increased the chance with about 30\%, while the HINT-1 rs38552209 SNP more than doubled this chance. The first three genotypes are relatively common in the population ( 30-40\%), but the HINT-1 rs3852209 SNP is not (<10\%).

This study has several limitations. Firstly, the data are based solely on the FTND as measure for ND, while several other tests are also available to assess ND. The FTND has been extensively validated and found to correlate significantly with several aspects of smoking behaviour, however it might not sufficiently sample the range of variables considered central to dependence. Thus the effects of genetic variants on some aspects of dependence (cognitive, behavioural, and psychological) could have been missed. Therefore, in new studies other measures of ND should also be included.

Secondly, DNA was collected from only about half of the participants of the original trials (52\%). Therefore, selection bias could have occurred. No significant differences were found for gender, number of cigarettes smoked, and level of ND between responders and the total group, but responders' age was somewhat higher and more had COPD. Furthermore, we can not exclude differences in other factors that have not been measured.

Thirdly, multiple testing in association studies may result in false discoveries. No single SNP and haplotype associations found in this study withstand correction for multiple testing. However, consistent results were found for the single SNP, haplotype and MDR analysis and robust results were also found for the direction of the effects (e.g. variants resulting in increased sensitivity resulted in higher FTND-scores, while variants resulting in increased nicotine availability resulted in decreased FTND-scores).

Fourthly, we pooled data from four different studies (e.g. ADC, COSMO, GOLD-0 and NicVAX). Participants of these studies were recruited and phenotyped in a similar way, however we can not fully rule out population stratification.

Fifthly, the studies included both smokers with and without COPD. Regression models were not corrected for COPD status, since COPD status was not available in all studies. However, the prevalence of undiagnosed COPD-patients among smokers in the general population has been shown to be relatively high as well [66], thus the study population 
is probably a good presentation of the general population anyways. Furthermore, COPD status will also not always be available in general practice.

Finally, the genes selected for analysis were based on literature available until November 2008, of variants previously shown in several studies to be significantly associated with ND and/or smoking cessation success. We acknowledge that more genes and variants are located in these pathways.

In conclusion, several variants in genes in smoking-related pathways influenced FTNDscore and ND level (e.g. CHRNA4, CYP2B6, DRD2, COMT, SLC6A4, OPRM1, HINT-1, and $A R R B 2)$. Overall, genetic variants that increase the sensitivity for smoking (e.g. reward deficit, or higher binding capacity) resulted in increased FTND-scores, while genetic variants that increase nicotine availability decreased FTND-scores. This information can help in unravelling the pathways involved in ND, which can guide treatment choices and help in the development of new medication to treat ND. Moreover, combinations of genetic variants had a significant effect, even if the variants did not show an effect on their own. Thus it is important to investigate the effect of combinations of genetic variants on ND. However, the analysis techniques currently available are not very suitable for these kinds of analysis and therefore there is a need for the development of new analysis techniques. However, future studies are needed to confirm our findings.

\section{REFERENCES}

1. Kaprio J, Hammar N, Koskenvuo M, Floderus-Myrhed B, Langinvainio H, Sarna S. Cigarette smoking and alcohol use in Finland and Sweden: a cross-national twin study. Int J Epidemiol. 1982; 11(4): 378-386.

2. Heath AC, Cates R, Martin NG, Meyer J, Hewitt JK, Neale MC, Eaves L. Genetic contribution to risk of smoking initiation: comparisons across birth cohorts and across cultures. J Subst Abuse. 1993; 5(3): 221-246.

3. Heath AC, Martin NG. Genetic models for the natural history of smoking: evidence for a genetic influence on smoking persistence. Addict Behav. 1993; 18(1): 19-34.

4. True WR, Heath AC, Scherrer JF, Waterman B, Goldberg J, Lin N, Eisen SA, Lyons MJ, Tsuang MT. Genetic and environmental contributions to smoking. Addiction. 1997; 92(10): 1277-1287.

5. Kendler KS, Neale MC, Sullivan P, Corey LA, Gardner CO, Prescott CA. A population-based twin study in women of smoking initiation and nicotine dependence. Psychol Med. 1999; 29(2): 299-308.

6. Sullivan PM, Kendler K. The genetic epidemiology of smoking. Nicotine and Tobacco Research. 1999; 1(Suppl 2): S51-S57.

7. Batra V, Patkar AA, Berrettini WH, Weinstein SP, Leone FT. The Genetic Determinants of Smoking. Chest. 2003; 123: 1730-1739.

8. Xian H, Scherrer JF, Madden PA, Lyons MJ, Tsuang M, True WR, Eisen SA. The heritability of failed smoking cessation and nicotine withdrawal in twins who smoked and attempted to quit. Nicotine Tob Res. 2003; 5(2): 245-254.

9. Pergadia ML, Heath AC, Martin NG, Madden PA. Genetic analyses of DSM-IV nicotine withdrawal in adult twins. Psychol Med. 2006; 36(7): 963-972.

10. True WR, Xian H, Scherrer JF, Madden PA, Bucholz KK, Heath AC, Eisen SA, Lyons MJ, Goldberg J, Tsuang M. Common genetic vulnerability for nicotine and alcohol dependence in men. Arch Gen Psychiatry. 1999; 56(7): 655-661. 
11. Rossing MA. Genetic influences on smoking: candidate genes. Environ Health Perspect. 1998; 106: 231-238.

12. Arinami T, Ishiguro $\mathrm{H}$, Onaivi ES. Polymorphisms in genes involved in neurotransmission in relation to smoking. European Journal of Pharmacology. 2000; 410: 215-226.

13. Al Koudsi N, Tyndale RF. Genetic influences on smoking: a brief review. Ther Drug Monit. 2005; 27(6): 704-709.

14. MacLeod SL, Chowdhury P. The genetics of nicotine dependence: relationship to pancreatic cancer. World J Gastroenterol. 2006; 12(46): 7433-7439.

15. Heatherton TF, Kozlowski LT, Frecker RC, Fagerstrom KO. The Fagerstrom Test for Nicotine Dependence: a revision of the Fagerstrom Tolerance Questionnaire. Br J Addict. 1991; 86(9): 1119-1127.

16. Payne TJ, Smith PO, McCracken LM, McSherry WC, Antony MM. Assessing nicotine dependence: a comparison of the Fagerstrom Tolerance Questionnaire (FTQ) with the Fagerstrom Test for Nicotine Dependence (FTND) in a clinical sample. Addict Behav. 1994; 19(3): 307-317.

17. Kozlowski LT, Porter CQ, Orleans CT, Pope MA, Heatherton T. Predicting smoking cessation with self-reported measures of nicotine dependence: FTQ, FTND, and HSI. Drug Alcohol Depend. 1994; 34(3): 211-216.

18. Wagena EJ, Knipschild PG, Huibers MJ, Wouters EF, van Schayck CP. Efficacy of bupropion and nortriptyline for smoking cessation among people at risk for or with chronic obstructive pulmonary disease. Arch Intern Med. 2005; 165(19): 2286-2292.

19. Van Schayck CP, Kaper J, Wagena EJ, Wouters EF, Severens JL. The cost-effectiveness of anti-depressants for smoking cessation in chronic obstructive pulmonary disease (COPD) patients. Addiction. 2009; 104(12): 2110-2117.

20. Kotz D, Wesseling G, Huibers MJ, van Schayck OC. Efficacy of confronting smokers with airflow limitation for smoking cessation. Eur Respir J. 2009; 33(4): 754-762.

21. Kotz D, Wesseling G, Aveyard P, van Schayck OC. Smoking cessation and development of respiratory health in smokers screened with normal spirometry. Respir Med. 105(2): 243-249.

22. Global Initiative for Chronic Obstructive Lung Disease. Global strategy for the diagnosis, management, and prevention of chronic obstructive pulmonary disease. GOLD Report. Update 2009; www.goldcopd.com.

23. Benjamini $Y$, Hochberg $Y$. Controlling for the false discovery rate: a practical and powerful approach to multiple testing. J R Stat Soc B. 1995; 57: 289-300.

24. Ritchie MD, Hahn LW, Moore JH. Power of multifactor dimensionality reduction for detecting gene-gene interactions in the presence of genotyping error, missing data, phenocopy, and genetic heterogeneity. Genet Epidemiol. 2003; 24(2): 150-157.

25. Yamazaki H, Inoue K, Hashimoto M, Shimada T. Roles of CYP2A6 and CYP2B6 in nicotine C-oxidation by human liver microsomes. Arch Toxicol. 1999; 73(2): 65-70.

26. Dicke KE, Skrlin SM, Murphy SE. Nicotine and 4-(methylnitrosamino)-1-(3-pyridyl)-butanone metabolism by cytochrome P450 2B6. Drug Metab Dispos. 2005; 33(12): 1760-1764.

27. Ring HZ, Valdes AM, Nishita DM, Prasad S, Jacob P, 3rd, Tyndale RF, Swan GE, Benowitz NL. Gene-gene interactions between CYP2B6 and CYP2A6 in nicotine metabolism. Pharmacogenet Genomics. 2007; 17(12): 1007-1015.

28. Boustead C, Taber H, Idle JR, Cholerton S. CYP2D6 genotype and smoking behaviour in cigarette smokers. Pharmacogenetics. 1997; 7(5): 411-414.

29. Pianezza ML, Sellers EM, Tyndale RF. Nicotine metabolism defect reduces smoking. Nature. 1998; 393(6687): 750.

30. Saarikoski ST, Sata F, Husgafvel-Pursiainen K, Rautalahti M, Haukka J, Impivaara O, Jarvisalo J, Vainio H, Hirvonen A. CYP2D6 ultrarapid metabolizer genotype as a potential modifier of smoking behaviour. Pharmacogenetics. 2000; 10(1): 5-10.

31. Tyndale RF, Sellers EM. Variable CYP2A6-mediated nicotine metabolism alters smoking behavior and risk. Drug metabolism and disposition. 2001; 29(4): 548-552.

32. O'Loughlin J, Paradis G, Kim W, DiFranza J, Meshefedjian G, McMillan-Davey E, Wong S, Hanley J, Tyndale RF. 
Genetically decreased CYP2A6 and the risk of tobacco dependence: a prospective study of novice smokers. Tob Control. 2004; 13(4): 422-428.

33. Malaiyandi V, Lerman C, Benowitz NL, Jepson C, Patterson F, Tyndale RF. Impact of CYP2A6 genotype on pretreatment smoking behaviour and nicotine levels from and usage of nicotine replacement therapy. $\mathrm{Mol}$ Psychiatry. 2006; 11(4): 400-409.

34. Lang T, Klein K, Fischer J, Nussler AK, Neuhaus P, Hofmann U, Eichelbaum M, Schwab M, Zanger UM. Extensive genetic polymorphism in the human CYP2B6 gene with impact on expression and function in human liver. Pharmacogenetics. 2001; 11(5): 399-415.

35. Thompson J, Thomas N, Singleton A, Piggott M, Lloyd S, Perry EK, Morris CM, Perry RH, Ferrier IN, Court JA. D2 dopamine receptor gene (DRD2) Taq1 A polymorphism: reduced dopamine D2 receptor binding in the human striatum associated with the A1 allele. Pharmacogenetics. 1997; 7(6): 479-484.

36. Noble EP, St. Jeor ST, Ritchie T, Syndulko K, St. Jeor SC, Fitch RJ, Brunner RL, Sparkes RS. D2 dopamine receptor gene and cigarette smoking: a reward gene? Medical Hypotheses. 1994; 42: 257-260.

37. Huang W, Payne TJ, Ma JZ, Beuten J, Dupont RT, Inohara N, Li MD. Significant association of ANKK1 and detection of a functional polymorphism with nicotine dependence in an African-American sample. Neuropsychopharmacology. 2009; 34(2): 319-330.

38. De Ruyck K, Nackaerts K, Beels L, Werbrouck J, De Volder A, Meysman M, Salhi B, Van Meerbeeck J, Thierens $\mathrm{H}$. Genetic variation in three candidate genes and nicotine dependence, withdrawal and smoking cessation in hospitalized patients. Pharmacogenomics. 11(8): 1053-1063.

39. Zadina JE, Hackler L, Ge $\sqcup$, Kastin AJ. A potent and selective endogenous agonist for the mu-opiate receptor. Nature. 1997; 386(6624): 499-502.

40. Boyadjieva NI, Sarkar DK. The secretory response of hypothalamic beta-endorphin neurons to acute and chronic nicotine treatments and following nicotine withdrawal. Life Sci. 1997; 61(6): PL59-66.

41. Davenport KE, Houdi AA, Van Loon GR. Nicotine protects against mu-opioid receptor antagonism by betafunaltrexamine: evidence for nicotine-induced release of endogenous opioids in brain. Neurosci Lett. 1990; 113(1): 40-46.

42. Bond C, LaForge KS, Tian M, Melia D, Zhang S, Borg L, Gong J, Schluger J, Strong JA, Leal SM, Tischfield JA, Kreek MJ, Yu L. Single-nucleotide polymorphism in the human mu opioid receptor gene alters betaendorphin binding and activity: possible implications for opiate addiction. Proc Natl Acad Sci U S A. 1998; 95(16): 9608-9613.

43. Hutchison KE, Allen DL, Filbey FM, Jepson C, Lerman C, Benowitz NL, Stitzel J, Bryan A, McGeary J, Haughey HM. CHRNA4 and tobacco dependence: from gene regulation to treatment outcome. Arch Gen Psychiatry. 2007; 64(9): 1078-1086.

44. Marubio LM, Gardier AM, Durier S, David D, Klink R, Arroyo-Jimenez MM, McIntosh JM, Rossi F, Champtiaux N, Zoli $\mathrm{M}$, Changeux JP. Effects of nicotine in the dopaminergic system of mice lacking the alpha4 subunit of neuronal nicotinic acetylcholine receptors. Eur J Neurosci. 2003; 17(7): 1329-1337.

45. Tapper AR, McKinney SL, Nashmi R, Schwarz J, Deshpande P, Labarca C, Whiteaker P, Marks MJ, Collins AC, Lester HA. Nicotine activation of alpha4* receptors: sufficient for reward, tolerance, and sensitization. Science. 2004; 306(5698): 1029-1032.

46. Feng $Y$, Niu T, Xing H, Xu X, Chen C, Peng S, Wang L, Laird N, Xu X. A common haplotype of the nicotine acetylcholine receptor alpha 4 subunit gene is associated with vulnerability to nicotine addiction in men. $A m J$ Hum Genet. 2004; 75(1): 112-121.

47. Li MD, Beuten J, Ma JZ, Payne TJ, Lou XY, Garcia V, Duenes AS, Crews KM, Elston RC. Ethnic- and genderspecific association of the nicotinic acetylcholine receptor alpha4 subunit gene (CHRNA4) with nicotine dependence. Hum Mol Genet. 2005; 14(9): 1211-1219.

48. Ribeiro EB, Bettiker RL, Bogdanov M, Wurtman RJ. Effects of systemic nicotine on serotonin release in rat 
brain. Brain Res. 1993; 621(2): 311-318.

49. Seth $\mathrm{P}$, Cheeta S, Tucci S, File SE. Nicotinic-serotonergic interactions in brain and behaviour. Pharmacol Biochem Behav. 2002; 71(4): 795-805.

50. Tyndale RF. Genetics of alcohol and tobacco use in humans. Ann Med. 2003; 35(2): 94-121.

51. Hitsman B, Spring B, Pingitore R, Munafo M, Hedeker D. Effect of tryptophan depletion on the attentional salience of smoking cues. Psychopharmacology (Berl). 2007; 192(3): 317-324.

52. Di Chiara G, North RA. Neurobiology of opiate abuse. Trends Pharmacol Sci. 1992; 13(5): 185-193.

53. Guang W, Wang $\mathrm{H}$, Su T, Weinstein IB, Wang JB. Role of $\mathrm{mPKCl}$, a novel mu-opioid receptor interactive protein, in receptor desensitization, phosphorylation, and morphine-induced analgesia. Mol Pharmacol. 2004; 66(5): 1285-1292.

54. Barbier E, Zapata A, Oh E, Liu Q, Zhu F, Undie A, Shippenberg T, Wang JB. Supersensitivity to amphetamine in protein kinase-C interacting protein/HINT1 knockout mice. Neuropsycho-pharmacology. 2007; 32(8): 1774-1782.

55. Jackson KJ, Chen Q, Chen J, Aggen SH, Kendler KS, Chen X. Association of the histidine-triad nucleotidebinding protein-1 (HINT1) gene variants with nicotine dependence. Pharmacogenomics J. 11(4): 251-257.

56. Beuten J, Payne TJ, Ma JZ, Li MD. Significant association of catechol-O-methyltransferase (COMT) haplotypes with nicotine dependence in male and female smokers of two ethnic populations. Neuropsychopharmacology. 2006; 31(3): 675-684.

57. Qiu Y, Law PY, Loh HH. Mu-opioid receptor desensitization: role of receptor phosphorylation, internalization, and representation. J Biol Chem. 2003; 278(38): 36733-36739.

58. Duan J, Wainwright MS, Comeron JM, Saitou N, Sanders AR, Gelernter J, Gejman PV. Synonymous mutations in the human dopamine receptor D2 (DRD2) affect mRNA stability and synthesis of the receptor. Hum Mol Genet. 2003; 12(3): 205-216.

59. Faraone SV, Su J, Taylor L, Wilcox M, Van Eerdewegh P, Tsuang MT. A novel permutation testing method implicates sixteen nicotinic acetylcholine receptor genes as risk factors for smoking in schizophrenia families. Hum Hered. 2004; 57(2): 59-68.

60. Sullivan PF, Neale BM, van den Oord E, Miles MF, Neale MC, Bulik CM, Joyce PR, Straub RE, Kendler KS. Candidate genes for nicotine dependence via linkage, epistasis, and bioinformatics. Am J Med Genet $B$ Neuropsychiatr Genet. 2004; 126B(1): 23-36.

61. Philibert RA, Todorov A, Andersen A, Hollenbeck N, Gunter T, Heath A, Madden P. Examination of the nicotine dependence (NICSNP) consortium findings in the lowa adoption studies population. Nicotine Tob Res. 2009; 11(3): 286-292.

62. Mann JJ, Malone KM, Nielsen DA, Goldman D, Erdos J, Gelernter J. Possible association of a polymorphism of the tryptophan hydroxylase gene with suicidal behavior in depressed patients. Am J Psychiatry. 1997; 154(10): 1451-1453.

63. Wills TA, Sandy JM, Shinar O. Cloninger's constructs related to substance use level and problems in late adolescence: a mediational model based on self-control and coping motives. Exp Clin Psychopharmacol. 1999; 7(2): 122-134.

64. Lerman C, Caporaso NE, Bush A, Zheng YL, Audrain J, Main D, Shields PG. Tryptophan hydroxylase gene variant and smoking behavior. Am J Med Genet. 2001; 105(6): 518-520.

65. Nielsen DA, Jenkins GL, Stefanisko KM, Jefferson KK, Goldman D. Sequence, splice site and population frequency distribution analyses of the polymorphic human tryptophan hydroxylase intron 7. Brain Res Mol Brain Res. 1997; 45(1): 145-148.

66. Lundback B, Gulsvik A, Albers M, Bakke P, Ronmark E, van den Boom G, Brogger J, Larsson LG, Welle I, van Weel C, Omenaas E. Epidemiological aspects and early detection of chronic obstructive airway diseases in the elderly. Eur Respir J Suppl. 2003; 40: 3s-9s. 
Background: Both genetic and environmental determinants are believed to contribute to smoking. However, so far most (candidate) gene studies investigated only single genes and only nicotine addiction in general.

Aim: Investigate the influence of multiple genetic variants in candidate genes in smokingrelated pathways on the different aspects of ND.

Methods: Smokers were recruited via four smoking and smoking cessation trials ( $\mathrm{N}=1502)$, and 783 (52\%) provided a DNA sample. Participants were genotyped for 35 genetic variants in 19 candidate genes in smoking-related pathways. The primary outcome measure was the separate items of the Fagerström Test of Nicotine Dependence (FTND). Results: The different items of the FTND questionnaire were found to be associated with several, often different, variants in smoking-related genes. Overall, item 3 (hate-most-togive-up) was mainly associated with genes that may influence the response to nicotine, while items 2 (forbidden-places), 4 (number-of-cigarettes/day), and 6 (smoke-if-ill) were mainly associated with genes that influence neurotransmitter pathways.

Conclusions: The different aspects of ND seem to be influenced by genetic variants in different pathways. 


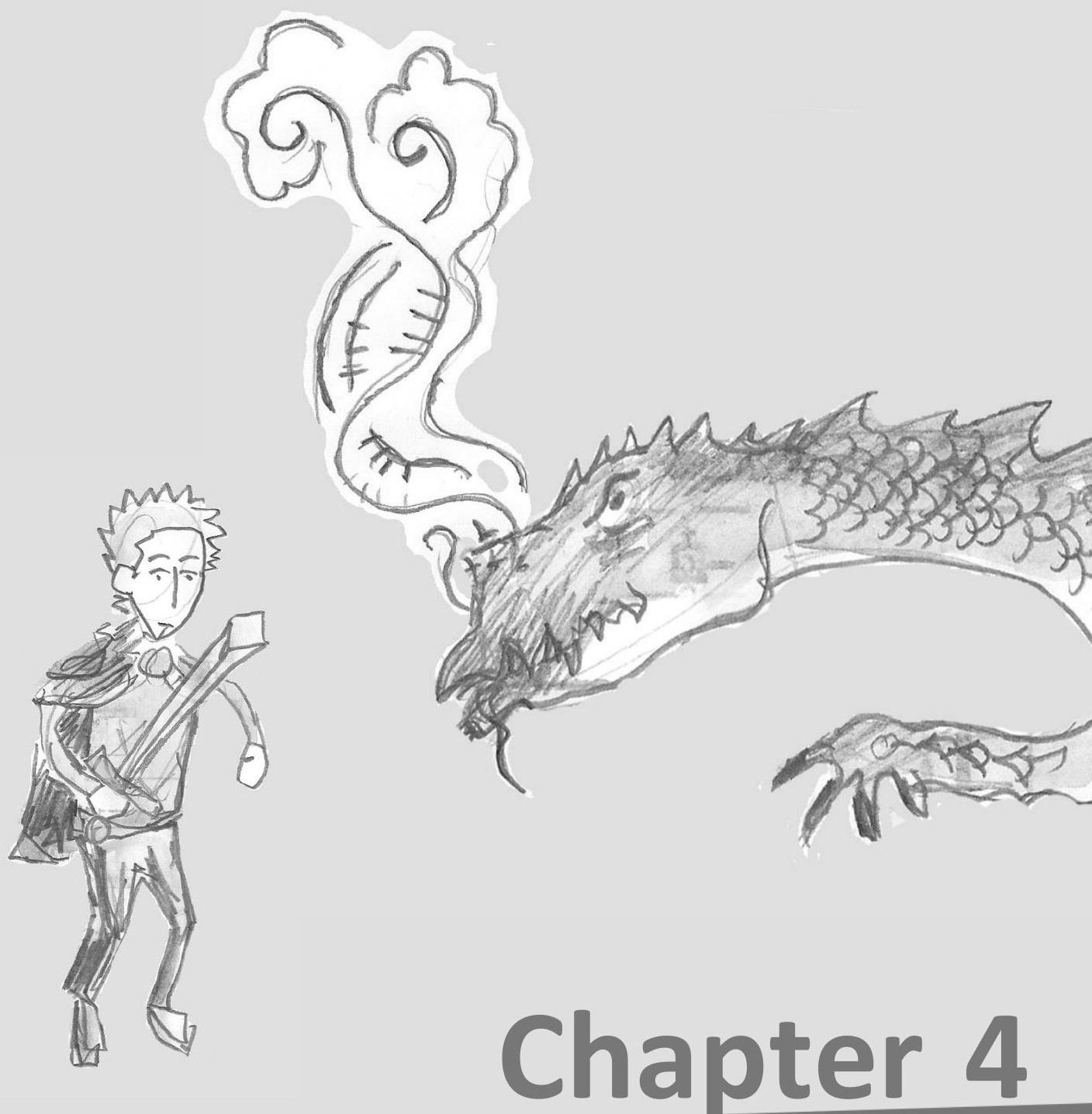

DIFFERENT ASPECTS OF NICOTINE DEPENDENCE ARE INFLUENCED BY GENETIC VARIANTS IN DISTINCT PATHWAYS

Marieke Quaak, Constant P. van Schayck, Dirkje S. Postma, Philippe H.J. Hoogsteder, Edwin J. Wagena, Daniel Kotz, Frederik J. van Schooten.

Submitted. 


\section{INTRODUCTION}

Both genetic and environmental determinants are thought to contribute to cigarette smoking. While early reports suggested that the influence of heredity on smoking was modest, more recent twin and adoption studies have found significant genetic influences on several aspects of smoking behaviour, including nicotine dependence (ND) [1-10].

Variations in several genes have been suggested to contribute to smoking behaviour, and research has been focused on two broad classes of candidate genes (for extended reviews see [7,11-14]): 1) genes that may influence the response to nicotine (e.g. nicotine metabolism, nicotinic receptors) and 2) genes that may predispose to addictive behaviour due to their effects on key neurotransmitter pathways (e.g. dopamine, serotonin, muopioid, acetylcholine). However, so far most (candidate) gene studies investigated only single genes. Since a large number of genes and several variants in these genes are likely to contribute to the individual susceptibility towards nicotine dependence this approach will probably fail to fully determine the role of genetic variation in nicotine dependence. Therefore, studies should focus on multiple functional variants and multiple genes operating within a single pathway.

Several self-administered tests are available to assess ND. The Fagerström Test for Nicotine Dependence (FTND) is the most widely used and studied test [15]. It has been found to correlate with several aspects of smoking, such as ability to stop smoking, biochemical measures of smoke exposure, and withdrawal symptoms [15-17]. However, it has been suggested that the FTND has a multi-factor structure [16]. Principal component analysis (PCA) revealed two factors: "morning smoking" (items 1,3, and 5) and "smoking pattern" (items 2, 4 and 6). Therefore, it will probably be valuable as well to investigate the influence of genetic variants on the different items of the FTND.

In this study we therefore investigated the influence of 35 genetic variants in 19 candidate genes in smoking-related pathways (Table S1) on the different items of the FTND questionnaire.

\section{MATERIALS AND METHODS}

\section{Subjects and procedures}

Smokers for this study were recruited via four smoking and smoking cessation trials from the Care and Public Health Research Institute (Caphri) from Maastricht University: 1) a cessation trial on efficacy of antidepressant therapy for smokers with and without COPD $[18,19], 2)$ a cessation trial on the efficacy of confronting smokers with airflow limitation for smoking cessation [20], 3) a study on smoking cessation and development of respiratory health in smokers screened with normal spirometry [21], 4) a phase 2B trial to assess efficacy and safety of nicotine vaccine (NicVAX ${ }^{\circledR}$ ) in combination with Varenicline (registred at ClinalTrials.gov; NCT0099503). These studies consisted of a total of 1502 smokers. All participants were aged $\geq 18$ years, had a smoking history of $\geq 5$ years, and smoked on average $\geq 10$ cigarettes/day during the last year.

During one of the follow-up visits, a $10-\mathrm{ml}$ blood sample $(\mathrm{N}=188,12 \%)$, buccal sample 
$(\mathrm{N}=225,15 \%)$, or saliva sample $(\mathrm{N}=343,23 \%)$ was collected, or participants were invited to provide a buccal sample by postal mail $(\mathrm{N}=27,2 \%)$, resulting in a total of 783 samples for genotyping (52\%).

Ethical approval was obtained from the medical ethics committee of the Maastricht University Medical Centre. Participants provided written informed consent for genotyping.

\section{Measures}

\section{Outcomes}

The primary outcome measure for the current study was the separate items of the Fagerström Test for Nicotine Dependence (FTND) (Table 1) [15]. This is a 6 item test developed with the aim to diagnose the degree of dependence among smokers coming to a clinic seeking for help with stopping. It can be filled out either by the provider or by the smoker. It contains a four answering category for the items regarding time until first cigarette and number of cigarettes smoked. The remaining 4 items (e.g. forbiddencigarettes, hate-most-to-give-up, smoke-more-first-hours after awakening, and smoke-if-ill) have two answering categories. This results in a total possible score of 10 [15].

\section{Participant characteristics}

Ethnicity was not assessed, however based on the make-up of the region where the participants were recruited (e.g. Dutch- and Belgian-Limburg), it is expected that virtually all participants are Caucasians. Other characteristics that were assessed included age, gender, the number of cigarettes per day and the severity of COPD, defined according to the definition provided by the Global Initiative for Chronic Obstructive Lung Disease (GOLD) [22].

Table 1: Fagerström Test for Nicotine Dependence (FTND)

\begin{tabular}{|c|c|c|}
\hline Question & Answering categories & Score \\
\hline \multirow[t]{4}{*}{ 1. How soon after you wake up do you have your first cigarette? } & $\leq 5$ minutes & 3 \\
\hline & 6-30 minutes & 2 \\
\hline & $31-60$ minutes & 1 \\
\hline & $\geq 60$ minutes & 0 \\
\hline \multirow{2}{*}{$\begin{array}{l}\text { 2. Do you find it difficult to refrain from smoking in places where it is } \\
\text { forbidden? }\end{array}$} & Yes & 1 \\
\hline & No & 0 \\
\hline \multirow[t]{2}{*}{ 3. Which cigarette would you hate most to give up? } & The first one in the morning. & 1 \\
\hline & Any other. & 0 \\
\hline \multirow[t]{4}{*}{ 4. How many cigarettes do you smoke per day? } & 10 or fewer & 0 \\
\hline & $11-20$ & 1 \\
\hline & $21-30$ & 2 \\
\hline & 31 or more & 3 \\
\hline \multirow{2}{*}{$\begin{array}{l}\text { 5. Do you smoke more often during the first hours after waking than } \\
\text { during the rest of the day? }\end{array}$} & Yes & 1 \\
\hline & No & 0 \\
\hline \multirow[t]{2}{*}{ 6. Do you smoke even if you are so ill that you are in bed most of the day? } & Yes & 1 \\
\hline & No & 0 \\
\hline TOTAL & & $0-10$ \\
\hline
\end{tabular}




\section{Genotyping}

Participants were genotyped for 35 genetic variants in 19 candidate genes (Table S1) using the mass-spectroscopy based, high-throughput MassARRAY ${ }^{\circledR}$ iPLEX $^{\mathrm{TM}}$ platform (Sequenom ${ }^{\circledR}$, Hamburg, Germany) or traditional PCR, if applicable. Details of primers and genotyping assays are available on request.

Genotype calls were then evaluated for 7 criteria:

1) First it was checked if genetic variants were determined in all of the studies. Genotyping for two variants was not performed in one of the studies (rs3892097 and rs5030655), and one completely failed in one of the studies and performed badly in the other studies (rs165599). These variants were therefore excluded from further analyses.

2) Chi-square analysis was used to test whether the distribution of genotypes was in accordance with Hardy-Weinberg equilibrium (HWE). One SNP (rs1917810) was excluded because it showed a significant deviation $(p<0.001)$ from HWE.

3) The minor allele frequency (MAF) was calculated. Two SNPs (rs1799835 and rs1801028) with an observed MAF $<0.01$ were excluded.

4) SNP call rates were calculated, and SNPs with a call rate $\leq 80 \%$ were excluded. No SNPS were removed and most of the remaining SNPs (28) had a call rate of $\geq 95 \%, 3$ SNPs had a call rate between $90 \%$ and $95 \%$, and the lowest call rate was $88.3 \%$ (1 SNP).

5) Individual call rates were calculated, and individuals with a call rate $\leq 75 \%$ were removed from the analysis $(\mathrm{N}=11)$. Of the remaining individuals $74.4 \%$ had a call rate $\geq 95 \%$, and $95.7 \%$ a call rate $\geq 85 \%$.

6) Data from men with a heterozygous genotype for the MAO-A uVNTR located on the X-chromosome was removed $(\mathrm{N}=5)$.

7) Linkage disequilibrium (LD) was calculated (Haploview version 4.2). To avoid redundant analyses, only one SNP was evaluated when SNPs were in strong linkage with other SNPs using a cut-off value of $r^{2}>0.85$. As a result 1 SNP ( $r$ 2292975) was removed from the analysis because it was in complete LD with another SNP (rs2292974) (see Figure S1).

Final analyses were performed with a total of 772 smokers and 29 genetic variants.

Table 2: Baseline characteristics of the participants

\begin{tabular}{|c|c|c|c|}
\hline & $\begin{array}{c}\text { total } \\
(N=1502)\end{array}$ & $\begin{array}{c}\text { genotyping study } \\
(\mathrm{N}=783)\end{array}$ & P-value \\
\hline Age (years), mean (SD) & $49.9(8.6)$ & $51.4(8.3)$ & $<0.01$ \\
\hline Women, No. $(\%)^{a}$ & $660(44.0)$ & $452(42.3)$ & NS \\
\hline No. of cigarettes smoked per day, mean $(S D)^{b}$ & $22.6(9.0)$ & $22.2(9.0)$ & NS \\
\hline COPD classification, No. $(\%)^{\mathrm{e}}$ & & & $<0.01$ \\
\hline No COPD (previously Stage 0: at risk for COPD) & $767(63.5)$ & $377(55.8)$ & \\
\hline Stage 1: mild COPD & $214(17.7)$ & $148(21.9)$ & \\
\hline Stage 2 \& 3: moderate \& severe COPD & $226(18.7)$ & $151(22.3)$ & \\
\hline
\end{tabular}

${ }^{a}$ For two participants gender was not known

${ }^{b}$ For 20 participants ( 6 in genotyping study) the number of cigarettes was not known

${ }^{c}$ For 103 participants (44 in genotyping study) the total FTND score could not be calculated

${ }^{d}$ For 52 participants ( 21 in genotyping study) the FTND cut-of value could not be calculated

${ }^{\text {e }}$ For participants of the NicVAX study (295 in total and 107 in genotyping study) COPD stage was not known 


\section{Statistical analysis}

Univariate associations between genotypes and the separate items of the FTND questionnaire were assessed using Pearson's chi-square tests. When associations reached $p$-values $<0.10$, we further determined the best fitting genetic model (additive, dominant, recessive or co-dominant) in linear regression. All regression models were adjusted for gender, and regression models for items 1-3 and 5-6, were also corrected for average number of cigarettes smoked. To control for multiple testing, we calculated the false discovery rate (FDR) according to Benjamini and Hochberg [23]. All analyses were performed using PASW statistics (v17.02) for windows (Chicago, Illinois, USA) and all tests were two-sided.

\section{RESULTS}

\section{Participant characteristics}

Table 2 presents the baseline characteristics of the total group of smokers from the various smoking trials and for the participants of this study.

The average age of the participants was 51.4 years $(S D=8.3)$, and $42.3 \%$ were women. Participants smoked on average 22.2 cigarettes/day ( $S D=9.0)$, had an average FTND-score of $5.3(\mathrm{SD}=2.0$ ), and $46.5 \%$ had a high level of ND (FTND-score $\geq 6$ ). When using the GOLD guideline [22] to classify participants, 377 (55.8\%) had no COPD, 148 (21.9\%) had mild COPD (Stage 1) and 151 (22.3\%) had moderate or severe COPD (Stage 2 or 3).

There were no differences in gender, number of cigarettes smoked, and level of nicotine dependence between the participants and the total group of smokers. Participants' had a somewhat higher age and had more frequently COPD (stage 1 and stage 2\&3).

\section{Single gene associations}

In total, 15 genetic variants in smoking-related genes were found to be associated $(p<0.10)$ with at least one of the items of the FTND questionnaire (Table 3). Of these variants, 5 were in genes influencing the response to nicotine, and 10 in genes in key neurotransmitter pathways involved in addiction ( 5 in dopamine pathway, 2 in serotonin pathway and 3 in mu-opioid pathway). P-values in this table were calculated without prior assumption of the mode of inheritance. Subsequently the $p$-value for the best fitting genetic model was calculated.

Table 4 gives the odds ratios (ORs) belonging to the best fitting genetic model for the separate FTND items. For the first item of the FTND (time-until-first-cigarette), the effect of only one of the SNPs (TPH1 rs1799913) could be confirmed. This SNP decreased the chance of smoking short after awakening (31-60 minutes, 6-30 minutes and within 5 minutes versus more than 60 minutes). However, this was only significant for 6-30 minutes $(\mathrm{OR}=0.37 ; 95 \% \mathrm{Cl}=0.20-0.70)$ and within 5 minutes $(\mathrm{OR}=0.50 ; 95 \% \mathrm{Cl}=0.26-0.93)$, but approached significance for 31-60 minutes ( $\mathrm{OR}=0.54 ; 95 \% \mathrm{Cl}=0.29-1.03 ; \mathrm{p}=0.06)$. For two other SNPs (rs6122429 and rs25531) ORs could not be computed for the best fitting model (recessive), probably due to the low number of participants in some of the groups. The association with the DRD2 rs6277 SNP did not reach significance. 
Table 3: Genetic variants in smoking-related genes significantly associated with FTND items

\begin{tabular}{|c|c|c|c|c|c|c|c|c|}
\hline gene & variant & $\mathrm{MAF}^{\mathrm{a}}$ & item 1 & item 2 & item 3 & item 4 & item 5 & item 6 \\
\hline CHRNA2 & rs2292974 & 0.44 & 0.39 & 0.19 & 0.03 & 0.50 & 0.11 & 0.34 \\
\hline CHRNA4 & rs2236196 & 0.31 & 0.14 & 0.53 & 0.08 & 0.99 & 0.10 & 0.29 \\
\hline CHRNA4 & rs6122429 & 0.17 & 0.08 & 0.33 & 0.49 & 0.30 & 0.49 & 0.41 \\
\hline CYP2A6 & rs1801272 & 0.03 & 0.62 & 0.19 & 0.09 & 0.77 & 0.30 & 0.33 \\
\hline CYP2B6 & rs3211371 & 0.13 & 0.29 & 0.24 & 0.04 & 0.38 & 0.10 & 0.78 \\
\hline$D R D 2$ & rs1800497 & 0.20 & 0.52 & 0.27 & 0.31 & 0.37 & 0.02 & 0.53 \\
\hline DRD2 & rs6277 & 0.46 & 0.07 & 0.72 & 0.55 & 0.03 & 0.96 & 0.91 \\
\hline COMT & rs737865 & 0.26 & 0.96 & 0.72 & 0.33 & 0.03 & 0.70 & 0.06 \\
\hline$M A O-A^{b}$ & uVNTR & 0.37 & 0.60 & 0.88 & 0.41 & 0.06 & 0.37 & 0.17 \\
\hline$D B H$ & rs77905 & 0.49 & 0.57 & 0.03 & 0.29 & 0.87 & 0.83 & 0.64 \\
\hline$T P H 1$ & rs1799913 & 0.37 & 0.01 & 0.60 & 0.54 & 0.32 & 0.28 & 0.55 \\
\hline SLC6A4 & rs25531 & 0.06 & 0.04 & 0.21 & 0.28 & 0.37 & 0.83 & 0.52 \\
\hline OPRM1 & rs1799971 & 0.15 & 0.25 & 0.85 & 0.46 & 0.08 & 0.76 & 0.02 \\
\hline HINT-1 & rs3852209 & 0.21 & 0.18 & 0.53 & 0.45 & 0.45 & 0.55 & 0.23 \\
\hline ARRB2 & rs3786047 & 0.33 & 0.45 & 0.26 & 0.06 & 0.03 & 0.72 & 0.23 \\
\hline
\end{tabular}

Bold $p$-values have a $p$-value $<0.05$ for the best fitting genetic model

${ }^{\mathrm{a}} \mathrm{MAF}$ : minor allele frequency ${ }^{\mathrm{b}}$ male heterozygotes excluded from analysis

Only one variant was found to influence the second item (forbidden-cigarettes), which remained significant in the logistic regression model. The presence of one or two T-alleles of the $D B H$ rs 77905 reduced the chance of having difficulty not to smoke at places were it is forbidden (OR=0.68; $95 \% \mathrm{Cl}=0.48-0.95)$.

The third item (hate-most-to-give-up) was found to be influenced mainly by variants in genes influencing nicotine. Two SNPs in the nicotinic acetylcholinic receptor (nAchR) subunits $\alpha 2$ and $\alpha 4$ (rs2292974 and rs2236196) were found to increase the chance that the first cigarette was the most difficult one to give up $(\mathrm{OR}=1.81 ; 95 \% \mathrm{Cl}=1.15-2.87$ and $\mathrm{OR}=1.35 ; 95 \% \mathrm{Cl}=1.06-1.72$, respectively), while a variant in the CYP2B6 gene (rs3211371) decreased this chance about 4 times $(\mathrm{OR}=0.27 ; 95 \% \mathrm{Cl}=0.09-0.83)$. The association with the SNP in CYP2A6 (rs1801272) was no longer significant. Furthermore, a SNP in ARRB2 (rs3786047) was found to decrease the chance with about $50 \%$ as well (OR=0.57; $95 \% \mathrm{Cl}=0.35-0.92)$.

The fourth item (number-of-cigarettes/day) was influenced only by variants in genes in key neurotransmitter pathways. However, the effects for the COMT rs737865, the MAO-A uVNTR, the OPRM1 rs1799971 and the ARRB2 rs3786047 SNPs could not be confirmed. The DRD2 rs6277 SNP was found to decrease the chance of smoking a higher number of cigarettes, however this was only significant for $21-30$ cigarettes ( $\mathrm{OR}=0.60 ; 95 \% \mathrm{Cl}=0.32-1.14$ ).

The effects of two SNPs on the fifth item (smoke-more-first-hours-awakening) were confirmed as well. The DRD2 rs1800497 SNP was found to decrease the chance of smoking more in the first hours after awakening with about $50 \%(\mathrm{OR}=1.44 ; 95 \% \mathrm{Cl}=1.06-1.95)$. On the other hand, the CYP2B6 rs3211371 seemed to result in an about four times decreased likelihood (OR=0.28; $95 \% \mathrm{Cl}=0.08-1.03)$, however, this was not significant $(\mathrm{p}=0.06)$.

The sixth item (smoke-if-ill) was significantly increased by the OPRM1 rs179971 SNP $(O R=1.60 ; 95 \% \mathrm{Cl}=1.12-2.28)$. The effect of the COMT rs737865 SNP failed to reach significance.

None of the associations remained significant after adjustment for multiple testing. 
INFLUENCE OF GENETIC VARIATION ON DIFFERENT ASPECTS OF ND 69

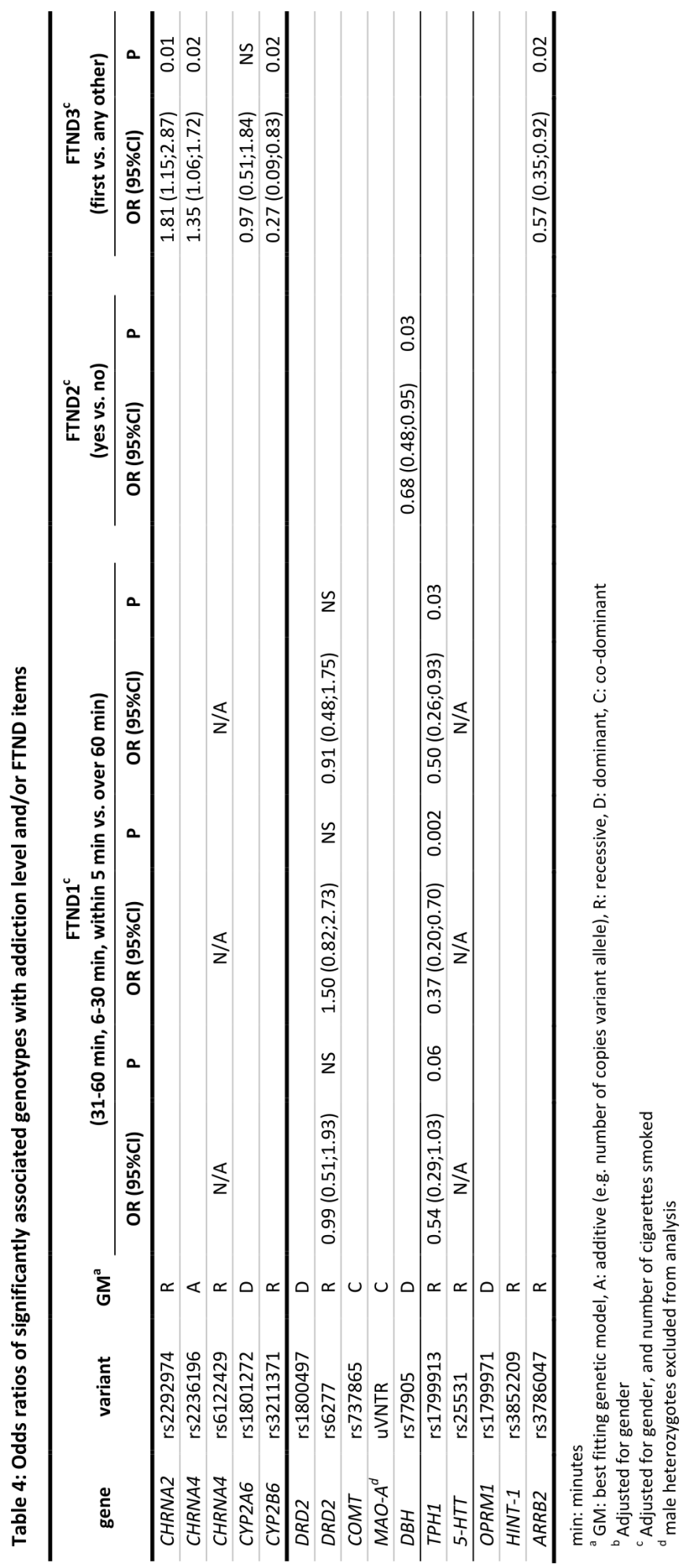









\section{DISCUSSION}

Earlier studies have provided evidence that several genetic variants in genes associated with the effects of nicotine (e.g. nicotine metabolism and nicotinic receptors) and genes in key neurotransmitter pathways associated with addiction have an effect on ND levels. However, most (candidate gene) studies have investigated one or a few genetic variants, and looked at overall measurements of the FTND only. However, it has been suggested that the FTND has a multi-factor structure [16] and might therefore also be influenced by distinct pathways. Therefore, in this study the effect of multiple genetic variants in smoking-related pathways on the seperate items of the FTND questionnaire was investigated.

The different items of the FTND questionnaire were found to be associated with several, often different, variants in smoking-related genes. Overall, item 3 was mainly associated with genes that may influence the response to nicotine, while items 2, 4, and 6 were mainly associated with genes that influence neurotransmitter pathways. This is in concordance with the results of the principal component analysis (PCA) on the FTND items by Payne et al. [16] which revealed two interpretable factors: "morning smoking" (items 1, 3 and 5) and "smoking pattern" (items 2, 4, and 6).

The chance of having difficulty not to smoke in places were it is forbidden (FTND item 2) was significantly lower among smokers with one or two DBH rs77905 SNP (G1368A) low activity A-alleles. Dopamine $\beta$-hydroxylase (DBH) converts dopamine to norepinephrine, thereby lowering dopamine levels. It has been proposed that individuals with low-activity dopamine metabolizing variants (from COMT) might experience a longer-lasting and more effective dopamine release in the brain, thereby increasing the magnitude and duration of reward by dopamine release derived from smoking [24]. Individuals with a decreased DBH activity might thus be able to last longer without smoking and can therefore avoid smoking at places were it is forbidden more easily.

Furthermore, the rs3786047 variant in the $\mu$-opioid receptor (MOR)-interacting protein $\beta$-arrestin 2 (ARRB2) was found to decrease the chance that the first cigarette was the most difficult one to give up (FTND item 2) as well. $\beta$-arrestin 2 binds to phosphorylated MOR and causes uncoupling of the signal transduction pathway, thereby increasing MOR internalization and desensitization [25]. However, the rs386047 variant does not seem to alter function and there are currently no known functional variants in ARRB2. Therefore it is not possible to rule on how this SNP may influence ND.

The number of cigarettes smoked (FTND item 4) was found to be associated with one variant in the dopamine pathway. The presence of one or two C-alleles of DRD2 rs6277 (C957T), resulting in increased mRNA stability and protein synthesis [26], leading to higher receptor availability and function, decreased the number of cigarettes smoked. This might be explained by the fact that these smokers experience a higher reward when smoking due to the higher number of available dopamine receptors and therefore need to smoke less.

A variant in the MOR significantly increased the chance that smokers would smoke even if they were ill and in bed most of the day (FTND item 6). MOR is the primary site of action for the rewarding effects of $\beta$-endorphin [27], which is released by nicotine $[28,29]$. The Asp40 variant (G-allele) of the rs1799971 variant has been found to result in 
a three-fold increased binding affinity of $\beta$-endorphin [30]. Therefore, nicotine has a greater effect in smokers with the Asp40 variant, resulting in higher rewarding effects of $\beta$-endorphin and thus higher ND. Carriers of the Asp40-allele might thus smoke more, eventhough they are feeling ill, since they are more addicted and the rewarding effects compensate for the discomfort experienced from smoking while feeling ill.

On the other hand, several genes that influence the response to nicotine (e.g. nicotinic receptors and nicotine metabolism) were found to influence the cigarette which smokers found most difficult to give up (FTND item 3). Two variants in nicotinic acetylcholinic receptor subunits (CHRNA2 rs229274 and CHRNA4 rs2236196) were found to increase the chance that the first cigarette in the morning was the most difficult one to give up, while the CYP2B6 rs3211371 was found to decrease this chance. The effect of the CHRNA2 SNP is not known, but previous studies have also provided evidence for an association of this SNP with ND [31-33]. Contrary to our results, the CHRNA4 low-activity rs2236196 G-allele, was expected to result in lower ND levels [34]. The T-allele of CYP2B6 rs3211371 has been associated with significantly reduced CYP2B6 protein expression and S-mephenytoin $\mathrm{N}$ demethylase activity [35] and might thus lower nicotine metabolism, although no significant effects of this variant on nicotine metabolism were found in one study [36]. Therefore nicotine levels might be maintained longer, decreasing the urge for a cigarette in the morning. This hypothesis is further supported by the association found in this study for this SNP with a lower amount of smoking in the first hours after awakening (FTND item 5).

Contrary to the expectations, the chance that a smoker smokes more in the first hour after awakening (FTND item 5) was also found to be associated with The Taq1A (DRD2 rs1800497). A possible explanation for this might be that since these smokers have a deficit in their reward system and experience enhanced reward when they are exposed to nicotine [37], as previously discussed, they need to smoke more in the first hours after awakening to get dopamine levels at a sufficient level to start the day.

Finally, the rs1799913 SNP in TPH1 was found to decrease the chance of smoking short after awakening (FTND item 1). It is plausible that tryptophan hydroxylase (TPH) has an effect on smoking, since it is involved in serotonin biosynthesis and nicotine has been shown to enhance serotonin release. The rs1799913 SNP has been related to poor impulse control [38], which is associated to tobacco and other substance abuse [39]. Alternatively, these individuals may find the mood-altering effects of serotonin more rewarding [40]. How this may decrease the chance for smoking short after awakening is unclear. However, the rs1799913 variant does not appear to result in an altered function or expression and may thus not be the etiological mutation responsible for this association, but may be in LD with an as yet unidentified polymorphism in the TPH1 gene [41].

This study has several limitations. Firstly, DNA was collected from only about half of the participants of the original trials (52\%). Therefore, selection bias could have occurred. No significant differences were found for gender, number of cigarettes smoked, and level of nicotine dependence between responders and the total group, but responders' age was somewhat higher and more had COPD. Furthermore, we can not exclude differences in other factors that have not been measured.

Secondly, multiple testing in association studies may result in false discoveries. No single SNP associations found in this study withstand correction for multiple testing. 
Thirdly, we pooled data from four different studies (e.g. ADC, COSMO, GOLD-0 and NicVAX). Participants for the studies were recruited and phenotyped for the studies in a similar way, however we can not fully rule out population stratification.

Fourthly, the studies included both smokers with and without COPD. Regression models were not corrected for COPD status, since COPD status was not available in all studies. However, the prevalence of undiagnosed COPD-patients among smokers in the general population has been shown to be relatively high as well [42], thus the study population is probably a good presentation of the general population anyways. Furthermore, COPD status will also not always be available in general practice.

Furthermore, in a previous study we have shown that combinations of genetic variants can have a significant effect, even if the variants do not have an effect on their own (see Chapter 3). Thus it is important to investigate the effect of combinations of genetic variants on both ND level and probably also the different aspects of ND. However, the analysis techniques currently available are not very suitable for these kinds of analysis and therefore there is a need for the development of new analysis techniques.

Finally, the genes selected for analysis were based on literature available until November 2008, of variants previously shown in several studies to be significantly associated with ND and/or smoking cessation success. We acknowledge that more genes and variants are located in these pathways.

In conclusion, several variants in genes in smoking-related pathways influenced the different aspects of ND (e.g. CHRNA2, CHRNA4, CYP2B6, DRD2, COMT, MAO-A, DBH, TPH1, SLC6A4, OPRM1, HINT-1, and ARRB2). Moreover, the different aspects of ND seem to be influenced by genetic variants in different pathways. Overall, "morning smoking" (mainly item 3) was mainly associated with genes that may influence the response to nicotine, while "smoking pattern" (items 2, 4, and 6) was mainly associated with genes that influence key neurotransmitter pathways. This information can help in unravelling the pathways involved in the different aspects of ND. This can guide treatment of smokers wanting to quit and help in the development of new forms of medication to treat the different aspects of ND. However, since we were the first to investigate the effects of genetic variants on the different items of FTND, future studies are needed first to confirm our findings.

\section{REFERENCES}

1. Kaprio J, Hammar N, Koskenvuo M, Floderus-Myrhed B, Langinvainio H, Sarna S. Cigarette smoking and alcohol use in Finland and Sweden: a cross-national twin study. Int J Epidemiol. 1982; 11(4): 378-386.

2. Heath AC, Cates R, Martin NG, Meyer J, Hewitt JK, Neale MC, Eaves L. Genetic contribution to risk of smoking initiation: comparisons across birth cohorts and across cultures. J Subst Abuse. 1993; 5(3): 221-246.

3. Heath AC, Martin NG. Genetic models for the natural history of smoking: evidence for a genetic influence on smoking persistence. Addict Behav. 1993; 18(1): 19-34.

4. True WR, Heath AC, Scherrer JF, Waterman B, Goldberg J, Lin N, Eisen SA, Lyons MJ, Tsuang MT. Genetic and environmental contributions to smoking. Addiction. 1997; 92(10): 1277-1287.

5. Kendler KS, Neale MC, Sullivan P, Corey LA, Gardner CO, Prescott CA. A population-based twin study in 
women of smoking initiation and nicotine dependence. Psychol Med. 1999; 29(2): 299-308.

6. Sullivan PM, Kendler K. The genetic epidemiology of smoking. Nicotine Tob Research. 1999; 1(Suppl 2): S51-S57.

7. Batra V, Patkar AA, Berrettini WH, Weinstein SP, Leone FT. The Genetic Determinants of Smoking. Chest. 2003; 123: 1730-1739.

8. Xian H, Scherrer JF, Madden PA, Lyons MJ, Tsuang M, True WR, Eisen SA. The heritability of failed smoking cessation and nicotine withdrawal in twins who smoked and attempted to quit. Nicotine Tob Res. 2003; 5(2): 245-254.

9. Pergadia ML, Heath AC, Martin NG, Madden PA. Genetic analyses of DSM-IV nicotine withdrawal in adult twins. Psychol Med. 2006; 36(7): 963-972.

10. True WR, Xian H, Scherrer JF, Madden PA, Bucholz KK, Heath AC, Eisen SA, Lyons MJ, Goldberg J, Tsuang M. Common genetic vulnerability for nicotine and alcohol dependence in men. Arch Gen Psychiatry. 1999; 56(7): 655-661.

11. Rossing MA. Genetic influences on smoking: candidate genes. Environ Health Perspect. 1998; 106: 231-238.

12. Arinami T, Ishiguro $\mathrm{H}$, Onaivi ES. Polymorphisms in genes involved in neurotransmission in relation to smoking. Eur J Pharmacol. 2000; 410: 215-226.

13. Al Koudsi N, Tyndale RF. Genetic influences on smoking: a brief review. Ther Drug Monit. 2005; 27(6): 704-709.

14. MacLeod SL, Chowdhury P. The genetics of nicotine dependence: relationship to pancreatic cancer. World J Gastroenterol. 2006; 12(46): 7433-7439.

15. Heatherton TF, Kozlowski LT, Frecker RC, Fagerstrom KO. The Fagerstrom Test for Nicotine Dependence: a revision of the Fagerstrom Tolerance Questionnaire. Br J Addict. 1991; 86(9): 1119-1127.

16. Payne TJ, Smith PO, McCracken LM, McSherry WC, Antony MM. Assessing nicotine dependence: a comparison of the Fagerstrom Tolerance Questionnaire (FTQ) with the Fagerstrom Test for Nicotine Dependence (FTND) in a clinical sample. Addict Behav. 1994; 19(3): 307-317.

17. Kozlowski LT, Porter CQ, Orleans CT, Pope MA, Heatherton T. Predicting smoking cessation with self-reported measures of nicotine dependence: FTQ, FTND, and HSI. Drug Alcohol Depend. 1994; 34(3): 211-216.

18. Wagena EJ, Knipschild PG, Huibers MJ, Wouters EF, van Schayck CP. Efficacy of bupropion and nortriptyline for smoking cessation among people at risk for or with chronic obstructive pulmonary disease. Arch Intern Med. 2005; 165(19): 2286-2292.

19. Van Schayck CP, Kaper J, Wagena EJ, Wouters EF, Severens JL. The cost-effectiveness of antidepressants for smoking cessation in chronic obstructive pulmonary disease (COPD) patients. Addiction. 2009;104(12): 2110-2117.

20. Kotz D, Wesseling G, Huibers MJ, van Schayck OC. Efficacy of confronting smokers with airflow limitation for smoking cessation. Eur Respir J. 2009; 33(4): 754-762.

21. Kotz D, Wesseling G, Aveyard P, van Schayck OC. Smoking cessation and development of respiratory health in smokers screened with normal spirometry. Respir Med. 105(2): 243-249.

22. Global Initiative for Chronic Obstructive Lung Disease. Global strategy for the diagnosis, management, and prevention of chronic obstructive pulmonary disease. GOLD Report. Update 2009; www.goldcopd.com.

23. Benjamini $Y$, Hochberg Y. Controlling for the false discovery rate: a practical and powerful approach to multiple testing. J R Stat Soc B. 1995; 57: 289-300.

24. Beuten J, Payne TJ, Ma JZ, Li MD. Significant association of catechol-O-methyltransferase (COMT) haplotypes with nicotine dependence in male and female smokers of two ethnic populations. Neuropsychopharmacology. 2006; 31(3): 675-684.

25. Qiu Y, Law PY, Loh HH. Mu-opioid receptor desensitization: role of receptor phosphorylation, internalization, and representation. J Biol Chem. 2003; 278(38): 36733-36739.

26. Duan J, Wainwright MS, Comeron JM, Saitou N, Sanders AR, Gelernter J, Gejman PV. Synonymous mutations in the human dopamine receptor D2 (DRD2) affect mRNA stability and synthesis of the 
receptor. Hum Mol Genet. 2003; 12(3): 205-216.

27. Zadina JE, Hackler L, Ge LJ, Kastin AJ. A potent and selective endogenous agonist for the mu-opiate receptor. Nature. 1997; 386(6624): 499-502.

28. Boyadjieva NI, Sarkar DK. The secretory response of hypothalamic beta-endorphin neurons to acute and chronic nicotine treatments and following nicotine withdrawal. Life Sci. 1997; 61(6): PL59-66.

29. Davenport KE, Houdi AA, Van Loon GR. Nicotine protects against mu-opioid receptor antagonism by beta-funaltrexamine: evidence for nicotine-induced release of endogenous opioids in brain. Neurosci Lett. 1990; 113(1): 40-46.

30. Bond C, LaForge KS, Tian M, Melia D, Zhang S, Borg L, Gong J, Schluger J, Strong JA, Leal SM, Tischfield JA, Kreek MJ, Yu L. Single-nucleotide polymorphism in the human mu opioid receptor gene alters betaendorphin binding and activity: possible implications for opiate addiction. Proc Natl Acad Sci USA. 1998; 95(16): 9608-9613.

31. Faraone SV, Su J, Taylor L, Wilcox M, Van Eerdewegh P, Tsuang MT. A novel permutation testing method implicates sixteen nicotinic acetylcholine receptor genes as risk factors for smoking in schizophrenia families. Hum Hered. 2004; 57(2): 59-68.

32. Sullivan PF, Neale BM, van den Oord E, Miles MF, Neale MC, Bulik CM, Joyce PR, Straub RE, Kendler KS. Candidate genes for nicotine dependence via linkage, epistasis, and bioinformatics. Am J Med Genet $B$ Neuropsychiatr Genet. 2004; 126B(1): 23-36.

33. Philibert RA, Todorov A, Andersen A, Hollenbeck N, Gunter T, Heath A, Madden P. Examination of the nicotine dependence (NICSNP) consortium findings in the lowa adoption studies population. Nicotine Tob Res. 2009; 11(3): 286-292.

34. Hutchison KE, Allen DL, Filbey FM, Jepson C, Lerman C, Benowitz NL, Stitzel J, Bryan A, McGeary J, Haughey HM. CHRNA4 and tobacco dependence: from gene regulation to treatment outcome. Arch Gen Psychiatry. 2007; 64(9): 1078-1086.

35. Lang T, Klein K, Fischer J, Nussler AK, Neuhaus P, Hofmann U, Eichelbaum M, Schwab M, Zanger UM. Extensive genetic polymorphism in the human CYP2B6 gene with impact on expression and function in human liver. Pharmacogenetics. 2001; 11(5): 399-415.

36. Ring HZ, Valdes AM, Nishita DM, Prasad S, Jacob P, 3rd, Tyndale RF, Swan GE, Benowitz NL. Gene-gene interactions between CYP2B6 and CYP2A6 in nicotine metabolism. Pharmacogenet Genomics. 2007; 17(12): 1007-1015.

37. Noble EP, St. Jeor ST, Ritchie T, Syndulko K, St. Jeor SC, Fitch RJ, Brunner RL, Sparkes RS. D2 dopamine receptor gene and cigarette smoking: a reward gene? Medical Hypotheses. 1994; 42: 257-260.

38. Mann JJ, Malone KM, Nielsen DA, Goldman D, Erdos J, Gelernter J. Possible association of a polymorphism of the tryptophan hydroxylase gene with suicidal behavior in depressed patients. Am J Psychiatry. 1997; 154(10): 1451-1453.

39. Wills TA, Sandy JM, Shinar O. Cloninger's constructs related to substance use level and problems in late adolescence: a mediational model based on self-control and coping motives. Exp Clin Psychopharmacol. 1999; 7(2): 122-134.

40. Lerman C, Caporaso NE, Bush A, Zheng YL, Audrain J, Main D, Shields PG. Tryptophan hydroxylase gene variant and smoking behavior. Am J Med Genet. 2001; 105(6): 518-520.

41. Nielsen DA, Jenkins GL, Stefanisko KM, Jefferson KK, Goldman D. Sequence, splice site and population frequency distribution analyses of the polymorphic human tryptophan hydroxylase intron 7. Brain Res Mol Brain Res. 1997; 45(1): 145-148.

42. Lundback B, Gulsvik A, Albers M, Bakke P, Ronmark E, van den Boom G, Brogger J, Larsson LG, Welle I, van Weel C, Omenaas E. Epidemiological aspects and early detection of chronic obstructive airway diseases in the elderly. Eur Respir J Suppl. 2003; 40: 3s-9s. 
Tobacco smoking continues to be the major preventable cause of premature morbidity and mortality throughout the world. Recent research strongly suggests that genetic background is associated with several aspects of smoking (e.g. initiation, maintenance, cessation, number of cigarettes smoked, indicators of nicotine dependence (ND) and nicotine withdrawal). Variations in two broad classes of genes have been shown to influence smoking: 1 ) genes that may influence the response to nicotine (e.g. nicotine metabolism, nicotinic receptors) and 2) genes that may predispose to addictive behaviour via their effects on key neurotransmitter pathways (e.g. dopamine, serotonin and opioid). Since these genetic variants might also influence the response to smoking cessation pharmacotherapies, smoking cessation rates might be increased by determining which treatment would be most effective based on the smoker's genetic background. This is expected to result in a more efficient use of smoking cessation therapies, increased cessation rates and ultimately, in reduced deaths from smoking.

Until now, most research on the influence of genetic variation on smoking cessation pharmacotherapy has been directed to the two most widely accepted and licensed forms of smoking cessation therapy: nicotine replacement therapy (NRT) and the antidepressant bupropion. Overall, genotypes associated with increased dopamine availability seem to predict a better response to bupropion, while smokers with genotypes associated with reduced dopamine levels probably achieve better quit rates with NRT. A decreased metabolism for the drug used (e.g. bupropion or NRT), results in increased cessation rates as well. Furthermore, smokers with reduced dopaminergic and nicotinic receptor activity variants may experience greater benefit from nicotine spray, while smokers with increased activity variants in the opioid receptor may have greater success with transdermal patches.

Thus it seems that genetic information may give directions in determining which treatment would be most effective for an individual smoker. However, several challenges will still have to be overcome before genetically tailored smoking cessation therapy can be implemented in standard clinical practice. 


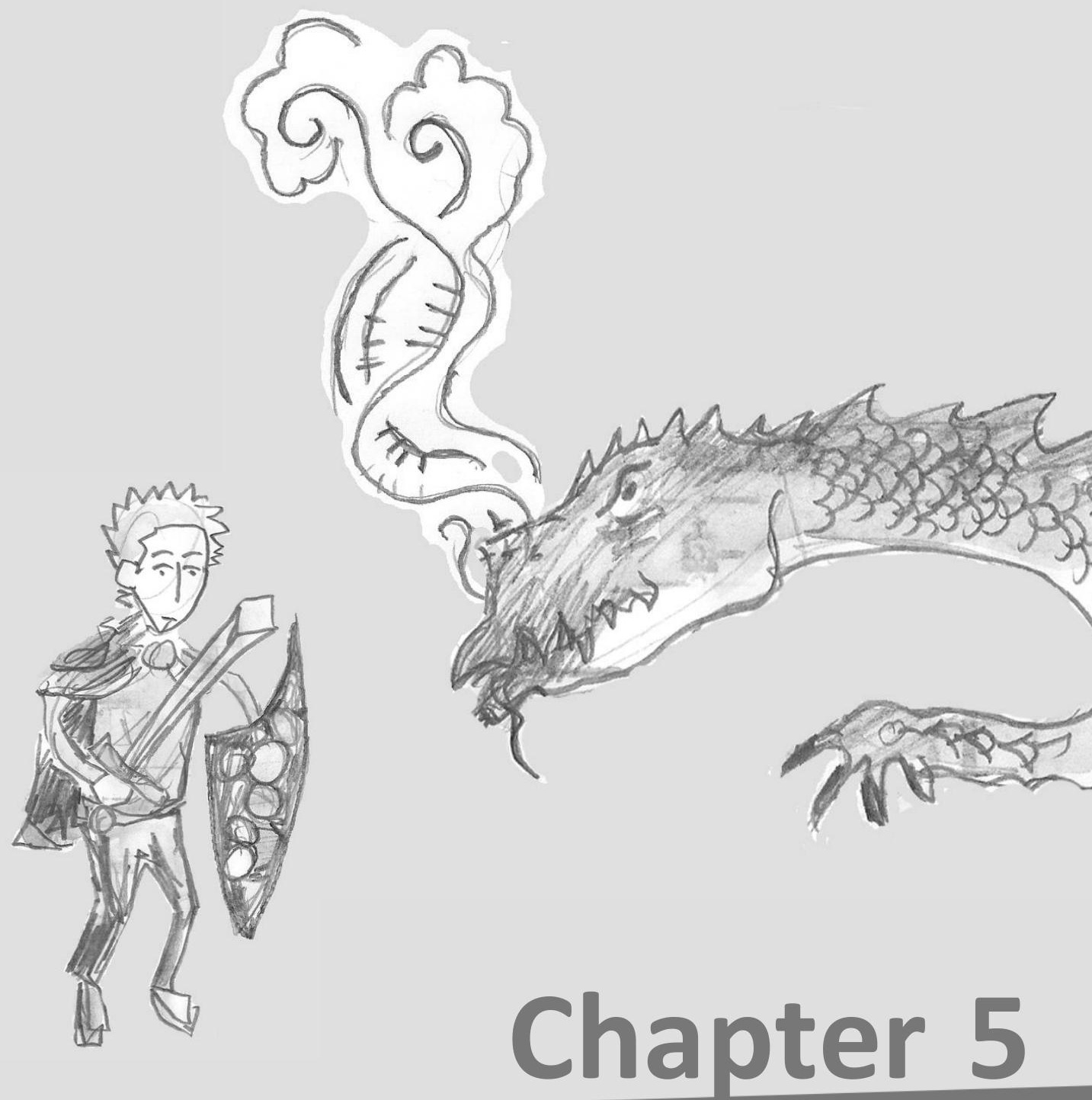

INFLUENCE OF GENETIC VARIANTS ON SMOKING CESSATION TREATMENT

Marieke Quaak, Constant P. van Schayck, Ad M. Knaapen, Frederik J. van Schooten. Based on: Mutat Res 2009; 667: 44-57; ERJ 2009; 33(3): 468-480 


\section{INTRODUCTION}

Tobacco smoking is believed to be a complex, multi-factorial behaviour with both genetic and environmental determinants. While early reports suggested that the influence of heredity on smoking was modest, more recent studies have found significant genetic influences on several aspects of smoking behaviour. It has been demonstrated that genetic factors account for approximately $40-75 \%$ of the variation in smoking initiation, $70-80 \%$ of the variation in smoking maintenance, about $50 \%$ of the variance in cessation success and $30-50 \%$ of the variance in risk of withdrawal symptoms [1-9]. Variations in several genes have been suggested to contribute to smoking behaviour, and has been focused on two broad classes of candidate genes (for extended reviews see $[7,10-13])$ :

1) Genes that may influence the response to nicotine (e.g. nicotine metabolism, nicotinic receptors)

2) Genes that may predispose to addictive behaviour due to their effects on key neurotransmitter pathways (e.g. dopamine and serotonin)

Since pharmacological therapies for smoking cessation are usually directed at the modulation of the pathways involved in smoking behaviour and addiction, genetic variation in candidate genes for smoking behaviour will probably also influence the efficacy of these smoking cessation therapies. Therefore, it seems that no medication will show efficacy for all smokers and the overall effectiveness of smoking cessation therapy might thus be increased if the therapy is targeted at those smokers most likely to respond. Research on the role of these inherited variations in the response to pharmacotherapy for nicotine addiction and smoking cessation may yield individualized treatments based on genotype. This is expected to result in a more efficient use of anti-smoking therapies, less frustration by smokers and in more effort by health care providers in stimulating smoking cessation attempts. This will lead to increased cessation rates and ultimately, in reduced deaths from smoking.

Most research on the mediating role of genetic variation on smoking cessation pharmacotherapy has been directed to the two most widely accepted and licensed forms of smoking cessation therapy: nicotine replacement therapy (NRT) [14-31] and the antidepressant bupropion (Zyban ) [19,29,32-40]. However, some studies on the pharmacogenetics of other smoking cessation therapies have been published as well: venlafaxine [41-43], d,I-fenfluramine [44,45], naltrexone [46], befloxatone [47] and acupuncture [48].

In the next section we will discuss the pharmacogenetic studies of NRT and bupropion. In Table 1 an overview of these pharmacogenetic studies is given. Because of the low number of studies and the infrequent use of the other smoking cessation therapies, the pharmacogenetics of these therapies will not be discussed in this review. Both placebocontrolled studies and studies comparing multiple active medications are included in the review. The former may be maximally informative to determine the underlying mechanisms of the pharmacogenetic effect, while the latter may help to identify subgroups of patients who will respond optimally to a particular medication given a range of therapeutic options. 


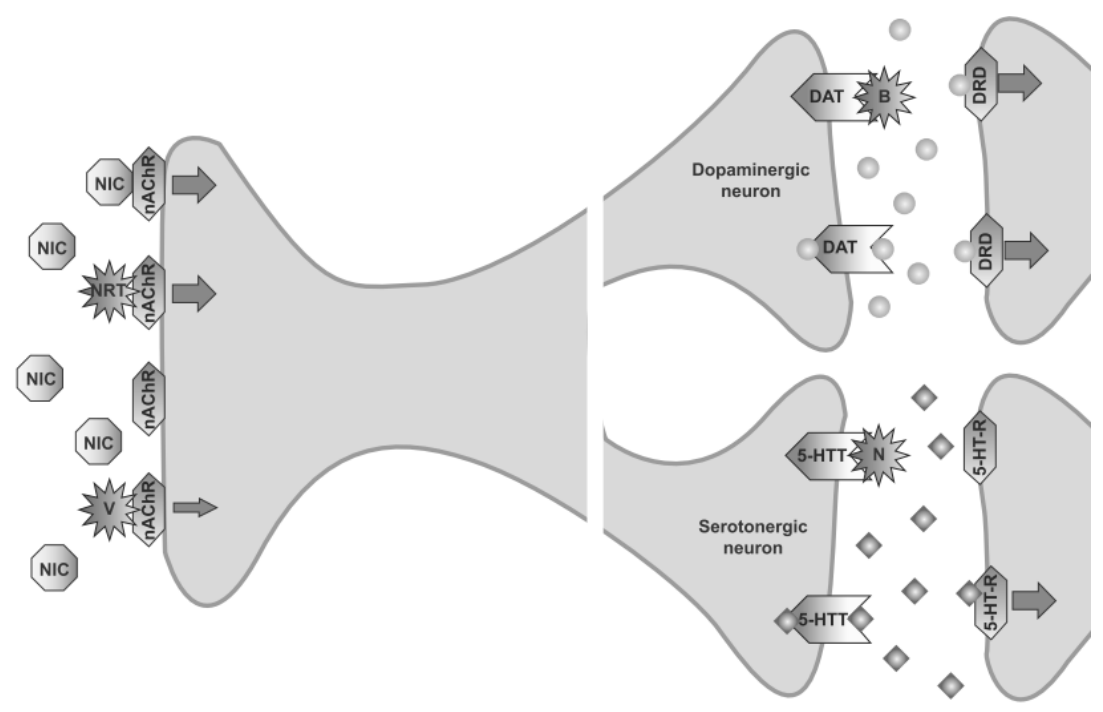

Figure 1: Mechanisms of smoking cessation treatments.

Nicotine replacement therapy (NRT) partly replaces the nicotine (NIC) from smoking. Varenicline (V) blocks nicotinic acetylcholinic receptors (nAChRs), but still triggers dopamine release (circles). Bupropion (B) inhibits re-uptake of dopamine, by occupying the dopamine transporter (DAT). Nortriptyline (N) inhibits the re-uptake of serotonin (diamonds) by occupying the serotonin transporter (5-HTT). DRD: dopamine receptor; 5-HT-R serotonin receptor

\section{PHARMACOGENETIC INVESTIGATIONS OF NICOTINE REPLACEMENT THERAPY}

Nicotine replacement therapy (NRT) is the standard recommended treatment for smoking cessation. It partially replaces the nicotine from cigarettes, which results in a decrease of withdrawal symptoms and the desire to smoke. Based on this mechanism of action (see Figure 1), candidate genes for NRT would include genes that govern the metabolism of nicotine, and genes coding for nicotinic receptors and the constituents of the neurotransmitter pathways activated by nicotine (e.g. dopamine, serotonin and opioid pathway).

To date, three NRT clinical trials have been published in which pharmacogenetics have been studied: (1) a double-blind, randomized, controlled trial of nicotine transdermal patch (TN) versus placebo (the PATCH trial) [49,50], (2) a randomized, open-label clinical trial of nicotine transdermal patch (TN) versus nicotine nasal spray (NS) (individualizing NRT trial) [51] and (3) a pharmacogenetic trial of NRT versus bupropion (NRT/bupropion trial) [29].

The pharmacogenetic studies of these clinical trials have mainly focused on the role of variations in the dopamine pathway, primarily the dopamine D2 receptor (DRD2) $[14,16,18,19]$, but also the dopamine D4 receptor (DRD4) [23], a dopamine receptor interacting protein (DRIP) [18], the dopamine transporter-1 (DAT1) [29], and dopamine synthesis and metabolism $[14,17,26]$. Others have focused on several variants in the cytochrome P450 enzymes governing the metabolism of nicotine (e.g. 2A6 [CYP2A6] and 2B6 [CYP2B6]) $[20,21,27]$, variants in the nicotinic acetylcholine receptor (nAchR) family [25], a $\mu$-opioid receptor (MOR) variant in combination with variations in MOR-interacting proteins $[15,28,30]$, and variants in the promoter region of the serotonin transporter $(5-\mathrm{HTT})[22,24]$. 


\section{Variants in genes influencing the metabolism of nicotine}

Since nicotine is the primary active component of NRT, variants in genes influencing the metabolism of nicotine are expected to influence the effectiveness of NRT. A more rapid metabolism of nicotine may result in lower nicotine blood levels from NRT products and therefore poorer smoking cessation outcomes, while a slower nicotine metabolism may result in higher nicotine blood levels and therefore higher smoking cessation success. Research has shown that slow metabolizers using TN have higher plasma nicotine levels and that faster metabolizers using TN have lower quit rates.

Since CYP2A6 is primarily responsible for the metabolic inactivation of nicotine to cotinine and the subsequent oxidation to 3 hydroxycotinine, variations in CYP2A6 are expected to influence smoking cessation rates with NRT [52,53]. Four CYP2A6 genetic variants $(* 2, * 4, * 9 A$ and $* 12 A)$ are common among Caucasians and are known to reduce or eliminate enzyme function [54]. Based on the impact of these variants, smokers can be grouped into normal metabolizers (100\% activity; no variants), intermediate metabolizers (75\% activity; either one *9A- or one *12A-allele), and slow metabolizers ( $\leq 50 \%$ activity; one or two copies of the inactive $* 2$ and $* 4$ variants or two *9A- and/or *12A-alleles). In the individualizing NRT trial [21] plasma nicotine levels were shown to be significantly higher in slow metabolizers than in normal metabolizers $(22.8 \pm 4.6 \mathrm{ng} / \mathrm{ml} \mathrm{vs} .15 .8 \pm 7.6 \mathrm{ng} / \mathrm{ml})$, while the same amount of TN was used. This is consistent with reduced rates of nicotine clearance. On the other hand, slow metabolizers in the NS group used significantly fewer

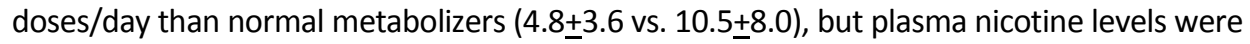
similar. This is probably the result of titration of NS by smokers to compensate for the slower rates of nicotine inactivation. In a later report of this study [95] it was shown that for smokers using TN the odds of quitting smoking was significantly lower for phenotypic faster metabolizers $(O R=0.72)$. No relation was found in the NS group (OR=1.05). However, no significant associations of genotype group with abstinence was found, possibly because the currently identified CYP2A6 gene variants explain only a small percentage of the variation in nicotine metabolism and cell sizes in these analyses were very small.

CYP2B6 can also metabolize nicotine but with a lower affinity and probably mainly in individuals where CYP2A6 activity is decreased. However, in both CYP2A6 normal and decreased activity groups, no differences in abstinence rates between normal $\left(C Y P 2 B 6^{*} 1\right)$ and increased activity $\left(C Y P 2 B 6^{*} 6\right)$ groups during NRT treatment (both TN and NS) were found [27]. Thus it seems that the $C Y P 2 B 6^{*} 6$ allele does not influence smoking cessation, regardless of CYP2A6 genotype.

\section{Variations in the nicotinic acetylcholine receptor}

One of the primary mechanisms underlying the addictive nature of tobacco use is the binding of nicotine to nicotinic acetylcholine receptors, especially to the $\alpha 4$-subunit (encoded by the CHRNA4 gene) and the $\beta 2$-subunit (encoded by the CHRNB2 gene) [55]. Individuals with increased $\alpha 4 \beta 2$ binding have been shown to be more likely to maintain abstinence on NS, but not on TN.

Individuals in the individualizing NRT trial with a TC-genotype for the CHRNA4 rs2236196 SNP, associated with increased $\alpha 4 \beta 2$ binding and greater sensitivity to the acute effects of smoking, were found to be more likely to maintain treatment gains during the follow-up 
period when they received NS [25]. No association with the rs6122429 SNP, resulting in an increased expression, was found [25]. Thus it seems that in individuals with increased nicotinic receptor activity forms of NRT that reach the central nervous system (CNS) more quickly (e.g. NS, nicotine gum, inhaler lozenge) may mimic their experience of cigarette smoking more closely and therefore be more useful as a cessation aid than TN. However, an independent clinical trial with a no-treatment control group is necessary to help clarify whether this variant plays a role in overall liability to relapse or in response to pharmacotherapy.

\section{Variations in the dopamine pathway}

Binding of nicotine from the NRT to the nicotinic acetylcholine receptors leads to the activation of the dopamine pathway and this has been shown to play an important role in nicotine's rewarding effects. Therefore, variants in several parts of the dopamine pathway have been investigated for their influence on the efficacy of NRT, such as the dopamine receptors 2 (DRD2) and -4 (DRD4), a receptor signalling regulator (neuronal calcium sensor-1 [NCS-1]), the dopamine transporter-1 (DAT1) and the dopamine synthesis and metabolism (DBH and COMT).

\section{Dopamine receptor polymorphisms}

Of the dopamine receptors, most research has focused on the dopamine receptor 2 (DRD2). Several variants in DRD2 have been investigated for their effect on smoking cessation using NRT (DRD2 Taq1A or DRD2 32806C/T [14, 16], DRD2 -141C Ins/Del [18, 19], DRD2 22316A/G [14] and DRD2 957C/T [19]) and one study has investigated the effect of two polymorphism in the dopamine receptor 4 (DRD4) (DRD4-VNTR and DRD4 -521C/T) [23]. Variants associated with lower DRD2 activity (DRD2 Taq1 A1, DRD2 -141DelC and DRD2 957T) have been shown to increase quit rates on NRT, while no association with DRD4 activity has been found.

In the PATCH-II trial the effect of the DRD2 Taq1A polymorphism, associated with a reduced receptor density, was investigated. However, it was shown recently that this SNP lies $10 \mathrm{~kb}$ downstream of $D R D 2$ in a kinase gene, named ankyrin repeat and kinase domain containing 1 (ANKK1) [56]. This gene is a member of an extensive family of proteins involved in signal transduction pathways. The DRD2 Taq1A SNP causes an amino acid substitution within the $11^{\text {th }}$ ankyrin repeat of $A N K K 1$, which may affect substrate binding specificity. This might provide an alternative explanation for the previously described association of this SNP with smoking. TN was found to be significantly more effective for smokers with the DRD2 Taq1 A1/A1 or $\mathrm{A} 1 / \mathrm{A} 2$ ( $\mathrm{TT}$ or $\mathrm{CT}$ ) genotype (OR=2.8) compared to smokers with the $A 2 / A 2(C C)$ genotype $(O R=1.4)$ after 1 week of treatment, but not after 12 weeks [14]. Another report from this study [16] showed that only women, but not men, with the variant A1-allele benefit from TN (OR=2.9 after 8 years of follow-up), because of a higher quit rate on TN and a lower quit rate with placebo compared to those with the A2/A2 genotype.

In the PATCH-II trial the DRD2 exon8 22316A/G polymorphism, which has been implicated in alcohol dependence and clinical outcome of withdrawal, was found to be coupled with the DRD2 Taq1A polymorphism [14]. It did not show any significant independent association 
with patch effectiveness either alone or when examined as a haplotype-based combination with DRD2 Taq1A.

In the individualizing NRT trial it was found that smokers carrying one or more copies of the DelC-allele of the DRD2 -141C Ins/Del SNP (associated with decreased transcriptional activity) and smokers homozygous for the T-allele of the DRD2 957C/T SNP (resulting in decreased mRNA stability and protein synthesis) respond better to NRT $[18,19]$. No evidence was found for effects of these two DRD2 variants on changes in withdrawal symptoms, side-effects, depression symptoms, and the average number of NS doses. However, there was a significantly lower patch use in days per week for the DRD2 -141CC-group and the 957TT-group, probably because participants who relapsed were advised to discontinue patch use.

Furthermore, in the PATCH-II trial the possession of one or more copies of the long, reduced activity, dopamine D4 (DRD4) VNTR-allele was significantly associated with a reduced likelihood of cessation at 12-week follow-up ( $O R=0.65)$, but not at 26-week follow-up [23]. However, no interaction with treatment was found. No relation with the DRD4 -521C/T SNP, associated with up to $40 \%$ lower transcription levels for the T-allele, and smoking cessation success at either 12- or 26-week follow-up was found either.

\section{Receptor signalling regulator polymorphisms}

Based on their ability to regulate signalling through dopamine receptors, dopamine receptor interacting proteins (DRIPs) may also influence the response to NRT. Higher abstinence rates have been found among individuals with the AA-genotype of the neuronal calcium sensor-1 (NCS-1) protein rs3780715 SNP in combination with $\geq 1$ copies of the DRD2 -141DelC-allele.

The NCS-1 protein (encoded by the FREQ gene) attenuates dopamine-induced DRD2 desensitization and internalization in a calcium-dependent manner, thereby changing D2 signalling. Both the FREQ rs3780715 and FREQ rs1054879 SNPs, with unknown effects, were not significantly associated with abstinence at end-of-treatment (EOT) or 6-month follow-up in the individualizing NRT trial [18]. However, a significant interaction between the FREQ rs1054879 and DRD2 -141C ins/del genotype was found (OR=2.32). This suggests that the higher abstinence rates found among smokers with at least one copy of the $D R D 2$-141DelC-allele is probably present only among the subset of smokers who are also homozygous for the A-allele of FREQ rs1054879 variant. No difference was found for type of NRT used. Because the trial did not include a placebo arm, it is not possible to determine whether the observed genetic effect is caused by an enhanced ability to quit smoking or a response to NRT.

\section{Dopamine transporter polymorphisms}

The dopamine transporter-1 (DAT1; encoded by the SLC6A3 gene) moves the dopamine released in the synapse into a neuron, glial cell or astrocyte to terminate the dopamine signal. A reduction in dopamine transporter levels will therefore result in less clearance and greater bio-availability of dopamine and probably thus greater rewarding effects of NRT. Higher initial cessation rates have been found among carriers of the decreased activity 9-repeat of the 3'UTR-VNTR and the linked increased activity 2-repeat of the intron8-VNTR. 
Carriers of a SLC6A3 3'UTR-VNTR 9-repeat, associated with lower transporter levels, were found to have a significantly higher initial cessation rate than those homozygous for the 10-repeat $(O R=2.0)$ [29]. The same pattern was present for carriers of a linked intron8-VNTR 2-repeat, associated with higher transporter levels, compared to those homozygous for the 3-repeat $(\mathrm{OR}=1.8)$. There was no evidence of an effect of three haplotype tagging SNPs (478G/T, rs11564752; 1036C/A, rs2963238; 2086A/G, rs27048) on smoking cessation. The relationship between the 3 'UTR-VNTR (or intron8-VNTR) and initial cessation was not modified by whether NRT or bupropion had been used to aid stopping, but since no placebo group was used, it is not possible to determine whether the genetic effect reflects an enhanced ability to quit smoking or a response to NRT.

\section{Dopamine synthesis and metabolism polymorphisms}

Several enzymes, such as tyrosine hydroxylase (TH), DOPA decarboxylase (DDC), dopamine beta-hydroxylase (DBH), catechol-O-methyl-transferase (COMT) and monoamine oxidase (MAO)-A and $-B$, are involved in the synthesis and metabolism of dopamine. However, the influence on NRT treatment of only one variant in $D B H$ and one variant in COMT has been investigated. Individuals with $D B H$ and $C O M T$ decreased activity variants were shown to have higher quit rates on NRT.

Patch effectiveness after 1 and 12 weeks of treatment tended to be higher for subjects in the PATCH-II trial with the reduced activity A-allele of the $D B H 1368 \mathrm{~A} / \mathrm{G}$ polymorphism, compared to those with $\mathrm{GG}$-genotypes (OR=2.13 vs. $\mathrm{OR}=1.34$ and $\mathrm{OR}=2.17$ vs. $\mathrm{OR}=1.36$, respectively) [14]. When combining with the $D R D 2$ Taq1A variant, smokers with at least one variant allele at each locus (DRD2 Taq1A2/A2 or A1/A2 and DBH 1368GA or AA) showed increased effectiveness on TN compared to placebo, because they tended to have higher quit rates on TN and lower quit rates on placebo. There was no association between genotype and patch effectiveness beyond 12 weeks.

Both the individualizing NRT trial [17] and the PATCH-II trial [26] found an increased likelihood of abstinence after NRT treatment among smokers homozygous for the reduced activity Met-allele of the catechol-O-methyltransferase Val108/158Met variant (COMT rs165688/rs6580, also known as COMT L/H). In the individualizing NRT trial [17] this association was restricted to women, while in the PATCH-II trial [26] the effects did not seem to differ between males and females. There is some evidence that oestrogen lowers COMT activity in the blood and brain of women. Therefore, the doubly reduced COMT activity in women, resulting from the Met-allele and oestrogen activity could result in the maintenance of higher dopamine levels and function in the brain. This might facilitate smoking cessation by minimizing the dopamine release by nicotine, thereby reducing the positive reinforcement from smoking.

\section{Variations in the serotonin pathway}

Since nicotine enhances serotonin release and diminished serotonergic neurotransmission has been associated with symptoms of nicotine withdrawal, variations in the serotonergic pathway are expected to influence smoking cessation success with NRT as well. However, no association between smoking cessation success on NRT and the increased activity 5-HTTLPR variant has been found. 
The serotonin transporter (5-HTT) gene (SLC6A4) encodes a transmembrane transporter responsible for reuptake of serotonin at the synapse, and in this way regulates the magnitude and duration of serotonergic signalling. The long (L) form of an insertion/deletion polymorphism in the promoter region of the serotonin transporter, named 5-HTTLPR, is associated with increased transcriptional activity $[57,58]$. This results in increased serotonin levels after activation by nicotine and thus more rewarding effects among carriers of the long form compared to carriers of the short (S) form. Therefore it is hypothesised that NRT is more effective in smokers carrying the S-allele compared to LL- or SL-genotypes.

However, no support for this hypothesis has been found in both the individualizing NRT trial [22] and the PATCH-II trial [24]. Recently it was suggested that there are two subtypes of the 5-HTTLPR L-allele and that only one of these subtypes $\left(L_{A}\right)$ has a higher activity [59]. Therefore, the lack of sub-classification of the 5-HTTLPR L-allele in these two studies might explain the lack of association with treatment response to NRT.

\section{Variations in the opioid pathway}

The $\mu$-opioid receptor ( $M O R$; encoded by the OPRM1 gene) is the primary target of $\beta$-endorphin, which is released after nicotine administration and mediates the pleasurable effects of nicotine. Variations in the MOR and MOR-interacting proteins are therefore expected to influence the effectiveness of NRT treatment. Carriers of the increased activity MOR Asp40-variant are more likely to be abstinent, especially on high dose $(21 \mathrm{mg}) \mathrm{TN}$. However, this is possibly only the case for women and reversed for men. Furthermore, these higher quit rates are probably only maintained among individuals homozygous wild-type for the MOR-interacting protein $\beta$-arrestin 2 (ARBB2). Quit rates are also increased among individuals with the C-allele of the rs3852209 SNP of the MOR-interacting protein histidine triad nucleotide binding protein 1 (HINT-1). Thus, although previous studies have not supported a sustained benefit of higher dose $(44 \mathrm{mg})$ patches or longer duration of treatment, subgroups of smokers defined by OPRM1 genotype may benefit from a longer $21 \mathrm{mg}$ dose phase, or even maintenance therapy.

Carriers of the Asp40-variant (G-allele) of a common OPRM1 Asn40Asp (118A/G) miss-sense SNP, resulting in a three-fold increased binding affinity of $\beta$-endorphin, were significantly more likely to be abstinent at EOT when using TN, but not for NS treatment [15]. This was due to the fact that smokers with the Asp40-variant had higher initial abstinence rates when using TN (52\%) compared to NS (30\%), whereas smokers without the variant did equally well on either TN (33\%) and NS (27\%). Moreover, smokers with the Asp40-variant where more likely to recover from a relapse during the first phase of TN treatment $(21 \mathrm{mg})$, but not during the following treatment phases and in the NS treatment group. Contrary to these results, the PATCH-II trial [28] found that this increased likelihood of abstinence after NRT treatment in the presence of the Asp40-variant was found only among women, while among male subjects an increased likelihood of abstinence was found in the Asn40/Asn40 (AA) group.

To extend previous findings the role of variants in two proteins that have been shown to interact with the MOR was investigated in another study of the individualizing NRT trial: $\beta$-arrestin 2 (ARRB2; binds to phosphorylated MOR causing uncoupling of the signal transduction process, increasing internalization and desensitization of the MOR) and histidine 
triad nucleotide binding protein 1 (HINT-1; decreases phosphorylation and desensitization) [30]. The quit rate data suggests that the higher abstinence rates observed at EOT among smokers with the low-activity OPRM1 Asp40-allele are maintained only among those homozygous for the ARRB2 variants (rs1045280, rs2036657, rs3786047). Furthermore, individuals with a C-allele of the HINT-1 rs3852209 SNP have a higher quit rate, but no relation with the rs2036657 SNP has been found.

\section{PHARMACOGENETIC INVESTIGATIONS OF BUPROPION}

Efficacy in smoking cessation of bupropion $\left(\right.$ Zyban $\left.^{\circledR}\right)$ may be mediated, in part, by inhibition of dopamine and norepinephrine reuptake (see Figure 1). Relevant candidate genes are therefore those in the dopamine and norepinephrine pathways $[60,61]$. Other relevant candidate genes include genes that govern the metabolism of bupropion (e.g. cytochrome P450 2B6 [CYP2B6]).

To date, four bupropion clinical trials have been published in which pharmacogenetics have been studied: (1) a placebo-controlled randomized trial at Georgetown University and State University of New York in Buffalo (Georgetown/Buffalo trial) [62], (2) a trial evaluating the differential effectiveness of two doses (150 and $300 \mathrm{mg}$ ) of bupropion SR among members of the Group Health Cooperative (GHC) in Washington State (Project EZ) [63,64], (3) a randomized placebo controlled 2x2 clinical trial (bupropion versus placebo; standard behavioural therapy versus standard plus cognitive behavioural treatment) from Brown University (Brown trial) [65], and (4) the previously mentioned pharmacogenetic trial of NRT versus bupropion (NRT/bupropion trial) [29].

The pharmacogenetic studies of these clinical trials have mainly focused on the role of variants in the dopamine pathway, especially DRD2 Taq1A [33-35,37-38,40], but also other variants in DRD2 [19], the dopamine transporter-1 (DAT-1) polymorphisms [29,34,38,40] and variations in the dopamine synthesis and metabolism [36]. Two studies have investigated the role of variants in the cytochrome P450 enzymes CYP2A6 and CYP2B6 [32,39].

\section{Variants in genes influencing the metabolism of bupropion}

Since bupropion is metabolized to its primary metabolite hydroxybupropion by the cytochrome P450 2B6 (CYP2B6) enzyme, variation in this enzyme is expected to affect the response to bupropion. Furthermore, variants in CYP2A6 may be coupled to variants in CYP2B6 since the cytochrome P450 2A6 (CYP2A6) enzyme is located in close proximity of CYP2B6. Bupropion has been shown to attenuate the increased cravings and higher chance of relapse among individuals with CYP2B6 decreased activity variants (CYP2B6 1459T-allele and CYP2B6*6 genotype). In this way decreased CYP2B6 activity increases abstinence rates and results in maintained abstinence rates after treatment. On the other hand, among smokers with a normal bupropion metabolism (CYP2B6*1) bupropion is no more effective and abstinence rates drop after the EOT. Furthermore, among individuals with a normal CYP2A6 metabolism abstinence rates are similar to the general population, but among individuals with a slow/intermediate CYP2A6 metabolism abstinence rates are high on placebo and low on bupropion. 
In the Georgetown/Buffalo trial [32] smokers, especially women, with the CYP2B6 1459C/T T-variant, associated with lower brain CYP2B6 levels, experienced greater increases in cravings for cigarettes and were less likely to be abstinent in the placebo-treated group, but not in the bupropion-treated group. However, bupropion appeared to attenuate this genetic predisposition on relapse among women (19\% abstinence on placebo vs. $54 \%$ on bupropion), which may be, in part, due to improved management of abstinence-induced negative-mood.

In another report of this study [39] bupropion was reported to significantly increase abstinence rates among smokers with the CYP2B6*6 genotype (516G/T + 785A/G SNPs), which probably leads to a lower enzyme activity, at EOT (32.5\% vs. $14.3 \%)$ and 6 -months (31.2\% vs. $12.9 \%$ ), but not in the wild-type (CYP2B6*1) group (EOT: $31.0 \%$ vs. $31.6 \%$; 6-months: $22.0 \%$ vs. $21.5 \%$ ). Abstinence rates after termination of treatment tend to drop as participants relapse, but this was not the case for the CYP2B6*6 group when treated with bupropion. On the other hand, the CYP2B6*1 group achieved a significantly higher abstinence rate on placebo compared with the $C Y P B 6^{*} 6$ group. This may reflect a function of CYP2B6 that is currently unknown or CYP2B6*1 may be in linkage disequilibrium with another gene conferring high abstinence rates.

In the Brown trial, the influence of CYP2A6 intermediate or slow metabolism ( ${ }^{*}$, stop codon change; $* 4$, gene deletion; $* 9$, resulting in decreased transcription; $* 12$, CYP2A6/ CYP2A7 hybrid) was investigated [39]. Among cases with a normal CYP2A6 metabolism, similar abstinence rates were seen compared with the general population on placebo $(21.5 \%)$ and bupropion (34.6\%). Among cases with intermediate or slow CYP2A6 metabolism abstinence rates were high on placebo (32.1\%) and low on bupropion (13.0\%). No CYP2A6-CYP2B6 gene-gene interaction was present.

\section{Variations in the dopamine pathway}

Since bupropion's efficacy in smoking cessation may be mediated, in part, by inhibition of dopamine, it is expected that variations in the dopamine pathway influence cessation rates during bupropion treatment. From the variants present in the dopamine pathway, the effect of variants in the dopamine D2 receptor (DRD2) has been investigated most extensively. Other candidate genes from the dopamine pathway that have been investigated are the dopamine transporter gene (SLC6A3) and cathechol-O-methyltransferase (COMT).

\section{Dopamine receptor polymorphisms}

All research of the effect of dopamine receptor polymorphisms has focused on the dopamine receptor 2 (DRD2). Several variants in $D R D 2$ have been investigated for their effect on smoking cessation using bupropion (DRD2 Taq1A or DRD2 32806C/T [33-35, 37-38,40], DRD2 -141C Ins/Del [19] and DRD2 957C/T [19]). Individuals homozygous for the DRD2 Taq1 A2-allele or the DRD2 -141InsC-allele, both associated with an increased DRD2 activity, have been shown to increase the efficacy of bupropion treatment, especially among women. The relationship with the DRD2 Taq1A genotype is possibly present only in individuals with a CYP2B6 1459T-allele and reverse in the presence of two C-alleles. No relationship with the DRD2 957C/T SNP has been found. 
Of the polymorphisms present in the DRD2 gene, most research has been directed on the DRD2 Taq1A SNP. In the Brown trial $[33,38]$ greater beneficial effects of bupropion on withdrawal symptoms for smokers with DRD2 Taq1 A2/A2 genotypes, associated with an increased receptor density, compared to those carrying an A1-allele were found. This is possibly a result of the fact that dopamine re-uptake inhibition by bupropion is more pronounced in DRD2 Taq1 A2-homozygotes than in Taq1 A1-carriers since they have a limited ability to stimulate postsynaptic dopamine receptors. In contrast, no long-term effects of the DRD2 Taq1A variant on smoking cessation rates during bupropion treatment were found in the Georgetown/Buffalo trial [34], Project EZ [35,40] and the Brown trial [38]. However, data of the Brown trial [38] suggested that bupropion was associated with a significantly higher odds of abstinence compared with placebo among those with the DRD2 Taq1 A2/A2 genotype, whereas virtually no difference was observed between treatments in the A1-allele carriers. Furthermore, gender differences were evident in two studies [34-35,40]. In Project EZ [35,40] it was found that women carrying at least one A1-allele were more likely to report having stopped taking bupropion due to adverse effects $(O R=1.91)$ and were somewhat less likely to quit smoking $(\mathrm{OR}=0.76)$. No association was observed in men $(\mathrm{OR}=1.09)$. Moreover, in a pooled analysis of the studies from the Georgetown/ Buffalo trial and the Brown trial [37] the DRD2 Taq1 A2/A2-genotype was significantly associated with relatively greater efficacy of bupropion treatment compared to DRD2 Taq1 A1-carriers. This suggests that the statistical power in the previous pharmacogenetic analyses was insufficient to detect the interaction. Furthermore, in the Brown trial [38] a significant interaction between DRD2 Taq1A and CYP2B6 1459C/T genotype was found. The odds of abstinence was found to be higher only among smokers homozygous for the DRD2 Taq1A A2-variant with at least one CYP2B6 1459T-allele (OR=2.51), while they were less likely to be abstinent in the presence of two CYP2B6 1459C-alleles (OR=0.62).

Another study of the Georgetown/Buffalo trial [19] found that smokers homozygous for the DRD2 -141InsC-allele, associated with an increased transcriptional activity, were significantly more likely to respond to bupropion. Those with a DelC-allele (CN or NN genotypes) responded better to placebo. This is possibly a result of the higher availability of D2-receptors to bind dopamine in individuals with the -141InsC-genotype, resulting in a more rewarding effect of smoking and therefore a greater liability to relapse. Bupropion treatment (via inhibition of dopamine re-uptake) may result in sustained elevations in extracellulair dopamine.

No association with the DRD2 957C/T variant, that decreased mRNA stability and protein synthesis, was found in the Georgetown/Buffalo trial [19].

\section{Dopamine transporter polymorphisms}

A reduction in dopamine transporter levels (DAT-1; SLC6A3 gene) will result in less clearance and greater bio-availability of dopamine and might therefore influence efficacy of bupropion treatment. Higher cessation rates have been found among carriers of the decreased activity 9-repeat of the 3 'UTR-VNTR and the linked increased activity 2-repeat of the intron8-VNTR. The short-term effect of the 9-repeat might be influenced by the DRD2 Taq1 A2-genotype, while the long-term effects might be influenced by the DRD2 Taq1 A1-allele. 
The role of the DAT-1 3'UTR variable number tandem repeat (SLC6A3 3'UTR VNTR) polymorphism, associated with lower transporter levels for the 9-repeat compared to the 10-repeat, was investigated in all four trials $[29,34,38,40]$. In the Georgetown/Buffalo trial [34], the Brown trial [38] and Project EZ [40] no evidence was found that this genotype significantly modifies the response to bupropion treatment by itself. However, in both the Georgetown/Buffalo trial [34] and Project EZ [40], the DRD2 Taq1A polymorphism was found to influence the effect of the SLC6A3 genotype. In the Georgetown/ Buffalo trial [34], the SLC6A3 9-repeat was associated with higher initial abstinence rates only among participants with DRD2 Taq1A A2-genotypes (OR=1.74), but not among those with A1-genotypes (OR=0.67). However, in Project EZ [40] the SLC6A3 9-repeat was associated with an increased long-term abstinence in the presence of the DRD2 Taq1A A1-allele $(O R=2.48)$, but not in the absence of the A1-allele $(O R=0.88)$. And, although non-significant, the same pattern for long-term abstinence was seen in the Georgetown/ Buffalo trial [34]. On the other hand, in the NRT/bupropion trial [29] carriers of the SLC6A3 3'UTR-VNTR 9-repeat (9/9 or $9 / 10)$ and the linked intron8-VNTR 2-repeat (2/2 or 2/3) had a significantly higher initial cessation rate. This association was no longer present during the last two weeks of treatment. The relationship between the 3'UTR- (or intron8-) VNTR and initial cessation was not modified by whether NRT or bupropion had been used to aid cessation, and due to the lack of a placebo group, it is not possible to determine whether the enhanced quit rates reflect a response to bupropion treatment.

There was no evidence of an effect of three DAT-1 haplotype tagging SNPs (478G/T, rs2963238; 1036C/A, rs11564752; 2086A/G, rs27048) on smoking cessation outcome in the NRT/bupropion trial [29].

\section{Dopamine synthesis and metabolism polymorphisms}

Since catechol-O-methyl-transferase (COMT) is involved in the metabolism of dopamine, thereby lowering dopamine levels, variants in this enzyme are expected to influence bupropion treatment as well. No effect on treatment of the decreased activity COMT Val108/158Met variant has been found. On the other hand, carriers of a haplotype including the rs165599 A-allele, probably resulting in a higher activity, benefit from bupropion treatment. Furthermore, African-Americans with a GG-haplotype of the rs737865 and rs165599 SNPs, seem to benefit from bupropion treatment as well.

One study of the Georgetown/Buffalo trial has investigated the effect of the low activity COMT Val108/158Met variant (rs165688/rs6580, also known as COMT L/H) and two variants with unknown effect (rs737865 and rs165599) in both EuropeanAmericans and African-American participants [36]. The Val108/158Met SNP did not even have a marginally significant effect on treatment in either ethnic group. On the other hand, smokers from both ethnic groups with rs165599 GG-genotypes quit more readily on placebo, while persons with genotypes including an A-allele responded well to bupropion treatment. Smokers carrying a haplotype including the rs165599 A-allele had a substantial probability of benefit from bupropion treatment as well. No advantage of the GG-haplotype for bupropion compared to placebo was found among EuropeanAmericans, while it was associated with a favourable response to bupropion compared to placebo in African-Americans. This is possibly because the GG-haplotype is in linkage disequilibrium with other functional variants in European-Americans, or due to chance. 
Table 1: Influence of genetic variations on nicotine replacement therapy (NRT) and bupropion treatment

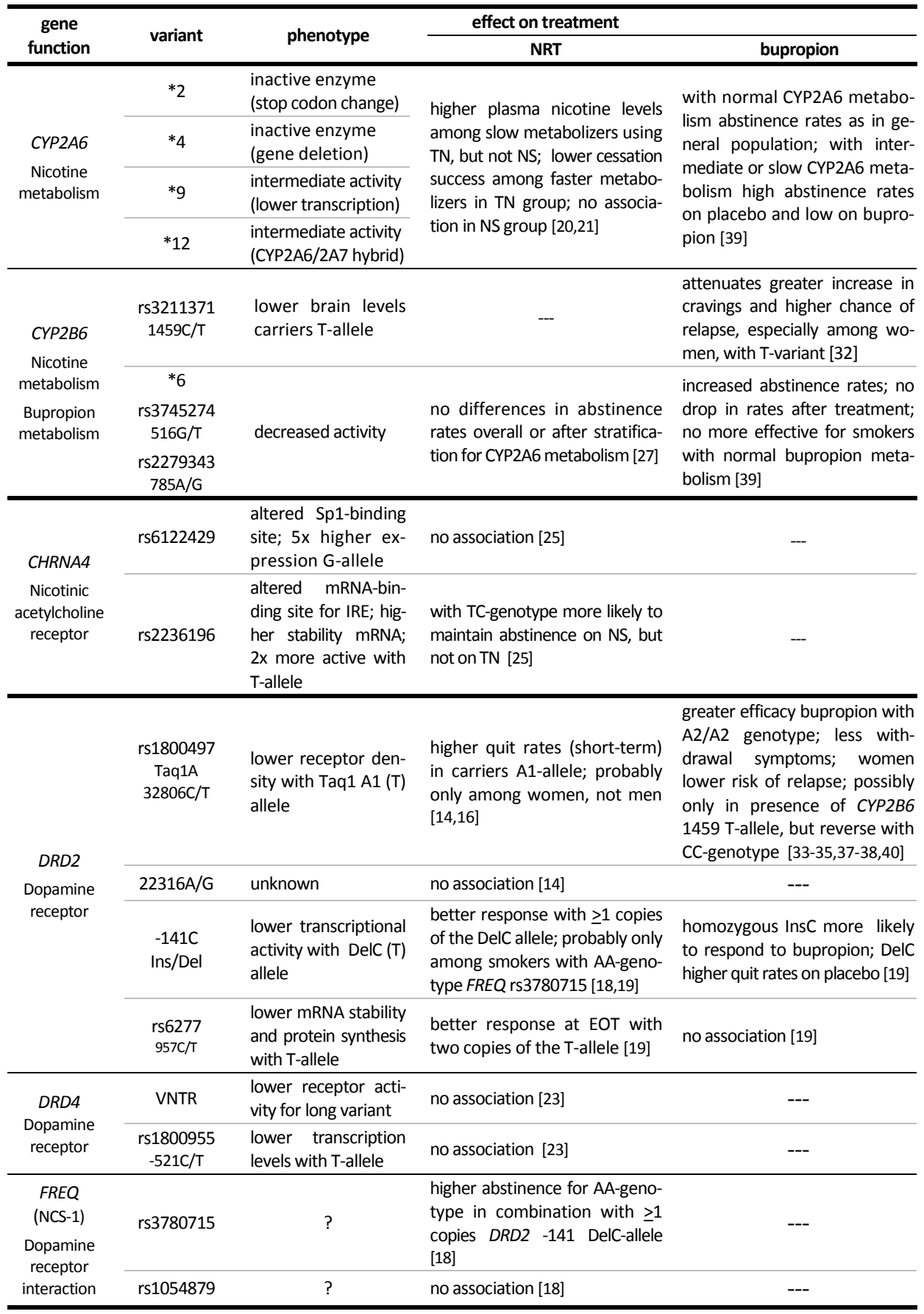


Table 1 - continued

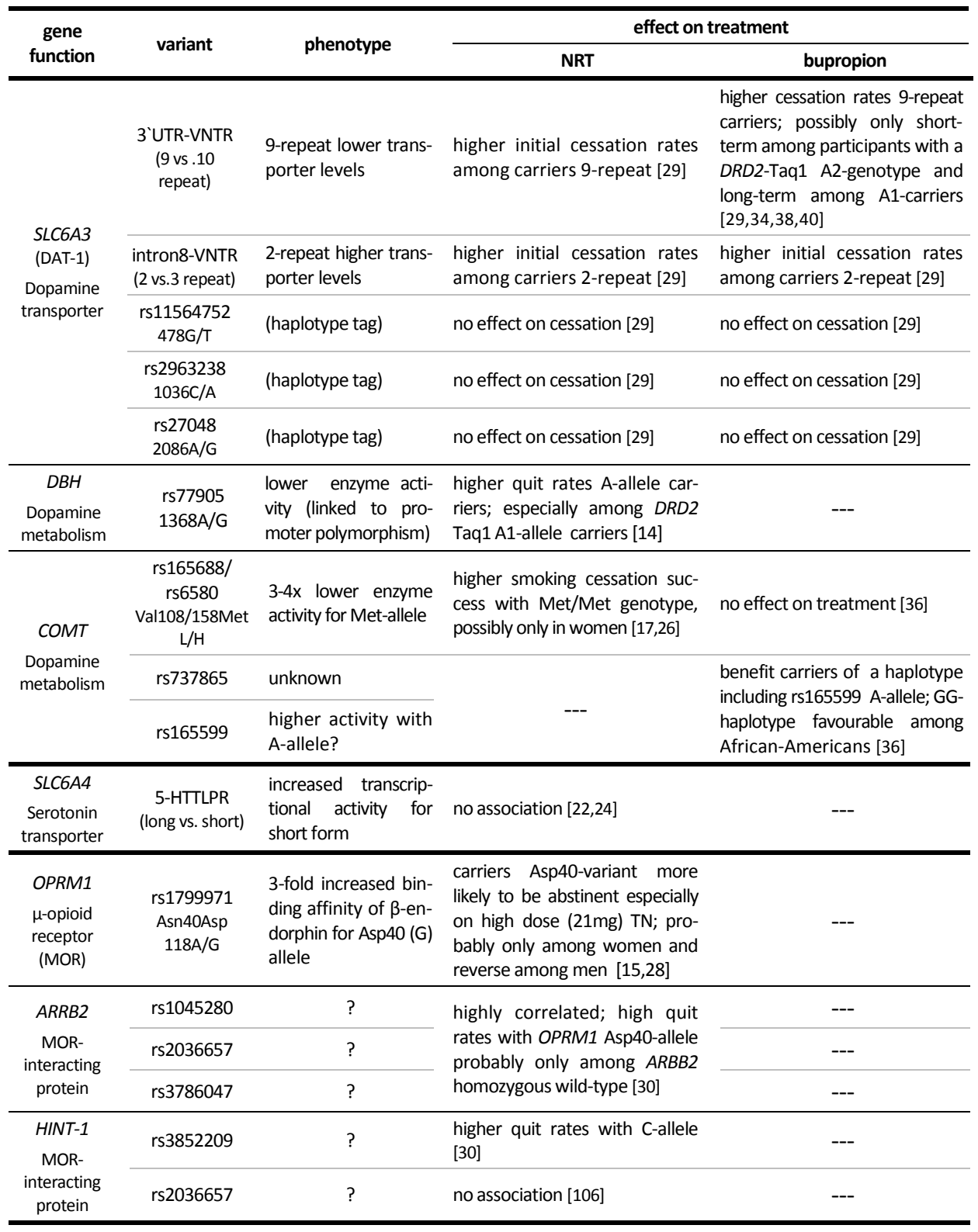




\section{FUTURE DIRECTIONS}

Despite all the progress made in the research on the pharmacogenetics of smoking cessation therapies, many challenges remain that have to be overcome before smoking cessation strategies based on genotype can be effectively integrated into standard clinical practice.

Firstly, so far most studies investigated only single genes. However, a large number of genes and several polymorphisms in these genes are likely to contribute to the individual susceptibility towards smoking cessation therapies. Therefore this approach will probably fail to fully determine the role of genetic variation in smoking cessation success. Future studies should focus on multiple functional variants and multiple genes operating within a single pathway. This will require far larger studies, of hundreds to thousands of participants, to achieve significant statistical power to evaluate these gene-gene interactions. While meta-analysis has offered an (imperfect) solution to this problem of lack of statistical power in other studies, this will probably not offer a viable solution for pharmacogenetic studies of smoking cessation therapies. A large heterogeneity exists between studies, because smoking cessation therapy is typically given in combination with behavioural support or other therapies. Therefore future studies should strive for comparability with existing studies.

Secondly, until now the pharmacogenetics of only a couple of smoking cessation therapies has been investigated. Newer compounds (e.g. varenicline), as well as current second-line medications for smoking cessation (e.g. nortriptyline), will also require investigation. Varenicline has been shown to bind with high affinity and selectivity at $\alpha_{4} \beta_{2}$ receptors, hereby stimulating dopamine release, while simultaneously preventing nicotine from binding (see Figure 1). Therefore, varenicline is expected to be more effective in smokers with genotypes associated with reduced dopamine availability, like NRT. Since nortriptyline has antidepressant properties, like bupropion, nortriptyline is expected to be more effective in smokers with genotypes associated with increased dopamine availability as well. However, differences in the metabolism or elimination of these drugs and pathways involved in the mechanism of action could make one drug more effective than the other or result in less side-effects in certain subgroups of smokers. In Figure 2 it is hypothesised how smoking cessation therapy might be genetically tailored based on present knowledge.

Thirdly, genetic associations with tolerability and side-effects should also be examined. Some individuals might have unusual reactions to drugs or combinations of drugs due to the presence of multiple genetic defects. Some pharmacogenetic studies have already shown that certain genotypes can result in poor drug adherence due to increased sideeffects, even if the medication is typically well-tolerated (e.g. variation in the DRD2 gene and bupropion adherence among females). On the other hand, certain subgroups of individuals may also exist who respond well to certain medications that are typically not well-tolerated.

Fourthly, several aspects of smoking behaviour (e.g. age of initiation, smoking rate, level of dependence) and the frequency of functional polymorphisms differ per race/ethnicity. However, most studies have been conducted in Caucasians to avoid population stratification. Therefore, larger scale pharmacogenetic trials confirming findings in different racial/ethnic groups are required to allow for genotype based selection of pharmacotherapy for nicotine dependence in practice. 


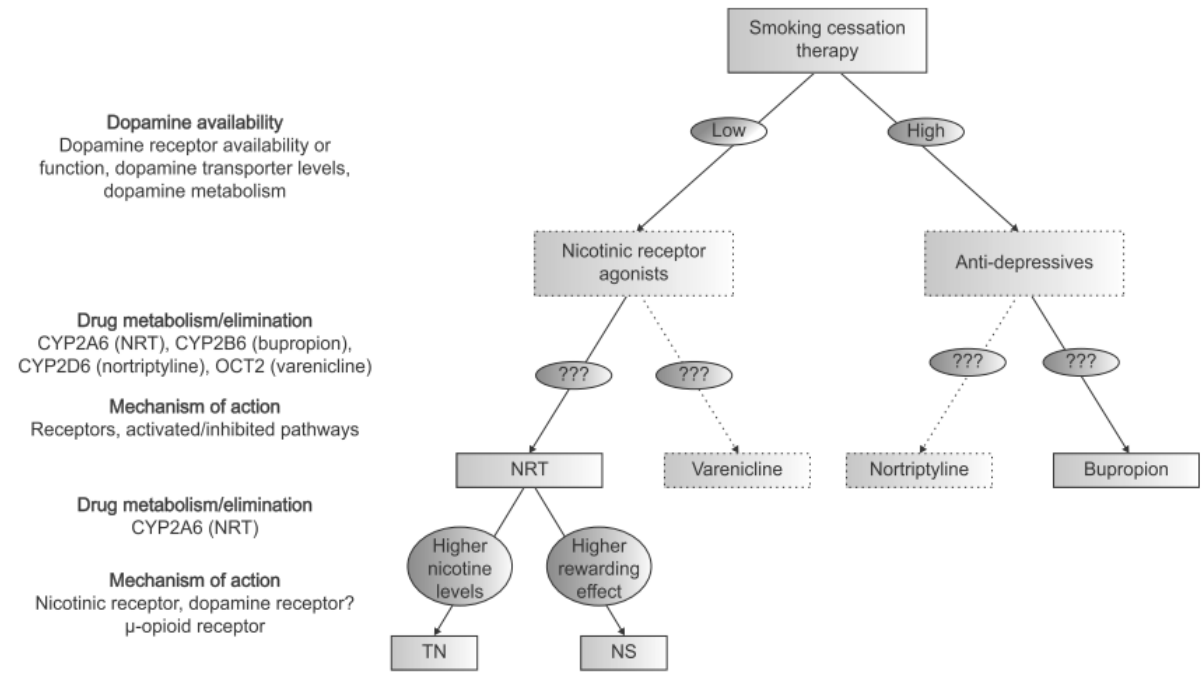

Figure 2: Hypothetical model for genetically tailored smoking cessation therapy.

NRT: nicotine replacement therapy; CYP2A6: cytochrome P450 2A6; CYP2B6: cytochrome P450 2B6; CYP2D6: cytochrome P450 2D6; OCT2: organic cation transporter; TN: transdermal nicotine patch; NS: nicotine nasal spray.

Fifthly, some research suggests that both NRT and bupropion work through different processes and/or are subject to different genetic influences in men and women. Therefore it is important that the effect of genetic variations will also be assessed for men and women separately.

Further, the findings should be validated across independent trials. Future studies should strive for comparability with existing studies in order to adequately assess to which extent previous findings are replicated. Moreover, most studies have been retrospective, however prospective studies should be set up to fully confirm the effect of the variants on smoking behaviour and cessation.

Finally, several practical, policy and ethical considerations have to be addressed to determine if, when, how and under what circumstances such genetically tailored treatment should be incorporated into clinical practice. The amount of improvement in outcomes based on genetic information, the cost-effectiveness, and how the costs of testing will be covered still remains to be determined. Little is known about the preparedness of primary care physicians and other healthcare providers to deliver genetically tailored treatment and regarding the attitudes of the smokers toward the use of genetic tests to tailor smoking cessation treatment as well. Furthermore, the potential psychosocial effects of genetic test disclosure will have to be investigated, because unintended adverse effects could occur (e.g. increased curiosity to try smoking or reduced likelihood of attempting to quit). Moreover, the risk for social stigma, because genotypes used to tailor treatment may also provide information on risk of other (more stigmatised) disorders, and discrimination (e.g. by health or life insurers), will need to be considered. Therefore, additional research should be conducted to examine the benefits, risks, and challenges of conveying genetic information about smoking predisposition to the patient, clinicians, and the public. Furthermore, economic analyses of the cost-effectiveness of using genotype information 
to tailor smoking treatment should be performed. And appropriate legal and regulatory frameworks should be set up to ensure privacy and to protect against genetic discrimination.

Thus, in future studies the effect of multiple susceptibility genes as well as their mutual interactions on several smoking cessation therapies should be studied in large-scale, comparable trials in different ethnic/racial and gender groups. Furthermore, prospective trials should be set up to fully confirm the effect of the variants. Finally, several practical, policy and ethical considerations will have to be addressed.

\section{CONCLUSIONS}

Smoking behaviour has been shown to be influenced by genetic variations. Therefore, the use of genetic information is expected to lead to higher quit rates by determining which treatment would be most effective based on the smoker's genetic background.

Recent pharmacogenetic research has shown that smokers with genotypes associated with reduced dopamine levels (reduced dopamine receptor availability or function, high dopamine transporter levels and higher dopamine metabolism) and decreased nicotine metabolism (determined primarily by CYP2A6 genotype) achieve better quit rates with nicotine replacement therapy (NRT). Moreover, smokers who carry genetic polymorphisms associated with reduced nicotinic receptor (and possibly also dopaminergic) activity may experience greater benefit from the greater rewarding effects of nicotine spray (NS). Smokers with increased activity variants in the $\mu$-opioid receptor (MOR) may have better success with the higher levels of nicotine delivered by transdermal nicotine patches (TN). Variants in the serotonin transporter do not seem to influence the response to NRT, but may be associated with the response to other pharmacologic treatments for smoking cessation. In particular treatments with an antidepressant action, including bupropion and nortriptyline, as well as selective serotonin re-uptake inhibitors may be influenced by variants in the serotonin pathway. On the other hand, genotypes associated with increased dopamine availability (increased or normal dopamine receptor availability or function, low dopamine transporter levels and low dopamine metabolism), and a decreased bupropion metabolism predict a better response to bupropion.

In conclusion, it seems that variants in several pathways related to smoking behaviour influence smoking cessation success. The effects of these variants often differ depending on the type of smoking cessation therapy used. Therefore a profile of several variants in these smoking-behaviour-related pathways could possibly be used to predict in advance which smoking cessation therapy is likely to be most effective for an individual smoker. Other (overlapping) sets might also be valuable to predict the most appropriate dosage of a particular drug and duration of treatment for individual patients. This would lead to a more effective use of smoking cessation therapies, resulting in less side-effects and increased cessation rates and ultimately in reduced morbidity and mortality from smoking-related disease.

However, before genetically tailored smoking cessation therapy can be implemented in clinical practice, future studies should investigate the effect of multiple susceptibility genes, as well as their mutual interactions on several smoking cessation therapies, in largescale, comparable trials in different ethnic/racial groups and different sexes. Additionally, prospective trials should be set up to fully confirm the effect of the variants. 


\section{REFERENCES}

1. Kaprio J, Hammar N, Koskenvuo M, Floderus-Myrhed B, Langinvainio H, Sarna S. Cigarette smoking and alcohol use in Finland and Sweden: a cross-national twin study. Int J Epidemiol. 1982; 11(4): 378-386.

2. Heath AC, Cates R, Martin NG, Meyer J, Hewitt JK, Neale MC, Eaves U. Genetic contribution to risk of smoking initiation: comparisons across birth cohorts and across cultures. J Subst Abuse. 1993; 5(3): 221-246.

3. Heath AC, Martin NG. Genetic models for the natural history of smoking: evidence for a genetic influence on smoking persistence. Addict Behav. 1993; 18(1): 19-34.

4. True WR, Heath AC, Scherrer JF, Waterman B, Goldberg J, Lin N, Eisen SA, Lyons MJ, Tsuang MT. Genetic and environmental contributions to smoking. Addiction. 1997; 92(10): 1277-1287.

5. Kendler KS, Neale MC, Sullivan P, Corey LA, Gardner CO, Prescott CA. A population-based twin study in women of smoking initiation and nicotine dependence. Psychol Med. 1999; 29(2): 299-308.

6. Sullivan PM, Kendler K. The genetic epidemiology of smoking. Nicotine and Tobacco Research. 1999; 1(Suppl 2): S51-S57.

7. Batra V, Patkar AA, Berrettini WH, Weinstein SP, Leone FT. The Genetic Determinants of Smoking. Chest. 2003; 123: 1730-1739.

8. Xian H, Scherrer JF, Madden PA, Lyons MJ, Tsuang M, True WR, Eisen SA. The heritability of failed smoking cessation and nicotine withdrawal in twins who smoked and attempted to quit. Nicotine Tob Res. 2003; 5(2): 245-254.

9. Pergadia ML, Heath AC, Martin NG, Madden PA. Genetic analyses of DSM-IV nicotine withdrawal in adult twins. Psychol Med. 2006; 36(7): 963-972.

10. Rossing MA. Genetic influences on smoking: candidate genes. Environ Health Perspect. 1998; 106: 231-238.

11. Arinami T, Ishiguro $\mathrm{H}$, Onaivi ES. Polymorphisms in genes involved in neurotransmission in relation to smoking. European Journal of Pharmacology. 2000; 410: 215-226.

12. Al Koudsi N, Tyndale RF. Genetic influences on smoking: a brief review. Ther Drug Monit. 2005; 27(6): 704-709.

13. MacLeod SL, Chowdhury P. The genetics of nicotine dependence: relationship to pancreatic cancer. World J Gastroenterol. 2006; 12(46): 7433-7439.

14. Johnstone EC, Yudkin PL, Hey K, Roberts SJ, Welch SJ, Murphy MF, Griffiths SE, Walton RT. Genetic variation in dopaminergic pathways and short-term effectiveness of the nicotine patch. Pharmacogenetics. 2004; 14(2): 83-90.

15. Lerman C, Wileyto EP, Patterson F, Rukstalis M, Audrain-McGovern J, Restine S, Shields PG, Kaufmann V, Redden D, Benowitz N, Berrettini WH. The functional mu opioid receptor (OPRM1) Asn40Asp variant predicts short-term response to nicotine replacement therapy in a clinical trial. Pharmacogenomics J. 2004; 4(3): 184-192.

16. Yudkin P, Munafo M, Hey K, Roberts S, Welch S, Johnstone E, Murphy M, Griffiths S, Walton R. Effectiveness of nicotine patches in relation to genotype in women versus men: randomised controlled trial. BMJ. 2004; 328(7446): 989-990.

17. Colilla S, Lerman C, Shields PG, Jepson C, Rukstalis M, Berlin J, DeMichele A, Bunin G, Strom BL, Rebbeck TR. Association of catechol-O-methyltransferase with smoking cessation in two independent studies of women. Pharmacogenet Genomics. 2005; 15(6): 393-398.

18. Dahl JP, Jepson C, Levenson R, Wileyto EP, Patterson F, Berrettini WH, Lerman C. Interaction between variation in the D2 dopamine receptor (DRD2) and the neuronal calcium sensor-1 (FREQ) genes in predicting response to nicotine replacement therapy for tobacco dependence. Pharmacogenomics J. 2006; 6(3): 194-199.

19. Lerman C, Jepson C, Wileyto EP, Epstein LH, Rukstalis M, Patterson F, Kaufmann V, Restine S, Hawk L, Niaura R, Berrettini W. Role of functional genetic variation in the dopamine D2 receptor (DRD2) in response to bupropion and nicotine replacement therapy for tobacco dependence: results of two randomized clinical trials. Neuropsychopharmacology. 2006; 31(1): 231-242. 
20. Lerman C, Tyndale R, Patterson F, Wileyto EP, Shields PG, Pinto A, Benowitz N. Nicotine metabolite ratio predicts efficacy of transdermal nicotine for smoking cessation. Clin Pharmacol Ther. 2006; 79(6): 600-608.

21. Malaiyandi V, Lerman C, Benowitz NL, Jepson C, Patterson F, Tyndale RF. Impact of CYP2A6 genotype on pretreatment smoking behaviour and nicotine levels from and usage of nicotine replacement therapy. $\mathrm{Mol}$ Psychiatry. 2006; 11(4): 400-409.

22. Munafo MR, Johnstone EC, Wileyto EP, Shields PG, Elliot KM, Lerman C. Lack of association of 5-HTTLPR genotype with smoking cessation in a nicotine replacement therapy randomized trial. Cancer Epidemiol Biomarkers Prev. 2006; 15(2): 398-400.

23. David SP, Munafò MR, Murphy MF, Proctor M, Walton RT, Johnstone EC. Genetic variation in the dopamine D4 receptor (DRD4) gene and smoking cessation: follow-up of a randomised clinical trial of transdermal nicotine patch. Pharmacogenomics J. 2007; Epub ahead of print.

24. David SP, Munafò MR, Murphy MFG, Walton RT, Johnstone EC. The serotonin transporter 5-HTTLPR polymorphism and treatment response to nicotine patch: follow-up of a randomized controlled trial. Nicotine Tob Res. 2007; 9(2): 225-231.

25. Hutchison KE, Allen DL, Filbey FM, Jepson C, Lerman C, Benowitz NL, Stitzel J, Bryan A, McGeary J, Haughey HM. CHRNA4 and tobacco dependence: from gene regulation to treatment outcome. Arch Gen Psychiatry. 2007; 64(9): 1078-1086.

26. Johnstone EC, Elliot KM, David SP, Murphy MF, Walton RT, Munafo MR. Association of COMT Val108/158Met genotype with smoking cessation in a nicotine replacement therapy randomized trial. Cancer Epidemiol Biomarkers Prev. 2007; 16(6): 1065-1069.

27. Lee AM, Jepson C, Shields PG, Benowitz N, Lerman C, Tyndale RF. CYP2B6 genotype does not alter nicotine metabolism, plasma levels, or abstinence with nicotine replacement therapy. Cancer Epidemiol Biomarkers Prev. 2007; 16(6): 1312-1314.

28. Munafo MR, Elliot KM, Murphy MF, Walton RT, Johnstone EC. Association of the mu-opioid receptor gene with smoking cessation. Pharmacogenomics J. 2007; 7(5): 353-361.

29. O'Gara C, Stapleton J, Sutherland G, Guindalini C, Neale B, Breen G, Ball D. Dopamine transporter polymorphisms are associated with short-term response to smoking cessation treatment. Pharmacogenet Genomics. 2007; 17(1): 61-67.

30. Ray R, Jepson C, Wileyto EP, Dahl JP, Patterson F, Rukstalis M, Pinto A, Berrettini W, Lerman C. Genetic variation in mu-opioid-receptor-interacting proteins and smoking cessation in a nicotine replacement therapy trial. Nicotine Tob Res. 2007; 9(11): 1237-1241.

31. Munafo MR, Johnstone EC, Guo B, Murphy MF, Aveyard P. Association of COMT Val108/158Met genotype with smoking cessation. Pharmacogenet Genomics. 2008; 18(2): 121-128.

32. Lerman C, Shields PG, Wileyto EP, Audrain J, Pinto A, Hawk L, Krishnan S, Niaura R, Epstein L. Pharmacogenetic investigation of smoking cessation treatment. Pharmacogenetics. 2002; 12(8): 627-634.

33. David SP, Niaura R, Papandonatos GD, Shadel WG, Burkholder GJ, Britt DM, Day A, Stumpff J, Hutchison K, Murphy M, Johnstone E, Griffiths SE, Walton RT. Does the DRD2-Taq1 A polymorphism influence treatment response to bupropion hydrochloride for reduction of the nicotine withdrawal syndrome? Nicotine Tob Res. 2003; 5(6): 935-942.

34. Lerman C, Shields PG, Wileyto EP, Audrain J, Hawk LH, Jr., Pinto A, Kucharski S, Krishnan S, Niaura R, Epstein LH. Effects of dopamine transporter and receptor polymorphisms on smoking cessation in a bupropion clinical trial. Health Psychol. 2003; 22(5): 541-548.

35. Swan GE, Valdes AM, Ring HZ, Khroyan TV, Jack LM, Ton CC, Curry SJ, McAfee T. Dopamine receptor DRD2 genotype and smoking cessation outcome following treatment with bupropion SR. Pharmacogenomics J. 2005; 5(1): 21-29.

36. Berrettini WH, Wileyto EP, Epstein L, Restine S, Hawk L, Shields P, Niaura R, Lerman C. Catechol-O- methyl 
transferase (COMT) gene variants predict response to bupropion therapy for tobacco dependence. Biol Psychiatry. 2007; 61(1): 111-118.

37. David SP, Strong DR, Munafo MR, Brown RA, Lloyd-Richardson EE, Wileyto PE, Evins EA, Shields PG, Lerman C, Niaura R. Bupropion efficacy for smoking cessation is influenced by the DRD2 Taq1A polymorphism: analysis of pooled data from two clinical trials. Nicotine Tob Res. 2007; 9(12): 1251-1257.

38. David SP, Brown RA, Papandonatos GD, Kahler CW, Lloyd-Richardson EE, Munafo MR, Shields PG, Lerman C, Strong D, McCaffery J, Niaura R. Pharmacogenetic clinical trial of sustained-release bupropion for smoking cessation. Nicotine Tob Res. 2007; 9(8): 821-833.

39. Lee AM, Jepson C, Hoffmann E, Epstein L, Hawk LW, Lerman C, Tyndale RF. CYP2B6 genotype alters abstinence rates in a bupropion smoking cessation trial. Biol Psychiatry. 2007; 62(6): 635-641.

40. Swan GE, Jack LM, Valdes AM, Ring HZ, Ton CC, Curry SJ, McAfee T. Joint effect of dopaminergic genes on likelihood of smoking following treatment with bupropion SR. Health Psychol. 2007; 26(3): 361-368.

41. Cinciripini P, Wetter D, Tomlinson G, Tsoh J, De Moor C, Cinciripini L, Minna J. The effects of the DRD2 polymorphism on smoking cessation and negative affect: evidence for a pharmacogenetic effect on mood. Nicotine Tob Res. 2004; 6(2): 229-239.

42. Robinson JD, Lam CY, Minnix JA, Wetter DW, Tomlinson GE, Minna JD, Chen TT, Cinciripini PM. The DRD2 TaqI-B polymorphism and its relationship to smoking abstinence and withdrawal symptoms. Pharmacogenomics J. 2007; 7(4): 266-274.

43. Munafo MR, Johnstone EC. Effects of dopamine D2 receptro gene polymorphisms on smoking cessation: abstinence and withdrawal symptoms. Pharmacogenomics J. 2007; 8(5): 513-517.

44. Ton TG, Rossing MA, Bowen DJ, Wilkerson HW, Farin FM. Cholecystokinin C-45T polymorphism and smoking cessation in women. Nicotine Tob Res. 2007; 9(1): 147-151.

45. Ton TG, Rossing MA, Bowen DJ, Srinouanprachan S, Wicklund K, Farin FM. Genetic polymorphisms in dopamine-related genes and smoking cessation in women: a prospective cohort study. Behav Brain Funct. 2007; 3: 22.

46. Ray R, Jepson C, Patterson F, Strasser A, Rukstalis M, Perkins K, Lynch KG, O'Malley S, Berrettini WH, Lerman C. Association of OPRM1 A118G variant with the relative reinforcing value of nicotine. Psychopharmacology (Berl). 2006; 188(3): 355-363.

47. Berlin I, Covey LS, Jiang H, Hamer D. Lack of effect of D2 dopamine receptor Taql A polymorphism on smoking cessation. Nicotine Tob Res. 2005; 7(5): 725-728.

48. Park HJ, Kim ST, Yoon DH, Jin SH, Lee SJ, Lee HJ, Lim S. The association between the DRD2 Taql A polymorphism and smoking cessation in response to acupuncture in Koreans. J Altern Complement Med. 2005; 11(3): 401-405.

49. Effectiveness of a nicotine patch in helping people stop smoking: results of a randomised trial in general practice. Imperial Cancer Research Fund General Practice Research Group. Bmj. 1993; 306(6888): 1304-1308.

50. Randomised trial of nicotine patches in general practice: results at one year. Imperial Cancer Research Fund General Practice Research Group. Bmj. 1994; 308(6942): 1476-1477.

51. Lerman C, Kaufmann V, Rukstalis M, Patterson F, Perkins K, Audrain-McGovern J, Benowitz N. Individualizing nicotine replacement therapy for the treatment of tobacco dependence: a randomized trial. Ann Intern Med. 2004; 140(6): 426-433.

52. Nakajima M, Yamamoto T, Nunoya K, Yokoi T, Nagashima K, Inoue K, Funae $Y$, Shimada N, Kamataki T, Kuroiwa Y. Role of human cytochrome P4502A6 in C-oxidation of nicotine. Drug Metab Dispos. 1996; 24(11): 1212-1217.

53. Messina ES, Tyndale RF, Sellers EM. A major role for CYP2A6 in nicotine C-oxidation by human liver microsomes. J Pharmacol Exp Ther. 1997; 282(3): 1608-1614.

54. Committee. CPCAN. Home Page of the Human Cytochrome P450 (CYP) Allele Nomenclature Committee. [Internet] 4-Sep-2008; Available from: http://www.cypalleles.ki.se/; accessed on 15 August 2008.

55. Buisson B, Bertrand D. Nicotine addiction: the possible role of functional upregulation. Trends Pharmacol 
Sci. 2002; 23(3): 130-136.

56. Neville MJ, Johnstone EC, Walton RT. Identification and characterization of ANKK1: a novel kinase gene closely linked to DRD2 on chromosome band 11q23.1. Hum Mutat. 2004; 23(6): 540-545.

57. Heils A, Teufel A, Petri S, Stober G, Riederer P, Bengel D, Lesch KP. Allelic variation of human serotonin transporter gene expression. J Neurochem. 1996; 66(6): 2621-2624.

58. Lesch KP, Bengel D, Heils A, Sabol SZ, Greenberg BD, Petri S, Benjamin J, Muller CR, Hamer DH, Murphy DL. Association of anxiety-related traits with a polymorphism in the serotonin transporter gene regulatory region. Science. 1996; 274(5292): 1527-1531.

59. Hu X, Oroszi G, Chun J, Smith TL, Goldman D, Schuckit MA. An expanded evaluation of the relationship of four alleles to the level of response to alcohol and the alcoholism risk. Alcohol Clin Exp Res. 2005; 29(1): 8-16.

60. Ascher JA, Cole JO, Colin JN, Feighner JP, Ferris RM, Fibiger HC, Golden RN, Martin P, Potter WZ, Richelson E, et al. Bupropion: a review of its mechanism of antidepressant activity. J Clin Psychiatry. 1995; 56(9): 395-401.

61. Sanchez C, Hyttel J. Comparison of the effects of antidepressants and their metabolites on reuptake of biogenic amines and on receptor binding. Cell Mol Neurobiol. 1999; 19(4): 467-489.

62. Lerman C, Roth D, Kaufmann V, Audrain J, Hawk L, Liu A, Niaura R, Epstein L. Mediating mechanisms for the impact of bupropion in smoking cessation treatment. Drug Alcohol Depend. 2002; 67(2): 219-223.

63. Jack LM, Swan GE, Thompson E, Curry SJ, McAfee T, Dacey S, Bergman K. Bupropion SR and smoking cessation in actual practice: methods for recruitment, screening, and exclusion for a field trial in a managed-care setting. Prev Med. 2003; 36(5): 585-593.

64. Swan GE, McAfee T, Curry SJ, Jack LM, Javitz H, Dacey S, Bergman K. Effectiveness of bupropion sustained release for smoking cessation in a health care setting: a randomized trial. Arch Intern Med. 2003; 163(19): 2337-2344.

65. Brown RA, Niaura R, Lloyd-Richardson EE, Strong DR, Kahler CW, Abrantes AM, Abrams D, Miller IW. Bupropion and cognitive-behavioral treatment for depression in smoking cessation. Nicotine Tob Res. 2007; 9(7): 721-730. 
Aims: We investigated whether variants in the serotonin transporter gene (SLC6A4) influence smoking cessation rates using antidepressant therapy (i.e. bupropion and nortriptyline).

Design: Pharmacogenetic (secondary) analysis of a randomized, placebo-controlled efficacy trial of bupropion and nortriptyline for smoking cessation.

Setting: Single-centre study, Maastricht University, the Netherlands.

Participants: 214 of 255 (84\%) current daily smokers participating in a randomized controlled efficacy trial.

Measurements: Subjects were genotyped for three functional variants in SLC6A4 (5-HTTLPR, STin2, rs25531). Primary outcome measures were prolonged abstinence from weeks 4-12, 4-26 and 4-52. Secondary outcome measures included 7-day point prevalence abstinence at weeks 4, 12, 26 and 52.

Findings: Carriers of the 5-HTTLPR high-activity L-variant had higher prolonged cessation rates with bupropion than placebo $(\mathrm{OR}=1.44,95 \% \mathrm{Cl}=1.01-2.05, \mathrm{p}=0.04)$. Combining the three variants resulted in increased prolonged cessation rates for both bupropion and nortriptyline among carriers of 4-5 high-activity variants (bupropion: $O R=2.00$, $95 \% \mathrm{Cl}=1.21-3.29, p=0.01$; nortriptyline: $\mathrm{OR}=1.91,95 \% \mathrm{Cl}=1.02-3.56, p=0.04)$. Similar results were found for point prevalence abstinence.

Conclusions: Bupropion and nortriptyline seem to be more effective in smoking cessation among SLC6A4 high-activity variant carriers, probably by blocking the increased serotonin transporter activity, thereby increasing serotonin levels. Prospective studies have to assess if this can improve cessation rates when treatment is targeted at individuals based on their genotypes. 


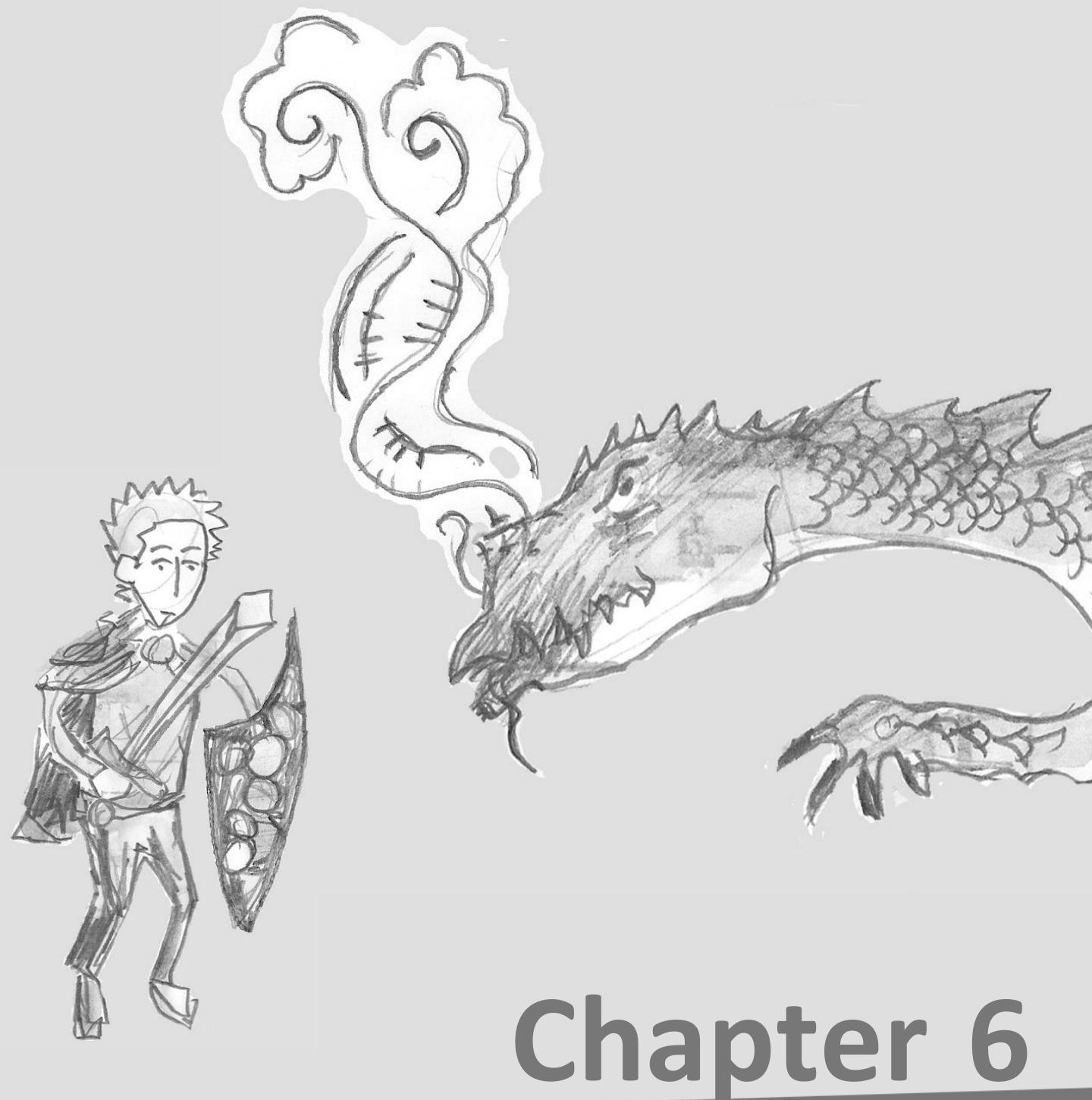

GENETIC VARIANTS IN THE SEROTONIN TRANSPORTER

INFLUENCE THE EFFICACY OF BUPROPION AND

NORTRIPTYLINE IN SMOKING CESSATION

Marieke Quaak, Constant P. van Schayck, Dirkje S. Postma, Edwin J. Wagena, Frederik J. van Schooten.

Addiction. 2012; 107(1): 178-187. Epub 2011 Sep 21. 


\section{INTRODUCTION}

Tobacco smoking continues to be the major preventable cause of premature morbidity and mortality throughout the world. Although the majority of smokers are highly motivated to quit, both smokers and healthcare practitioners are confronted with high relapse rates. Only $15-30 \%$ of individuals respond with long-term smoking cessation to the various treatments currently available [1]. Therefore, multiple quit attempts are often required, which leads to frustration and demotivation of smokers and health care providers as well as to unnecessary high costs (e.g. direct and indirect medical costs).

Only a few types of medication with proven efficacy for smoking cessation are available, including antidepressant therapy. Currently, there are two antidepressant drugs used for smoking cessation: bupropion and nortriptyline. Both are predominantly norepinephrine uptake inhibitors, but their mechanisms of action also involve serotonergic effects [2-5]. It is thus plausible that variations in serotonergic genes, mainly in the serotonin transporter (5-HTT) gene (SLC6A4), will affect the ability to stop smoking when using bupropion or nortriptyline as a smoking cessation aid. The SLC6A4 gene, located at chromosome 17, encodes a transmembrane transporter responsible for reuptake of serotonin at the synapse, thereby regulating the magnitude and duration of serotonergic signaling. This gene possesses several polymorphic loci that affect its expression or function and are common in the population [6-11].

We therefore investigated the influence of three functional genetic variants in SLC6A4 (Table 1) on smoking cessation rates in a randomized placebo-controlled trial

Table 1: Serotonin transporter (SLC6A4) variants

\begin{tabular}{cccccc}
\hline variant & position & $\begin{array}{c}\text { type of } \\
\text { polymorphism }\end{array}$ & (common) alleles & phenotype & references \\
\hline 5-HTTLPR & $\begin{array}{c}\text { promoter } \\
\text { region }\end{array}$ & $\begin{array}{c}\text { VNTR } \\
\text { 43bp insertion/ } \\
\text { deletion }\end{array}$ & $\begin{array}{c}\text { S-allele (short) } \\
\text { L-allele (long) }\end{array}$ & $\begin{array}{l}\text { L-allele has higher transcription } \\
\text { levels compared to the S-allele }\end{array}$ & [6, 7] \\
\hline $\begin{array}{c}\text { STin2 } \\
\text { (intron 2 } \\
\text { VNTR) }\end{array}$ & intron 2 & $\begin{array}{c}\text { VNTR1 } \\
\text { 16-17bp repetitive } \\
\text { element }\end{array}$ & $\begin{array}{c}\text { STin2.9 } \\
\text { STin2.10 } \\
\text { STin2.12 }\end{array}$ & $\begin{array}{l}\text { STin2.12 is a stronger transcrip- } \\
\text { tional regulator, resulting in higher } \\
\text { transcription levels }\end{array}$ & [8, 9]
\end{tabular}


of bupropion (sustained release; SR) and nortriptyline for smoking cessation. In the original efficacy trial only the difference in abstinence between bupropion (SR) and placebo at 6-month follow-up was significantly different (difference $=13.1 \%$, $95 \% \mathrm{Cl}=1.2 \%-25.1 \%, \mathrm{p}=0.03)$. No significant effects of bupropion treatment at 12 -week (end-of-treatment; EOT) and 12-month follow-up were found, nor for nortriptyline treatment at all three time-points (EOT, 6- and 12-month follow-up) [12,13].

Information about the influence of genetic variants on treatment response (pharmacogenetics) may help to better understand underlying pharmacological mechanisms. Ultimately this may lead to individualized treatment, by pre-selection of individuals who are expected to have the best treatment response based on their genetic profile. This will then likely result in higher cessation rates, and consequently less frustration by both smokers and healthcare practitioners.

\section{MATERIALS AND METHODS}

\section{Subjects and procedures}

In the original randomized controlled trial on the efficacy of bupropion (SR) and nortriptyline in smoking cessation among people with and without COPD, 255 current daily smokers were included between March 2002 and August 2004 [12,13]. In short, participants were aged 30-70 years, had a smoking history of $>5$ years, smoked on average $>10$ cigarettes/day during the last year, and were motivated to stop smoking. Eligible individuals were randomly assigned to receive bupropion SR (150-mg once/day for days 1-6, followed by 150-mg twice/day for days 7-84), nortriptyline (25-mg once/day for days 1-3, followed by 50-mg once/day for days 3-7, and 75-mg once/day for days 8-84), or matched placebo.

During one of the follow-up visits, a $10-\mathrm{ml}$ blood sample was collected ( $N=187,73 \%)$ or participants were invited to provide a buccal sample by postal mail $(\mathrm{N}=27,11 \%)$, resulting in a total of 214 samples for genotyping (84\%).

Ethical approval was obtained from the medical ethics committee of the University Hospital Maastricht/Maastricht University. Participants provided written informed consent for genotyping.

\section{Measures}

\section{Smoking outcomes}

In accordance with the recommendations of the Society for Research on Nicotine and Tobacco [14] we report prolonged abstinence rates as the primary outcome measure and 7-day point prevalence rates as the secondary outcome measure.

Prolonged abstinence was defined as a participant's report of zero cigarettes per day (not even a puff), confirmed by urinary cotinine values of $60 \mathrm{ng} / \mathrm{mL}$ or less [15] at weeks 4, 12, 26 and 52. Seven-day point prevalence abstinence was defined as having smoked no cigarettes, not even a puff, during the previous 7 days, confirmed by 
urinary cotinine values of $60 \mathrm{ng} / \mathrm{mL}$ or less). Missing data were considered indic ative of smoking.

Prolonged abstinence from smoking was measured from week 4-12 (EOT), week 4-26 (6-month follow-up), and week 4-52 (12-month follow-up) after the target quit date (TQD) and 7-day point prevalence at weeks 4, 12, 26 and 52.

\section{Participant characteristics}

Ethnicity was not assessed, however based on the make-up of the region where the participants were recruited (e.g. Dutch- and Belgian-Limburg), it is expected that virtually all participants are Caucasians.

Smoking characteristics comprised the number of cigarettes per day, the number of previous quit attempts (at least 24 hours abstinence from smoking), and the level of nicotine dependence (ND). ND was assessed with the Fagerström Test for Nicotine Dependence (FTND) [16]; scores of $>6$ indicate greater levels of ND. Clinical characteristics measured included severity of COPD, defined according to the definition provided by the Global Initiative for Chronic Obstructive Lung Disease (GOLD) [17].

\section{Genotyping}

Participants were genotyped for the three SLC6A4 variants (5-HTTLPR, STin2 (intron 2 VNTR) and rs25531) simultaneously by a duplex-PCR method amplifying the 5-HTTLPR/ rs25531 and intron 2 loci followed by a single Hpall digestion (based on the method by Wendland et al, 2006 [18]). Genotypes were determined by agarose gel-electrophoreses.

\section{Statistical analysis}

Statistical analyses were performed using PASW statistics (v17.02) for windows (Chicago, Illinois, USA). Chi-square analysis was used to test whether the distribution of genotypes was in accordance with Hardy-Weinberg equilibrium. Longitudinal logistic regression models of prolonged abstinence at EOT and 6- and 12-month follow-up and of 7-day point prevalence abstinence at week 4, 12, 26 and 52 were performed, using the mixed models procedure. All statistical tests were two-sided.

\section{RESULTS}

\section{Validity of the population used for the genotyping study}

Prolonged abstinence rates at all three time points (EOT, 6- and 12-month follow-up) and 7-day point prevalence abstinence rates at all 4 time points (4, 12, 26 and 52 weeks) among participants in the genotyping study $(\mathrm{N}=214)$ did not differ significantly from participants in the original study $(\mathrm{N}=255)$. There were also no differences on type of treatment, gender, age, average number of cigarettes smoked per day prior to treatment, number of previous quit attempts, level of nicotine dependence, and COPD stage. 
Table 2: Baseline characteristics of the participants

\begin{tabular}{|c|c|c|c|}
\hline & $\begin{array}{c}\text { placebo } \\
(n=75)\end{array}$ & $\begin{array}{c}\text { bupropion SR } \\
(\mathrm{n}=70)\end{array}$ & $\begin{array}{c}\text { nortriptyline } \\
(n=69)\end{array}$ \\
\hline \multicolumn{4}{|l|}{ Demographic characteristics } \\
\hline Age, mean (SD), years & $51.3 \quad(8.9)$ & $51.5 \quad(7.7)$ & $51.8 \quad(9.3)$ \\
\hline Women, No. (\%) & $37(49.3)$ & $43(61.4)$ & $29(42.0)$ \\
\hline \multicolumn{4}{|l|}{ Smoking characteristics } \\
\hline No. of cigarettes smoked per day, mean (SD) & $23.2(8.9)$ & $24.0 \quad(9.5)$ & $22.6 \quad(7.8)$ \\
\hline No. of previous attempts to quit, mean (SD) 1 & $2.6(1.6)$ & $2.5 \quad(1.9)$ & $2.7 \quad(2.0)$ \\
\hline FTND score, mean (SD)2 & $5.7 \quad(2.1)$ & $6.1(2.1)^{3}$ & $6.0 \quad(2.2)$ \\
\hline FTND score $>6$, No. $(\%) 2$ & $46(61.3)$ & $44(63.8)^{3}$ & $42(60.9)$ \\
\hline \multicolumn{4}{|l|}{ Clinical characteristics } \\
\hline \multicolumn{4}{|l|}{ COPD classification, No. (\%) } \\
\hline No COPD (previously Stage 0: at risk for COPD) & $35(46.7)$ & $37(52.9)$ & $26(37.7)$ \\
\hline Stage 1: mild COPD & $14(18.7)$ & $11(15.7)$ & $20(29.0)$ \\
\hline Stage 2 \& 3: moderate \& severe COPD & $26(34.7)$ & $22(31.4)$ & $23(33.3)$ \\
\hline
\end{tabular}

\section{Participant characteristics}

Table 2 presents the baseline characteristics of the study participants. The average age of the participants was 51.5 years $(S D=8.5)$, and $50.9 \%$ were women. Participants smoked on average 23.3 cigarettes/day $(S D=8.8)$, and in the past had tried 2.6 times to quit smoking ( $S D=1.8)$. Participants had an average FTND-score of $5.9(S D=2.1)$, and $61.7 \%$ had a high level of ND (FTND-score>6). When using the GOLD guideline [17] to classify participants, 98 (45.8\%) had no COPD (a normal spirometry, but chronic cough and sputum production; previously classified as Stage 0: at risk for COPD), 45 (21.0\%) had mild COPD (Stage 1) and 71 (33.2\%) had moderate or severe COPD (Stage 2 or 3 ).

There were some imbalances after randomization. The bupropion group consisted of relatively more women (61.4\%) compared with the nortriptyline $(42.0 \%)$ and placebo (49.3\%) groups. And the nortriptyline group consisted of relatively fewer participants without COPD (37.7\%) compared with the bupropion $(52.9 \%)$ and placebo $(46.7 \%)$ group, but relatively more participants with mild COPD $(29.0 \%$ versus $15.7 \%$ and $18.7 \%$ respectively).

\section{Genotyping}

All samples were genotyped successfully. Genotype frequencies can be found in Table 3. We combined individuals carrying high-activity alleles (e.g. at least one high-activity allele) as one group. Genotypes for al three variants were in Hardy-Weinberg equilibrium ( $P=0.34, P=0.44$ and $P=0.99$ for $5-H T T L P R, ~ S T i n 2$ and rs25531, respectively). There were no significant differences between treatment groups in genotype frequencies for all variants. Furthermore, genotype frequencies were comparable to frequencies previously reported in other healthy (control) or smoking populations (Table 3). 
Table 3: Genotype frequencies

\begin{tabular}{|c|c|c|c|c|c|}
\hline & $\begin{array}{c}\text { total } \\
(n=214)\end{array}$ & $\begin{array}{c}\text { placebo } \\
(n=75)\end{array}$ & $\begin{array}{c}\text { bupropion } \\
(n=70)\end{array}$ & $\begin{array}{c}\text { nortriptyline } \\
(n=69)\end{array}$ & $\begin{array}{c}\text { prevalence in } \\
\text { other populations }{ }^{1}\end{array}$ \\
\hline \multicolumn{6}{|l|}{ 5-HTTLPR } \\
\hline$S / S$ & $50(23.4 \%)$ & $11(14.7 \%)$ & $15(21.4 \%)$ & $8(11.6 \%)$ & $11-32 \%$ \\
\hline $\mathrm{L} / \mathrm{S}$ & $114(53.2 \%)$ & $37(49.3 \%)$ & $40(57.2 \%)$ & $37(53.6 \%)$ & $40-60 \%$ \\
\hline $\mathrm{L} / \mathrm{L}$ & $50(23.4 \%)$ & $27(36.0 \%)$ & $15(21.4 \%)$ & $24(34.8 \%)$ & $20-45 \%$ \\
\hline $\mathrm{S}(\mathrm{S} / \mathrm{S})$ & $50(23.4 \%)$ & $11(14.7 \%)$ & $15(21.4 \%)$ & $8(11.6 \%)$ & \\
\hline $\mathrm{L}(\mathrm{L} / \mathrm{S}+\mathrm{L} / \mathrm{L})$ & $164(76.6 \%)$ & $64(85.3 \%)$ & $55(78.6 \%)$ & $61(88.4 \%)$ & \\
\hline \multicolumn{6}{|l|}{ STin2 (intron 2 VNTR) } \\
\hline $9 / 10$ & $3(1.4 \%)$ & 1 (1.3\%) & 1 (1.4\%) & $1(1.5 \%)$ & $0-4 \%$ \\
\hline $10 / 10$ & $24(11.2 \%)$ & $11(14.7 \%)$ & $6(8.6 \%)$ & $7(10.1 \%)$ & $6-19 \%$ \\
\hline $9 / 12$ & $4(1.9 \%)$ & $1(1.3 \%)$ & $2(2.8 \%)$ & $1(1.5 \%)$ & $1-4 \%$ \\
\hline $10 / 12$ & $108(50.5 \%)$ & $32(42.7 \%)$ & $37(52.9 \%)$ & 39 (56.5\%) & $34-58 \%$ \\
\hline $12 / 12$ & $75(35.0 \%)$ & $30(40.0 \%)$ & $24(34.3 \%)$ & $21(30.4 \%)$ & $32-56 \%$ \\
\hline $9 / 10(9 / 10+10 / 10)$ & $27(12.6 \%)$ & $12(16.0 \%)$ & $7(10.0 \%)$ & $8(11.6 \%)$ & \\
\hline$* / 12(9 / 12+10 / 12+12 / 12)$ & $187(87.4 \%)$ & $63(84.0 \%)$ & $63(90.0 \%)$ & $61(88.4 \%)$ & \\
\hline \multicolumn{6}{|l|}{ rs25531 } \\
\hline $\mathrm{A} / \mathrm{A}$ & $186(86.9 \%)$ & $66(88.0 \%)$ & $61(87.1 \%)$ & $59(85.5 \%)$ & $81-92 \%$ \\
\hline$A / G$ & $27(12.6 \%)$ & $9(12.0 \%)$ & $9(12.9 \%)$ & $9(13.0 \%)$ & $8-19 \%$ \\
\hline $\mathrm{G} / \mathrm{G}$ & $1(0.5 \%)$ & $0 \quad(0.0 \%)$ & $0 \quad(0.0 \%)$ & $1(1.5 \%)$ & $0-2 \%$ \\
\hline$A(A / A)$ & $186(86.9 \%)$ & 66 (88.0\%) & $61(87.1 \%)$ & 59 (85.5\%) & \\
\hline$G(A / G+G / G)$ & $28(13.1 \%)$ & $9(12.0 \%)$ & $9(12.9 \%)$ & $10(14.5 \%)$ & \\
\hline
\end{tabular}

${ }^{1}$ References see addendum

\section{Effects of the serotonin transporter variants on smoking abstinence rates}

The longitudinal logistic regression model of prolonged abstinence at EOT, 6- and 12month follow-up showed a significant effect of time-point and ND level (Table 4), with lower odds of abstinence at 6 - and 12-month follow-up compared to EOT (OR=0.96, $95 \% \mathrm{Cl}=0.93-0.99, \mathrm{p}<0.01$, and $\mathrm{OR}=0.92,95 \% \mathrm{Cl}=0.89-0.95, \mathrm{P}=0.01$, respectively) and with a high ND level compared to a low ND level (OR=0.87, 95\% $\mathrm{Cl}=0.77-0.97, p=0.01)$. No effects of gender, COPD status, treatment, STin2 genotype, and rs25531 genotype were found. The main effect of 5-HTTLPR genotype was not significant either, however a significant interaction between 5-HTTLPR genotype and bupropion treatment was found $(\mathrm{OR}=1.44,95 \% \mathrm{Cl}=1.01-2.05, \mathrm{p}=0.04)$. This interaction was broken down by conducting separate multilevel models on the two genotype groups (e.g. S/S and L/S or $L / L)$. The model specified included only time-point, level of ND, and treatment. These analyses showed that all effects were non-significant for those with a $\mathrm{S} / \mathrm{S}$ genotype. However, for those with a L/S or L/L genotype, abstinence levels increased significantly when treated with bupropion $(\mathrm{OR}=1.23,95 \% \mathrm{Cl}=1.06-1.43, \mathrm{p}<0.01)$, and approached statistical significance with nortriptyline treatment $(\mathrm{OR}=1.13,95 \% \mathrm{Cl}=0.98-1.31$, $\mathrm{p}=0.09$ ). These data are presented graphically in Figure 1.

The longitudinal logistic regression model of 7-day point abstinence at week 4, 12, 26 and 52 gave similar results (see Table 4). However, contrary to the results for prolonged abstinence, the main effect of nortriptyline treatment and the interaction between nortriptyline treatment and 5-HTTLPR genotype approached statistical significance (both P-values are 0.06). 
Table 4: Longitudinal Logistic Regression Models of Smoking Abstinence

\begin{tabular}{|c|c|c|c|c|}
\hline \multirow[b]{2}{*}{ Predictor } & \multicolumn{2}{|c|}{ prolonged abstinence } & \multicolumn{2}{|c|}{ 7-day point abstinence } \\
\hline & OR $(95 \% \mathrm{Cl})$ & p-value & OR $(95 \% \mathrm{Cl})$ & p-value \\
\hline Timepoint $^{1}-1$ & $0.96(0.93-0.99)$ & 0.01 & $0.93(0.89-0.98)$ & 0.01 \\
\hline-2 & $0.92(0.89-0.95)$ & $<0.01$ & $0.91(0.86-0.95)$ & $<0.01$ \\
\hline-3 & & & $0.89(0.85-0.94)$ & $<0.01$ \\
\hline ND level (high vs. low) & $0.87(0.77-0.97)$ & 0.01 & $0.87(0.78-0.97)$ & 0.01 \\
\hline Gender (male vs. female) & $0.99(0.88-1.10)$ & 0.81 & $0.99(0.89-1.11)$ & 0.89 \\
\hline COPD (vs. no COPD) & $0.94(0.84-1.05)$ & 0.24 & $0.95(0.85-1.07)$ & 0.40 \\
\hline \multicolumn{5}{|l|}{ Treatment (vs. placebo) } \\
\hline Bupropion & $0.76(0.47-1.22)$ & 0.25 & $0.75(0.47-1.19)$ & 0.22 \\
\hline Nortriptyline & $0.70(0.40-1.23)$ & 0.22 & $0.59(0.34-1.03)$ & 0.06 \\
\hline \multicolumn{5}{|l|}{ Genotype } \\
\hline 5-HTTLPR (S/L or L/L vs. S/S) & $0.91(0.70-1.18)$ & 0.48 & $0.86(0.66-1.11)$ & 0.24 \\
\hline rs 25531 (A/G or $G / G$ vs. $A / A)$ & $0.99(0.75-1.31)$ & 0.95 & $1.10(0.83-1.44)$ & 0.51 \\
\hline STin $2(* / 12$ vs. $9 / 10$ or $10 / 10)$ & $1.02(0.81-1.28)$ & 0.87 & $0.99(0.80-1.24)$ & 0.96 \\
\hline \multicolumn{5}{|l|}{ Genotype * treatment } \\
\hline Bupropion * 5-HTTLPR & $1.44(1.01-2.05)$ & 0.04 & 1.55 (1.09-2.19) & 0.01 \\
\hline Bupropion * rs25531 & $1.19(0.79-1.79)$ & 0.39 & $1.16(0.78-1.72)$ & 0.47 \\
\hline Bupropion * STin2 & $1.11(0.77-1.62)$ & 0.57 & $1.03(0.71-1.48)$ & 0.87 \\
\hline Nortriptyline * 5-HTTLPR & $1.28(0.86-1.91)$ & 0.22 & $1.45(0.98-2.14)$ & 0.06 \\
\hline Nortriptyline * rs25531 & $1.11(0.75-1.64)$ & 0.62 & $0.96(0.65-1.40)$ & 0.82 \\
\hline Nortriptyline * STin2 & $1.25(0.81-1.95)$ & 0.31 & $1.37(0.89-2.10)$ & 0.15 \\
\hline
\end{tabular}

${ }^{1}$ Timepoints prolonged abstinence: 1: 4-26 weeks, 2: 4-52 weeks (vs. 4-12 weeks)

Timepoints 7-day point abstinence: 1: 12 weeks, 2: 26 weeks, 3: 52 weeks (vs. 4 weeks)

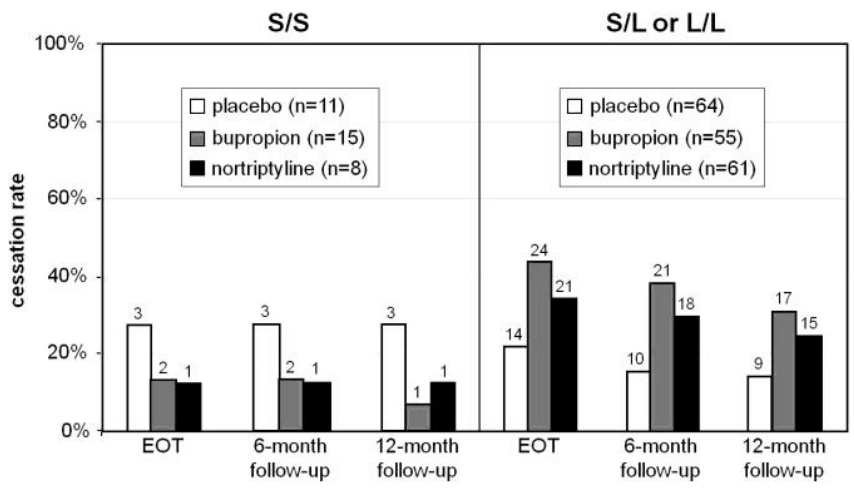

Figure 1: Prolonged abstinence by 5-HTTLPR genotype and treatment group.

The number of participants abstinent in the treatment groups is presented. Participants in the $S / L$ or $\mathrm{L} / \mathrm{L}$ group derive more benefit from antidepressant therapy compared with placebo.

\section{Combined effect of the three variants on smoking abstinence rates}

The three genetic variants tested influence serotonin transporter levels via different mechanisms; hence we investigated whether there is a cumulative effect of the number of high-activity variants present in each individual. 
Again a significant effect of time-point and ND level was found in the longitudinal logistic regression model of prolonged abstinence (Table 5). A lower odds of abstinence was found at week 12, 26 and 52 compared to week 4 (OR=0.93, 95\% Cl=0.89-0.98, $\mathrm{p}=0.01 ; \mathrm{OR}=0.91,95 \% \mathrm{Cl}=0.86-0.95, \mathrm{P}<0.01 ; \mathrm{OR}=0.89,95 \% \mathrm{Cl}=0.86-0.94, \mathrm{P}<0.01$, respectively) and with a high ND level compared to a low ND level (OR=0.87, $95 \% \mathrm{Cl}=0.78-0.98, \mathrm{p}=0.02$ ). Again no effects of gender, and COPD status were found. No main effects for treatment and combined genotype were found, however a significant interaction effect of antidepressant therapy among carriers of high-activity variants was found. A significant effect on smoking cessation among carriers of 4-5 risk alleles was found with both bupropion $(\mathrm{OR}=2.00,95 \% \mathrm{Cl}=1.21-3.29, \mathrm{p}<0.01)$ and nortriptyline treatment $(\mathrm{OR}=1.91,95 \% \mathrm{Cl}=1.02-3.56, \mathrm{p}=0.04)$. This interaction was broken down by conducting separate multilevel models on the genotype groups (e.g. 0-1, 2-3, and 4-5 high-activity variants). The model specified included only time-point, level of ND, and treatment. These analyses showed that for those with 4-5 high-activity alleles abstinence levels significantly increased when treated with bupropion (OR=1.70, $95 \% \mathrm{Cl}=1.13-2.55, \mathrm{p}=0.01)$ or nortriptyline $(\mathrm{OR}=1.59,95 \% \mathrm{Cl}=1.07-2.35, \mathrm{p}=0.02)$. For those with 0-1 high-activity variants and 2-3 high-activity no significant effects of treatment were found, however abstinence rates seem to be slightly lower among those with $0-1$ variants $(O R=0.85$ and $O R=0.77$ for bupropion and nortriptyline, respectively) and slightly increased among those with $2-3$ variants ( $O R=1.13$ and $\mathrm{OR}=1.05$, respectively). These data are presented graphically in Figure 2.

The longitudinal logistic regression model of 7-day point abstinence at week 4, 12, 26 and 52 gave similar results (see Table 5).

Table 5: Longitudinal Logistic Regression Models of Smoking Abstinence for variants combined

\begin{tabular}{|c|c|c|c|c|}
\hline \multirow[b]{2}{*}{ Predictor } & \multicolumn{2}{|c|}{ prolonged abstinence } & \multicolumn{2}{|c|}{ 7-day point abstinence } \\
\hline & OR $(95 \% \mathrm{Cl})$ & p-value & OR $(95 \% \mathrm{Cl})$ & p-value \\
\hline Timepoint $^{1}-1$ & $0.96(0.93-0.99)$ & 0.01 & $0.93(0.89-0.98)$ & 0.01 \\
\hline-2 & $0.92(0.89-0.95)$ & $<0.01$ & $0.91(0.86-0.95)$ & $<0.01$ \\
\hline-3 & & & $0.89(0.85-0.94)$ & $<0.01$ \\
\hline ND level (high vs. low) & $0.87(0.78-0.98)$ & 0.02 & $0.87(0.78-0.98)$ & 0.02 \\
\hline Gender (female vs. male) & $1.00(0.89-1.11)$ & 0.93 & $1.00(0.89-1.12)$ & 0.97 \\
\hline COPD (vs. no COPD) & $0.94(0.84-1.05)$ & 0.24 & $0.94(0.84-1.05)$ & 0.24 \\
\hline \multicolumn{5}{|l|}{ Treatment (vs. placebo) } \\
\hline Bupropion & $0.85(0.61-1.21)$ & 0.37 & $0.81(0.58-1.14)$ & 0.22 \\
\hline Nortriptyline & $0.82(0.49-1.38)$ & 0.45 & $0.80(0.48-1.34)$ & 0.40 \\
\hline \multicolumn{5}{|l|}{ Genotype (vs. 0-1 risk alleles) } \\
\hline 2-3 risk alleles & $0.89(0.68-1.16)$ & 0.37 & $0.89(0.68-1.15)$ & 0.37 \\
\hline 4-5 risk alleles & $0.80(0.56-1.16)$ & 0.24 & $0.84(0.58-1.15)$ & 0.33 \\
\hline \multicolumn{5}{|l|}{ Genotype ${ }^{*}$ treatment } \\
\hline Bupropion * 2-3 high-activity alleles & $1.31(0.90-1.92)$ & 0.16 & $1.37(0.94-1.99)$ & 0.10 \\
\hline Bupropion * 4-5 high-activity alleles & $2.00(1.21-3.29)$ & 0.01 & $1.97(1.21-3.23)$ & 0.01 \\
\hline Nortriptyline $* 2-3$ high-activity alleles & $1.28(0.74-2.19)$ & 0.37 & $1.31(0.77-2.23)$ & 0.32 \\
\hline Nortriptyline * 4-5 high-activity alleles & $1.91(1.02-3.56)$ & 0.04 & $1.84(1.00-3.40)$ & 0.05 \\
\hline
\end{tabular}




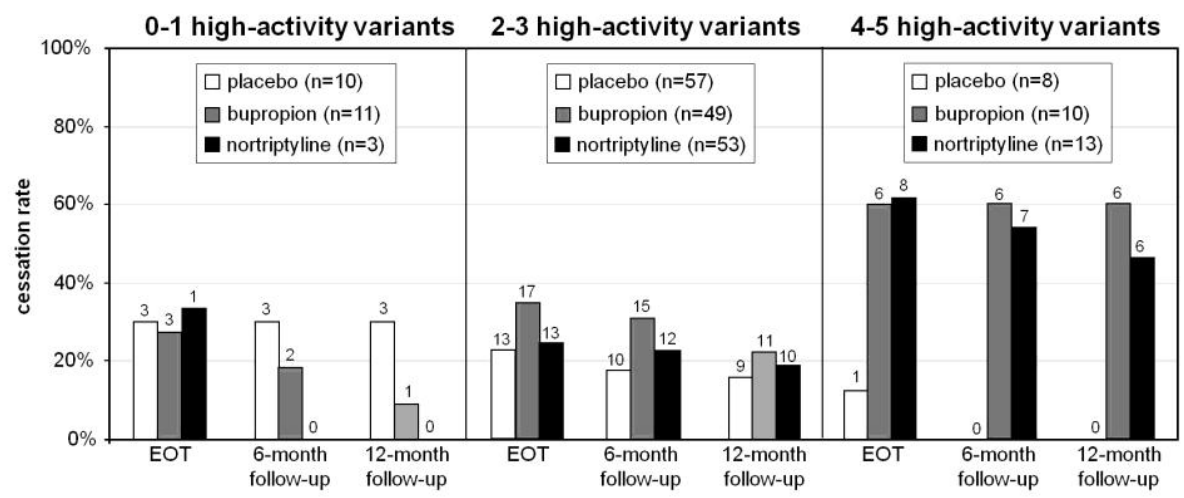

Figure 2: Prolonged abstinence by a combination of high-activity alleles and treatment group

The number of participants abstinent in the treatment groups is presented. Participants with 4-5 highactivity variants derive significantly more benefit from antidepressant therapy compared with placebo. For those with 0-1 or 2-3 high-activity variants no significant effects of treatment were found.

\section{DISCUSSION}

The results of this study provide evidence that genetic variations in the serotonin transporter gene (SLC6A4) may influence the response to both bupropion (SR) and nortriptyline. Abstinence rates were significantly increased in individuals carrying the high-activity L-variant of 5-HTTLPR when treated with bupropion compared to placebo and approached significance with nortriptyline treatment. No significant effects for the rs25531 and STin2 variants were found, although the pattern of cessation rates for the rs25531 genotype resembled the pattern observed for the 5-HTTLPR variant. Combining the three variants, however, resulted in a pronounced increase in cessation rates in both the bupropion and nortriptyline group among individuals with a combination of 4 to 5 high-activity variants.

Nicotine has been shown to increase the release of serotonin in the brain and there is strong evidence that serotonergic tone plays a role in nicotine's effects [19]. Thus, carriers of high-activity variants may have lower serotonin levels and therefore an increased sensitivity to the short-term serotonin releasing effects of smoking. This may increase the risk of smoking initiation and nicotine dependence, and decrease smoking cessation success in these individuals. Furthermore, nortriptyline, and to a lesser extent its metabolites, have been shown to inhibit serotonin reuptake, by blocking the serotonin transporter $[2,3]$. On the other hand, bupropion seems to have little serotonergic effects $[2,4,5]$, although electrophysiological studies indicate that sub-acute bupropion exposure may increase serotonin levels, which is probably a downstream effect of a primary noradrenalin release $[20,21]$. Therefore, nortriptyline treatment may have been more effective among carriers of high-activity SLC6A4 variants, by blocking the increased serotonin transporter activity in these individuals. The current findings, 
however, show that bupropion was also more effective among carriers of high-activity SLC6A4 variants, a finding that was even more pronounced than with nortriptyline. This can not be explained by an increased serotonin release, since then the effect would have been greatest in individuals carrying low-activity transporter variants, given the fact that serotonin levels would have been maintained longer in these individuals than by high-activity variant carriers. This suggests that bupropion might work, partly, via blocking the serotonin transporter as well.

To our knowledge only one other study has investigated the effects of genetic variants in the serotonin pathway on smoking cessation rates using antidepressant therapy. The effect of the 5-HTTLPR variant on bupropion treatment in Korean male smokers was investigated [22]. Increased abstinence rates were observed among L-allele carriers, especially the LL-genotype, compared to SS-homozygotes (SS: 37.1\%; SL: 40.5\%; LL: 66.7\%). However, these differences were not statistically significant. This might be explained by the fact that this study did not include a placebo group; in our study no main effect of 5-HTTLPR genotype was found either. Furthermore, Han et al. provided only 4 weeks of treatment, had a short follow-up period (4 weeks after bupropion administration), included only males, and participants had another ethnicity, resulting in a difference in genotype distribution.

Three pharmacogenetic smoking cessation studies have investigated the effect of serotonergic candidate-genes on nicotine replacement therapy (NRT). Genotypes associated with reduced synaptic serotonin activity (e.g. decreased synthesis, decreased receptor activity, increased serotonin transporter activity) might be associated with greater efficacy of NRT for smoking cessation, given the theoretical need to selfmedicate nicotine withdrawal [23]. However, two studies found no main effects or interactions of the 5-HTTLPR genotype for smoking cessation using NRT [24,25]. A third study found no significant effects of the 5-HTTLPR genotype and two other serotonin pathway variants (e.g. serotonin synthesis: TPH1 A779C, serotonin receptor: HTR1A C-1019G) on smoking relapse using NRT either [26]. Moreover, a pooled analysis of all three trials ( $\mathrm{N}=1398)$ showed no significant effect of 5-HTTLPR genotype on prolonged abstinence at 12- or 26-week follow-up [26]. A possible explanation for this lack of an effect is that there is no evidence that serotonin is a critical neurological substrate during smoking cessation or that it plays a role in suppression of nicotine withdrawal in smokers using NRT.

Thus, the effects of genetic variation in the serotonin transporter on smoking cessation success seem to be limited to antidepressant therapy.

As discussed above, the increased smoking cessation rates among carriers of high-activity serotonin transporter variants when using bupropion and nortriptyline are probably a consequence of a blockage of the serotonin transporter by these antidepressant drugs. However, currently no evidence for a clinically important benefit of selective serotonin reuptake inhibitors (SSRIs) for smoking cessation has been found (pooled estimate $\mathrm{OR}=0.90,95 \% \mathrm{Cl}=0.69-1.18$ ) [27]. Thus the efficacy of bupropion and nortriptyline can probably not be explained solely by their effects on the serotonin transporter.

Several studies have investigated the influence of genetic variants in the serotonin transporter gene on the effect of SSRIs in depression. A systematic review [28] showed 
that the response to SSRIs seems to be less favorable for Caucasian patients with the $\mathrm{S} / \mathrm{S}$ genotype compared to those with the $\mathrm{S} / \mathrm{L}$ and $\mathrm{L} / \mathrm{L}$ genotypes. On the other hand, effects in both directions were observed among Asian patients. Asian patients with the STin2 10/12-variant showed a less favorable response to SSRI treatment compared to those with the 12/12-variant [28]. These results are comparable with the higher efficacy that was found in this study for bupropion and nortriptyline among carriers of the 5-HTTLPR L-allele and STin2 12-variant.

This suggests that the effects of bupropion and nortriptyline might indeed be, at least partly, a consequence of a blockage of the serotonin transporter activity. However, their effects on other neurotransmitter pathways are also needed for successful smoking cessation.

In the original trial, the use of bupropion (SR) as well as nortriptyline resulted in slightly higher prolonged abstinence rates compared to placebo at EOT, 6- and 12-month follow-up, but only the difference for bupropion at 6-month follow-up was significantly different $(p=0.03)[12,13]$. Our data suggests that smoking cessation rates could have been significantly higher compared to placebo when participants would have been genotyped at forehand and antidepressant therapy would have been given to participants with 4 or 5 high-activity variants only. Furthermore, even when just the 5-HTTLPR genotype would have been determined in advance and bupropion therapy would have been given to L-carriers only abstinence rates would have been significantly higher as well.

Both VNTRs (5-HTTLPR and STin2) are very common in the population; 70-90\% of the population has one or two high-activity alleles of these variants. Furthermore, $\sim 10-20 \%$ of the population has at least one high-activity allele of the rs25531 SNP. Overall, this means that about $10 \%$ of the population has 0 or 1 high-activity variants, about $75 \%$ has 2 or 3 high-activity variants and about $15 \%$ has 4 or 5 high-activity variants.

Based on our findings it seems that antidepressant therapy is therefore most effective in about $15 \%$ of the population (e.g. with a combination of high-activity serotonin transporter variants), resulting in considerably higher cessation rates than found in current efficacy studies [27]. On the other hand, the use of antidepressant therapy might be less effective in about $10-30 \%$ of the population (e.g. with low serotonin transporter activity). However, the results should be considered as hypothesis generating and new prospective studies have to confirm these results before definite conclusions can be drawn.

A limitation of this study is that it was not originally designed for this purpose and therefore the sample size was small for genetic analyses. Therefore, the power of the study was too low to detect an association with smoking cessation of genetic variants with a small effect and/or a low allele-frequency. However, we found consistent effects for the different genetic variants and when the variants were combined. Furthermore, as described above, comparable results for genetic variants in the serotonin transporter gene have been reported when using SSRIs for the treatment of depression [28]. And increased cessation rates, however non-significant, were also found among carriers of high-activity 5-HTTLPR variants in a study in Korean male smokers [22]. 
Another limitation of this study is that the original study included both smokers with and without COPD. In the original study much smaller differences in prolonged abstinence rates were found among participants without COPD compared to participants with COPD. Thus, the differences in abstinence rates might be inflated due to the presence of COPD-patients in the study. However, in the longitudinal models in this study no significant effects of COPD status on abstinence rates were found. Furthermore, the prevalence of undiagnosed COPD-patients among smokers in the general population has been shown to be relatively high as well [29]. Thus, the study population might be a good presentation of the general population anyways.

In conclusion, both bupropion and nortriptyline seem to block the serotonin transporter, thereby increasing smoking cessation rates among carriers of high-activity serotonin transporter variants. Therefore, it might be possible to increase smoking cessation rates using bupropion and nortriptyline by selecting at forehand individuals with highactivity serotonin transporter variants.

However, because of the small sample size, our results have to be confirmed in further studies, before any definite conclusions can be drawn. Preferably, prospective studies randomizing on high-activity carrier status should be set up to fully confirm the effect of these variants on the efficacy of antidepressant therapy as an aid for smoking cessation.

\section{REFERENCES}

1. Quaak M, van Schayck CP, Knaapen AM, van Schooten FJ. Genetic variation as a predictor of smoking cessation success. A promising preventive and intervention tool for chronic respiratory diseases? Eur Respir J. 2009; 33(3): 468-480.

2. Richelson E, Pfenning M. Blockade by antidepressants and related compounds of biogenic amine uptake into rat brain synaptosomes: most antidepressants selectively block norepinephrine uptake. Eur J Pharmacol. 1984; 104(3-4): 277-286.

3. Sanchez C, Hyttel J. Comparison of the effects of antidepressants and their metabolites on reuptake of biogenic amines and on receptor binding. Cell Mol Neurobiol. 1999; 19(4): 467-489.

4. Dwoskin LP, Rauhut AS, King-Pospisil KA, Bardo MT. Review of the pharmacology and clinical profile of bupropion, an antidepressant and tobacco use cessation agent. CNS Drug Rev. 2006; 12(3-4): 178-207.

5. Paterson NE. Behavioural and pharmacological mechanisms of bupropion's anti-smoking effects: recent preclinical and clinical insights. Eur J Pharmacol. 2009; 603(1-3): 1-11.

6. Heils A, Teufel A, Petri S, Stober G, Riederer P, Bengel D, Lesch KP. Allelic variation of human serotonin transporter gene expression. J Neurochem. 1996; 66(6): 2621-2624.

7. Lesch KP, Bengel D, Heils A, Sabol SZ, Greenberg BD, Petri S, Benjamin J, Muller CR, Hamer DH, Murphy DL. Association of anxiety-related traits with a polymorphism in the serotonin transporter gene regulatory region. Science. 1996; 274(5292): 1527-1531.

8. Fiskerstrand CE, Lovejoy EA, Quinn JP. An intronic polymorphic domain often associated with susceptibility to affective disorders has allele dependent differential enhancer activity in embryonic stem cells. FEBS Lett. 1999; 458(2): 171-174. 
9. MacKenzie A, Quinn J. A serotonin transporter gene intron 2 polymorphic region, correlated with affective disorders, has allele-dependent differential enhancer-like properties in the mouse embryo. Proc Natl Acad Sci U S A. 1999; 96(26): 15251-15255.

10. Kraft JB, Slager SL, McGrath PJ, Hamilton SP. Sequence analysis of the serotonin transporter and associations with antidepressant response. Biol Psychiatry. 2005; 58(5): 374-381.

11. Hu X, Oroszi G, Chun J, Smith TL, Goldman D, Schuckit MA. An expanded evaluation of the relationship of four alleles to the level of response to alcohol and the alcoholism risk. Alcohol Clin Exp Res. 2005; 29(1): 8-16.

12. Wagena EJ, Knipschild PG, Huibers MJ, Wouters EF, van Schayck CP. Efficacy of bupropion and nortriptyline for smoking cessation among people at risk for or with chronic obstructive pulmonary disease. Arch Intern Med. 2005; 165(19): 2286-2292.

13. Van Schayck CP, Kaper J, Wagena EJ, Wouters EF, Severens JL. The cost-effectiveness of antidepressants for smoking cessation in chronic obstructive pulmonary disease (COPD) patients. Addiction. 2009; 104(12): 2110-2117.

14. Hughes JR, Keely JP, Niaura RS, Ossip-Klein DJ, Richmond RL, Swan GE. Measures of abstinence in clinical trials: issues and recommendations. Nicotine Tob Res. 2003; 5(1): 13-25 [published correction in Nicotine Tob Res. 2003; 2005: 2603].

15. Jarvis MJ, Tunstall-Pedoe H, Feyerabend C, Vesey C, Saloojee Y. Comparison of tests used to distinguish smokers from nonsmokers. Am J Public Health. 1987; 77(11): 1435-1438.

16. Heatherton TF, Kozlowski LT, Frecker RC, Fagerstrom KO. The Fagerstrom Test for Nicotine Dependence: a revision of the Fagerstrom Tolerance Questionnaire. Br J Addict. 1991; 86(9): 1119-1127.

17. Global Initiative for Chronic Obstructive Lung Disease. Global strategy for the diagnosis, management, and prevention of chronic obstructive pulmonary disease. GOLD Report. Update 2009; www.goldcopd.com.

18. Wendland JR, Martin BJ, Kruse MR, Lesch KP, Murphy DL. Simultaneous genotyping of four functional loci of human SLC6A4, with a reappraisal of 5-HTTLPR and rs25531. Mol Psychiatry. 2006; 11(3): 224-226.

19. Seth $P$, Cheeta S, Tucci S, File SE. Nicotinic-serotonergic interactions in brain and behaviour. Pharmacol Biochem Behav. 2002; 71(4): 795-805.

20. Dong J, Blier P. Modification of norepinephrine and serotonin, but not dopamine, neuron firing by sustained bupropion treatment. Psychopharmacology (Berl). 2001; 155(1): 52-57.

21. El Mansari M, Ghanbari R, Janssen S, Blier P. Sustained administration of bupropion alters the neuronal activity of serotonin, norepinephrine but not dopamine neurons in the rat brain. Neuropharmacology. 2008; 55(7): 1191-1198.

22. Han DH, Joe $\mathrm{KH}, \mathrm{Na} \mathrm{C}$, Lee YS. Effect of genetic polymorphisms on smoking cessation: a trial of bupropion in Korean male smokers. Psychiatr Genet. 2008; 18(1): 11-16.

23. Lerman C, Audrain J, Orleans CT, Boyd R, Gold K, Main D, Caporaso N. Investigation of mechanisms linking depressed mood to nicotine dependence. Addict Behav. 1996; 21(1): 9-19.

24. David SP, Munafò MR, Murphy MFG, Walton RT, Johnstone EC. The serotonin transporter 5-HTTLPR polymorphism and treatment response to nicotine patch: follow-up of a randomized controlled trial. Nicotine Tob Res. 2007; 9(2): 225-231.

25. Munafo MR, Johnstone EC, Wileyto EP, Shields PG, Elliot KM, Lerman C. Lack of association of 5-HTTLPR genotype with smoking cessation in a nicotine replacement therapy randomized trial. Cancer Epidemiol Biomarkers Prev. 2006; 15(2): 398-400.

26. David SP, Johnstone EC, Murphy MF, Aveyard P, Guo B, Lerman C, Munafo MR. Genetic variation in the serotonin pathway and smoking cessation with nicotine replacement therapy: new data from the Patch in Practice trial and pooled analyses. Drug Alcohol Depend. 2008; 98(1-2): 77-85.

27. Hughes JR, Stead LF, Lancaster T. Antidepressants for smoking cessation. Cochrane Database Syst Rev. 
2007; (1): CD000031.

28. Smits KM, Smits LJ, Schouten JS, Stelma FF, Nelemans P, Prins MH. Influence of SERTPR and STin2 in the serotonin transporter gene on the effect of selective serotonin reuptake inhibitors in depression: a systematic review. Mol Psychiatry. 2004; 9(5): 433-441.

29. Lundback B, Gulsvik A, Albers M, Bakke P, Ronmark E, van den Boom G, Brogger J, Larsson LG, Welle I, van Weel $C$, Omenaas E. Epidemiological aspects and early detection of chronic obstructive airway diseases in the elderly. Eur Respir J Suppl. 2003; 40: 3s-9s. 


\section{ADDENDUM}

A1. Ogilvie $A D$, Russell $M B$, Dhall $P$, et al. Altered allelic distributions of the serotonin transporter gene in migraine without aura and migraine with aura. Cephalalgia. 1998; 18(1): 23-6.

A2. Kaiser R, Tremblay PB, Schmider J, et al. Serotonin transporter polymorphisms: no association with response to antipsychotic treatment, but associations with the schizoparanoid and residual subtypes of schizophrenia. Mol Psychiatry. 2001; 6(2): 179-85.

A3. Smits KM, Smits LJ, Schouten JS, Stelma FF, Nelemans P, Prins MH. Influence of SERTPR and STin2 in the serotonin transporter gene on the effect of selective serotonin reuptake inhibitors in depression: a systematic review. Mol Psychiatry. 2004; 9(5): 433-41.

A4. Gerra G, Garofano L, Zaimovic A, et al. Association of the serotonin transporter promoter polymorphism with smoking behavior among adolescents. Am J Med Genet B Neuropsychiatr Genet. 2005; 135B(1): 73-8.

A5. Munafò MR, Johnstone EC, Wileyto EP, Shields PG, Elliot KM, Lerman C. Lack of association of 5-HTTLPR genotype with smoking cessation in a nicotine replacement therapy randomized trial. Cancer Epidemiol Biomarkers Prev. 2006; 15(2): 398-400.

A6. David SP, Munafo MR, Murphy MF, Walton RT, Johnstone EC. The serotonin transporter 5-HTTLPR polymorphism and treatment response to nicotine patch: follow-up of a randomized controlled trial. Nicotine Tob Res. 2007; 9(2): 225-231.

A7. Saiz PA, Garcia-Portilla MP, Arango C, et al. Association study between obsessive-compulsive disorder and serotonergic candidate genes. Prog Neuropsychopharmacol Biol Psychiatry. 2008; 32(3): 765-70.

A8. Sieminska A, Buczkowski K, Jassem E, Tkacz E. Lack of association between serotonin transporter gene polymorphism 5-HTTLPR and smoking among Polish population: a case-control study. BMC Med Genet. 2008; 9: 76.

A9. Kohen R, Cain KC, Mitchell PH, et al. Association of serotonin transporter gene polymorphisms with poststroke depression. Arch Gen Psychiatry. 2008; 65(11): 1296-302.

A10. Grabe HJ, Spitzer C, Schwahn C, et al. Serotonin transporter gene (SLC6A4) promoter polymorphisms and the susceptibility to posttraumatic stress disorder in the general population. Am J Psychiatry. 2009; 166(8): 926-33.

A11. Albani D, Vittori A, Batelli S, et al. Serotonin transporter gene polymorphic element 5-HTTLPR increases the risk of sporadic Parkinson's disease in Italy. Eur Neurol. 2009; 62(2): 120-3.

A12. Kohen R, Jarrett ME, Cain KC, et al. The Serotonin Transporter Polymorphism rs25531 Is Associated with Irritable Bowel Syndrome. Dig Dis Sci. 2009; 54(12): 2663-70.

A13. Tadić A, Elsässer A, Storm N, et al. Association analysis between gene variants of the tyrosine hydroxylase and the serotonin transporter in borderline personality disorder. World J Biol Psychiatry. 2010; 11(1): 45-58.

A14. Iordanidou M, Tavridou A, Petridis I, et al. Association of polymorphisms of the serotonergic system with smoking initiation in Caucasians. Drug Alcohol Depend. 2010; 108(1-2):70-6. 
Background: Variants in smoking-related genes have been shown to influence smoking behaviour. Since smoking cessation therapy is directed at the pathways involved in smoking behaviour, variants in these candidate genes are also expected to influence the efficacy of cessation therapy. Furthermore, genetic variants in genes influencing the metabolism and/or secretion of cessation therapy are also likely to influence the efficacy. However, so far most (candidate) gene studies investigated only single genes.

Aim: Investigate the influence of multiple genetic variants in candidate genes in smokingrelated and treatment-related pathways on the efficacy of antidepressant therapy (e.g. bupropion and nortriptyline) for smoking cessation.

Methods: Pharmacogenetic (secondary) analysis of a randomized, placebo-controlled efficacy trial of bupropion and nortriptyline for smoking cessation. 214 of 255 (84\%) participants were genotyped for 35 genetic variants in 19 candidate genes in smokingrelated pathways. Primary outcome measures were prolonged abstinence from weeks 4-12, 4-26 and 4-52. Secondary outcome measures included 7-day point prevalence abstinence at weeks 4, 12, 26 and 52 .

Results: The odds of prolonged abstinence was found to be increased in the presence of a variant in the serotonin biosynthesis (two TPH1 rs1799913 A-alleles; OR=1.44, 95\% Cl=1.121.84). Furthermore, a significant interaction effect was found between bupropion treatment and the nicotinic acetylcholinic receptor (CHRNA4 rs6122429; OR=1.34, 95\%Cl=1.00-1.78), the dopamine metabolism ( $D B H$ rs4531; OR=1.44, 95\%Cl=1.04-2.00), the serotonin synthesis ( $T P H 1$ rs1799913; OR=0.65, 95\%Cl=0.45-0.93), and the serotonin transporter (SLC6A4 5 -HTTLPR; OR=0.70, $95 \% \mathrm{Cl}=0.49-0.99)$, and between nortriptyline treatment and the nicotinic acetylcholinic receptor (CHRNA2 rs2292974; OR=1.48, 95\% Cl=1.02-2.15) and the acetylcholine sysnthesis (CHAT rs2269338; OR=1.46, 95\% Cl=1.13-1.90).

Conclusions: Several variants in genes in smoking-related and treatment-related pathways were found to influence cessation rates when treated with bupropion and nortriptyline. Some of these variants had comparable effects for both bupropion and nortriptyline treatment, but also some genetic variants were identified that had distinct effects depending on the type of antidepressant that was used. Thus it seems that genotyping smokers before a cessation attempt may give directions in determining which treatment would be most effective for an individual smoker. 


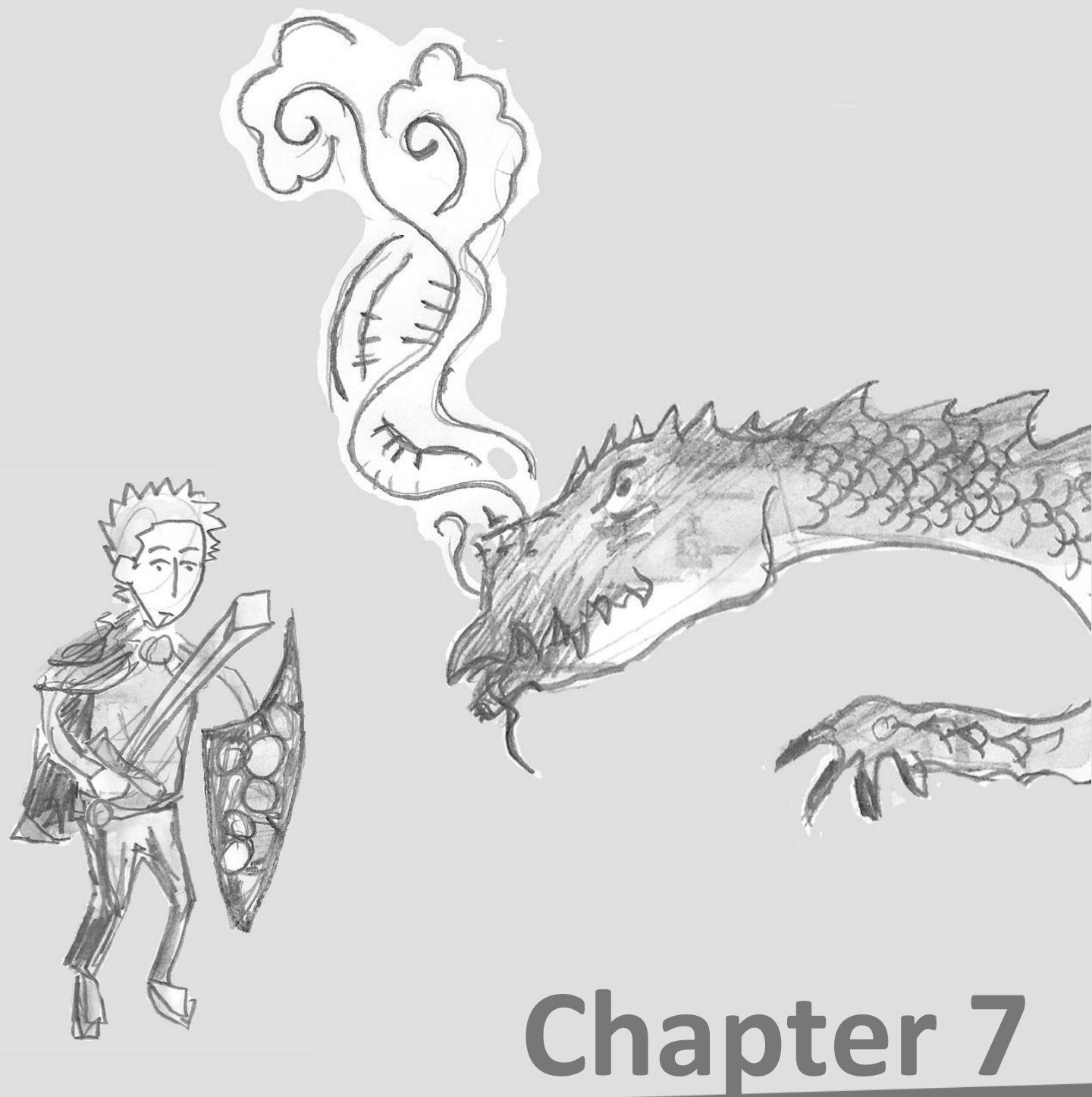

INFLUENCE OF MULTIPLE GENETIC VARIANTS ON ANTIDEPRESSANT THERAPY FOR SMOKING CESSATION 


\section{INTRODUCTION}

Both genetic and environmental determinants are believed to contribute to smoking. While early reports suggested that the influence of heredity on smoking was modest, more recent twin and adoption studies have found significant genetic influences on several aspects of smoking behaviour [1-9]. Variations in several genes have been suggested to contribute to smoking behaviour, and has been focused on two broad classes of candidate genes (for extended reviews see [7, 10-13]): 1) genes that may influence the response to nicotine (e.g. nicotine metabolism, nicotinic receptors), and 2) genes that may predispose to addictive behaviour due to their effects on key neurotransmitter pathways (e.g. dopamine and serotonin). Since pharmacotherapy used for smoking cessation are directed at the pathways involved in smoking behaviour variants in these candidate genes are also expected to influence the efficacy of smoking cessation therapy. Furthermore, genetic variants in genes influencing the metabolism and/or secretion of smoking cessation pharmacotherapy, thereby determining the level and duration of the medication in the body, are also expected to influence the efficacy of smoking cessation treatment.

Only a few types of medication with proven efficacy for smoking cessation are available, including antidepressant therapy. Currently, there are two antidepressant drugs used for smoking cessation: bupropion and nortriptyline. An overview of their working mechanism can be found in Figure 1. In short, bupropion is considered to be an atypical antidepressant and the mechanism of its therapeutic actions is not well understood. Preclinical and clinical studies have shown that bupropion mainly inhibits dopamine (DA) and norepinephrine (NE) reuptake, but seems to have little effect on serotonergic (5-HT) neurotransmission [14-20]. Furthermore, bupropion has been shown to act as a noncompetitive antagonist on the postsynaptic nicotinic acetylcholinic receptors (nAChRs) [18-20]. Nortriptyline is a tri-cyclic antidepressant (TCA). Nortriptyline, and to a lesser extent its metabolites, have been shown to inhibit both NE and 5-HT reuptake, but is preferentially a NE reuptake inhibitor [15,21-28]. DA reuptake appears to be of minor importance $[26,28]$. Furthermore, nortriptyline has been shown to have an anticholinergic effect and serotonergic (5- $\left.\mathrm{HT}_{2}\right)$ receptor antagonist activity [23,27-31].

Pharmacogenetic research has shown that smokers with genotypes associated with increased dopamine availability (increased or normal dopamine receptor availability or function, low dopamine transporter levels and low dopamine metabolism), and a decreased bupropion metabolism achieve better quit rates with bupropion [32, 33]. In contrast, cessation rates when using bupropion seem to be decreased in the presence of an intermediate/slow CYP2A6 metabolism. Furthermore, in a previous study we have shown that both bupropion and nortriptyline seem to increase smoking cessation rates among carriers of high-activity serotonin transporter variants [34].

However, so far most studies investigated only single genes. Since a large number of genes and several polymorphisms in these genes are likely to contribute to the individual susceptibility towards smoking cessation therapies this approach will probably fail to fully determine the role of genetic variation in smoking cessation success. Therefore, studies should focus on multiple functional variants and multiple genes operating within a single pathway. Furthermore, until now the pharmacogenetics of only a couple of smoking cessation therapies (nicotine replacement therapy (NRT) and bupropion) has been 
investigated extensively. The current second-line medication nortriptyline still requires investigation.

We therefore investigated the influence of 35 genetic variants in 19 candidate genes (Table S2) on smoking cessation rates in a randomized placebo-controlled trial of bupropion (sustained release; SR) and nortriptyline for smoking cessation. In the original efficacy trial only the difference in abstinence between bupropion (SR) and placebo at 6-month follow-up was significantly different (difference=13.1\%, 95\% Cl=1.2\%-25.1\%, $\mathrm{P}=0.03$ ). No significant effects of bupropion treatment at 12-week (end-of-treatment; EOT) and 12-month follow-up were found, nor for nortriptyline treatment at all three time-points (EOT, 6- and 12-month follow-up) [35,36].

Information about the influence of genetic variants on treatment response (pharmacogenetics) may help to better understand underlying pharmacological mechanisms. Ultimately this may lead to individualized treatment, by pre-selection of individuals who are expected to have the best treatment response based on their genetic profile. This will then likely result in higher cessation rates, and consequently less frustration by both smokers and healthcare practitioners.

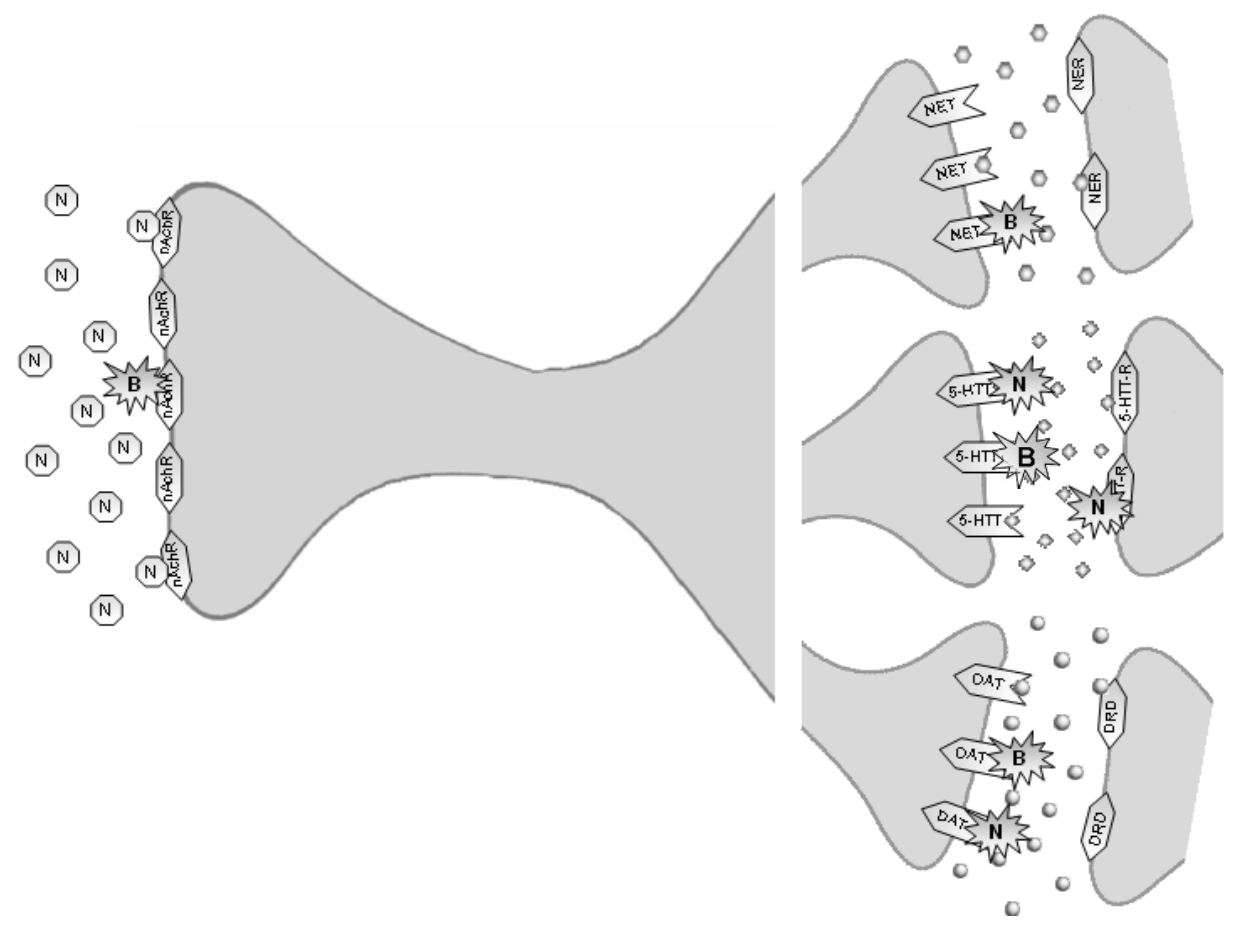

Figure 1: Working mechanisms of bupropion and nortriptyline

nicotine $(\mathrm{N})$; dopamine $(\mathrm{O})$; serotonin $(\diamond)$; Norepinephrine $(\mathrm{O})$; bupropion $(\mathrm{B})$; nortriptyline $(\mathrm{N})$; nicotinic acetylcholinic receptor (nAchR); dopamine receptor (DRD); norepinephrine receptor (NER); serotonin receptor (5-HTT-R); norepinephrine transporter (NET); dopamine transporter (DAT); serotonin transporter (5-HTT) 


\section{MATERIALS AND METHODS}

\section{Subjects and procedures}

In the original randomized controlled trial on the efficacy of bupropion (SR) and nortriptyline in smoking cessation among people with and without COPD, 255 current daily smokers were included between March 2002 and August 2004 [35, 36]. In short, participants were aged $30-70$ years, had a smoking history of $>5$ years, smoked on average $>10$ cigarettes/ day during the last year, and were motivated to stop smoking. Eligible individuals were randomly assigned to receive bupropion SR (150-mg once/day for days 1-6, followed by 150-mg twice/day for days 7-84), nortriptyline (25-mg once/day for days 1-3, followed by 50-mg once/day for days 3-7, and 75-mg once/day for days 8-84), or matched placebo.

During one of the follow-up visits, a $10-\mathrm{ml}$ blood sample was collected ( $\mathrm{N}=187,73 \%)$ or participants were invited to provide a buccal sample by postal mail $(\mathrm{N}=27,11 \%)$, resulting in a total of 214 samples for genotyping (84\%).

Ethical approval was obtained from the medical ethics committee of the Maastricht University Medical Centre. Participants provided written informed consent for genotyping.

\section{Measures}

\section{Smoking outcomes}

In accordance with the recommendations of the Society for Research on Nicotine and Tobacco [37] we report prolonged abstinence rates as the primary outcome measure and 7-day point prevalence rates as the secondary outcome measure.

Prolonged abstinence was defined as a participant's report of zero cigarettes per day (not even a puff), confirmed by urinary cotinine values of $60 \mathrm{ng} / \mathrm{mL}$ or less [38] at weeks 4, 12,26 and 52. Seven-day point prevalence abstinence was defined as having smoked no cigarettes, not even a puff, during the previous 7 days, confirmed by urinary cotinine values of $60 \mathrm{ng} / \mathrm{mL}$ or less). Missing data were considered indicative of smoking.

Prolonged abstinence from smoking was measured from week 4-12 (end-oftreatment; EOT), week 4-26 (6-month follow-up), and week 4-52 (12-month follow-up) after the target quit date (TQD) and 7-day point prevalence at weeks 4, 12, 26 and 52.

\section{Participant characteristics}

Ethnicity was not assessed, however based on the make-up of the region where the participants were recruited, it is expected that virtually all participants are Caucasians.

Smoking characteristics comprised the number of cigarettes per day, the number of previous quit attempts (at least 24 hours abstinence from smoking), and the level of nicotine dependence (ND). ND was assessed with the Fagerström Test for Nicotine Dependence (FTND) [39]; scores of $>6$ indicate greater levels of ND. Clinical characteristics measured included severity of COPD, defined according to the definition provided by the Global Initiative for Chronic Obstructive Lung Disease (GOLD) [40]. 


\section{Genotyping}

Participants were genotyped for 35 genetic variants in 19 candidate genes using the mass-spectroscopy based, high-throughput MassARRAY ${ }^{\circledR}$ iPLEX $^{\text {TM }}$ platform (Sequenom ${ }^{\circledR}$, Hamburg, Germany) or traditional PCR, if applicable. Details of primers and genotyping assays are available on request.

Genotype calls were then evaluated for 6 criteria:

1) Chi-square analysis was used to test whether the distribution of genotypes was in accordance with Hardy-Weinberg equilibrium (HWE). One SNP ( $r$ 1917810) was excluded because it showed a significant deviation $(p<0.001)$ from HWE.

2) The minor allele frequency (MAF) was calculated. Two SNPs (rs1799835 and rs1801028) with an observed MAF<0.01 were excluded.

3) SNP call rates were calculated, and SNPs with a call rate $\leq 80 \%$ were excluded. No SNPs were removed and most of the SNPs (37) had a call rate of even $>95 \%$.

4) Individual call rates were calculated, and individuals with a call rate $<70 \%$ were removed from the analysis $(n=1)$. Of the remaining individuals $96.3 \%$ had a call rate $\geq 95 \%$, and $98.6 \%$ a call rate $\geq 85 \%$.

5) Data from men with a heterozygous genotype for the MAO-A uVNTR located on the X-chromosome was removed $(n=1)$.

6) Linkage disequilibrium (LD) was calculated (Haploview version 4.2). To avoid redundant analyses, only one SNP was evaluated in the univariate and MDR analysis when SNPs were in strong linkage with other SNPs using a cut-off value of $r^{2}>0.85$. As a result 2 SNPs ( $r$ 22292975 and $r$ 2279343) were removed from the analysis (see Figure S2).

\section{Statistical analysis}

Univariate associations between genotypes and abstinence (prolonged and 7-day point prevalence) were assessed using Pearson's chi-square tests. When associations reached $p$-values $<0.10$, we further determined the best fitting genetic model (codominant, dominant, recessive or additive) in multiple logistic regression. All regression models were adjusted for time-point, ND level, gender and COPD status.

PHASE (version2.1), a program for reconstructing haplotypes from population genotype data, was used to generate haplotypes for candidate genes with more than one variant. Then the effect of haplotypes on prolonged abstinence rates was assessed using logistic regression for the separate time-points (e.g. EOT, 6-month follow-up and 12-month follow-up). All regression models were adjusted for ND level, gender and COPD status.

All analyses were performed using PASW statistics (v17.02) for windows (Chicago, Illinois, USA) and all tests were two-sided, unless otherwise specified. To control for multiple testing, we calculated the false discovery rate (FDR) according to Benjamini and Hochberg [41]. 


\section{RESULTS}

\section{Validity of the population used for the genotyping study}

Prolonged abstinence rates at all three time points (EOT, 6- and 12-month follow-up) and 7day point prevalence abstinence rates at all 4 time points $(4,12,26$ and 52 weeks) among participants in the genotyping study $(\mathrm{N}=214)$ did not differ significantly from participants in the original study $(\mathrm{N}=255)$. There were also no differences on type of treatment, gender, age, average number of cigarettes smoked per day prior to treatment, number of previous quit attempts, level of nicotine dependence, and COPD stage.

\section{Participant characteristics}

Table 1 presents the baseline characteristics of the study participants. The average age of the participants was 51.5 years $(S D=8.5)$, and $50.9 \%$ were women. Participants smoked on average 23.3 cigarettes/day $(S D=8.8)$, and in the past had tried 2.6 times to quit smoking $(S D=1.8)$. Participants had an average FTND-score of $5.9(S D=2.1)$, and $61.7 \%$ had a high level of ND (FTND-score $>6$ ). When using the GOLD guideline [40] to classify participants, 98 (45.8\%) had no COPD (a normal spirometry, but chronic cough and sputum production; previously classified as Stage 0: at risk for COPD), 45 (21.0\%) had mild COPD (Stage 1) and 71 (33.2\%) had moderate or severe COPD (Stage 2 or 3).

There were some imbalances after randomization. The bupropion group consisted of relatively more women $(61.4 \%)$ compared with the nortriptyline $(42.0 \%)$ and placebo (49.3\%) groups. And the nortriptyline group consisted of relatively fewer participants without COPD $(37.7 \%)$ compared with the bupropion $(52.9 \%)$ and placebo $(46.7 \%)$ group, but relatively more participants with mild COPD $(29.0 \%$ versus $15.7 \%$ and $18.7 \%$ respectively).

Table 1: Baseline characteristics of the participants

\begin{tabular}{|c|c|c|c|}
\hline & $\begin{array}{c}\text { placebo } \\
(n=75)\end{array}$ & $\begin{array}{c}\text { bupropion SR } \\
(n=70)\end{array}$ & $\begin{array}{c}\text { nortriptyline } \\
(n=69)\end{array}$ \\
\hline \multicolumn{4}{|l|}{ Demographic characteristics } \\
\hline Age, mean (SD), years & $51.3 \quad(8.9)$ & $51.5 \quad(7.7)$ & $51.8 \quad(9.3)$ \\
\hline Women, No. (\%) & $37(49.3)$ & $43(61.4)$ & $29(42.0)$ \\
\hline \multicolumn{4}{|l|}{ Smoking characteristics } \\
\hline No. of cigarettes smoked per day, mean (SD) & $23.2(8.9)$ & $24.0(9.5)$ & $22.6 \quad(7.8)$ \\
\hline No. of previous attempts to quit, mean (SD) ${ }^{1}$ & $2.6(1.6)$ & $2.5 \quad(1.9)$ & $2.7 \quad(2.0)$ \\
\hline FTND score, mean $(S D)^{2}$ & $5.7 \quad(2.1)$ & $6.1(2.1)^{3}$ & $6.0 \quad(2.2)$ \\
\hline FTND score $\geq 6$, No. $(\%)^{2}$ & $46(61.3)$ & $44(63.8)^{3}$ & $42(60.9)$ \\
\hline \multicolumn{4}{|l|}{ Clinical characteristics } \\
\hline \multicolumn{4}{|l|}{ COPD classification, No. (\%) } \\
\hline No COPD (previously Stage 0: at risk for COPD) & $35(46.7)$ & 37 (52.9) & $26(37.7)$ \\
\hline Stage 1: mild COPD & $14(18.7)$ & $11(15.7)$ & $20(29.0)$ \\
\hline Stage 2 \& 3: moderate \& severe COPD & $26(34.7)$ & $22(31.4)$ & $23(33.3)$ \\
\hline
\end{tabular}




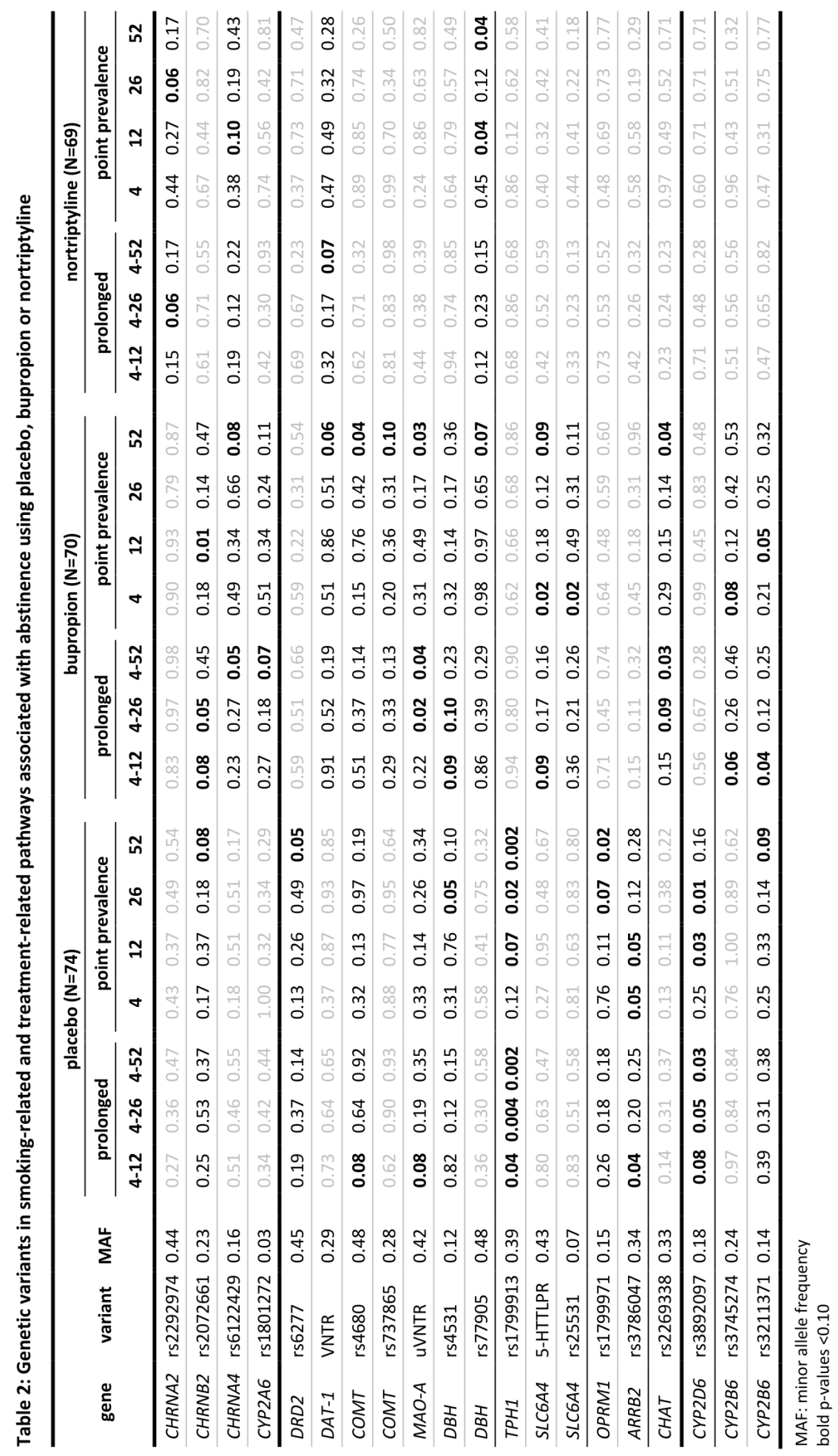




\section{Single gene associations}

In total 20 genetic variants in smoking-related and treatment-related genes were found to be associated $(p<0.10)$ with at least one of the time-points (Table 2). Of these variants, 10 influenced placebo-treatment, 15 influenced bupropion treatment, and only 4 were found to influence nortriptyline treatment. P-values in this table were calculated without prior assumption of the mode of inheritance. Subsequently the $p$-value for the best fitting genetic model was calculated.

Tables $3 A$ and $3 B$ give the odds ratios and $95 \%$ confidence intervals of the longitudinal logistic regression model for prolonged abstinence and 7-day point prevalence abstinence rates belonging to the best genetic model (adjusted for time-point, level of ND, gender and COPD status).

These analyses showed a significant main effect of the TPH1 rs1799913 variant on prolonged abstinence. The odds of prolonged abstinence was found to be increased in the presence of two TPH1 rs1799913 A-alleles (OR=1.44, 95\% Cl=1.12-1.84). Similar results were found for 7-day point prevalence abstinence. However, the odds of abstinence was found to be increased as well among individuals homozygous for DRD2 rs6277 (OR=1.22, $95 \% \mathrm{Cl}=1.02-1.47)$ and in the presence of one or two CHAT rs2269338 T-alleles (OR=1.26, $95 \% \mathrm{Cl}=1.02-1.56)$, but decreased among individuals with two ARRB2 rs3786047 A-alleles (OR=0.77, 95\% Cl=0.60-0.99).

Moreover, a significant interaction effect was found between bupropion treatment and CHRNA4 rs6122429 (OR=1.34, 95\%Cl=1.00-1.78), DBH rs4531 (OR=1.44, 95\%Cl=1.04-2.00), TPH1 rs1799913 (OR=0.65, 95\%Cl=0.45-0.93), and SLC6A4 5-HTTLPR (OR=0.70, 95\% Cl=0.49-0.99), and between nortriptyline treatment and CHRNA2 rs2292974 (OR=1.48, 95\% $\mathrm{Cl}=1.02-2.15)$ and $C H A T$ rs2269338 (OR=1.46, 95\% $\mathrm{Cl}=1.13-1.90)$. These interactions were broken down by conducting separate multilevel models on the genotype groups (see Table 4). The model specified included time-point, level of ND, gender, COPD status and treatment. These data are also presented graphically in Figure S3.

The odds of prolonged abstinence was found to be increased compared to placebo with both bupropion and nortriptyline treatment among carriers of one or two TPH1 rs17799913 G-alleles (B: OR=1.23, 95\%Cl=1.06-1.44, $p=0.005 ; \mathrm{N}$ : $\mathrm{OR}=1.17,95 \% \mathrm{Cl}=1.02$ 1.34, $\mathrm{p}=0.03$ ), and among those homozygous for the $D B H$ rs4531 variant ( $\mathrm{B}: \mathrm{OR}=1.58$, $95 \% \mathrm{Cl}=1.21-2.06, \mathrm{p}=0.001 ; \mathrm{N}: \mathrm{OR}=1.43,95 \% \mathrm{Cl}=1.06-1.95, \mathrm{p}=0.02)$. And similar effects were found for the SLC6A4 5-HTTLPR variant, were for those with one or two L-alleles abstinence rates increased significantly when treated with bupropion (OR=1.24, $95 \% \mathrm{Cl}=1.06-1.44, \mathrm{p}=0.006)$, and approached significance when treated with nortriptyline $(\mathrm{OR}=1.15,95 \% \mathrm{Cl}=0.99-1.32, \mathrm{p}=0.07)$. Furthermore, prolonged abstinence rates were increased with buprupion treatment only among carriers of one or two CHRNA2 rs229274 C-alleles (OR=1.19, 95\%Cl=1.02-1.38, $\mathrm{p}=0.03$ ), CHRNA4 rs6122429 A-alleles $(\mathrm{OR}=1.41,95 \% \mathrm{Cl}=1.14-1.75, \mathrm{p}=0.002)$, and among individuals with a CYP2D6 rs3892097 GG-genotype $(\mathrm{OR}=1.23,95 \% \mathrm{Cl}=1.06-1.43, \mathrm{p}=0.007)$. In contrast, nortriptyline treatment was found to increase abstinence levels compared to placebo among those with the CHRNA2 rs229274 T/T genotype (OR=1.66, 95\%Cl=1.22-2.27, $\mathrm{p}=0.002)$ and among those with at least one CHAT rs2269338 T-allele (OR=1.45, 95\% Cl=1.10-1.77, $\mathrm{p}=0.01)$. 
Table 4: Interaction between treatment and genotype on prolonged abstinence broken down for genotype

\begin{tabular}{|c|c|c|c|c|c|c|}
\hline & & & \multicolumn{2}{|c|}{ bupropion (vs. placebo) } & \multicolumn{2}{|c|}{ nortriptyline (vs. placebo) } \\
\hline & & & OR (95\%Cl) & $p$ & OR (95\%Cl) & $\mathbf{p}$ \\
\hline \multirow[t]{2}{*}{ CHRNA2 } & rs2292974 & $\mathrm{C} / \mathrm{C}+\mathrm{C} / \mathrm{T}$ & $1.19(1.02 ; 1.38)$ & 0.03 & $1.08(0.93 ; 1.25)$ & 0.29 \\
\hline & & $\mathrm{T} / \mathrm{T}$ & $1.31(0.85 ; 1.50)$ & 0.38 & $1.66(1.22 ; 2.27)$ & 0.002 \\
\hline \multirow[t]{2}{*}{ CHRNA4 } & rs6122429 & $\mathrm{G} / \mathrm{G}$ & $1.06(0.90 ; 1.25)$ & 0.49 & $1.14(0.97 ; 1.34)$ & 0.49 \\
\hline & & $G / A+A / A$ & $1.41(1.14 ; 1.75)$ & 0.002 & $0.98(0.78 ; 1.23)$ & 0.87 \\
\hline \multirow[t]{2}{*}{$\overline{D B H}$} & rs4531 & $\mathrm{G} / \mathrm{G}+\mathrm{T} / \mathrm{T}$ & $1.08(0.93 ; 1.26)$ & 0.31 & $1.07(0.92 ; 1.25)$ & 0.36 \\
\hline & & $\mathrm{G} / \mathrm{T}$ & $1.58(1.21 ; 2.06)$ & 0.001 & $1.43(1.06 ; 1.95)$ & 0.02 \\
\hline \multirow[t]{2}{*}{ TPH1 } & rs1799913 & $\mathrm{A} / \mathrm{A}$ & $0.80(0.55 ; 1.16)$ & 0.22 & $0.83(0.55 ; 1.25)$ & 0.36 \\
\hline & & $\mathrm{A} / \mathrm{C}+\mathrm{C} / \mathrm{C}$ & $1.23(1.06 ; 1.44)$ & 0.005 & $1.17(1.02 ; 1.34)$ & 0.03 \\
\hline \multirow[t]{2}{*}{ SLC6A4 } & 5-HTTLPR & $L / L+S / L$ & $1.24(1.06 ; 1.44)$ & 0.006 & $1.15(0.99 ; 1.32)$ & 0.07 \\
\hline & & $\mathrm{S} / \mathrm{S}$ & $0.87(0.65 ; 1.15)$ & 0.32 & $0.90(0.63 ; 1.28)$ & 0.54 \\
\hline \multirow[t]{2}{*}{ CHAT } & rs2269338 & G/G & $1.11(0.95 ; 1.29)$ & 0.18 & $0.99(0.85 ; 1.15)$ & 0.86 \\
\hline & & $\mathrm{G} / \mathrm{T}+\mathrm{T} / \mathrm{T}$ & $1.28(0.95 ; 1.72)$ & 0.10 & $1.45(1.10 ; 1.77)$ & 0.01 \\
\hline \multirow[t]{2}{*}{ CYP2D6 } & rs3892097 & $\mathrm{G} / \mathrm{G}$ & $1.23(1.06 ; 1.43)$ & 0.007 & $1.13(0.96 ; 1.32)$ & 0.14 \\
\hline & & $A / G+A / A$ & $0.98(0.73 ; 1.32)$ & 0.89 & $1.04(0.79 ; 1.38)$ & 0.76 \\
\hline
\end{tabular}

OR: odds ratio; $\mathrm{Cl}$ : confidence interval

\section{Haplotype analysis}

For candidate genes with more than one variant haplotypes were generated to investigate the combined effect of the variants. Haplotypes in two candidate genes (SLC6A4 and CYP2B6) were identified that were associated with prolonged abstinence rates among those treated with bupropion (Table 5). No haplotypes were found that significantly influenced prolonged cessation rates among those treated with either placebo or nortriptyline, although haplotypes in three candidate genes did approach significance after treatment with nortriptyline (e.g. CYP2D6, COMT, and $D B H$ ).

Smokers with the 12-L-G haplotype in SLC6A4 achieved higher prolonged abstinence rates when treated with bupropion compared to those with a *-S-A haplotype (* indicates the presence of any other possible allele than the 12 -allele), however, this was only significant at 12 -month follow-up $(p=0.03)$.

Table 5: Prolonged abstinence rates and haplotypes among smokers treated with bupropion

\begin{tabular}{|c|c|c|c|c|c|c|c|c|c|c|}
\hline & \multirow[b]{2}{*}{$\mathbf{N}$} & \multicolumn{3}{|c|}{ EOT } & \multicolumn{3}{|c|}{ 6-month follow-up } & \multicolumn{3}{|c|}{ 12-month follow-up } \\
\hline & & stopped & OR $(95 \% \mathrm{Cl})$ & p & stopped & OR $(95 \% \mathrm{Cl})$ & p & stopped & OR $(95 \% \mathrm{Cl})$ & p \\
\hline \multicolumn{11}{|c|}{ SLC6A4 STin2, 5-HTTLPR, rs25531 } \\
\hline$*-S-A^{a}$ & 13 & $30.8 \%$ & $1.00^{b}$ & & $23.1 \%$ & $1.00^{b}$ & & $7.7 \%$ & $1.00^{\mathrm{b}}$ & \\
\hline$*-L-A^{a}$ & 40 & $35.0 \%$ & $1.29(0.32 ; 5.26)$ & 0.72 & $27.5 \%$ & $1.38(0.31 ; 6.19)$ & 0.68 & $25.0 \%$ & $4.53(0.51 ; 40.46)$ & 0.18 \\
\hline $12-\mathrm{S}-\mathrm{A}$ & 57 & $31.6 \%$ & $1.17(0.30 ; 4.56)$ & 0.82 & $29.8 \%$ & $1.50(0.35 ; 6.39)$ & 0.58 & $22.8 \%$ & $3.96(0.56 ; 34.31)$ & 0.21 \\
\hline${ }^{*}-\mathrm{L}-\mathrm{G}^{\mathrm{a}}$ & 2 & $0.0 \%$ & & $\mathrm{~N} / \mathrm{A}$ & $0.0 \%$ & & $\mathrm{~N} / \mathrm{A}$ & $0.0 \%$ & & $\mathrm{~N} / \mathrm{A}$ \\
\hline $12-L-A$ & 20 & $55.0 \%$ & $2.07(0.44 ; 9.70)$ & 0.36 & $50.0 \%$ & $3.20(0.63 ; 16.17)$ & 0.16 & $40.0 \%$ & $8.05(0.83 ; 77.95)$ & 0.07 \\
\hline 12-L-G & 8 & $62.5 \%$ & $4.85(0.69 ; 34.09)$ & 0.11 & $62.5 \%$ & $6.67(0.90 ; 49.40)$ & 0.06 & $50.0 \%$ & $15.69(1.24 ; 198.06)$ & 0.03 \\
\hline \multicolumn{11}{|c|}{ CYP2B6 rs3745274, rs3211371 } \\
\hline G-C & 77 & $41.0 \%$ & $1.00^{b}$ & & $37.2 \%$ & $1.00^{b}$ & & $29.5 \%$ & $1.00^{\mathrm{b}}$ & \\
\hline G-T & 27 & $18.5 \%$ & $0.31(0.10 ; 0.95)$ & 0.04 & $18.5 \%$ & $0.37(0.12 ; 1.13)$ & 0.08 & $14.8 \%$ & $0.40(0.12 ; 1.33)$ & 0.13 \\
\hline $\mathrm{T}-\mathrm{C}$ & 34 & $37.1 \%$ & $0.89(0.38 ; 2.08)$ & 0.78 & $34.3 \%$ & $0.61(0.34 ; 1.90)$ & 0.57 & $25.7 \%$ & $0.75(0.30 ; 1.89)$ & 0.54 \\
\hline
\end{tabular}

a $*$ : any other allele than 12 -allele

${ }^{\mathrm{b}}$ reference group 
For CYP2B6 the G-T haplotype significantly decreased prolonged cessation rates using bupropion treatment at EOT $(\mathrm{OR}=0.31,95 \% \mathrm{Cl}=0.10-0.95, \mathrm{p}=0.04)$. Cessation rates remained lower at the later time-points, although this was no longer significant, probably due to the steep decline in cessation rates among smokers with the reference $(G-C)$ haplotype.

\section{DISCUSSION}

Earlier studies have provided evidence that several genetic variants in smokingrelated genes (e.g. genes influencing the response to nicotine and genes that may predispose to addictive behaviour due to their effects on key neurotransmitter pathways) have an effect on smoking behaviour and may also influence the efficacy of smoking-cessation treatments. Furthermore, genetic variants in genes influencing the metabolism of smoking cessation pharmacotherapy, thereby determining the level and duration of the medication in the body, have also been shown to influence the efficacy of smoking cessation treatment. However, so far investigated only single genes, and the pharmacogenetics of only a couple of smoking cessation therapies (e.g. NRT and bupropion) has been investigated extensively. Therefore, in this study the effect of multiple genetic variants on smoking cessation rates of two antidepressants used for smoking cessation, bupropion (sustained release; SR) and nortriptyline, was investigated.

The results of this study provide evidence that several genetic variants in smokingrelated and treatment-related genes may influence smoking cessation rates and the response to both bupropion (SR) and nortriptyline treatment.

\section{Influence of genetic variants on smoking cessation rates}

Prolonged abstinence rates were found to be significantly increased among individuals with the TPH1 rs1799913 AA-genotype. It is plausible that tryptophan hydroxylase (TPH) has an effect on smoking cessation, since it is involved in serotonin biosynthesis and nicotine has been shown to enhance serotonin release. The C-allele of the rs1799913 (A779C) has been related to poor impulse control [42], which is associated to tobacco and other substance abuse [43], an earlier onset of smoking and reduced levels of cerebrospinal fluid 5-hydroxyindoleacetic acid (a metabolite of 5-HT), indicating decreased serotonin levels [44-46]. However, no association with smoking behaviour has been found $[44,45]$. Therefore, individuals carrying the C-allele may find the mood-altering effects of serotonin by nicotine more rewarding [44], resulting in an increase in nicotine dependence (ND) and more difficulty to stop smoking. In line with this hypothesis abstinence rates were found to be increased among individuals with the TPH1 rs1799913 AA-genotype. However, the rs1799913 variant does not appear to result in an altered function or expression and may thus not be the etiological mutation responsible for this association, but may be in LD with an as yet unidentified polymorphism in the TPH1 gene [47]. 
Furthermore, odds of 7-day point prevalence abstinence was found to be increased as well among individuals homozygous for DRD2 rs6277 and in the presence of at least one CHAT rs2269338 T-allele, but decreased in the presence of two ARRB2 rs3786047 A-alleles.

\section{Influence of genetic variants on treatment response}

A significant effect on prolonged abstinence rates using bupropion treatment was found with CHRNA4 rs6122429, DBH rs4531, TPH1 rs1799913, SLC6A4 5-HTTLPR, and CYP2D6 rs3892097, and on prolonged abstinence rates using nortriptyline with CHRNA2 rs2292974 and CHAT rs2269338. Overall, genetic variants associated with a dopamine or serotonin deficiency resulted in increased cessation rates using both bupropion and nortriptyline. Furthermore, antidepressant therapy seemed to attenuate the decreased cessation rates among individuals with a higher nicotine metabolism (CYP2D6), although this was not significant for nortriptyline. Moreover, cessation rates using bupropion were found to be decreased among individuals with a lower bupropion metabolism. On the other hand, a variant in the acetylcholine pathway was found to be associated with nortriptyline only. Finally, variants in nicotinic receptor subunits also seem to play a role, but the nature of this association was not clear.

Carriers of one or two CHRNA2 rs229274 C-alleles achieved higher prolonged abstinence rates with bupropion, but, in contrast, nortriptyline treatment was found to be more effective among those with the T/T genotype. Several studies have linked CHRNA2 with smoking, possibly because variants in this gene can alter binding or the response to nicotine [48, 49]. The CHRNA2 rs2292974 C-allele has been reported to be associated with ND [50]. Therefore, smokers carrying a C-allele could have more difficulty to quit, but pharmacotherapy might help to overcome this difficulty in quitting. This is in line with our results found for bupropion treatment, but not for nortriptyline treatment. A previous study, reported a positive effect of bupropion treatment among SNP carriers (C/T and T/T) [51]. Therefore, we re-ran our multiple logistic regression analysis assuming a recessive mode of inheritance. This analysis showed a significant effect of bupropion treatment in the presence of one or two T-alleles (OR=1.19, $95 \% \mathrm{Cl}=1.02-1.41, p=0.03)$, comparable to the results of this previous study. The results for nortriptyline treatment were no longer significant in this analysis.

Among those with at least one CHRNA4 rs6122429 A-allele, abstinence rates were increased when using bupropion, but not with nortriptyline treatment. The CHRNA4 rs6122429 variant alters an SP1-binding site, resulting in a 5-fold greater expression with the G-allele [52]. Studies indicate that activation of receptors containing $\alpha 4$-subunits play an important role in nicotine-induced reward, tolerance, and sensitization $[53,54]$ and smokers with a high-expression genotype have been reported to be more sensitive to the acute effects of smoking and to experience a higher reward from smoking, and might therefore be more likely to be addicted [52]. Bupropion has been shown to act as a noncompetitive antagonist on the postsynaptic nAChRs [18-20], therefore it might block the acute effects and higher reward from smoking among individuals with the highexpression genotypes. However, contrary to this hypothesis, in this study, bupropion was found to be more effective among carriers of low-expression alleles. The effects of this 
variant on the efficacy of bupropion and nortriptyline for smoking cessation has not been previously investigated.

Both bupropion and nortriptyline treatment increased prolonged abstinence rates for those homozygous for the $D B H$ rs4531 variant (also known as DBH G910T). Dopamine $\beta$-hydroxylase is involved in the synthesis of noradrenalin from dopamine and a low DBH activity has been shown to lead to increased dopamine levels. Low activity DBH variants have been associated with an increase in amount smoked, but also with a decreased chance of being a smoker $[55,56]$. This variant has been suggested to result in a reduced enzyme activity, but this has not been confirmed and the effect of this variant on the efficacy of smoking-cessation has not been previously investigated. Therefore, it is unclear how this variant may affect smoking cessation rates using bupropion or nortriptyline.

The presence of one or two C-alleles of the TPH1 rs1799913 (also known as TPH1 A779C) was shown to increase the odds of prolonged abstinence for both bupropion treated and nortriptyline treated individuals. As stated before, individuals with this variant might have an increased sensitivity to the short-term serotonin releasing effects of smoking, resulting in an increase in ND. Both bupropion and nortriptyline have been shown to have serotonergic effects, thus the use of these treatments might thus help to overcome this serotonin deficiency, thereby increasing cessation rates. This is in line with the results of this study, since a significant decrease in the odds of abstinence was observed among C-allele carriers, but this decrease was attenuated by both bupropion and nortriptyline treatment.

For those with one or two L-alleles of the SLC6A4 5-HTTLPR variant, abstinence rates were significantly increased when treated with bupropion and approached significance with nortriptyline treatment $(p=0.07)$. Moreover, in the bupropion treated group, prolonged cessation rates were increased among smokers with the SLC6A412-L-G haplotype. As described in a previous article based on these results [34], the increased smoking cessation rates among carriers of high-activity serotonin transporter variants when using bupropion, and nortriptyline, are probably a consequence of a blockage of the increased serotonin transporter activity among carriers of high-activity variants (e.g. STin2 12-allele, 5-HTTLPR L-allele and/or rs25531 G-allele) by these antidepressant drugs, thereby increasing serotonin levels.

In the presence of at least one CHAT rs2269338 T-allele, prolonged abstinence rates were increased significantly when treated with nortriptyline, but not with bupropion. The role of choline acetyltransferase is to join Acetyl-CoA to choline, resulting in the formation of the neurotransmitter acetylcholine [57]. The rs2269338 SNP is located in the 3 'UTR, however its function is unknown. Therefore we can not rule on the mechanism behind the association between this variant and nortriptyline. However, contrary to our results, in a previous study a large effect of bupropion treatment was found among smokers carrying this variant as well [51].

Individuals with one or two G-alleles of the CYP2D6 rs392097 variant (also known as CYP2D6*4) achieved significantly higher abstinence rates with bupropion, and increased abstinence rates were also observed with nortriptyline treatment, however this was not significant. Next to metabolizing nortriptyline, cytochrome P450 2D6 (CYP2D6) is also capable of metabolizing nicotine, however, its catalytic activity towards nicotine might be negligible in the presence of functional CYP2A6. Individuals with a high nicotine 
metabolism may have a greater chance to continue smoking and become addicted, while slow nicotine metabolizers require fewer cigarettes to maintain nicotine titers at an optimal level once smoking is initiated [58]. The CYP2D6 rs3892097 variant results in a splicing defect, leading to an inactive enzyme [59], thereby possibly decreasing nicotine metabolism. Smokers with this variant might thus require fewer cigarettes and are therefore probably less addicted to smoking, and therefore more likely to be able to quit smoking. The reverse is truth for smokers without this variant and these smokers are therefore more likely to benefit from smoking cessation therapy. In line with this hypothesis, smokers with one or two variant alleles achieved higher abstinence rates compared to placebo using both bupropion and nortriptyline treatment, which was caused mainly by a decrease in abstinence rates among the placebo-treated group. However, this effect was not significant for nortriptyline treatment, possibly because nortriptyline treatment is also higher among smokers without this variant, thereby making the treatment less effective.

Finally, prolonged cessation rates were found to be decreased among bupropiontreated individuals with the CYP2B6 (rs3745274-rs3211371) G-T haplotype compared to the G-C haplotype. The T-allele of the CYP2B6 rs3211371 SNP has been associated with significantly reduced CYP2B6 protein expression and S-mephenoytoin $\mathrm{N}$-demethylase activity [60]. This allele might thus have resulted in a decreased bupropion metabolism, thereby increasing bupropion levels. This is expected to result in higher cessation rates. However, contrary to this hypothesis we found decreased cessation rates. A possible cause for this is that by lowering the bupropion metabolism, bupropion levels became so high that instead of helping smokers to stop, it causes more side-effects of the medication, which resulted in participants stopping the use of the medication. Unfortunately this data was not available in our study and therefore we could not investigate this. Furthermore, a previous study did report that bupropion attenuated the greater increase in cravings and higher chance of relapse, especially among women, with the T-variant [61]. Due to the low number of participants we could not investigate the effects for men and women separately, however, no significant effect of gender was found.

\section{Limitations}

This study has several limitations.

Firstly, this study was not originally designed for this purpose and therefore the sample size was small for genetic analyses. Because of this the power of the study was too low to detect an association with smoking cessation of genetic variants with a small effect and/or a low allele-frequency.

Secondly, combinations of variants can have an effect, even if the variants do not show an effect on their own. However, due to the small sample size it was not possible to investigate gene-gene interactions in this study. Furthermore the analysis techniques currently available are not very suitable for these kinds of analysis and therefore there is a need for new analysis techniques.

Thirdly, multiple testing in association studies may result in false discoveries. No single SNP and haplotype associations found in this study withstand correction for multiple testing. 
Fourthly, the original study included both smokers with and without COPD. In the original study much smaller differences in prolonged abstinence rates were found among participants without COPD compared to participants with COPD. Thus, the differences in abstinence rates might be inflated due the presence of COPD-patients in this study. However, all effects were corrected for COPD status. Furthermore, the prevalence of undiagnosed COPD-patients in the general population has been shown to be relatively high as well [62]. Thus the study population might be a good presentation of the general population anyways.

Finally, the genes selected for analysis were based on literature available until November 2008, of variants previously shown in several studies to be significantly associated with ND and/or smoking cessation success. We acknowledge that more genes and variants are located in these pathways.

\section{CONCLUSIONS}

In conclusion, several variants in genes in smoking-related and treatment-related pathways were found to influence cessation rates when treated with bupropion and nortriptyline (e.g. CHRNA2, CHRNA4, DBH, TPH1, SLC6A4, CHAT, CYP2D6 and CYP2B6). Some of these variants had comparable effects for both bupropion and nortriptyline treatment, but also some genetic variants were identified that had distinct effects depending on the type of antidepressant that was used. Thus it seems that genotyping smokers before a cessation attempt may give directions in determining which treatment would be most effective for an individual smoker. This would lead to a more efficient use of smoking cessation therapies, increased cessation rates, less frustration by both smokers and healthcare providers and ultimately, in reduced deaths from smoking.

Furthermore, the exact mechanisms by which bupropion and nortriptyline act as smoking cessation aids is unknown, as is its exact mechanism of antidepressant activity. Therefore, the results from the genetic analyses may provide us with clues how these treatments exert their effects.

However, future studies are needed to confirm our findings.

\section{REFERENCES}

1. Kaprio J, Hammar N, Koskenvuo M, Floderus-Myrhed B, Langinvainio H, Sarna S. Cigarette smoking and alcohol use in Finland and Sweden: a cross-national twin study. Int J Epidemiol. 1982; 11(4): 378-386.

2. Heath AC, Cates R, Martin NG, Meyer J, Hewitt JK, Neale MC, Eaves LJ. Genetic contribution to risk of smoking initiation: comparisons across birth cohorts and across cultures. J Subst Abuse. 1993; 5(3): 221-246.

3. Heath AC, Martin NG. Genetic models for the natural history of smoking: evidence for a genetic influence on smoking persistence. Addict Behav. 1993; 18(1): 19-34.

4. True WR, Heath AC, Scherrer JF, Waterman B, Goldberg J, Lin N, Eisen SA, Lyons MJ, Tsuang MT. Genetic and environmental contributions to smoking. Addiction. 1997; 92(10): 1277-1287.

5. Kendler KS, Neale MC, Sullivan P, Corey LA, Gardner CO, Prescott CA. A population-based twin study in 
women of smoking initiation and nicotine dependence. Psychol Med. 1999; 29(2): 299-308.

6. Sullivan PM, Kendler K. The genetic epidemiology of smoking. . Nicotine and Tobacco Research. 1999; 1(Suppl 2): S51-S57.

7. Batra V, Patkar AA, Berrettini WH, Weinstein SP, Leone FT. The Genetic Determinants of Smoking. Chest. 2003; 123: 1730-1739.

8. Xian H, Scherrer JF, Madden PA, Lyons MJ, Tsuang M, True WR, Eisen SA. The heritability of failed smoking cessation and nicotine withdrawal in twins who smoked and attempted to quit. Nicotine Tob Res. 2003; 5(2): 245-254.

9. Pergadia ML, Heath AC, Martin NG, Madden PA. Genetic analyses of DSM-IV nicotine withdrawal in adult twins. Psychol Med. 2006; 36(7): 963-972.

10. Rossing MA. Genetic influences on smoking: candidate genes. Environ Health Perspect. 1998; 106: 231-238.

11. Arinami T, Ishiguro $\mathrm{H}$, Onaivi ES. Polymorphisms in genes involved in neurotransmission in relation to smoking. European Journal of Pharmacology. 2000; 410: 215-226.

12. Al Koudsi N, Tyndale RF. Genetic influences on smoking: a brief review. Ther Drug Monit. 2005; 27(6): 704-709.

13. MacLeod SL, Chowdhury P. The genetics of nicotine dependence: relationship to pancreatic cancer. World J Gastroenterol. 2006; 12(46): 7433-7439.

14. Ferris RM, Beaman OJ. Bupropion: a new antidepressant drug, the mechanism of action of which is not associated with down-regulation of postsynaptic beta-adrenergic, serotonergic (5-HT2), alpha 2-adrenergic, imipramine and dopaminergic receptors in brain. Neuropharmacology. 1983; 22(11): 1257-1267.

15. Richelson E, Pfenning M. Blockade by antidepressants and related compounds of biogenic amine uptake into rat brain synaptosomes: most antidepressants selectively block norepinephrine uptake. Eur J Pharmacol. 1984; 104(3-4): 277-286.

16. Martin P, Massol J, Colin JN, Lacomblez L, Puech AJ. Antidepressant profile of bupropion and three metabolites in mice. Pharmacopsychiatry. 1990; 23(4): 187-194.

17. Nomikos GG, Damsma G, Wenkstern D, Fibiger HC. Effects of chronic bupropion on interstitial concentrations of dopamine in rat nucleus accumbens and striatum. Neuropsychopharmacology. 1992; 7(1): 7-14.

18. Fryer JD, Lukas RJ. Noncompetitive functional inhibition at diverse, human nicotinic acetylcholine receptor subtypes by bupropion, phencyclidine, and ibogaine. J Pharmacol Exp Ther. 1999; 288(1): 88-92.

19. Warner C, Shoaib M. How does bupropion work as a smoking cessation aid? Addict Biol. 2005; 10(3): 219-231.

20. Slemmer JE, Martin BR, Damaj MI. Bupropion is a nicotinic antagonist. J Pharmacol Exp Ther. 2000; 295(1): 321-327.

21. Bertilsson L, Mellstrom B, Sjoqvist F. Pronounced inhibition of noradrenaline uptake by 10-hydroxymetabolites of nortriptyline. Life Sci. 1979; 25(15): 1285-1292.

22. Potter WZ, Rudorfer MV, Lane EA. Active metabolites of antidepressants: pharmacodynamics and relevant pharmacokinetics. Adv Biochem Psychopharmacol. 1984; 39: 373-390.

23. Bertilsson L, Aberg-Wistedt A, Gustafsson LL, Nordin C. Extremely rapid hydroxylation of debrisoquine: a case report with implication for treatment with nortriptyline and other tricyclic antidepressants. Ther Drug Monit. 1985; 7(4): 478-480.

24. Malmgren R, Aberg-Wistedt A, Bertilsson L. Serotonin uptake inhibition during treatment of depression with nortriptyline caused by parent drug and not by 10-hydroxymetabolites. Psychopharmacology (Berl). 1987; 92(2): 169-172.

25. Nordin C, Bertilsson L, Siwers B. Clinical and biochemical effects during treatment of depression with nortriptyline: the role of 10-hydroxynortriptyline. Clin Pharmacol Ther. 1987; 42(1): 10-19.

26. Hyttel J. Pharmacological characterization of selective serotonin reuptake inhibitors (SSRIs). Int Clin Psychopharmacol. 1994; 9 Suppl 1: 19-26.

27. Nordin C, Bertilsson L. Active hydroxymetabolites of antidepressants. Emphasis on E-10-hydroxy- 
nortriptyline. Clin Pharmacokinet. 1995; 28(1): 26-40.

28. Sanchez C, Hyttel J. Comparison of the effects of antidepressants and their metabolites on reuptake of biogenic amines and on receptor binding. Cell Mol Neurobiol. 1999; 19(4): 467-489.

29. Wagner A, Ekqvist B, Bertilsson L, Sjoqvist F. Weak binding of 10-hydroxymetabolites of nortriptyline to rat brain muscarinic acetylcholine receptors. Life Sci. 1984; 35(13): 1379-1383.

30. Rudorfer MV, Potter WZ. Antidepressants. A comparative review of the clinical pharmacology and therapeutic use of the 'newer' versus the 'older' drugs. Drugs. 1989; 37(5): 713-738.

31. Rudorfer MV, Manji HK, Potter WZ. Comparative tolerability profiles of the newer versus older antidepressants. Drug Saf. 1994; 10(1): $18-46$.

32. Quaak M, van Schayck CP, Knaapen AM, van Schooten FJ. Genetic variation as a predictor of smoking cessation success. A promising preventive and intervention tool for chronic respiratory diseases? Eur Respir J. 2009; 33(3): 468-480.

33. Quaak M, van Schayck CP, Knaapen AM, van Schooten FJ. Implications of gene-drug interactions in smoking cessation for improving the prevention of chronic degenerative diseases. Mutat Res. 2009; 667(1-2): 44-57.

34. Quaak M, van Schayck CP, Postma DS, Wagena EJ, van Schooten FJ. Genetic variants in the serotonin transporter influence the efficacy of bupropion and nortriptyline in smoking cessation. Addiction. 2012; 107(1): 178-187.

35. Wagena EJ, Knipschild PG, Huibers MJ, Wouters EF, van Schayck CP. Efficacy of bupropion and nortriptyline for smoking cessation among people at risk for or with chronic obstructive pulmonary disease. Arch Intern Med. 2005; 165(19): 2286-2292.

36. Van Schayck CP, Kaper J, Wagena EJ, Wouters EF, Severens JL. The cost-effectiveness of antidepressants for smoking cessation in chronic obstructive pulmonary disease (COPD) patients. Addiction. 2009; 104(12): 2110-2117.

37. Hughes JR, Keely JP, Niaura RS, Ossip-Klein DJ, Richmond RL, Swan GE. Measures of abstinence in clinical trials: issues and recommendations. Nicotine Tob Res. 2003; 5(1): $13-25$ [published correction in Nicotine Tob Res. 2003; 2005: 2603].

38. Jarvis MJ, Tunstall-Pedoe H, Feyerabend C, Vesey C, Saloojee Y. Comparison of tests used to distinguish smokers from nonsmokers. Am J Public Health. 1987; 77(11): 1435-1438.

39. Heatherton TF, Kozlowski LT, Frecker RC, Fagerstrom KO. The Fagerstrom Test for Nicotine Dependence: a revision of the Fagerstrom Tolerance Questionnaire. Br J Addict. 1991; 86(9): 1119-1127.

40. Global Initiative for Chronic Obstructive Lung Disease. Global strategy for the diagnosis, management, and prevention of chronic obstructive pulmonary disease. GOLD Report. Update 2009; www.goldcopd.com.

41. Benjamini $Y$, Hochberg Y. Controlling for the false discovery rate: a practical and powerful approach to multiple testing. J R Stat Soc B. 1995; 57: 289-300.

42. Mann JJ, Malone KM, Nielsen DA, Goldman D, Erdos J, Gelernter J. Possible association of a polymorphism of the tryptophan hydroxylase gene with suicidal behavior in depressed patients. Am J Psychiatry. 1997; 154(10): 1451-1453.

43. Wills TA, Sandy JM, Shinar O. Cloninger's constructs related to substance use level and problems in late adolescence: a mediational model based on self-control and coping motives. Exp Clin Psychopharmacol. 1999; 7(2): 122-134.

44. Lerman C, Caporaso NE, Bush A, Zheng YL, Audrain J, Main D, Shields PG. Tryptophan hydroxylase gene variant and smoking behavior. Am J Med Genet. 2001; 105(6): 518-520.

45. Sullivan PF, Jiang $\mathrm{Y}$, Neale MC, Kendler KS, Straub RE. Association of the tryptophan hydroxylase gene with smoking initiation but not progression to nicotine dependence. Am J Med Genet. 2001; 105(5): 479-484. 
46. Nielsen DA, Goldman D, Virkkunen M, Tokola R, Rawlings R, Linnoila M. Suicidality and 5hydroxyindoleacetic acid concentration associated with a tryptophan hydroxylase polymorphism. Arch Gen Psychiatry. 1994; 51(1): 34-38.

47. Nielsen DA, Jenkins GL, Stefanisko KM, Jefferson KK, Goldman D. Sequence, splice site and population frequency distribution analyses of the polymorphic human tryptophan hydroxylase intron 7. Brain Res Mol Brain Res. 1997; 45(1): 145-148.

48. Faraone SV, Su J, Taylor L, Wilcox M, Van Eerdewegh P, Tsuang MT. A novel permutation testing method implicates sixteen nicotinic acetylcholine receptor genes as risk factors for smoking in schizophrenia families. Hum Hered. 2004; 57(2): 59-68.

49. Sullivan PF, Neale BM, van den Oord E, Miles MF, Neale MC, Bulik CM, Joyce PR, Straub RE, Kendler KS. Candidate genes for nicotine dependence via linkage, epistasis, and bioinformatics. Am J Med Genet B Neuropsychiatr Genet. 2004; 126B(1): 23-36.

50. Philibert RA, Todorov A, Andersen A, Hollenbeck N, Gunter T, Heath A, Madden P. Examination of the nicotine dependence (NICSNP) consortium findings in the lowa adoption studies population. Nicotine Tob Res. 2009; 11(3): 286-292.

51. Heitjan DF, Guo M, Ray R, Wileyto EP, Epstein LH, Lerman C. Identification of pharmacogenetic markers in smoking cessation therapy. Am J Med Genet B Neuropsychiatr Genet. 2008; 147B(6): 712-719.

52. Hutchison KE, Allen DL, Filbey FM, Jepson C, Lerman C, Benowitz NL, Stitzel J, Bryan A, McGeary J, Haughey HM. CHRNA4 and tobacco dependence: from gene regulation to treatment outcome. Arch Gen Psychiatry. 2007; 64(9): 1078-1086.

53. Marubio LM, Gardier AM, Durier S, David D, Klink R, Arroyo-Jimenez MM, Mclntosh JM, Rossi F, Champtiaux N, Zoli M, Changeux JP. Effects of nicotine in the dopaminergic system of mice lacking the alpha4 subunit of neuronal nicotinic acetylcholine receptors. Eur J Neurosci. 2003; 17(7): 1329-1337.

54. Tapper AR, McKinney SL, Nashmi R, Schwarz J, Deshpande P, Labarca C, Whiteaker P, Marks MJ, Collins AC, Lester HA. Nicotine activation of alpha4* receptors: sufficient for reward, tolerance, and sensitization. Science. 2004; 306(5698): 1029-1032.

55. McKinney EF, Walton RT, Yudkin P, Fuller A, Haldar NA, Mant D, Murphy M, Welsh KI, Marshal SE. Association between polymorphisms in dopamine metabolic enzymes and tobacco consumption in smokers. Pharmacogenetics. 2000; 10(6)(6): 483-491.

56. Freire MT, Marques FZ, Hutz MH, Bau CH. Polymorphisms in the DBH and DRD2 gene regions and smoking behavior. Eur Arch Psychiatry Clin Neurosci. 2006; 256(2): 93-97.

57. Oda Y. Choline acetyltransferase: the structure, distribution and pathologic changes in the central nervous system. Pathol Int. 1999; 49(11): 921-937.

58. Pianezza ML, Sellers EM, Tyndale RF. Nicotine metabolism defect reduces smoking. Nature. 1998; 393(750).

59. Hanioka N, Kimura S, Meyer UA, Gonzalez FJ. The human CYP2D locus associated with a common genetic defect in drug oxidation: a G1934----A base change in intron 3 of a mutant CYP2D6 allele results in an aberrant 3' splice recognition site. Am J Hum Genet. 1990; 47(6): 994-1001.

60. Lang T, Klein K, Fischer J, Nussler AK, Neuhaus P, Hofmann U, Eichelbaum M, Schwab M, Zanger UM. Extensive genetic polymorphism in the human CYP2B6 gene with impact on expression and function in human liver. Pharmacogenetics. 2001; 11(5): 399-415.

61. Lerman C, Shields PG, Wileyto EP, Audrain J, Pinto A, Hawk L, Krishnan S, Niaura R, Epstein L. Pharmacogenetic investigation of smoking cessation treatment. Pharmacogenetics. 2002; 12(8): 627-634.

62. Lundback B, Gulsvik A, Albers M, Bakke P, Ronmark E, van den Boom G, Brogger J, Larsson LG, Welle I, van Weel C, Omenaas E. Epidemiological aspects and early detection of chronic obstructive airway diseases in the elderly. Eur Respir J Suppl. 2003; 40: 3s-9s. 
Objectives: Recent research strongly suggests that genetic variation influences smokers' ability to stop. Therefore, the use of (pharmaco)genetic testing may increase cessation rates. This study aims to assess the intention of smokers concerning undergoing genetic testing for smoking cessation, and their knowledge, attitudes and preferences about this subject.

Design: Online cross-sectional survey.

Setting: Database internet research company of which every inhabitant of the Netherlands of $\geq 12$ years with an e-mail address and capable of understanding Dutch can become a member.

Participants: 587 of 711 Dutch smokers aged $\geq 18$ years, daily smokers for $\geq 5$ years and smoke on average $\geq 10$ cigarettes/day (response rate $=83 \%$ ).

Primary and secondary outcome measures: Smokers' knowledge, attitudes, and preferences and their intention to undergo genetic testing for smoking cessation.

Results: Knowledge on the influence of genetic factors in smoking addiction and cessation were found to be low. Smokers underestimated their chances of having a genetic predisposition and the influence of this on smoking cessation. Participants perceived few disadvantages, some advantages, and showed moderate self-efficacy towards undergoing a genetic test and dealing with the results. Smokers were mildly interested in receiving information and participating in genetic testing, especially when offered by their GP.

Conclusions: For successful implementation of genetic testing for smoking in general practice, several issues should be addressed, such as the knowledge on smoking cessation, genetics and genetic testing (including advantages and disadvantages), and the influence of genetics on smoking addiction and cessation. Furthermore, smokers allocate their GPs a crucial role in the provision of information and the delivery of a genetic test for smoking; however it is unclear whether GPs will be able and willing to take on this role. 


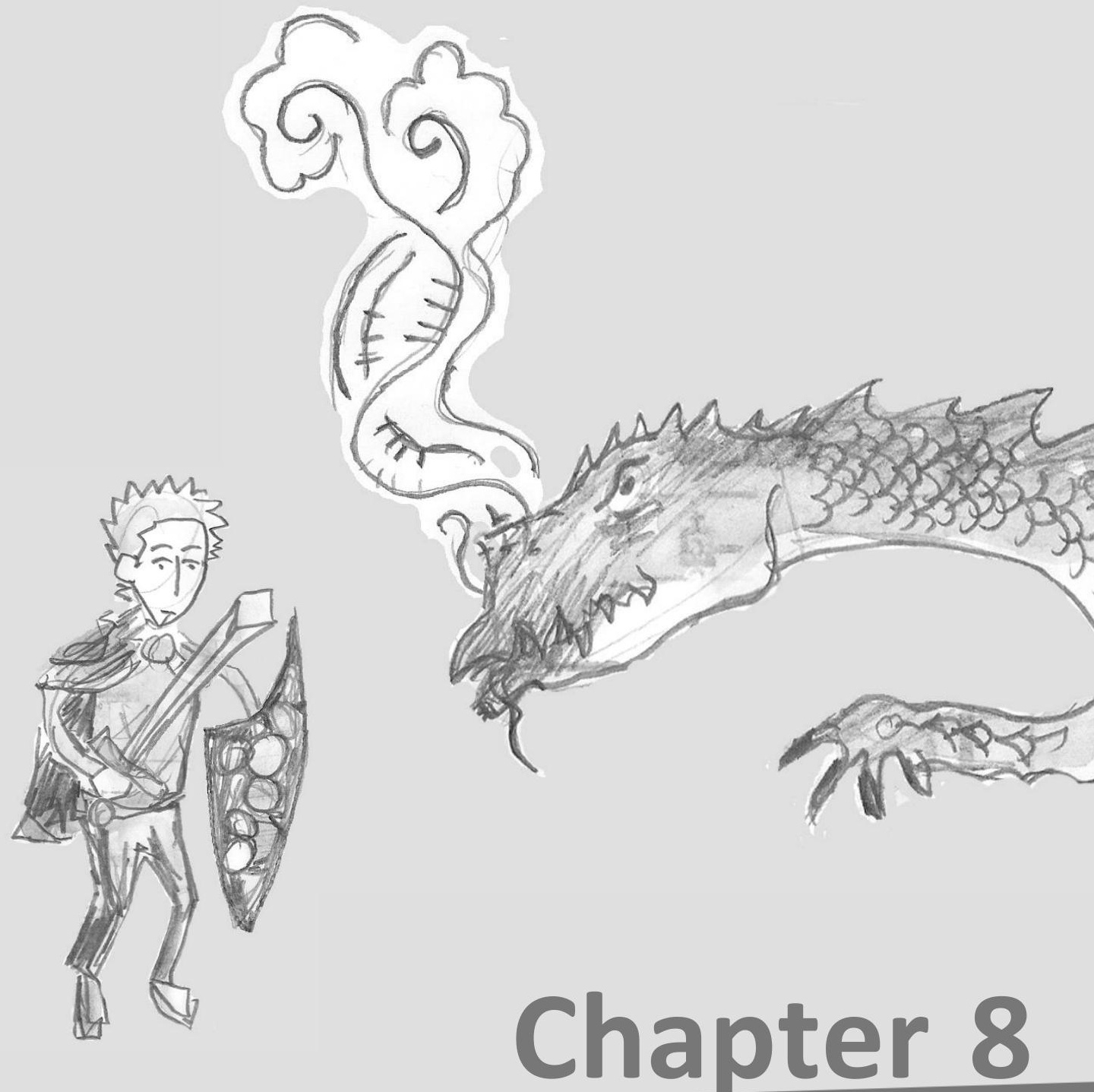

KNOWLEDGE, ATTITUDES, AND PREFERENCES REGARDING GENETIC TESTING FOR SMOKING CESSATION. A CROSSSECTIONAL SURVEY AMONG DUTCH SMOKERS 


\section{INTRODUCTION}

With currently still over 1.2 billion smokers world-wide, tobacco smoking continues to be the largest preventable cause of disease and premature death [1-3]. Cessation reverses most adverse effects of smoking [4]. Although most smokers are highly motivated to quit, and many (pharmacological) treatments are available to help them, cessation rates remain low; the average 12-month success rate ranges from 15 to 30\% [5], but substantial variability exists in success rates across smokers. Therefore, multiple quit attempts are often required.

Recent research strongly suggests that smokers vary in their underlying genetic susceptibility to become addicted to smoking and their ability to stop smoking [5-8]. Genetic variation may also influence a smoker's response to a particular smoking cessation pharmacotherapy. Hence, overall effectiveness of smoking cessation pharmacotherapy may potentially be increased if it will be targeted at smokers most likely to respond to a particular type of pharmacotherapy. Reviews concerning preliminary findings of studies investigating the effect of genetic polymorphisms on smoking cessation suggest promising effects $[5,9,10]$, making the use of (pharmaco)genetic testing for smoking in clinical practice for increasing quit rates by genetically-tailored smoking cessation treatment in the near future more likely.

Future implementation of (pharmaco)genetic testing for smoking in daily medical practice, however, will ultimately depend upon patients' acceptance of these tests. At present there is relatively little knowledge about the willingness and preferences of patients concerning genetic testing for smoking addiction and cessation, and about individuals' knowledge and attitudes on this subject.

The goal of this study, therefore, is to investigate the intention of patients to undergo genetic testing for smoking cessation, and their knowledge, risk perceptions, attitudes, and self-efficacy beliefs. Additionally, we assessed their preferences concerning a genetic test for smoking cessation, such as topics and channels of interest, and test characteristics. This information can be used to guide the future development of a (pharmaco)genetic test for smoking cessation.

\section{METHODS}

\section{Study design}

Smokers' knowledge, attitudes, and preferences and their intention to undergo genetic testing were assessed using an online cross-sectional survey.

\section{Recruitment}

Participants were selected from the database of an internet research company originating from Maastricht University (Flycatcher Internet Research B.V., Maastricht, The Netherlands). The company has a database of $\sim 20.000$ members from which 
representative samples can be drawn. Every inhabitant of the Netherlands of $>12$ years with an e-mail address and capable of understanding Dutch can become a member. Members are recruited via digital media, written invitations, face-to-face contacts, and intermediaries. Since 2009 the panel is certified with a quality mark (ISO-26326).

Participants were eligible for inclusion if they were aged $>18$ years, were daily smokers for $>5$ years and smoked on average $>10$ cigarettes/day. In total, 711 participants that met the inclusion criteria were approached for this study. Two e-mails could not be delivered. Of the remaining invitations, 614 people responded. However, 26 questionnaires were not completely filled out and one case was removed because the fill out time indicated that this participant could not have read the questions before answering. Thus, a total of 587 participants were included in the present study (response rate $=83 \%$ ).

\section{Questionnaire}

The questionnaire was conducted in Dutch (questions in manuscript translated by authors) and took about 30 minutes to complete. Respondents were compensated for their time according to the standard of the research company (e.g. respondents receive a number of points which can be exchanged for a gift-certificate when a certain amount is reached).

\section{Participant characteristics}

Participants' age, gender, and education level were available from the company. In addition, participants were asked questions regarding their smoking behavior (type of tobacco product, number of cigarettes and/or shags per day, level of nicotine dependence (assessed by the Fagerström Test for Nicotine Dependence [FTND] [11]), previous quit attempts (number, duration, period until last attempt), and intention and intended period to quit.

\section{Knowledge}

Knowledge was assessed using ten statements (see Table 2); two regarding smoking cessation in general, four regarding the influence of genetics on nicotine dependence, and four regarding the influence of genetics on smoking cessation (treatment). Participants were asked whether they agreed or disagreed with the statements, or did not know the answer. In addition, participants were asked how important environment, personal behavior and genetic predisposition were according to them as a cause for smoking.

\section{Risk perceptions}

Participants were requested to estimate their probability that they have a genetic predisposition as a result of which they will have more difficulty to stop smoking, or they will experience more withdrawal symptoms (1: very small - 5: very high), as well as to indicate the seriousness of this (1: completely not serious -5 : very serious). 
Table 1: Baseline characteristics of the research sample (compared to the general smoking population)

\begin{tabular}{|c|c|c|c|c|}
\hline & \multicolumn{3}{|c|}{ sample $(n=587)$} & \multirow{2}{*}{$\begin{array}{l}\text { Dutch smoking } \\
\text { population }^{\mathrm{a}}\end{array}$} \\
\hline & No./mean & $\% / S D$ & range & \\
\hline \multicolumn{5}{|l|}{ Demographic characteristics } \\
\hline \multicolumn{5}{|l|}{ Gender (No., \%) } \\
\hline male & 292 & 49.7 & & $53.6 \%$ \\
\hline female & 295 & 50.3 & & $46.4 \%$ \\
\hline \multicolumn{5}{|l|}{ Age (No., \%) } \\
\hline 20-39 years & 192 & 32.7 & & $41.0 \%$ \\
\hline $40-64$ years & 336 & 57.2 & & $50.7 \%$ \\
\hline$>65$ years & 59 & 10.1 & & $8.3 \%$ \\
\hline \multicolumn{5}{|l|}{ Level of education } \\
\hline low & 184 & 31.3 & & $39.0 \%$ \\
\hline medium & 267 & 45.5 & & $36.6 \%$ \\
\hline high & 136 & 23.2 & & $24.4 \%$ \\
\hline \multicolumn{5}{|l|}{ Smoking characteristics } \\
\hline \multicolumn{5}{|l|}{ Type of tobacco product smoked (No., \%) } \\
\hline cigarettes & 430 & 73.3 & & $67.0 \%$ \\
\hline shag (rolling tobacco) & 360 & 61.3 & & $48.0 \%$ \\
\hline pipe/cigars/cigarillo's & 28 & 4.8 & & $17.0 \%$ \\
\hline other & 5 & 0.8 & & - \\
\hline No. of cigarettes smoked per day ( mean, SD) & 19.0 & 7.5 & $10-50$ & 14.4 \\
\hline FTND score (mean, SD) & 4.6 & 2.1 & $0-10$ & - \\
\hline FTND score $\geq 6$ (No., \%) & 215 & 36.6 & & - \\
\hline \multicolumn{5}{|l|}{ Cessation characteristics } \\
\hline Previously attempted to quit (No., \%) & 437 & 74.4 & & $65.0 \%$ \\
\hline No. of previous attempts to quit (mean, SD) & 2.9 & 3.1 & $1-40$ & 2.2 \\
\hline Duration longest quit attempt, days (mean, SD) & 269.7 & 623.1 & $0-4015$ & - \\
\hline Period until last quit attempt, years (mean, SD) & 3.9 & 5.1 & $0-30$ & - \\
\hline Intention to quit smoking (No., \%) & 305 & 52.0 & & $78.0 \%$ \\
\hline \multicolumn{5}{|l|}{ Intended period until quit attempt, years (No., \%) } \\
\hline Within 1 month & 22 & 3.7 & & $11.0 \%$ \\
\hline Within 3 months & 53 & 9.0 & & $13.0 \%$ \\
\hline Within 6 months & 50 & 8.5 & & \\
\hline Within 1 year & 109 & 18.6 & & $14.0 \%$ \\
\hline More than 1 year from now & 71 & 12.1 & & $40.0 \%$ \\
\hline
\end{tabular}

${ }^{a}$ TNS Nipo/STIVORO. Continu Onderzoek rookgewoonten (COR) [continuous research smoking habits]. 2009

\section{Attitudes and self-efficacy beliefs}

Attitudes towards undergoing genetic testing were assessed by 10 questions on the perceived advantages and 10 questions on the disadvantages, and self-efficacy (e.g. ability to undergo a genetic test and to deal with the results) using 4 questions (1: completely disagree - 5: completely agree; see Table 3).

\section{Topics and channels of interest}

Participants were asked about which of the given topics they would like to receive more information, via which channels they would prefer to receive more information regarding a genetic test to help them stop smoking, and via which channels they would prefer to actually obtain the test. 


\section{Test characteristics}

Participants were asked how important a number of test characteristics (easily performable, reliability, fast result, sharp increased cessation rates, low price, covered by insurance) were for them when they would consider to undergo a genetic test to help them stop smoking (1: very unimportant - 5: very important). Further, participants were asked which maximum price they would be willing to pay for the genetic test.

\section{Intention to undergo genetic testing}

Participants were asked if they were planning to undergo a genetic test to determine which smoking cessation therapy they could use best, and if they were planning to undergo a genetic test if it was offered by their general practitioner (GP), or if they would ask their GP for a genetic test (1: strongly disagree - 5: strongly agree).

\section{RESULTS}

\section{Participant characteristics}

Participant characteristics and characteristics of the general Dutch smoking population can be found in Table 1. No significant differences were found in terms of gender, age-group, education level, amount of cigarette smokers, and number of cigarettes smoked. Slightly more participants had attempted to quit smoking and they had undertaken slightly more quit attempts. A larger part of the sample smoked shag (rolling tobacco), but fewer smoked pipe/cigar/cigarillo's. Furthermore, participants seemed less interested in quitting than the general smoking population.

\section{Knowledge}

Table 2 presents the percentage of correct, incorrect and "don't know" answers.

The first set of statements concerned respondents' knowledge about smoking cessation. Overall, $88.9 \%$ knew that it is important to quit. About half $(49.1 \%)$ of the respondents knew that less than half of the smokers who want to quit succeed, while $29.8 \%$ could not answer this question.

The second set measured whether respondents were aware of how genetic factors influence smoking addiction levels. About half of the participants could not answer these questions (42.6-59.6\%). The lowest percentage of correct scores were found for the statements regarding the transfer of a genetic predisposition to the offspring by a non-smoking parent, and the existence of genes that decrease the chance of becoming addicted to smoking ( $14.0 \%$ and $15.5 \%$, respectively). About one-third knew that the chance to become addicted to smoking is influenced by genes (29.5\%), and that genes exist that increase the chance of becoming addicted to smoking (33.4\%). 
Table 2: Knowledge of smoking cessation, and influence of genetic factors on addiction and cessation (treatment)

\begin{tabular}{|c|c|c|c|}
\hline & correct & incorrect & don't know \\
\hline \multicolumn{4}{|l|}{ Smoking cessation } \\
\hline It is important to quit smoking, even if you already smoke for a very long time. (T) & $88.9 \%$ & $4.3 \%$ & $6.8 \%$ \\
\hline More than half of the smokers who want to quit smoking succeed in quitting. (F) & $49.1 \%$ & $21.1 \%$ & $29.8 \%$ \\
\hline \multicolumn{4}{|l|}{ Influence of genetic factors on smoking addiction levels } \\
\hline $\begin{array}{l}\text { The chance to become addicted to smoking is influenced by the presence of } \\
\text { certain hereditary traits (genes). (T) }\end{array}$ & $29.5 \%$ & $27.9 \%$ & $42.6 \%$ \\
\hline Genes exist that increase the chance to become addicted to smoking. (T) & $33.4 \%$ & $15.5 \%$ & $51.1 \%$ \\
\hline Genes exist that decrease the chance to become addicted to smoking. (T) & $15.5 \%$ & $24.9 \%$ & $59.6 \%$ \\
\hline $\begin{array}{l}\text { A parent with a genetic predisposition to get addicted to smoking will transfer } \\
\text { this predisposition to its children, even when the parent doesn't smoke or has } \\
\text { never smoked. (T) }\end{array}$ & $14.0 \%$ & $33.2 \%$ & $52.8 \%$ \\
\hline \multicolumn{4}{|l|}{ Influence of genetic factors on smoking cessation (treatment) } \\
\hline $\begin{array}{l}\text { A genetic predisposition to get addicted to smoking might also influence ones } \\
\text { chance to quit smoking. }(T)\end{array}$ & $25.4 \%$ & $21.1 \%$ & $53.5 \%$ \\
\hline $\begin{array}{l}\text { Due to a genetic predisposition can a smoking cessation therapy (e.g. nicotine } \\
\text { patches) be less effective for certain smokers. (T) }\end{array}$ & $26.4 \%$ & $17.6 \%$ & $56.0 \%$ \\
\hline $\begin{array}{l}\text { Due to a genetic predisposition can a smoking cessation therapy (e.g. nicotine } \\
\text { patches) be more effective for certain smokers. (T) }\end{array}$ & $15.2 \%$ & $24.5 \%$ & $60.3 \%$ \\
\hline $\begin{array}{l}\text { A genetic predisposition can influence the chance on withdrawal symptoms } \\
\text { during a cessation attempt. }(T)\end{array}$ & $23.9 \%$ & $18.7 \%$ & $57.4 \%$ \\
\hline
\end{tabular}

$\mathrm{T}$ : this statement is true; $\mathrm{F}$ : this statement is false

The third set assessed knowledge of the influence of genetic factors on smoking cessation and smoking cessation treatment. More than half of the respondents could not answer these (53.5-60.3\%). About a quarter knew that a genetic predisposition might also influence ones chances to quit (25.4\%), can make cessation therapy less effective for certain smokers $(26.4 \%)$, and influences the chance on withdrawal symptoms during cessation (23.9\%). Only $15.2 \%$ knew that a genetic predisposition can also make a cessation therapy more effective for certain smokers.

Furthermore, most respondents believed that environment and personal behavior were (very) important causes for smoking ( $80 \%$ and $84 \%$, respectively), while only $36 \%$ believed that genetic predisposition is a (very) important cause of smoking (Figure S4).

\section{Risk perceptions}

About one-third of the participants believed their probability to be (very) small to have a genetic predisposition as a result of which they will have more difficulty to stop smoking (38.3\%), or have more withdrawal symptoms (39.4\%) (Table S3). On the other hand, about one-fifth (16.8\%, and $15.3 \%$, respectively) believed their probability to be (very) big.

About half of the participants believed this to be (very) serious (53.9\% and $51.5 \%$ ), about two-fifth (35.6 and 39.2\%) to be neutral, and about one-tenth (9.4 and 10.6\%) to be (completely) not serious (Table S3). 


\section{Attitudes and self-efficacy beliefs}

Attitudes regarding genetic testing (perceived advantages and disadvantages), and self-efficacy beliefs can be found in Table 3 .

About one-third to half of the participants did not agree with the statements about the disadvantages of genetic testing, about one-third to two-fifth had a neutral reaction, while only less then one-third (completely) agreed with these statements. Especially the chance that the results would become known at work or to the employer and that they would not be able to tell others was perceived as low ( $4.8 \%$ and $8.0 \%$ (completely) agreed, respectively).

On the other hand, only about one-third or less (completely) disagreed with the statements on the advantages of genetic testing (12.8-34.2\%), while about half (43.1-61.0\%) had a neutral reaction and $12.8-33.2 \%$ (completely) agreed. Participants were least convinced that they would be relieved by the results and most convinced that a genetic test would give a reliable result about the presence of a genetic predisposition to become addicted to smoking, and that it could help to determine the correct dose of smoking cessation medication.

About a quarter of the participants were unsure if they would be able to ask their GP for a genetic test or undergo a genetic test ( $27.6 \%$ and $25.7 \%$, respectively), while about two-fifth $(39.7 \%$ and $38.0 \%)$ had a neutral reaction, and one-third $(32.7 \%$ and $36.3 \%$ ) (totally) agreed with these statements. Further, they agreed even somewhat more to the beliefs that they would be able to undergo the correct treatment based on the results of the test, and to understand the results of the genetic test. Only, about 10$15 \%$ (totally) disagreed with these statements, about half ( 48.9 and $49.2 \%$, respectively) did not agree or disagree with them and about two-fifth (39.9\% and $35.6 \%$ ) (totally) agreed with them.

\section{Topics and channels of interest}

About one-third of the participants (29.3\%) were not interested in more information (see Figure S5-A). However, 28.4\% were interested in more information on how DNA works, $35.8 \%$ in what a genetic predisposition is, and $50.9 \%$ in the working mechanism of a genetic test. Further, $42.9 \%$ were interested in where more information can be found about the genetic background of smoking, and $43.1 \%$ in more information about the influence of genetic differences on (smoking cessation) treatments.

Most participants (73.6\%) would prefer to receive more information from their GP (Figure S5-B). Other channels via which participants would prefer to receive more information are the internet $(48.0 \%)$, specialists $(37.6 \%)$, leaflets $(22.5 \%)$, TV $(12.4 \%)$, newspapers $(7.7 \%)$, friends $(6.0 \%)$, a telephonic help-desk (5.3\%), magazines $(4.9 \%)$, radio $(2.4 \%)$, and books $(2.2 \%)$.

Most participants (67.6\%) would also prefer to obtain the genetic test via their GP (Figure S5-C). Other preferred channels for obtaining the test were expert/specialist $(33.4 \%)$, the pharmacy $(18.1 \%)$, internet $(15.5 \%)$, and the pharmacist $(9.2 \%)$, while $15.5 \%$ was not interested in obtaining a genetic test. 
Table 3: Attitudes and self-efficacy beliefs

\begin{tabular}{|c|c|c|c|c|c|}
\hline & $\begin{array}{l}\text { completely } \\
\text { disagree }\end{array}$ & disagree & neutral & agree & $\begin{array}{l}\text { completely } \\
\text { agree }\end{array}$ \\
\hline \multicolumn{6}{|l|}{ Disadvantages } \\
\hline \multicolumn{6}{|l|}{ If I would undergo a genetic test... } \\
\hline $\begin{array}{l}\text {...the results will become known at my work / to my } \\
\text { employer. }\end{array}$ & $39.9 \%$ & $29.3 \%$ & $26.1 \%$ & $3.9 \%$ & $0.9 \%$ \\
\hline ...the results will become known to my health insurance. & $23.7 \%$ & $20.6 \%$ & $33.2 \%$ & $18.9 \%$ & $3.6 \%$ \\
\hline $\begin{array}{l}\text {... and it will show that I am addicted to smoking will it be } \\
\text { more difficult to get a mortgage or life-insurance. }\end{array}$ & $19.4 \%$ & $22.1 \%$ & $32.7 \%$ & $19.9 \%$ & $5.8 \%$ \\
\hline ...the results may be passed on to all kinds of agencies. & $21.8 \%$ & $26.6 \%$ & $34.6 \%$ & $12.9 \%$ & $4.1 \%$ \\
\hline ...I will learn about other diseases I have a predisposition for. & $11.8 \%$ & $15.5 \%$ & $43.3 \%$ & $26.1 \%$ & $3.4 \%$ \\
\hline ...I will be worried for the results. & $9.0 \%$ & $24.7 \%$ & $40.4 \%$ & $23.2 \%$ & $2.7 \%$ \\
\hline ...I will be afraid of the results. & $10.9 \%$ & $27.4 \%$ & $42.2 \%$ & $16.5 \%$ & $2.9 \%$ \\
\hline ...I will regret it due to possible consequences. & $10.4 \%$ & $27.9 \%$ & $44.5 \%$ & $14.8 \%$ & $2.4 \%$ \\
\hline ...I will worry about the possible results of the genetic test. & $9.7 \%$ & $22.7 \%$ & $40.0 \%$ & $23.9 \%$ & $3.7 \%$ \\
\hline ...I will not be able to tell the results to others. & $15.0 \%$ & $38.2 \%$ & $38.8 \%$ & $6.6 \%$ & $1.4 \%$ \\
\hline \multicolumn{6}{|l|}{ Advantages } \\
\hline \multicolumn{6}{|l|}{ If I would undergo a genetic test... } \\
\hline $\begin{array}{l}\text {...this will indicate the correct smoking cessation therapy } \\
\text { for me. }\end{array}$ & $4.6 \%$ & $13.5 \%$ & $55.5 \%$ & $21.5 \%$ & $4.9 \%$ \\
\hline $\begin{array}{l}\text {...this will increase the chances that I succeed to stop } \\
\text { smoking. }\end{array}$ & $6.1 \%$ & $13.8 \%$ & $54.9 \%$ & $20.6 \%$ & $4.6 \%$ \\
\hline $\begin{array}{l}\text {...this will help to determine the correct dose of smoking } \\
\text { cessation medication. }\end{array}$ & $5.1 \%$ & $10.6 \%$ & $51.4 \%$ & $27.8 \%$ & $5.1 \%$ \\
\hline $\begin{array}{l}\text {...I will have less side-effects from smoking cessation } \\
\text { treatments. }\end{array}$ & $6.0 \%$ & $16.5 \%$ & $61.0 \%$ & $13.5 \%$ & $3.1 \%$ \\
\hline $\begin{array}{l}\text {...this can prevent that I take/undergo an incorrect } \\
\text { smoking cessation treatment. }\end{array}$ & $5.5 \%$ & $11.1 \%$ & $56.4 \%$ & $22.0 \%$ & $5.1 \%$ \\
\hline $\begin{array}{l}\text {...I will feel better since I know I have done everything I } \\
\text { can to understand my smoking addiction. }\end{array}$ & $12.6 \%$ & $21.6 \%$ & $50.3 \%$ & $14.1 \%$ & $1.4 \%$ \\
\hline ...I will feel relieved by the results. & $7.8 \%$ & $15.8 \%$ & $43.1 \%$ & $29.5 \%$ & $3.7 \%$ \\
\hline ...I will be proud of myself. & $9.0 \%$ & $21.3 \%$ & $52.5 \%$ & $14.8 \%$ & $2.4 \%$ \\
\hline ...I will be happy that I know my genetic risk. & $9.5 \%$ & $19.9 \%$ & $45.5 \%$ & $21.3 \%$ & $3.7 \%$ \\
\hline ...I will feel reassured. & $12.6 \%$ & $21.6 \%$ & $50.3 \%$ & $14.1 \%$ & $1.4 \%$ \\
\hline \multicolumn{6}{|l|}{ Self-efficacy } \\
\hline \multicolumn{6}{|l|}{ Do you believe you will be able to... } \\
\hline ...undergo a genetic test? & $7.5 \%$ & $18.2 \%$ & $38.0 \%$ & $20.3 \%$ & $16.0 \%$ \\
\hline ....ask you GP for a genetic test when you have a need for it? & $7.2 \%$ & $20.4 \%$ & $39.7 \%$ & $20.1 \%$ & $12.6 \%$ \\
\hline ...understand the results of the genetic test? & $3.2 \%$ & $8.0 \%$ & $48.9 \%$ & $27.3 \%$ & $12.6 \%$ \\
\hline $\begin{array}{l}\text {...undergo the correct treatment based on the results of the } \\
\text { genetic test? }\end{array}$ & $4.6 \%$ & $10.6 \%$ & $49.2 \%$ & $17.5 \%$ & $18.1 \%$ \\
\hline
\end{tabular}




\section{Test characteristics}

The most important test characteristic according to the participants of this study is reliability (Figure S6); $82 \%$ of the participants believed this to be (very) important. Other test characteristics were also indicated as (very) important by most participants; covered by insurance $(78 \%)$, a low price $(74 \%)$, a sharp increase in cessation rates (71\%), and a fast result (65\%).

Most participants (64.7\%) indicated not to be willing to pay more than $€ 50$ for the genetic test. About a quarter of the participants (24.2\%) are willing to pay $€ 50-€ 150$, $8.9 \%$ will pay $€ 150-€ 200$, and only $2.2 \%$ is willing to pay more than $€ 200$.

\section{Intention to undergo genetic testing}

Only a low number of participants (16.6\%) were (completely) interested in undergoing a genetic test to determine which smoking cessation therapy they could use best (13.2\% and $16.6 \%$, respectively) (see Table S4). From the remaining participants, slightly less than half were (completely) not interested in undergoing a genetic test (43.5\%) and about the same proportion was undecided as to whether or not they would be willing to undergo a genetic test $(40.0 \%)$.

The intention to undergo genetic testing increased considerably when it would be offered by their GP (38.3\%). On the other hand, only $7.8 \%$ would ask their GP for the genetic test, while about half of the participants (50.6\%) would not ask their GP for the test.

\section{DISCUSSION}

Significant advances have been made in elucidating the role of genetic factors in nicotine dependence and response to smoking cessation treatment. Although much work still remains to be done, the use of genetic testing for increasing quit rates by geneticallytailored smoking cessation treatment in clinical practice is on the horizon. However, at present few studies have investigated the needs and attitudes of smokers on this subject. Therefore, in this study we investigated knowledge, attitudes, and preferences of smokers on genetics of smoking, and their willingness to undergo genetic testing for smoking addiction and treatment.

This study provides valuable information, which can aid decisions on the most appropriate strategies for counseling patients and communicating their test results.

The results showed that misconceptions regarding smoking cessation rates using current smoking cessation (pharmaco)therapies need attention. Even though most smokers knew it is important to quit smoking, only about half of them knew that less than half of the smokers who want to quit smoking will succeed. In practice cessation rates are even much lower; only $15-30 \%$ will succeed in long-term quitting using the available treatments [5] and these rates are even lower when no treatment is used. Since smokers overestimate their chances to be able to quit smoking using the current (pharmaco)therapies, they might underestimate the positive effects of a genetic test 
for smoking. However, we should be careful with presenting this information to smokers, since this might also demotivate smokers to start a quit attempt.

The knowledge level on the influence of genetic factors on smoking addiction and cessation, and possibly also basic mechanisms of heredity, is highly inadequate and should be addressed as well. These results are comparable with a previous study [12], which also found that smokers, ex-smokers and non-smokers had little knowledge about genetic contributions to smoking and smoking-related behaviours. Furthermore, the most popular topics for receiving more information were the working mechanism of a genetic test, where more information about the genetic background of smoking can be found, and the influence of genetic differences on (smoking cessation) treatments. This confirms the lack of knowledge about the influence of genetics on smoking and smoking cessation that was found in this study. Moreover, about one-third of the participants were also interested in more information on what a genetic predisposition is and how DNA works, indicating a further lack of knowledge on genetics in general.

Besides, smokers seem to considerably underestimate their chances of having a genetic predisposition and the influence of this on smoking and smoking cessation, which could lead to an underestimation of the importance of undergoing a genetic test for smoking as well. Respondents were found to perceive the probability of having a genetic predisposition to be (very) small to average, even though many of the genetic variants that have been shown to influence smoking behavior are prevalent in the population $[13,14]$. Comparable results were found by another study [12], in which 53\% perceived themselves as "not at all likely" or "somewhat likely" to have inherited a genetic predisposition to smoking, while $47 \%$ perceived themselves to be "moderately" to "extremely likely". Furthermore, we found that most participants did not belief that a genetic predisposition is a (very) important cause of smoking, while it has been shown that genetic factors account for a vast part of the variance in smoking initiation, maintenance and cessation success [5-8]. In the previous mentioned study also only a small part of the participants believed that inheriting a gene that predisposes them to smoke is the most important factor that causes people to smoke, although smokers were significantly more likely to agree with this [12]. Recently, we have shown in a theoretical modelling study based on the results of this survey, that smokers who perceive a higher susceptibility or severity have a higher intention to undergo genetic testing [15]. Thus increasing awareness of the probability and consequences of having a genetic predisposition might also be an effective strategy to motivate smokers to undergo a genetic test for smoking cessation.

Moreover, participants were found to perceive little disadvantages of genetic testing for smoking addiction and cessation, but some advantages. Only a small part of the participants in this study were concerned that the results would become known at their work or to their employer, their health insurance or other agencies, and that it would become more difficult to get a mortgage or life-insurance when a genetic test would show that they were addicted to smoking. On the contrary, research in other areas has shown that those in the USA are particularly concerned about the potential for genetic test results to become available to their employer, health insurance or life insurance $[16,17]$. These differences might be explained by the difference in 
laws in place to protect against the misuse of genetic information by employers and insurers. In some countries genetic testing is explicitly regulated with regard to all aspects (e.g. Austria, Netherlands and Norway), in others the regulation has focused only on the insurance industry (e.g. Denmark, and Sweden) or even only on group health insurers (e.g. USA) [18]. Therefore, to motivate smokers to undergo a genetic test they could be made more aware of the advantages of genetic testing as well. However, disadvantages should not be under-represented either, because smokers may than inaccurately perceive the benefits and risks associated with genetic testing. Since fear has been shown to decrease intention to undergo genetic testing in our theoretical modelling study [15], increasing awareness of advantages and disadvantages could decrease fear for genetic testing and might thereby result in an increased uptake of a genetic test for smoking cessation.

Uptake might be further increased when smoker's ability to undergo a genetic test and deal with the results (e.g. self-efficacy) is improved. Currently, only $30-40 \%$ of the participants believed to be able to cope with a genetic test for smoking cessation. In our theoretical modelling study intention to undergo genetic testing was found to increase when smokers feel they would be able to cope with the results [15].

Finally, it seems that smokers allocate their GPs a crucial role in the provision of information on this subject and the delivery of a genetic test for smoking. Thus, it seems likely that GPs will play an important role in the counseling of patients about undergoing genetic testing. However, several studies indicate that they may not have the knowledge, willingness or training to take on this role [19-22]. Many GPs were not sure if they would be able to understand the meaning of genetic test results, how such information should direct clinical care, and their ability to effectively communicate genetic information to patients [21]. Furthermore, physicians are concerned that integrating genetic testing into their practice would also add to their already restricted time constraints [21].

Thus, for successful implementation of genetic testing for smoking in general practice, several issues should be addressed, such as the knowledge on smoking cessation, genetics and genetic testing (including advantages and disadvantages), and the influence of genetics on smoking addiction and cessation. Of course patients are not expected to be experts in this field. However, patients will need to have a certain level of insight on this subject. Without this knowledge, smokers will not be able to understand the test and the results properly. Therefore, they will not be able to make an accurate decision whether or not to undergo a genetic test for smoking nor to undergo the right treatment based on the results. GPs are likely to play an important role in the information provision, since they will have to help their patients to make the decision to undergo a genetic test and provide them with the treatment based on this test. However, due to the time-constraints it will probably not possible for a GP to fully explain this test to their patients during a consult. And furthermore, patients might not be interested in such a test if they do not have some knowledge about the influence of genetic factors on smoking and smoking cessation. Therefore, these issues should also be addressed via other channels of communication; for instance information leaflets or information campaigns on TV, radio or in magazines or newspapers. 
This study is subject to several limitations.

Firstly, the field of pharmacogenetic influences on smoking cessation is still in its infancy, and therefore no well-accepted tests to tailor smoking cessation treatment are commonly available. However, it is of crucial importance to investigate the expectations of the smokers that are willing to quit before a genetic test can be developed that will enter the market. This knowledge on smokers' expectations can drive the implementation, promotional strategy and the information given when the test will become available. Therefore, from a health promotion and marketing perspective it is appropriate to start asking these questions at this time.

Secondly, as smokers may not be familiar with genetic testing for smoking addiction and genetically-tailored cessation treatments, or even genetics in general, it is questionable whether they were able to give a well-considered answer to all our questions.

Thirdly, as Sanderson and colleagues argued [23], interest in undergoing genetic testing may reflect a generally positive attitude towards genetic testing rather than actual uptake. Thus, to determine actual uptake of genetic testing further studies are needed were respondents are offered the possibility to undergo genetic testing.

Fourthly, our sample underrepresented smokers intending to stop smoking, which could have led to an underestimation of the willingness to undergo genetic testing.

Fifthly, since participants were recruited via an internet research company, selection bias might have occurred, due to the non-representative nature of the internet population and the self-selection of participants (volunteer effect). The effect of bias due to the non-representative nature of the internet population will probably be minimal, since no difference in internet use is expected among smokers. The potential for self-selection bias can be estimated by measuring the response rate; the fairly high response rate $(83 \%)$ decreases the chance for selection bias. Furthermore, several studies have shown that the validity and reliability of data obtained online are comparable to those obtained by classical methods [24-28].

Finally, since this survey was conducted among Dutch smokers only, the results might not be completely generalisable to other smoking populations. Genetic testing is explicitly regulated in the Netherlands [18], therefore it is to be expected that smokers perceive less disadvantages of genetic testing than smokers in other countries were regulation is less explicit. Smokers are thus likely to perceive more disadvantages of genetic testing in countries with less regulation, as has been found in the USA $[16,17]$, which might decrease their intention to undergo genetic testing for smoking cessation. Furthermore, the level of education is likely to influence the knowledge level. However, since the education level in the Netherlands is relatively high, and even here the knowledge level is low, it is not to be expected that the knowledge level is adequate in other countries. Indeed, comparable results have been found before [12]. Moreover, in the Netherlands, the GP plays a central role in the provision of health care and that is probably why Dutch smokers allocate their GPs an important role in the provision of information and the genetic test itself. This could be different for countries with another healthcare system. However, it is to be expected that intention will be increased when it is offered by the primary health care provider in other countries as well, regardless of the type of primary health care provider. However, 
the general conclusions will probably also apply to other countries. And the results from this study also provide a good starting point for the investigation of this issue among other populations.

In general, we may conclude that Dutch smokers are interested in genetic testing for smoking cessation, especially when offered by their GP. However, before successful implementation of genetic testing for smoking in general practice will be possible, several issues should be addressed, such as the knowledge on smoking cessation, genetics and genetic testing (including advantages and disadvantages), and the influence of genetics on smoking addiction and cessation. Furthermore, GPs attitudes and knowledge should be addressed as well.

\section{REFERENCES}

1. Guindon GE, Boisclair D. Past, current and future trends in tobacco use. HNP discussion paper no.6. Economics of tobacco control paper no. 6. 2003.

2. World Health Organization. The world health report 2003 - shaping the future; 2003.

3. Mucha L, Stephenson J, Morandi N, Dirani R. Meta-analysis of disease risk associated with smoking, by gender and intensity of smoking. Gend Med. 2006; 3(4): 279-291.

4. Taylor DH, Jr., Hasselblad V, Henley SJ, Thun MJ, Sloan FA. Benefits of smoking cessation for longevity. Am J Public Health. 2002; 92(6): 990-996.

5. Quaak M, van Schayck CP, Knaapen AM, van Schooten FJ. Genetic variation as a predictor of smoking cessation success. A promising preventive and intervention tool for chronic respiratory diseases? Eur Respir J. 2009; 33(3): 468-480.

6. Li MD, Cheng R, Ma JZ, Swan GE. A meta-analysis of estimated genetic and environmental effects on smoking behavior in male and female adult twins. Addiction. 2003; 98(1): 23-31.

7. Munafo MR, Johnstone EC. Genes and cigarette smoking. Addiction. 2008; 103(6): 893-904.

8. Kaprio J. Genetic epidemiology of smoking behavior and nicotine dependence. COPD 2009; 6(4): 304-306.

9. Kortmann GL, Dobler CJ, Bizarro L, Bau CH. Pharmacogenetics of smoking cessation therapy. Am J Med Genet B Neuropsychiatr Genet. 2010; 153B(1): 17-28.

10. Quaak M, van Schayck CP, Knaapen AM, van Schooten FJ. Implications of gene-drug interactions in smoking cessation for improving the prevention of chronic degenerative diseases. Mutat Res. 2009; 667(1-2): 44-57.

11. Heatherton TF, Kozlowski LT, Frecker RC, Fagerstrom KO. The Fagerstrom Test for Nicotine Dependence: a revision of the Fagerstrom Tolerance Questionnaire. Br J Addict. 1991; 86(9): 1119-1127.

12. Houfek JF, Atwood JR, Wolfe RM, Agrawal S, Reiser GM, Schaefer GB, Rennard SI. Knowledge and beliefs about genetics and smoking among visitors and staff at a health care facility. Public Health Nurs. 2008; 25(1): 77-87.

13. Lerman C, Caporaso N, Main D, Audrain J, Boyd NR, Bowman ED, Shields PG. Evidence suggesting the role of specific genetic factors in cigarette smoking. Health Pschology. 1999; 18(1): 14-20.

14. Batra V, Patkar AA, Berrettini WH, Weinstein SP, Leone FT. The Genetic Determinants of Smoking. Chest. 2003; 123: 1730-1739.

15. Smerecnik C, Quaak M, van Schayck CP, van Schooten FJ, de Vries H. Are smokers interested in genetic testing for smoking addiction? A socio-cognitive approach. Psychol Health.2011 [Epub ahead of print]

16. Lapham EV, Kozma C, Weiss JO. Genetic discrimination: perspectives of consumers. Science. 1996; 274(5287): 621-624. 
17. Hall MA, McEwen JE, Barton JC, Walker AP, Howe EG, Reiss JA, Power TE, Ellis SD, Tucker DC, Harrison BW, McLaren GD, Ruggiero A, Thomson EJ. Concerns in a primary care population about genetic discrimination by insurers. Genet Med. 2005; 7(5): 311-316.

18. Murthy A, Dixon A, Mossialos E. Genetic testing and insurance. J R Soc Med. 2001; 94(2): 57-60.

19. Baars MJ, Henneman L, Ten Kate LP. Deficiency of knowledge of genetics and genetic tests among general practitioners, gynecologists, and pediatricians: a global problem. Genet Med. 2005; 7(9): 605-610.

20. Shields AE, Blumenthal D, Weiss KB, Comstock CB, Currivan D, Lerman C. Barriers to translating emerging genetic research on smoking into clinical practice. Perspectives of primary care physicians. J Gen Intern Med. 2005; 20(2): 131-138.

21. Park ER, Kleimann S, Pelan JA, Shields AE. Anticipating clinical integration of genetically tailored tobacco dependence treatment: perspectives of primary care physicians. Nicotine Tob Res. 2007; 9(2): 271-279.

22. Suther S, Goodson P. Barriers to the provision of genetic services by primary care physicians: a systematic review of the literature. Genet Med. 2003; 5(2): 70-76.

23. Sanderson SC, O'Neill SC, Bastian LA, Bepler G, McBride CM. What can interest tell us about uptake of genetic testing? Intention and behavior amongst smokers related to patients with lung cancer. Public Health Genomics. 2010; 13(2): 116-124.

24. Krantz JH, Ballard J, Scher J. Comparing the results of laboratory and World-Wide Web samples on the determinants of female attractiveness. Behav Res Methods Instrum Comput. 1997; 29(2): 264-269.

25. Buchanan T, Smith JL. Using the Internet for psychological research: personality testing on the World Wide Web. Br J Psychol. 1999; 90 ( Pt 1): 125-144.

26. Buchanan T, Smith JL. Research on the Internet: validation of a World-Wide Web mediated personality scale. Behav Res Methods Instrum Comput. 1999; 31(4): 565-571.

27. Nathanson AT, Reinert SE. Windsurfing injuries: results of a paper- and Internet-based survey. Wilderness Environ Med. 1999; 10(4): 218-225.

28. Senior C, Phillips ML, Barnes J, David AS. An investigation into the perception of dominance from schematic faces: a study using the World-Wide Web. Behav Res Methods Instrum Comput. 1999; 31(2): 341-346. 
SMOKERS' KNOWLEDGE, ATtITUdes, AND PREFERENCES 149 
Introduction Recent research strongly suggests that genetic variation influences smokers' ability to stop. Therefore, the use of (pharmaco)genetic testing may increase cessation rates. This study aims to assess the intention of GPs to offer genetic testing for smoking addiction and cessation, and their knowledge, attitudes and preferences about this subject.

Methods: GPs' knowledge, attitudes, preferences and their intention to provide genetic testing were assessed using a cross-sectional survey among 53 Dutch GPs and 18 students.

Results: Most GPs undertake smoking cessation activities. However, knowledge on the efficacy of smoking cessation therapy was found to be relatively low, and even lower for the influence of genetic factors in smoking addiction and cessation. Most GPs felt they were not able to offer a genetic test and to deal with the results and they perceived some advantages and disadvantages of genetic testing for smoking. Furthermore, most GPs felt that more information and the genetic test should be provided by GPs. And most GPs were interested in providing a genetic test for smoking addiction, but even more for smoking cessation.

Conclusions: GPs were interested in offering a genetic test, especially to determine which smoking cessation therapy could be used best. However, for successful implementation of genetic testing for smoking in general practice, several issues should be addressed, such as the knowledge on efficacy of smoking cessation therapies, genetics and genetic testing (including advantages and disadvantages). 


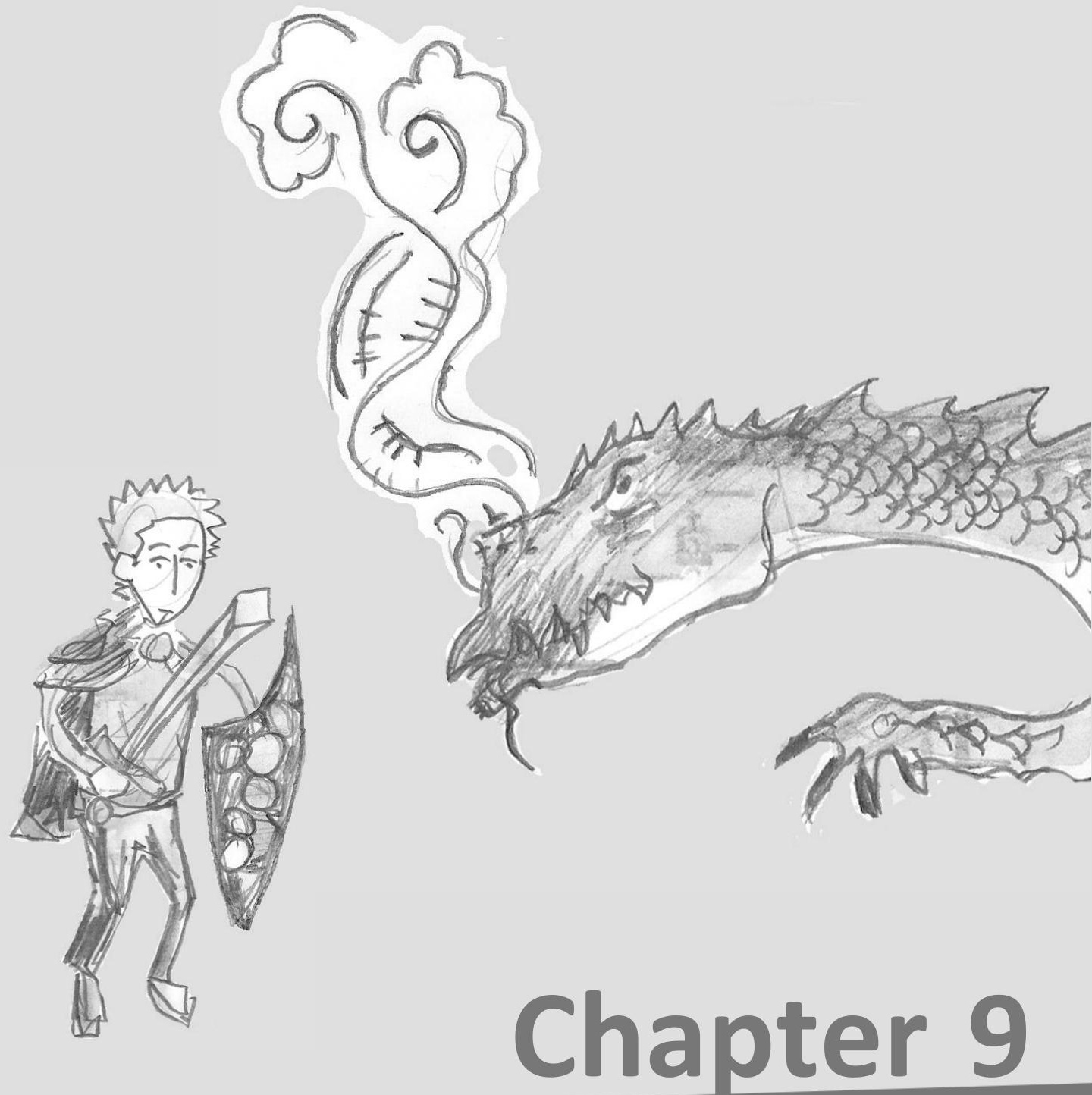

GPs KNOWLEDGE, ATTITUDES, AND PREFERENCES

REGARDING GENETIC TESTING FOR SMOKING CESSATION

Marieke Quaak, Chris Smerecnik, Frederik J. van Schooten, Hein de Vries, Constant P. van Schayck.

In preparation. 


\section{INTRODUCTION}

With currently still over 1.2 billion smokers world-wide, tobacco smoking continues to be the largest preventable cause of disease and premature death [1-3]. Cessation reverses most adverse effects of smoking [4]. Although most smokers are highly motivated to quit, and many (pharmacological) treatments are available to help them, cessation rates remain low; the average 12-month success rate ranges from 15 to $30 \%$ [5], but substantial variability exists in success rates across smokers. Therefore, multiple quit attempts are often required.

Recent research strongly suggests that smokers vary in their underlying genetic susceptibility to become addicted to smoking and their ability to stop smoking [5-8]. Genetic variation may also influence a smoker's response to a particular smoking cessation pharmacotherapy. Hence, overall effectiveness of smoking cessation pharmacotherapy may potentially be increased if it will be targeted at smokers most likely to respond to a particular type of pharmacotherapy. Reviews concerning preliminary findings of studies investigating the effect of genetic polymorphisms on smoking cessation suggest promising effects $[5,9,10]$, making the use of (pharmaco)genetic testing for smoking in clinical practice for increasing quit rates by genetically-tailored smoking cessation treatment in the near future more likely.

Future implementation of (pharmaco)genetic testing for smoking in daily medical practice, however, will ultimately depend upon smokers' and health care providers' acceptance of these tests. The insufficient number of trained medical geneticists and the fact that GPs are the first contact for patients who want to quit, makes it very likely that general practitioners (GPs) will play an important role in the provision of genetic testing for smoking. Furthermore, in a previous study among Dutch smokers we found that they were interested in receiving information and participating in genetic testing for smoking, especially when offered by their GP [11]. However, several studies have shown that GPs may not have the knowledge, willingness or training to take on this role [12-15].

The goal of this study, therefore, is to investigate the intention of GPs to offer genetic testing for smoking, and their knowledge, attitudes, and preferences (such as topics and channels of interest, and test characteristics) concerning a genetic test for smoking. This information could be used to guide the future development of a (pharmaco)genetic test for smoking and its implementation in daily medical practice. Both GPs and students were included in this study, because we expected that the knowledge level and attitudes regarding genetic testing might be different for these two groups, since the education about genetics in the medical study has changed substantially over the years.

\section{METHODS}

\section{Study design}

GPs' and students' knowledge, attitudes, and preferences and their intention to offer genetic testing for smoking were assessed using a cross-sectional survey. 


\section{Recruitment}

GPs were selected from the database of the Coordination bureau First Line Care (CEL) of the department of General Practice of the University of Maastricht. All selected GPS worked in practices located in the south of the Netherlands. A paper questionnaire was send to their practice.

Furthermore, students from the General Practice training of Maastricht University were approached via their education coordinator. They received a digital version of the questionnaire, which they were asked to fill in and then return via e-mail.

In total, $200 \mathrm{GPs}$ and 187 students were approached for this study. A total of 55 GPs and 19 students responded. However, 2 questionnaires (GPs) were not completely filled out and from 1 (students) data could not be obtained. As a result, a total of 53 GPs and 18 students were included in the present study (response rates of $26.5 \%$ and $9.6 \%$, respectively).

\section{Questionnaire}

The questionnaire was conducted in Dutch (questions in manuscript translated by the authors) and took about 30 minutes to complete. Respondents were compensated for their time with the possibility of being randomly selected for a gift-certificate.

The questionnaire was comparable to the questionnaire used before to test knowledge, attitudes and preferences of smokers concerning genetic testing for smoking [16]. An extensive description of the questionnaire can be found in the supplementary methods. In short, the questionnaire contained items regarding participant characteristics, smoking cessation activities, knowledge about smoking cessation, the influence of genetics on smoking addiction and smoking cessation, attitudes towards genetic testing (e.g. perceived ability, advantages and disadvantages), test characteristics, channels of interest for providing smokers with more information regarding a genetic test for smoking and for actually providing the genetic test itself, and intention of GPs to offer a genetic test to their patients.

\section{RESULTS}

\section{Participant characteristics}

Participant characteristics, separate for GPs and students, can be found in Table 1. About two-third (69.1\%) of the GPs was male and one-third (30.9\%) female, while this was reversed among the students ( $22.2 \%$ and $77.8 \%$, respectively). The average age of the GPs was 51.8 (SD=8.4, range: $33-64$ ) and 30.8 ( $S D=5.0$, range: $26-46)$ for the students. GPs graduated between 8 and 37 years ago $(M=25.1, S D=8.3)$ and have been working as a GP for 4-37 years ( $M=21.1, S D=9.3)$. Students graduated between 1 and 19 years ago $(M=3.9, S D=4.1)$. The GPs worked on average 44.2 hours/week $(S D=13.0$, range: $6-70)$, while the students work on average 36.0 hours/week ( $S D=3.5$, range: $30-38)$. GPs worked in practices where, on average, work about 2-3 GPs (including themselves), while 
Table 1: Baseline characteristics of GPs and students

\begin{tabular}{|c|c|c|c|c|c|c|}
\hline & \multicolumn{3}{|c|}{ GPs $(n=53)$} & \multicolumn{3}{|c|}{ students $(\mathrm{N}=18)$} \\
\hline & No. / M & $\% / S D$ & range & No. / M & $\% / S D$ & range \\
\hline \multicolumn{7}{|l|}{ Demographics } \\
\hline \multicolumn{7}{|l|}{ Gender (No., \%) } \\
\hline male & 38 & 69.1 & & 4 & 22.2 & \\
\hline female & 17 & 30.9 & & 14 & 77.8 & \\
\hline Age $(\text { mean, SD) })^{5}$ & 51.8 & 8.4 & $33-64$ & 30.8 & 5.0 & $26-46$ \\
\hline Years since graduation (mean, SD) ${ }^{b}$ & 25.1 & 8.3 & $8-37$ & 3.9 & 4.1 & $1-19$ \\
\hline Years as GP $\left(\right.$ mean, SD) ${ }^{c}$ & 21.1 & 9.3 & $4-37$ & - & - & - \\
\hline Working hours (mean, SD) ${ }^{d}$ & 44.2 & 13.0 & $6-70$ & 36.0 & 3.5 & $30-38$ \\
\hline Number of GPs at practice (mean, SD) ${ }^{d}$ & 2.6 & 1.6 & $1-8$ & 4.4 & 2.5 & $2-10$ \\
\hline \multicolumn{7}{|l|}{ Smoking characteristics } \\
\hline \multicolumn{7}{|l|}{ Smoking status } \\
\hline Current smoker & 3 & 5.7 & & 3 & 16.7 & \\
\hline Former smoker & 18 & 34.0 & & 2 & 11.1 & \\
\hline Never smoker & 32 & 60.4 & & 13 & 72.2 & \\
\hline \multicolumn{7}{|l|}{ Cessation characteristics } \\
\hline \multicolumn{7}{|l|}{ Former smokers } \\
\hline Time since cessation, years (mean, SD) & 20.6 & 10.4 & $6-41$ & 6.7 & 5.7 & $2-13$ \\
\hline \multicolumn{7}{|l|}{ Current smokers } \\
\hline Previously attempted to quit (No., \%) & 3 & 5.5 & & 2 & 11.1 & \\
\hline No. of previous attempts to quit (mean, SD) & 4.3 & 4.9 & $1-8$ & 5.7 & 8.1 & $1-10$ \\
\hline Period until last quit attempt, years (mean, SD) & 5.7 & 8.1 & $1-15$ & 5.3 & 6.7 & $0-10$ \\
\hline
\end{tabular}

students seemed to work, on average, in bigger practices with about 4-5 GPs. Of the GPs $5.7 \%$ was currently smoking, $34.0 \%$ was a former smoker, and $60.4 \%$ had never smoked. Slightly more students (72.2\%) had never smoked, fewer (11.1\%) were former smokers and more were current smokers (16.7\%). GPs had stopped smoking between 6 and 41 years ago $(M=20.6, S D=10.4)$ and students $2-13$ years ago $(M=6.7, S D=5.7)$. Of the current smokers, $5-10 \%$ had previously attempted to quit. On average they had attempted 4.4 times to quit ( $S D=4.3$, range: 1-10); this was slightly higher among students compared to GPs. And their last quit attempt was $0-15$ years ago $(M=5.5, S D=6.6)$.

\section{Smoking cessation activities}

Most participants (78.9\%) indicated that they regularly ask their patients about their smoking status during a consult, while $4.2 \%$ always asks their patients, and $16.9 \%$ only sometimes (Table S5). About $20 \%$ will also always advise their smoking patients to stop, $63.4 \%$ will do this regularly, $14.1 \%$ sometimes and $1.4 \%$ never.

When a patient wants to quit, $11.3 \%$ would always prescribe medication, $60.6 \%$ regularly, $26.8 \%$ sometimes and $1.4 \%$ never. The preference of the patient would always determine the type of medication for $22.5 \%$ of the participants, regularly for $47.9 \%$, sometimes for $28.2 \%$ and never for $1.4 \%$. And $22.4 \%$ would also always refer their patients to a smoking cessation program or expert, while $41.4 \%$ would do this regularly, $34.3 \%$ sometimes and $2.8 \%$ would never do so. 
In about half of the practices (52.2\%) there was always a trained staff member available to advice patients who want to quit, regularly in $34.8 \%$ of the practices, sometimes in $5.8 \%$ and never in $7.2 \%$.

\section{Knowledge}

Table 2 presents the percentage of correct, and "don't know" answers for the knowledge statements.

The first set of statements concerned respondents' knowledge about smoking cessation. All of the participants knew that it is important to quit, even if you already smoke for a long time. Furthermore, all students and almost all GPs (98.1\%) knew that this will decrease the risk for smoking-related diseases. About two-third (67.6\%) knew that less than half of the smokers who want to quit succeed, while $14.1 \%$ could not answer this question. Significantly more women than men and less older participants (50-65 years) could not answer this question, and more GPs than students seemed to know this, however this difference was not significant.

The second set measured whether respondents were aware of how genetic factors influence smoking addiction levels. The lowest percentage of correct scores were found for the statements regarding the existence of genes that decrease the chance of becoming addicted to smoking, and the transfer of a genetic predisposition to the offspring by a non-smoking parent ( $8.5 \%$ and $15.5 \%$, respectively); more than two-third could not answer these questions $(76.1 \%$ and $69.0 \%$, respectively). Women were significantly more likely to know that smoking addiction is influenced by genetic factors. None of the students knew that a genetic predisposition is also transferred when a parent does not smoke and the number of participants in the middle age group (30-49 years) that could answer this question was about twice as low as in the other groups. Slightly more than half $(57.7 \%)$ knew that the chance to become addicted to smoking is influenced by genes, while $38.0 \%$ could not answer this question. Women were significantly more likely to answer this correctly. Slightly less than half $(47.9 \%)$ knew that genes exist that increase the chance to become addicted to smoking, and about half could not answer this question (49.3\%).

The third set assessed knowledge of the influence of genetic factors on smoking cessation and smoking cessation treatment. About half of the respondents could not answer these questions (45.1-57.7\%). About half knew that a genetic predisposition might also influence ones chances to quit (49.3\%), and about one-third that it can make cessation therapy more effective for certain smokers (28.2\%), and influences the chance on withdrawal symptoms during cessation (29.6\%). Only $14.1 \%$ knew that a genetic predisposition can also make a cessation therapy less effective for certain smokers. Women were significantly more likely to know that a genetic predisposition can make a smoking cessation therapy more effective, and also more students seemed to be able to answer this question correctly (non-significant). Older participants (50-65 years) were significantly more likely not to know that a genetic predisposition can also influence the chance on withdrawal symptoms.

Furthermore, almost all participants believed that environment and personal behavior were (very) important causes for smoking (both 99\%), while only about half $(51 \%)$ believed this to be the case for genetic predisposition (Figure S7). 


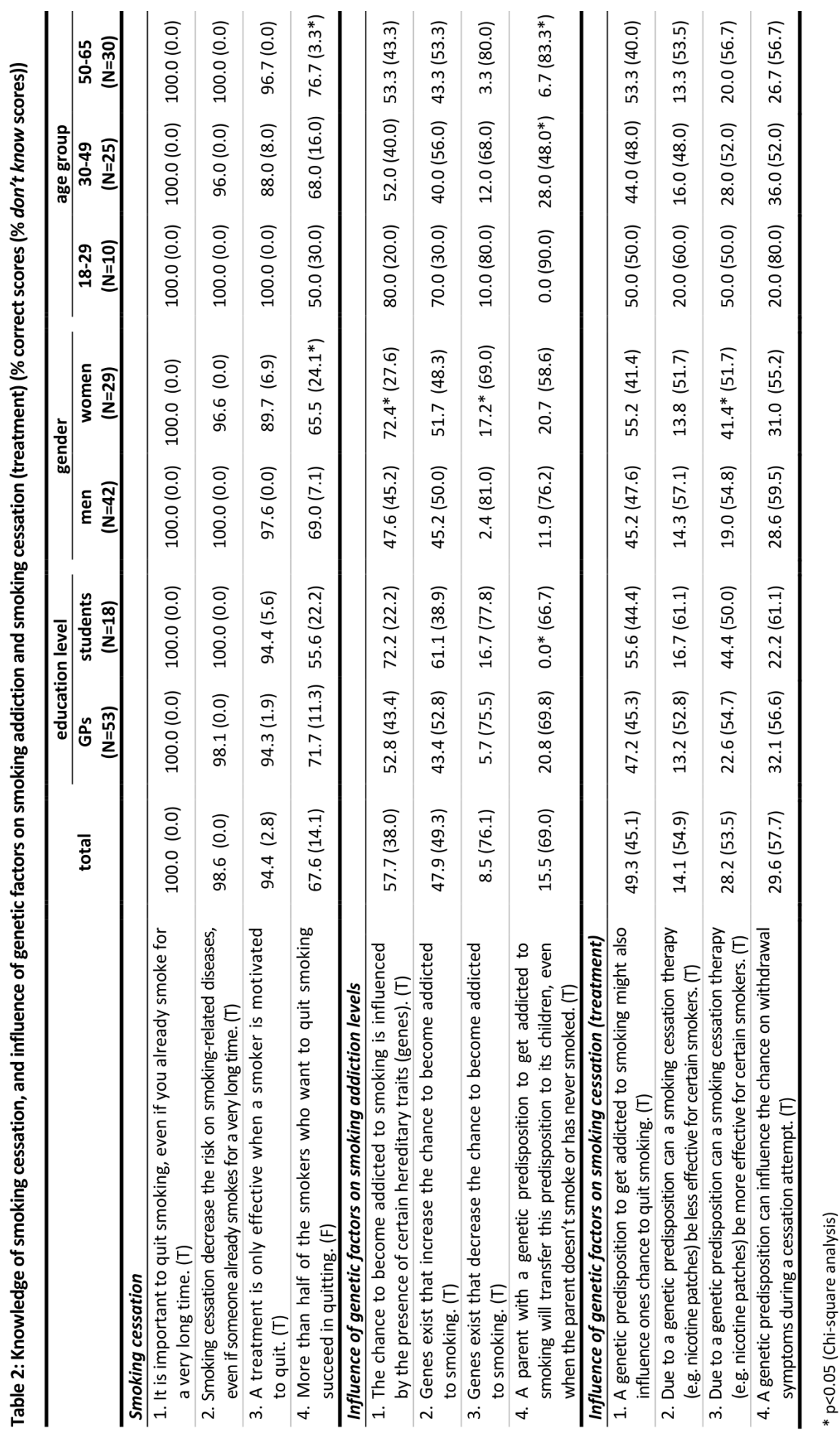




\section{Attitudes}

We assessed the attitudes of participants regarding their ability to offer a genetic test (in general) and to deal with the results (Table S6). About one-quarter believed that the treatment time per patient is not sufficient to offer a genetic test $(23.2 \%)$, slightly more (29\%) that the treatment time is sufficient, and the remaining participants (47.8\%) were undecided. Most GPs (73.3\%) believed they did not have sufficient knowledge to be able to offer a genetic test to their patients, while only $4.2 \%$ believed they would have sufficient knowledge for this. Furthermore, about half believed they did not have sufficient knowledge to understand the results of a genetic test (54.9\%), to explain the results of a genetic test to a patient (47.9\%), or to prescribe the right treatment based on the results (57.7\%). And only $15.5 \%, 25.3 \%$, and $12.7 \%$, respectively, believed to have sufficient knowledge to do this.

Furthermore, attitudes regarding the advantages and disadvantages of genetic testing for smoking were assessed (Table 3). Only about 10.0-42.2\% (completely) agreed, while about half to two-third (45.1-70.0\%) had a neutral reaction and. $1.4-29.4 \%$ (completely) disagreed with the statements on the advantages of genetic testing. Participants were least convinced that a genetic test could help to determine the correct dose of smoking cessation medication and could decrease the chance on side-effects from smoking cessation treatments ( $10.0 \%$ and $11.8 \%$ (completely) agreed, respectively). On the other hand, $42.2 \%$ (completely) agreed with the statement that a genetic test will increase the motivation of smokers. Only a few participants (completely) disagreed with the statements that a genetic test will give a reliable result about a genetic predisposition to become addicted to smoking, and that it will indicate the correct smoking cessation therapy ( $1.4 \%$ and $4.3 \%$, respectively).

About two-fifthof the participants (completely) agreed with most of the statements about the disadvantages of genetic testing, about one-third had a neutral reaction to most of the statements, and the amount that (completely) disagreed varied between $15.5 \%$ and $44.2 \%$. Especially the chance that the results would become known at work or to the employer was perceived as low (21.4\% (completely) agreed and $44.2 \%$ (completely) disagreed). Also, only $23.1 \%$ (completely) agreed that a genetic test can also reveal information about a predisposition to other diseases, $17.3 \%$ (completely) disagreed, and $59.4 \%$ had a neutral reaction. On the other hand, participants were most convinced that patients who have been found to be addicted will have more difficulty to get a mortgage or life-insurance (53.5\% (completely) agreed), and that focusing on the biological factors will decrease the interest in psychological and behavioural factors (48.5\%).

\section{Selection criteria}

Most participants believed that a genetic test for smoking should not be used for patients who never tried to stop before, patients with smoking-related diseases, and patients with a familiar risk for smoking-related disease $(59 \%, 62 \%$, and $62 \%$ (completely) disagreed, respectively) (Figure S8). Only a small proportion believed a genetic test should be used for these groups (11\%, $8 \%$ and $7 \%$, respectively). 


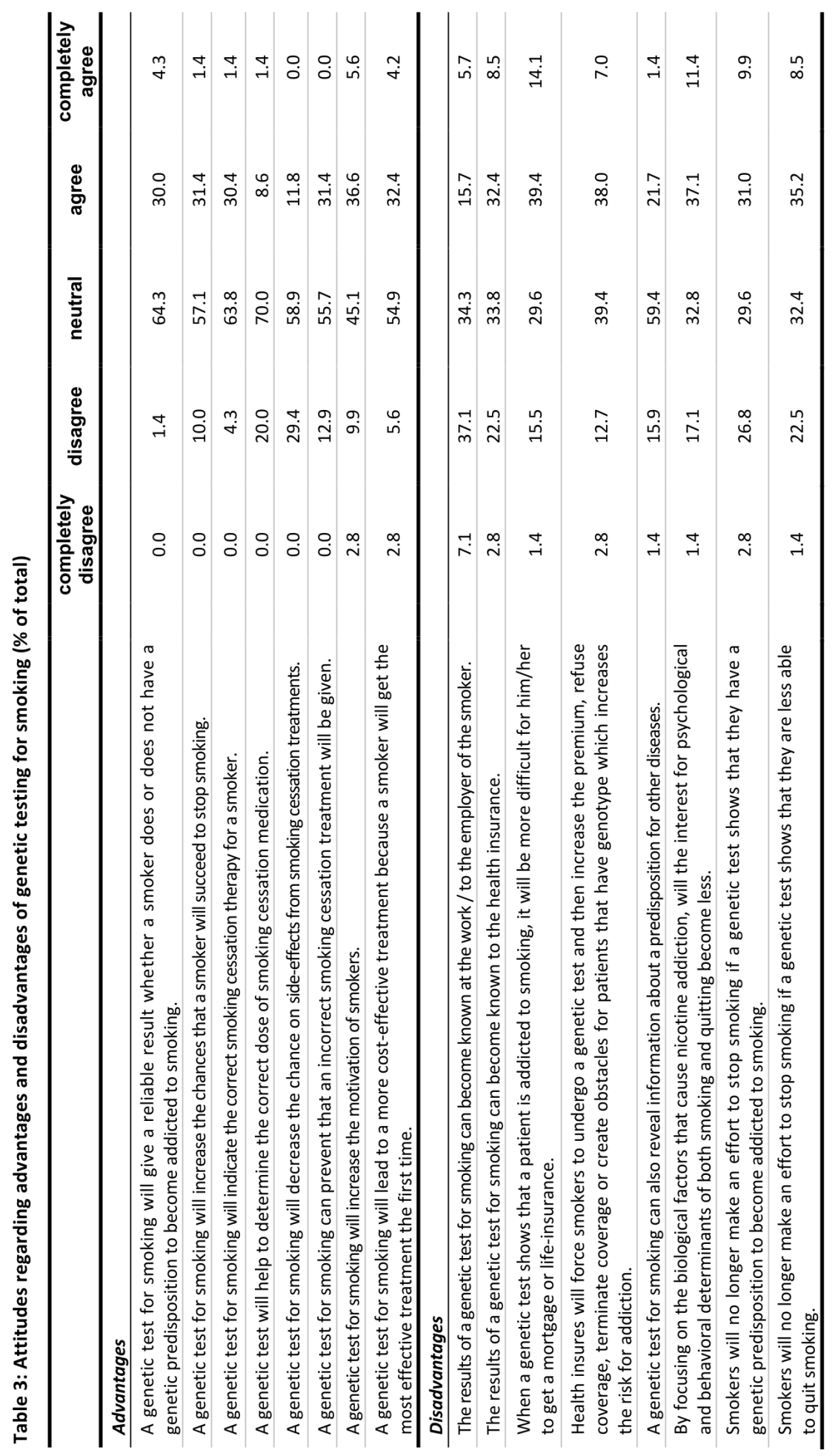


On the other hand, participants were slightly more positive about using a genetic test for smoking for patients who have exhausted all treatment options and non-smoking patients or starting smokers to prevent them from starting or continuing to smoke; $35 \%$ and $25 \%$, respectively (completely) agreed with this, $30 \%$ and $35 \%$, respectively, (completely) disagreed and $35 \%$ and $40 \%$, respectively, had a neutral reaction to this.

\section{Test characteristics}

The most important test characteristic according to the participants of this study was reliability (Figure S9); $100 \%$ of the participants believed this to be (very) important. Furthermore, almost all also believed that easily performable and a sharp increase in cessation rates was (very) important ( $97 \%$ and $95 \%$, respectively). Other test characteristics, however, were also indicated as (very) important by most of the participants; covered by insurance (79\%), a low price (74\%), and a fast result (58\%).

Most participants would like to receive an overview of variants with an explanation of the effects of these variants in combination with an overview of the expected success rates per treatment (39.4\%). Furthermore, $18.3 \%$ would like to receive only the overview of the variants with explanation, $15.5 \%$ only the expected success rates per treatment, $9.9 \%$ only which smoking cessation treatment is most effective, and $1.4 \%$ only an overview of the genetic variants.

\section{Channels of interest}

Most participants (85.7\%) would prefer that smokers would be able to get more information regarding a genetic test for smoking via their GPs (Figure S10-A). Other channels via which GPs would prefer smokers to be able to get more information were specialists (58.6\%), the internet (47.1\%), leaflets (37.1\%), genetic counsellor $(34.3 \%)$, TV $(28.6 \%)$, magazines $(28.6 \%)$, newspapers $(27.1 \%)$, radio $(20.0 \%)$, a telephonic help-desk $(12.9 \%)$, friends $(8.6 \%)$, books $(7.1 \%)$, a nurse practitioner $(2.8 \%)$, or pharmacist $(1.4 \%)$.

Most participants (74.6\%) would also prefer smokers to be able to actually obtain the genetic test via their GPs (Figure S10-A). Other preferred channels for obtaining the test were specialists (23.9\%), genetic counsellor (8.5\%), and the pharmacy $(2.8 \%)$, while $7.0 \%$ was not interested in offering a genetic test.

\section{Intention to offer genetic testing}

About two-third of the participants (67.6\%) were (completely) interested in offering their patients a genetic test to determine if they are addicted to smoking, and only $15.5 \%$ was (completely) not interested. Even slightly more participants were (completely) interested in offering their patients a genetic test to determine which smoking cessation therapy could be used best ( $80.3 \%), 8.5 \%$ had a neutral reaction, and only $11.2 \%$ was (completely) not interested.

Next we investigated which variables influenced interest to offer a genetic test (Table 4). A median-split procedure was used to determine whether participants were interested or not in offering a genetic test ( $<3$ : not interested; $\geq 3$ : interested). 
Intention to offer genetic testing (combined for smoking addiction and cessation) was found to be significantly influenced by the perceived ability and advantages; participants were more likely to be interested in offering a genetic test when they felt more able to offer a genetic test and to deal with the results (2.5 vs. 2.0, respectively) and perceived more advantages of genetic testing for smoking (3.2 vs. 2.8). The association with genetic predisposition as a cause of smoking approached significance; participants who perceive genetic predisposition as a more important cause of smoking (3.5 vs. 2.9) seemed to be more interested in offering a genetic test. Furthermore, it seems that female participants might be more interested in offering a genetic test for smoking, as well as current smokers, while former smokers seemed less interested in offering a genetic test for smoking. However, no significant effects were found.

Table 4: Factors influencing intention to undergo genetic testing

\begin{tabular}{|c|c|c|c|c|c|c|}
\hline & \multicolumn{2}{|c|}{ combined score } & \multicolumn{2}{|c|}{ for smoking addiction } & \multicolumn{2}{|c|}{ determine best therapy } \\
\hline & $\begin{array}{c}\text { not interested } \\
(\mathrm{N}=9)\end{array}$ & $\begin{array}{c}\text { interested } \\
(\mathrm{N}=62)\end{array}$ & $\begin{array}{c}\text { not interested } \\
(\mathrm{N}=11)\end{array}$ & $\begin{array}{c}\text { interested } \\
(N=60)\end{array}$ & $\begin{array}{c}\text { not interested } \\
(\mathrm{N}=8)\end{array}$ & $\begin{array}{c}\text { interested } \\
(\mathrm{N}=63)\end{array}$ \\
\hline \multicolumn{7}{|l|}{ Demographic characteristics } \\
\hline Gender, women (no., \%) ${ }^{a}$ & $2(22.2)$ & $27(43.5)$ & $5(45.5)$ & $24(40.0)$ & $1(12.5)$ & $28(44.4)$ \\
\hline Age, years (mean, SD) ${ }^{b}$ & $50.1(10.1)$ & $45.8(12.3)$ & $44.1(11.3)$ & $46.8(12.2)$ & $50.1(10.1)$ & $45.8(12.3)$ \\
\hline \multicolumn{7}{|l|}{ Education level (no., \%) ${ }^{a}$} \\
\hline GP & $7(77.8)$ & $46(74.2)$ & $11(100.0)$ & $60(84.5)$ & 7 (87.5) & $46(73.0)$ \\
\hline student & $2(22.2)$ & $16(25.8)$ & $4(36.4)$ & $14(23.3)$ & $1(12.5)$ & $17(27.0)$ \\
\hline Years since graduation (mean, SD) ${ }^{b}$ & $20.3(11.2)$ & $19.4(12.1)$ & $16.0(11.5)$ & $20.2(12.0)$ & $22.5(9.8)$ & $19.1(12.2)$ \\
\hline Years working as GP (mean, SD) ${ }^{b}$ & $16.0(11.4)$ & $15.6(12.5)$ & $11.6(10.6)$ & $16.4(12.5)$ & $18.0(10.4)$ & $15.3(12.6)$ \\
\hline Working hours (mean, SD) ${ }^{b}$ & $45.0(15.0)$ & $43.0(12.3)$ & $44.6(15.6)$ & $43.0(12.2)$ & $45.0(15.0)$ & $43.0(12.3)$ \\
\hline Number of GPs (mean, SD) ${ }^{\mathrm{C}}$ & $3.0(2.4)$ & $2.9(1.8)$ & $2.3(1.6)$ & $3.0(1.9)$ & $3.0(2.4)$ & $2.9(1.8)$ \\
\hline \multicolumn{7}{|l|}{ Smoking status (no.,\%) } \\
\hline current & $4(44.4)$ & $41(66.1)$ & $6(66.7)$ & $39(62.9)$ & $4(50.0)$ & $41(65.1)$ \\
\hline former & $4(44.4)$ & $16(25.8)$ & $3(33.3)$ & $17(27.4)$ & $3(37.5)$ & $17(27.0)$ \\
\hline never & $1(11.1)$ & $5(8.1)$ & $2(22.2)$ & $4(6.5)$ & $1(12.5)$ & $5(7.9)$ \\
\hline \multicolumn{7}{|c|}{ Smoking cessation activities (0: never - 3: always) } \\
\hline Ask smoking status ${ }^{c}$ & $1.7(0.5)$ & $1.9(0.4)$ & $1.6(0.5)$ & $1.9(0.4)^{*}$ & $1.6(0.5)$ & $1.9(0.4)$ \\
\hline Advise to stop unasked ${ }^{c}$ & $1.9(0.8)$ & $2.1(0.6)$ & $1.7(0.8)$ & $2.1(0.6)^{*}$ & $1.9(0.8)$ & $2.1(0.6)$ \\
\hline Prescribing cessation therapyc & $1.7(0.7)$ & $1.8(0.6)$ & $1.6(0.9)$ & $1.9(0.6)$ & $1.8(0.7)$ & $1.8(0.6)$ \\
\hline Preference patient $^{\mathrm{c}}$ & $1.7(0.7)$ & $2.0(0.8)$ & $1.6(0.5)$ & $2.0(0.8)$ & $1.8(0.7)$ & $1.9(0.8)$ \\
\hline Referral of patients willing to stop ${ }^{c}$ & $1.8(1.3)$ & $1.8(0.7)$ & $1.8(1.2)$ & $1.8(0.7)$ & $1.9(1.4)$ & $1.8(0.7)$ \\
\hline Trained staff member available ${ }^{c}$ & $2.0(1.1)$ & $2.4(0.9)$ & $2.0(1.1)$ & $2.4(0.8)$ & $2.1(1.1)$ & $2.3(0.9)$ \\
\hline \multicolumn{7}{|l|}{ Knowledge (0: low - 2: high) } \\
\hline Smoking cessation $^{c}$ & $1.6(0.1)$ & $1.6(0.2)$ & $1.5(0.1)$ & $1.6(0.2)^{*}$ & $1.6(0.1)$ & $1.6(0.2)$ \\
\hline Genetics of addiction $^{c}$ & $0.8(0.6)$ & $0.7(0.6)$ & $0.9(0.6)$ & $0.7(0.6)$ & $0.7(0.6)$ & $0.8(0.6)$ \\
\hline Genetics of cessation (therapy) ${ }^{c}$ & $0.8(0.6)$ & $0.8(0.7)$ & $0.9(0.7)$ & $0.8(0.6)$ & $0.8(0.6)$ & $0.8(0.7)$ \\
\hline \multicolumn{7}{|c|}{ Importance as cause of smoking (1: very unimportant - 5: very important) } \\
\hline Environment (mean, SD) ${ }^{\mathrm{C}}$ & $4.6(0.5)$ & $4.7(0.5)$ & $4.5(0.7)$ & $4.7(0.5)$ & $4.5(0.5)$ & $4.7(0.5)$ \\
\hline Personal behavior $(\text { mean, } \mathrm{SD})^{\mathrm{c}}$ & $4.6(0.7)$ & $4.5(0.5)$ & $4.6(0.7)$ & $4.5(0.5)$ & $4.5(0.8)$ & $4.5(0.5)$ \\
\hline Genetic predisposition (mean, SD) ${ }^{\mathrm{c}}$ & $2.9(1.2)$ & $3.5(0.8)$ & $3.1(1.2)$ & $3.5(0.9)$ & $2.9(1.3)$ & $3.5(0.8)$ \\
\hline \multicolumn{7}{|c|}{ Attitudes (1: completely disagree - 5: completely agree) } \\
\hline Ability (mean, SD) ${ }^{c}$ & $2.0(0.6)$ & $2.5(0.8)^{*}$ & $2.2(0.6)$ & $2.5(0.8)$ & $2.0(0.7)$ & $2.5(0.8)^{*}$ \\
\hline Advantages $(\text { mean, } S \mathrm{SD})^{\mathrm{c}}$ & $2.8(0.7)$ & $3.2(0.4)^{*}$ & $2.9(0.7)$ & $3.2(0.3)$ & $2.9(0.7)$ & $3.2(0.4)$ \\
\hline Disadvantages (mean, SD) ${ }^{c}$ & $3.3(0.6)$ & $3.2(0.6)$ & $3.3(0.5)$ & $3.2(0.6)$ & $3.3(0.6)$ & $3.2(0.6)$ \\
\hline
\end{tabular}


Participants who more often ask their patients about their smoking status (1.9 vs. 1.6), advise them more often to quit smoking even when their smoking patients do not ask for it themselves (2.1 vs. 1.7), and have a higher knowledge about smoking cessation (1.6 vs. 1.5) were significantly more interested in offering a genetic test for smoking addiction. The association with perceived ability and advantages was not significant, but the same trend as for the overall score was observed, and the association did approach significance. Other associations that approached significance were that interest was higher when working longer as a GP (16.4 years vs. 11.6 years) and when working in a practice with more other GPs (3.0 vs. 2.3).

Interest in a genetic test to determine the most appropriate smoking cessation therapy was only significantly influenced by the perceived ability of participants to offer a genetic test and to deal with the results; a higher ability score (2.5 vs. 2.0) was associated with a higher intention to offer a genetic test. However, several of the previously found associations also approached significance, e.g. interest in genetic testing seemed higher among female participants, among participants who perceive more advantages (3.2 vs. 2.9) and find genetic predisposition a more important cause of smoking (3.5 vs. 2.9), and among participants who more often ask their patients about their smoking status.

\section{DISCUSSION}

Significant advances have been made in elucidating the role of genetic factors in nicotine dependence and the response to smoking cessation treatment. Although much work still remains to be done, the use of (pharmaco)genetic testing for increasing quit rates by genetically-tailored smoking cessation treatment in clinical practice is on the horizon. In a previous study we found that smokers were mildly interested in receiving information and participating in genetic testing, especially when offered by their GP [11]. However, at present few studies have investigated the needs and attitudes of GPs on this subject. Therefore, in this study we investigated knowledge, attitudes, and preferences of GPs on genetics of smoking, and their willingness to offer genetic testing for smoking addiction and treatment to their patients.

Firstly, the results showed that GPs regularly ask their patients about their smoking status, advise them to stop smoking even when their patients do not ask for it, and prescribe medication when patients want to stop. And in most of the practices there is always or regularly a trained staff member available to advice patients who want to quit. Thus it seems that most GPs and practices follow current smoking cessation guidelines to routinely ask patients about their smoking status and to stimulate them to quit, contrary to previously reported results from the USA $[17,18]$.

Secondly, knowledge regarding smoking cessation was found to be relatively high, although about one-third did not know that currently less than half of the smokers who want to quit will be able to quit. In practice cessation rates are even much lower; only $15-30 \%$ will succeed in long-term quitting using the available treatments and these rates are even lower when no treatment is used [5].Knowledge about the influence of genetic factors on smoking addiction and smoking cessation (treatment) was found to be much lower. Although slightly more than half did know that the 
chance to become addicted to smoking is influenced by genetic factors, about half of the participants could not answer further questions about this relationship, and the number of correct answers varied from only $8.5 \%$ to $49.3 \%$. Contrary to our expectations, no clear differences were found between GPs and students. Our findings are consistent with previous studies in other fields, which also documented a lack of knowledge about genetics [19-22].

Thirdly, we found that although most participants believed that environment and personal behaviour are an important cause of smoking, only about half believed that a genetic predisposition is a (very) important cause of smoking. Contrary to their expectations, it has been shown that genetic factors account for a vast part $(50-70 \%)$ of the variance in smoking initiation, maintenance and cessation success [5-8].

Fourthly, about a quarter of participants believed that the time available per patient is not sufficient to offer a genetic test. This confirms the results of previous studies were physicians expressed there concerns that integrating genetic testing into their practice would add to their already restricted time constraints [15, 23]. Furthermore, most participants believed they do not have sufficient knowledge to be able to offer a genetic test, to understand the results, to explain the results to patients, and to prescribe the right treatment based on the results. These results are comparable to the results of previous studies, in which many GPs reported that they were not sure if they would be able to understand the meaning of genetic test results, how such information should direct clinical care, and if they would be able to effectively communicate genetic information to patients [15, 23-26].

Fifthly, GPs perceived some advantages and some disadvantages of genetic testing for smoking. Participants were least convinced that a genetic test could help to determine the correct dose of smoking cessation therapy and could decrease the chance on sideeffects from it. They were most convinced that it could help to increase the motivation of smokers. This is comparable with the results of a previous study, which also found that physicians felt the greatest benefit was to better direct treatment and therefore increasing the motivation for quitting and many physicians also saw potential in using the genetic test as a preventive tool for non-smoking patients [15]. Only a small part of the participants in this study were concerned that the results would become known at work or to the employer $(21.4 \%)$ and that it could also reveal information about a predisposition to other diseases (23.1\%). On the other hand, about half of the participants were concerned that it would become more difficult to get a mortgage or lifeinsurance when a genetic test would show that they were addicted to smoking. On the contrary, our previous study showed that only a small number of Dutch smokers were concerned about this [11].

Furthermore, most participants felt GPs should provide smokers with more information on a genetic test for smoking and that the actual genetic test should also be provided by GPs. This is consistent with the expectations of Dutch smokers, who would prefer to obtain more information and the genetic test itself via their GPs [11].

Finally, most GPs seemed interested in offering a genetic test to determine whether a smoker is addicted to smoking (67.6\%) and even more interested in offering a test to determine which smoking cessation therapy should be used (80.3\%). This is comparable to the results of a previous study by Shields et al $[14,27]$. Intention to offer genetic 
testing was found to be higher among GPs who ask their patients more often about their smoking status and advise them to stop even when the do not ask for it, who have more knowledge about smoking cessation, who perceive a higher ability to deal with a genetic test and its results, and who perceive more advantages. Possibly gender, smoking status and perceived importance of genetic factors as a cause for smoking also influence intention to offer genetic testing.

This study is subject to several limitations.

Firstly, our sample size was small. The power of the study might have been to low to detect small differences. Some of the associations with intention to offer a genetic test approached significance, and might become significant in a larger population. Therefore, this study should be repeated in a larger population to confirm the results that have been found in this study and to further investigate the trends that were observed for some of the other variables in this study.

Secondly, as a genetic test for smoking addiction and genetically-tailored cessation treatments is not yet commonly available, some GPs might have found it difficult to answer some of the questions. However, these answers can provide us with valuable information which can be used during the development and implementation of such a test.

Thirdly, since all participants came from the south of the Netherlands (province of Limburg), this might have biased the results. Since there is only one medical faculty in this area, it is likely that most of the GPs attended the same university. The lack of knowledge might thus reflect the lack of genetic education at this university, rather than a general lack of genetic education in the Netherlands. Furthermore, since much research on smoking and smoking cessation is done at Maastricht University, it is likely that these GPs have come into contact with more research on this subject and that there knowledge is therefore more updated. This might explain the high adherence to smoking guidelines.

Finally, due to the low response rate (26.5\% for GPs and $9.6 \%$ for students) selection bias might have occurred. However, several GPs that were not at all interested in this subject also returned the questionnaire. This population is known to be difficult to reach, and in general low response rates are achieved.

Despite the limitations described above, this study provides valuable information, which can aid decisions on the most appropriate strategies for implementing a genetic test for smoking in daily clinical practice.

Firstly, misconceptions regarding smoking cessation rates using current smoking cessation (pharmaco)therapies need attention. Since GPs overestimate smoking cessation rates of current (pharmaco)therapies, they might underestimate the positive effects of a genetic test for smoking. However, we should be careful with presenting this information, since this might also demotivate GPs to help smokers during a quit attempt.

Secondly, the knowledge level on the influence of genetic factors on smoking addiction and cessation, and possibly also basic mechanisms of heredity, should be addressed. Currently, GPs seem to underestimate the influence of genetic factors on smoking addiction and cessation, which might lead to an underestimation of the importance of a genetic test for smoking. 
Thirdly, GPs will need to feel more able to understand the test and the results properly, and to communicate these results to their patients. Improving knowledge might help for this, but also teaching GPs counselling strategies might make them feel more assure about their capabilities to offer a genetic test.

Furthermore, arrangements should be made to make sure that enough time (and money) will be available to offer genetic testing and proper counselling (before and after genetic testing).

Finally, to motivate GPs to offer a genetic test they could be made more aware of the advantages of genetic testing and disadvantages should be addressed as well. GPs should be made more aware of the laws in place to protect people undergoing a genetic test.

In general, we may conclude that most Dutch GPs are interested in offering a genetic test for smoking addiction and even slightly more in a genetic test to determine the most effective smoking cessation therapy. However, GPs still have much to learn about this subject to make a successful implementation in daily practice possible.

\section{REFERENCES}

1. Guindon GE, Boisclair D. Past, current and future trends in tobacco use. HNP discussion paper no.6. Economics of tobacco control paper no. 6. 2003.

2. World Health Organization. The world health report 2003 - shaping the future; 2003.

3. Mucha L, Stephenson J, Morandi N, Dirani R. Meta-analysis of disease risk associated with smoking, by gender and intensity of smoking. Gend Med. 2006; 3(4): 279-291.

4. Taylor DH, Jr., Hasselblad V, Henley SJ, Thun MJ, Sloan FA. Benefits of smoking cessation for longevity. Am J Public Health. 2002; 92(6): 990-996.

5. Quaak M, van Schayck CP, Knaapen AM, van Schooten FJ. Genetic variation as a predictor of smoking cessation success. A promising preventive and intervention tool for chronic respiratory diseases? Eur Respir J. 2009; 33(3): 468-480.

6. Li MD, Cheng R, Ma JZ, Swan GE. A meta-analysis of estimated genetic and environmental effects on smoking behavior in male and female adult twins. Addiction. 2003; 98(1): 23-31.

7. Munafo MR, Johnstone EC. Genes and cigarette smoking. Addiction. 2008; 103(6): 893-904.

8. Kaprio J. Genetic epidemiology of smoking behavior and nicotine dependence. COPD. 2009; 6(4): 304-306.

9. Kortmann GL, Dobler CJ, Bizarro L, Bau CH. Pharmacogenetics of smoking cessation therapy. Am J Med Genet B Neuropsychiatr Genet. 2010; 153B(1): 17-28.

10. Quaak M, van Schayck CP, Knaapen AM, van Schooten FJ. Implications of gene-drug interactions in smoking cessation for improving the prevention of chronic degenerative diseases. Mutat Res. 2009; 667(1-2): 44-57.

11. Quaak M, Smerecnik C, van Schooten FJ, De Vries H, van Schayck CP. Knowledge, attitudes, and preferences regarding genetic testing for smoking cessation. A cross-sectional survey among Dutch smokers. BMJ Open 2011 [accepted with minor revisions].

12. Suther $S$, Goodson P. Barriers to the provision of genetic services by primary care physicians: a systematic review of the literature. Genet Med. 2003; 5(2): 70-76.

13. Baars MJ, Henneman L, Ten Kate LP. Deficiency of knowledge of genetics and genetic tests among general practitioners, gynecologists, and pediatricians: a global problem. Genet Med. 2005; 7(9): 605-610. 
14. Shields $A E$, Blumenthal D, Weiss KB, Comstock CB, Currivan D, Lerman C. Barriers to translating emerging genetic research on smoking into clinical practice. Perspectives of primary care physicians. J Gen Intern Med. 2005; 20(2): 131-138.

15. Park ER, Kleimann S, Pelan JA, Shields AE. Anticipating clinical integration of genetically tailored tobacco dependence treatment: perspectives of primary care physicians. Nicotine Tob Res. 2007; 9(2): 271-279.

16. Quaak M, van Schayck CP, Postma DS, Wagena EJ, van Schooten FJ. Genetic variants in the serotonin transporter influence the efficacy of bupropion and nortriptyline in smoking cessation. Addiction. 2011.

17. Jaen CR, Stange KC, Tumiel LM, Nutting P. Missed opportunities for prevention: smoking cessation counseling and the competing demands of practice. J Fam Pract. 1997; 45(4): 348-354.

18. Thorndike AN, Rigotti NA, Stafford RS, Singer DE. National patterns in the treatment of smokers by physicians. JAMA. 1998; 279(8): 604-608.

19. Stratakis CA, Cavuto NJ, Nelson D, Rennert OM. Molecular genetics in pediatric training: how much do we really know? Md Med J. 1995; 44(3): 210-213.

20. Fetters MD, Doukas DJ, Phan KL. Family physicians' perspectives on genetics and the human genome project. Clin Genet. 1999; 56(1): 28-34.

21. Watson EK, Shickle D, Qureshi N, Emery J, Austoker J. The 'new genetics' and primary care: GPs' views on their role and their educational needs. Fam Pract. 1999; 16(4): 420-425.

22. Emery J, Hayflick S. The challenge of integrating genetic medicine into primary care. BMJ. 2001; 322(7293): 1027-1030.

23. Suchard MA, Yudkin P, Sinsheimer JS. Are general practitioners willing and able to provide genetic services for common diseases? J Genet Counsel. 1999; 8(5): 301-311.

24. Hunter A, Wright $P$, Cappelli M, Kasaboski A, Surh L. Physician knowledge and attitudes towards molecular genetic (DNA) testing of their patients. Clin Genet. 1998; 53(6): 447-455.

25. Emery J, Watson E, Rose $P$, Andermann A. A systematic review of the literature exploring the role of primary care in genetic services. Fam Pract. 1999; 16(4): 426-445.

26. Freedman AN, Wideroff L, Olson L, Davis W, Klabunde C, Srinath KP, Reeve BB, Croyle RT, Ballard-Barbash R. US physicians' attitudes toward genetic testing for cancer susceptibility. Am J Med Genet A. 2003; 120A(1): 63-71.

27. Shields AE, Levy DE, Blumenthal D, Currivan D, McGinn-Shapiro M, Weiss KB, Yucel R, Lerman C. Primary care physicians' willingness to offer a new genetic test to tailor smoking treatment, according to test characteristics. Nicotine Tob Res. 2008; 10(6): 1037-1045. 


\section{SUPPLEMENTARY METHODS}

\section{Questionnaire}

\section{Participant characteristics}

Participants' age and gender were assessed. Furthermore, graduation year, years working as a GP, hours working as GP, and the number of GPs working at their practice were recorded. In addition, participants were asked questions regarding their smoking behaviour (smoking status and quit attempts).

\section{Smoking cessation activities}

Participants were asked to indicate the frequency of several smoking cessation activities done by them or at the practice they work to stimulate smokers to stop (e.g. ask smoking status, advise to stop even when not asked by smoker, prescribing of cessation therapy, referral of patients willing to stop smoking to specialist, and is a trained staff member available to advice smokers willing to stop). Participants were asked to indicate whether this occurs never, sometimes, regularly or always.

\section{Knowledge}

Knowledge was assessed using 13 statements (see Table 2); five regarding smoking cessation in general, four regarding the influence of genetics on nicotine dependence, and four regarding the influence of genetics on smoking cessation (treatment). Participants were asked whether they agreed or disagreed with the statements, or did not know the answer. In addition, participants were asked how important environment, personal behaviour and genetic predisposition were according to them as a cause for smoking (1: very unimportant - 5: very important).

\section{Attitudes}

The attitudes of GPs about their ability to offer a genetic test (in general) and to deal with the results were assessed (1: completely disagree - 5: completely agree; see Table 3). Further, attitudes towards undergoing genetic testing for smoking were assessed by 8 questions on the perceived advantages and 8 questions on the disadvantages (1: completely disagree - 5: completely agree; see Table 4).

\section{Selection criteria}

Criteria based on which patients should or should not be selected for genetic testing for smoking according to GPs were assessed, e.g. 1) only smokers who have not tried to stop before, 2) only smokers who have exhausted all other treatment options, 3) non-smokers or starting smokers to assess possible increased risk to get addicted to prevent them from starting or continuing to smoke, 4) only patients with a smoking-related disease, or 5) only patients were smoking-related diseases occur in the family (1: completely disagree - 5: completely agree). 


\section{Test characteristics}

Participants were asked how important a number of test characteristics (easily performable, reliability, fast result, sharp increased cessation rates, low price, covered by insurance) were for them when they would consider to undergo a genetic test to help them stop smoking (1: very unimportant - 5: very important). Further, GPs were asked in which manner they would like to receive the results of a genetic test for smoking. The could choose between one or more of the following manners: 1) overview variants, 2) overview variants with an explanation of their effects, 3) expected success percentages different treatments, 4) which treatment will be most effective.

Channels for obtaining information and genetic test

Participants were asked via which channels smokers should be able to get more information regarding a genetic test to help them stop smoking, and via which channels the test should be made available.

Intention to offer genetic testing

Participants were asked if they were planning to offer a genetic test to determine if a smoker is addicted to smoking or which smoking cessation therapy could be use best (1: strongly disagree - 5: strongly agree). 





GENERAL DISCUSSION 
Although the risk of cigarette smoking is well documented, smoking continues to be the largest preventable cause of disease and premature death throughout the world. It is estimated that there are currently still over 1.5 billion smokers and this is expected to rise to about 1.6-1.9 billion by 2025 [1-4]. This is partly because of an increase in the adult population, and partly because of an increased consumption in the lowand middle-income countries and among teenagers and women in high-income countries, while the smoking prevalence among men in the high-income countries is declining $[1,3]$.

Smoking harms nearly every organ of the body, causing many diseases and compromising health of smokers in general. Even at low levels of intensity, smoking raises the risk of disease to about 3 times that of non-smokers and the risk increases even more with a higher intensity of smoking [5-6]. Health consequences of smoking include many of the diseases with the highest world-wide prevalence, such as cancer, cardiovascular disease (CVD), and chronic respiratory diseases such as chronic obstructive pulmonary disease (COPD) and asthma [1]. Moreover, about half of all smokers who continue to smoke will eventually die from a smoking-related disease, resulting in over 6 million deaths world-wide per year [1,4-5,7-8]. And this number might even increase to about 10 million by 2030, which means that currently about 1 in 10 deaths is related to smoking, but that this figure could rise to 1 in 6 by $2030[1,5,9]$.

Cessation reverses most adverse effects of smoking [10-12]. Smoking cessation as early as possible is important, but cessation at any age results in meaningful life extensions $[11,13]$. However, although the majority of smokers are highly motivated to quit, both smokers and healthcare practitioners are confronted with high relapse rates after initial successful smoking cessation attempts. Even with a combination of pharmacological and behavioural therapy, only $5-30 \%$ of the smokers continue to abstain from smoking [14-22] and therefore often multiple quit attempts are required.

Recent research strongly suggests that smokers vary in their underlying genetic susceptibility to become addicted to smoking [23-31] and might also influence the efficacy of pharmacotherapies used for smoking cessation. Therefore, cessation rates might be increased by genetic-tailoring of smoking cessation therapy. This is expected to result in a more efficient use of smoking cessation therapies, increased cessation rates and ultimately, in reduced deaths from smoking. To accomplish this, the effect of multiple susceptibility genes as well as their mutual interactions on several smoking cessation therapies will have to be investigated to make genetically based personalized treatments in the near future possible.

Therefore, in this thesis we investigated the relevance and possibilities of determining multiple genetic variants in smoking-related genes to predict the efficacy of different smoking cessation therapies. For this, we have investigated which candidate genes contribute to the variation in nicotine dependence (ND). Subsequently, the effect of genetic variants on smoking cessation therapy was investigated. And finally, the knowledge, attitudes and preferences of both smokers and GPs regarding a genetic test for smoking were investigated to determine possibilities and barriers for the implementation of such a genetic test in daily medical practice.

Here the main findings will be summarized, the implications of these results will be discussed and directions for future research will be formulated. 


\section{MAIN FINDINGS}

\section{Genetic influences on nicotine dependence}

In order to identify genes and genetic variants that may influence smoking behaviour, we first performed a literature review (Chapter 2). Research has been focused on two broad classes of genes. First, since nicotine is the primary reward component in tobacco products, genes that may influence the response to nicotine (e.g. nicotine metabolism and nicotinic receptors) are biologically plausible candidates. The major genes responsible for the metabolism of nicotine are the hepatic enzymes cytochrome P450 2A6 (CYP2A6) and 2D6 (CYP2D6) [32,33] and in the presence of low CYP2A6 activity, the CYP2B6 enzyme might also influence nicotine metabolism. The pharmacological effects of nicotine are mediated by the activation of nicotinic acetylcholine receptors (nAChRs), mainly of they $\alpha 4 \beta 2 *$ subtype (* indicates that another subunit may be included) [34-36], and variants in the genes coding for the different nAChR subunits $\left(\alpha_{2}-\alpha_{10}\right.$ and $\left.\beta_{2}-\beta_{4}\right)$ may therefore also influence the response to nicotine. A second group of candidate genes consists of those that predispose to addictive behaviour due to their effects on key neurotransmitter pathways. Since the mesolimbic dopamine system plays an important role in nicotine's rewarding effects [37-40], the association between smoking behaviour and variants in several genes involved in the dopamine pathway has been investigated, such as receptors, transporter, and enzymes involved in the synthesis and metabolism. Furthermore, nicotine enhances serotonin release and diminished serotonergic neurotransmission has been associated with symptoms of nicotine withdrawal [41-44]. Candidate polymorphisms include those involved in serotonin biosynthesis and re-uptake (e.g. transporter). Overall, it seems that smokers with a reduced nicotine metabolism and increased dopamine levels are less addicted to smoking, smoke fewer cigarettes, have an increased likelihood of quitting and quit for a longer period of time. In contrast, smokers with an increased nicotine metabolism and reduced dopamine levels seem to be more addicted, have a higher chance of becoming a smoker, a younger age of onset, smoke more cigarettes, and undergo fewer and less succesfull quit attempts. There also seems to be a relationship with variants in the nicotinic acetylcholinic receptors and the serotonin pathway, but the nature of this relationship is not yet clear.

Based on this literature review, and further literature on this subject, 35 genetic variants in 19 candidate genes were selected which were expected to influence smoking behaviour (see Table 1). In Chapter 3 the effect of these genetic variants on level of nicotine dependence (ND), as measured by the Fagerström Test of Nicotine Dependence (FTND) and level of addiction (e.g. low: FTND-score<6 or high: FTND-score $\geq 6$ ) was investigated among smokers participating in four smoking or smoking cessation trials. Several variants in genes in smoking-related pathways were found to influence ND (e.g. CHRNA4, CYP2B6, DRD2, COMT, SLC6A4, OPRM1, HINT-1, and ARRB2). Overall, genetic variants or combinations of variants that increase the sensitivity for smoking, due to a reward deficit (e.g. decreased dopamine receptor binding and density, increased serotonin re-uptake) or higher binding capacity (e.g. increased $\beta$-endorphin binding capacity), resulted in increased FTND scores. On the other hand, genetic variants 
Table 1: Selected genetic variants in smoking-related and treatment-related pathways

\begin{tabular}{|c|c|c|c|}
\hline gene & chromosome & variants & function \\
\hline \multicolumn{4}{|c|}{ Genes influencing the response to nicotine } \\
\hline CYP2A6 & $19 q 13.2$ & rs1801272, rs28399433 & nicotine metabolism \\
\hline CYP2D6 & $22 q 13.2$ & rs382097, rs5030655 & ncotine metabolism (nortriptyline metabolism) \\
\hline CYP2B6 & $19 q 13.2$ & rs3745274, rs2279343, rs3211371 & ncotine metabolism (bupropion metabolism) \\
\hline CHRNA2 & $8 p 21.2$ & rs2292974, rs2292975 & nicotinic receptor subunit \\
\hline CHRNA4 & 20q13.33 & rs2236196, rs6122429 & nicotinic receptor subunit \\
\hline CHRNB2 & $1 q 21.3$ & rs2072661 & nicotinic receptor subunit \\
\hline \multicolumn{4}{|c|}{ Genes influencing key neurotransmitter pathways } \\
\hline DRD2 & $11 q 23.2$ & rs1800497, rs6277, rs180128, rs1799732 & dopamine receptor (DRD) \\
\hline FREQ & $9 q 34.11$ & rs1054879 & DRD-interacting protein \\
\hline SLC6A3 & $5 p 15.33$ & 3'UTR VNTR & dopamine transporter \\
\hline COMT & $22 q 11.21$ & rs737865, rs4680, rs1265599 & dopamine metabolism \\
\hline$M A O-A$ & Xp11.3 & uVNTR, rs17998325 & dopamine metabolism \\
\hline$D B H$ & $9 q 34.2$ & rs4531, rs 77905 & dopamine metabolism \\
\hline TPH1 & $11 \mathrm{p} 15.1$ & rs1799913 & serotonin synthesis \\
\hline TDO2 & $4 q 32.1$ & rs10517626 & serotonin synthesis \\
\hline SLC6A4 & $17 q 11.2$ & STin2, 5-HTTLPR, rs25531 & serotonin transporter \\
\hline OPRM1 & $6 q 25.2$ & rs1799971 & $\mu$-opioid receptor (MOR) \\
\hline HINT1 & $5 q 23.3$ & rs3852209 & MOR-interacting protein \\
\hline ARRB2 & $17 p 13.2$ & rs3786047 & MOR-interacting protein \\
\hline CHAT & $10 q 11.23$ & rs2269338, rs191780 & acetylcholine synthesis \\
\hline
\end{tabular}

or combinations of variants that increase nicotine or neurotransmitter availability (e.g. decreased nicotine metabolism, decreased serotonin re-uptake) decreased FTND scores. Moreover, a combination of a variant in the dopamine pathway with a variant in the opioid pathway was associated with increased FTND-scores. This interaction is plausible since opioids may reduce the inhibition of dopaminergic neurons, thereby causing an increased reinforcement leading to addiction [45]. Secondly, a combination of three SNPs in the dopamine pathway was found to be associated with FTND score as well. Finally, most of the associations found for FTND score, were also observed in the analysis on level of addiction. No association with the $\mu$-opioid receptor (MOR) was found, however an increased chance of having a high level of addiction with a SNP in the MOR-interacting protein HINT-1, associated with a dysregulation of postsynaptic dopamine transmission [46] and an increased risk of ND [47], was found. Furthermore, a positive association with the COMT rs737865 variant was found.

Since it has been suggested that the FTND has a multi-factor structure [48] (e.g. "morning smoking" consisting of items 1,3 and 5, and "smoking pattern" consisting of items 2,4 and 6), the effect of the same 35 genetic variants on the different items of the FTND among the participants of the four smoking and smoking cessation trials was subsequently investigated in Chapter 4. In concordance with the results of the principal component analysis (PCA) on the FTND items by Payne et al. [48] two groups of items were identified which were influenced by different categories of smoking-related genes: "morning smoking" (especially item 3 ) seemed to be influenced mainly by genes that influence the response to nicotine, while "smoking pattern" (items 2, 4, and 6) was mainly associated with genes that influence neurotransmitter pathways. 
Overall, Chapters 2, 3, and 4, provide evidence that several variants in smokingrelated pathways (e.g. genes influencing the response to nicotine and genes in key neurotransmitter pathways associated with addiction) influence smoking behaviour, ND level and the different aspects of ND. Moreover, combinations of genetic variants were found to be able to have a significant effect, even if the variants do not show an effect on their own. Therefore, we may conclude that it is important to investigate the effect of multiple genetic variants in smoking-related pathways on both ND level and the different aspects of ND.

\section{Genetic influences on smoking cessation therapy}

Since pharmacotherapies used for smoking cessation are directed at the pathways involved in ND it is likely that genetic variants in smoking-related pathways will also influence the efficacy of these smoking cessation therapies. Furthermore, genetic variants in genes influencing the metabolism and/or elimination of smoking cessation pharmacotherapy, thereby determining the level and duration of the medication in the body, are also expected to influence the efficacy of smoking cessation treatment.

In Chapter $\mathbf{5}$ the literature on the influence of genetic variants on smoking cessation therapy is reviewed. So far, most research on the influence of genetic variation on smoking cessation pharmacotherapy has been directed to the two most widely accepted and licensed forms of smoking cessation therapy: nicotine replacement therapy (NRT) and the antidepressant bupropion (Zyban ). Overall, genotypes associated with increased dopamine availability seemed to predict a better response to bupropion, while smokers with genotypes associated with reduced dopamine levels probably achieve better quit rates with NRT. A decreased metabolism for the drug used (e.g. bupropion or NRT), resulted in increased cessation rates as well. Furthermore, smokers with reduced dopaminergic and nicotinic receptor activity variants might experience greater benefit from nicotine spray (NS), while smokers with increased activity variants in MOR may have greater success with transdermal nicotine patches (TN). Variants in the serotonin pathway did not seem to have an effect on quit rates using NRT treatment.

Eventhough it was suggested that variants in the serotonin pathway, and especially the serotonin transporter, are likely to influence the efficacy of antidepressant therapy for smoking cessation, this has not been investigated yet. We therefore investigated the influence of three functional genetic variants in SLC6A4 (5-HTTLPR, STin2, and rs25531) on smoking cessation rates in a randomized placebo-controlled trial of bupropion (sustained release; SR) and nortriptyline for smoking cessation, as described in Chapter 6. In the original efficacy trial only the difference in abstinence between bupropion (SR) and placebo at 6-month follow-up was significantly different (difference= $13.1 \%, 95 \% \mathrm{Cl}=1.2 \%-25.1 \%, \mathrm{p}=0.03$ ) [49,50]. However, in this genotyping study we showed that carriers of the 5-HTTLPR high-activity L-variant had higher prolonged cessation rates with bupropion compared to placebo for all three timepoints combined. Furthermore, combining the three variants resulted in increased prolonged cessation rates for both bupropion and nortriptyline among carriers of 4-5 high-activity variants. Similar results were found for point prevalence abstinence. Thus, both bupropion and nortriptyline significantly increased smoking cessation rates among carriers of high- 
activity serotonin transporter variants, probably by blocking the serotonin transporter. Therefore, it might be possible to increase smoking cessation rates using bupropion and nortriptyline by selecting at forehand individuals with high-activity serotonin transporter variants. Based on these findings it seems that antidepressant therapy is most effective in about $15 \%$ of the population (e.g. with a combination of high-activity serotonin transporter variants), resulting in considerably higher cessation rates than found in current efficacy studies [17]. On the other hand, the use of antidepressant therapy might be less effective in about $10-30 \%$ of the population (e.g. with low serotonin transporter activity).

However, regarding the number of genes that have been shown to be implicated in smoking and smoking cessation, and the large number of variants present in these genes, approaches analysing single variants or single genes will probably fail to fully determine the influence of genetic variation on antidepressant therapy. As shown in Chapter $\mathbf{3}$ both combinations of variants within one gene and combinations of variants in different genes may have an effect, even if the variants do not have an effect on their own. Therefore, in Chapter 7, the effect of the same 35 genetic variants in 19 genes, previously used in Chapter $\mathbf{3}$ and 4, was investigated among the participants of the randomized placebocontrolled trial of bupropion (SR) and nortriptyline for smoking cessation (also used in Chapter 6). Several variants in genes in smoking-related and treatment-related pathways were found to influence cessation rates using bupropion (SR) and nortriptyline treatment (e.g. CHRNA2, CHRNA4, DBH, TPH1, SLC6A4, CHAT, CYP2D6, and CYP2B6). Overall, several genetic variants in smoking-related and treatment-related genes influenced the efficacy of antidepressant therapy used for smoking cessation (e.g. bupropion and nortriptyline). Some of these variants had comparable effects for both bupropion and nortriptyline treatment, but also some genetic variants were identified that had distinct effects depending on the type of antidepressant that was used. Genetic variants associated with a dopamine or serotonin deficiency (e.g. decreased synthesis, increased re-uptake, or increased metabolism) resulted in increased cessation rates using bupropion and nortriptyline. Furthermore, antidepressant therapy seemed to attenuate the decreased cessation rates among individuals with a higher nicotine metabolism (CYP2D6), although this was not significant for nortriptyline, possibly because this variant also results in an increased nortriptyline metabolism. Moreover, cessation rates using bupropion were found to be decreased among individuals with a lower bupropion metabolism. On the other hand, a variant in the acetylcholine pathway was found to be associated with nortriptyline only. Finally, variants in nicotinic receptor subunits also seem to play a role, but the nature of this association was not clear.

In conclusion, as reported in Chapters 5, 6 and 7, it seems that several genetic variants in smoking-related and treatment-related genes influence the efficacy of smoking cessation therapy and that these effects are often distinctive for the different forms of pharmacotherapy, especially when they have a different mechanism of action. Therefore, the use of genetic information has the potential to give directions in determining which treatment would be most effective for an individual smoker thereby increasing smoking cessation rates by selecting at forehand individuals with genotypes that have been shown to increase the efficacy of these treatments. However, prospective studies are needed to confirm these results before definite conclusions can be drawn. 


\section{Smokers' and GPs' views on genetic testing for smoking}

As discussed above, studies investigating the effect of genetically tailoring smoking cessation research show promising results. Therefore, the use of (pharmaco)genetic testing for smoking in clinical practice for increasing quit rates is getting closer. Future implementation of (pharmaco)genetic testing for smoking in daily medical practice, however, will ultimately depend upon patients' and health care providers' acceptance of these tests.

At present there is relatively little knowledge about the willingness and preferences of smokers concerning genetic testing for smoking cessation, and about their knowledge and attitudes on this subject. Therefore, we assessed smokers' knowledge, attitudes, and preferences and their intention to undergo genetic testing using an online crosssectional questionnaire among 587 Dutch smokers (Chapter 8). Overall, smokers were found to be mildly interested in receiving information and participating in genetic testing for smoking cessation, especially when offered by their general practitioner (GP). However, knowledge on the influence of genetic factors in smoking addiction and cessation were found to be low. Furthermore, smokers underestimated their chances of having a genetic predisposition and the influence of this on smoking cessation. Participants perceived few disadvantages, some advantages, and showed moderate self-efficacy towards undergoing a genetic test and dealing with the results.

The insufficient number of trained medical geneticists, the fact that general practitioners (GPs) are the first contact for patients who want to quit, and the results of the previous study which showed that smokers allocate their GP an important role in the provision of more information and the genetic test itself, makes it very likely that GPs will play an important role in the provision of genetic testing for smoking. However previous research suggests that GPs do not feel able and willing to take on this role. Therefore, we assessed the intention of GPs to offer genetic testing for smoking addiction and cessation, and their knowledge, attitudes and preferences about this subject (Chapter 9). For this, data from a cross-sectional survey among 53 Dutch GPs and 18 students was used. Most GPs were found to undertake several smoking cessation activities in their current situation. And although most GPs knew it is important to stop smoking at any age and this will decrease the chance for smoking-related diseases, knowledge on the efficacy of smoking cessation therapy was found to be relatively low. Knowledge on the influence of genetic factors in smoking addiction and cessation was found to be even much lower. Furthermore, most GPs felt they were not able to offer a genetic test and to deal with the results. They perceived some advantages and disadvantages of genetic testing for smoking. However, most GPs did believe that they are the ones who should provide smokers with more information and the genetic test itself. Overall, most GPs were interested in providing a genetic test for smoking addiction, and even more in a genetic test for smoking cessation.

From these two surveys (Chapters 8 and 9) we may conclude that both smokers and GPs seem to be interested in a genetic test for smoking cessation and agree that more information on such a genetic test and the genetic test itself should be offered by GPs. However, for successful implementation of genetic testing for smoking in general practice, several issues should be addressed. First, the knowledge on the efficacy of current smoking cessation therapies should be addressed, mainly for GPs, but this might also be important 
for smokers, because an overestimation of the efficacy of current smoking cessation therapies wil lead to an underestimation of the importance of genetic testing. Second, knowledge on the influence of genetic factors on smoking and smoking cessation, and possibly even genetics in general, should be addressed. Both smokers and GPs were found to have little knowledge about how genetic factors can influence smoking behaviour and smoking cessation. Furthermore, they were both found to underestimate the chances of having a genetic predisposition that may influence smoking or smoking cessation, and the effect of this. Thirdly, knowledge on genetic testing should be addressed, including advantages and disadvantages. This may help GPs to get confident enough to offer a genetic test and to deal with the results, and may help smokers to make a wellconsidered decision whether or not to undergo a genetic test.

\section{IMPLICATIONS}

\section{More insight in biological mechanisms underlying nicotine dependence}

Several variants in smoking-related pathways (e.g. genes influencing the response to nicotine and genes in key neurotransmitter pathways associated with addiction) were found to influence ND levels. Furthermore, in this thesis we showed that the different aspects of ND seem to be influenced by genetic variants in different pathways. While "morning smoking" was found to be associated mainly with genes that influence the response to nicotine, "smoking pattern" was found to be associated mainly with genes that influence key neurotransmitter pathways. These results confirm that ND is multifactorial rather than one common trait.

Knowledge on which genes and pathways influence ND and the different aspects of ND could help to better understand the underlying biological mechanisms that cause ND and the different aspects of ND. This can help direct treatment (both pharmacological and non-pharmacological) to the individual needs of smokers who want to stop smoking. Furthermore, it can guide the development of new pharmacotherapies, since these can then be directed at the pathways found to be involved in ND.

\section{More insight in the mechanism-of-action of current smoking cessation therapies}

Often it is not known how the current smoking cessation therapies exert their effects in helping smokers to quit. Genetic research might help unravel the working mechanisms of smoking cessation therapy.

The exact mechanisms by which bupropion and nortriptyline act as smoking cessation aids is unknown, as is its exact mechanism of antidepressant activity. The results from genetic analyses may provide us with clues on how these treatments exert their effects. Nortriptyline, and to a lesser extent its metabolites, have been shown to inhibit serotonin reuptake by blocking the serotonin transporter [51,52]. Bupropion, on the other hand, seems to have little serotonergic effects [51,53,54], although electrophysiological studies indicate that sub-acute bupropion exposure may increase serotonin levels, which is probably a downstream effect of a primary noradrenalin release $[55,56]$. 
The results from this thesis (for instance Chapter 4), suggest that bupropion might actually work, at least partly, via blocking the serotonin transporter, eventhough this has not been found in studies investigating the mechanism-of-action of bupropion.

Not only for antidepressant therapy like bupropion, but also for other types of smoking cessation therapy (for instance NRT and varenicline), genetic analyses might help to (further) unravel their exact mechanisms of action.

Ultimately this knowledge on the working mechanisms of smoking cessation therapies might help to better understand how these treatments support smokers during their quit attempt, thereby providing valuable information which can help to better direct the treatment at the needs of smokers willing to quit and the development of new pharmacotherapies for smoking cessation.

\section{Genetic tailoring of smoking cessation therapy}

In this thesis we showed that several genetic variants in smoking-related and treatmentrelated genes influence the efficacy of smoking cessation therapy. These effects are often distinctive for the different forms of pharmacotherapy, especially when they have a different mechanism of action (e.g. nicotine receptor agonist action or antidepressant action). Thus it seems that genotyping smokers before a cessation attempt may give directions in determining which treatment would be most effective for an individual smoker. Therefore, genetic tailoring of smoking cessation therapy has the potential to lead to a more efficient use of smoking cessation therapies, increased cessation rates, less frustration by both smokers and healthcare providers and, ultimately, in reduced deaths from smoking.

In Figure 1 it is hypothesised how smoking cessation therapy might be genetically tailored based on the present knowledge. Smokers with variants resulting in a dopamine or serotonin deficiency (e.g. decreased synthesis, increased re-uptake, or increased metabolism) seem to achieve better quit rates with anti-depressant therapies, such as bupropion and nortriptyline. On the other hand, smokers with an effective neurotransmitter response and effective nicotinic receptors (e.g. increased/normal number and activity receptors) and decreased nicotine metabolism (determined primarily by CYP2A6 genotype) achieve better quit rates with nicotine replacement therapy (NRT). Since varenicline is a (partial) nicotinic receptor agonist, like NRT, it is expected to be more effective among smokers with genotypes associated with an effective neurotransmitter response and nicotinic receptors as well. However, differences in the metabolism or elimination of these drugs and pathways involved in their mechanism-of-action could make one drug within these categories more effective than the other, or result in less side-effects in certain subgroups of smokers. For instance, bupropion has been found to be more effective in the presence of a low bupropion metabolism and the presence of high-expression nicotinic receptors, while nortriptyline was found to be more effective among carriers of variants resulting in a low nortriptyline metabolism and differences in the acetylcholine pathway. Furthermore, since NRT has been found to be less effective among smokers with a high nicotine metabolism, varenicline might be indicated for smokers with genotypes resulting in an increased nicotine metabolism. In contrast, since varenicline is eliminated by the organic cation transporter 2 (OCT2), carriers of variants resulting in high- activity 


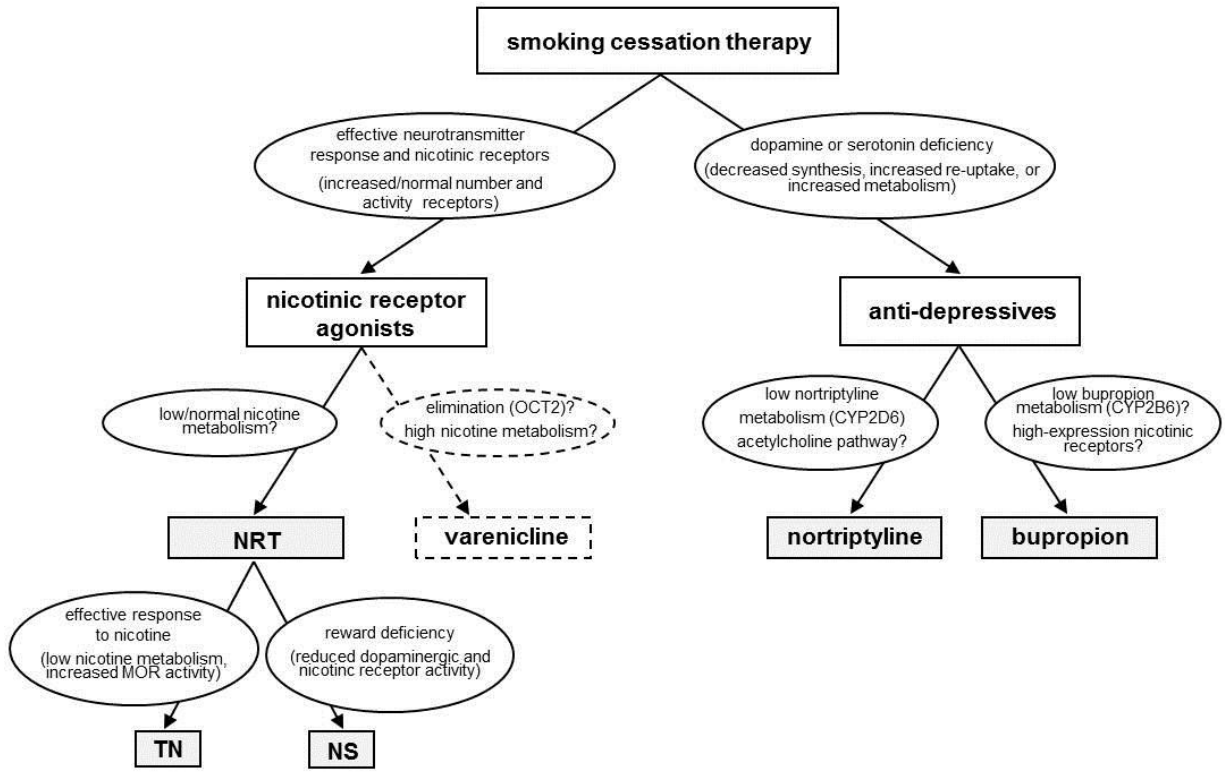

Figure 1: Hypothetical model for genetically tailored smoking cessation therapy.

NRT: nicotine replacement therapy; CYP2A6: cytochrome P450 2A6; CYP2B6: cytochrome P450 2B6; CYP2D6: cytochrome P450 2D6; OCT2: organic cation transporter-2; TN: transdermal nicotine patch; NS: nicotine nasal spray.

variants of this transporter might benefit more from NRT. Moreover, smokers who carry genetic polymorphisms associated with reduced nicotinic receptor (and possibly also dopaminergic) activity, may experience greater benefit from the greater rewarding effects of nicotine spray (NS), while smokers with increased activity variants in the $\mu$-opioid receptor (MOR) may have better success with the higher levels of nicotine delivered by transdermal nicotine patches (TN).

\section{Importance of assessing multiple genetic variants}

Regarding the number of genes that have been shown to be implicated in smoking and smoking cessation, and the large number of variants present in these genes, approaches analysing single variants or single genes will probably fail to fully determine the influence of genetic variation on smoking and smoking cessation. The commonly occurring alleles have only relatively small effects (ORs in the range of 1.1-2.0) and have been found to explain only a minor proportion of the observed phenotypic variance.

Our research showed that combinations of genetic variants can have a significant effect, even if the variants do not have an effect on their own. Thus, it is important to investigate the combined effect of multiple genetic variants in smoking-related, and possibly also treatment-related pathways on both ND, the different aspects of ND and probably also the efficacy of smoking cessation therapies. However, this will require larger scale genetic trials, of hundreds to thousands of participants, to achieve significant statistical power to evaluate these gene-gene interactions. 


\section{Barriers for the implementation of genetic testing in general practice}

Both smokers and GPs were found to be interested in a genetic test for smoking cessation. However, the knowledge level on genetics of smoking and smoking cessation, genetic testing (including advantages and disadvantages), and probably even genetics in general, was found to be low. Therefore, the knowledge level should be addressed before successful implementation of genetic testing for smoking in general practice will be possible.

Smokers will not need to be experts on this subject, however they will need a sufficient level of knowledge to be able to make a well-considered decision whether or not to undergo a (pharmaco)genetic test for smoking. When this test will be offered by their GP, GPs will have to play an important role in the information provision, since they will have to help their patients to make a decision on whether or not to undergo the genetic test for smoking. However, due to the time-constraints during a consult it will probably not be possible for a GP to fully explain this test to their patients during a consult. And furthermore, patients might not be interested in such a test if they do not have some knowledge about the influence of genetic factors on smoking and smoking cessation. Therefore, these issues should also be addressed via other channels of communication; for instance via information leaflets or via information campaigns on $\mathrm{TV}$, radio or in magazines or newspaper.

For GPs a training programm could be set up to provide them with a sufficient knowledge level in genetics so they are able to understand the test, the results and the consequences of the results of a (pharmaco)genetic test for smoking and to explain this to their smoking patients. In this training knowledge on genetics in general should be discussed shortly, as well as the efficacy of current smoking cessation treatments. Furthermore, it should be explained how genetic variants can influence smoking and smoking cessation, and what their impact is on smoking and smoking cessation. Moreover, it should be explained more clearly to GPs how a (pharmaco)genetic test for smoking works. Finally, also consequences of genetic testing, both positive and negative, should be discussed.

\section{FUTURE DIRECTIONS}

Although much progress has been made in unreaveling the effect of genetic variants on smoking behaviour and smoking cessation treatment, and promising results have been found, much research still remains to be done before genetically tailored smoking cessation therapy can be implemented in standard clinical practice.

Firstly, so far most studies investigated only single genes. However, a large number of genes and several polymorphisms in these genes are likely to contribute to the individual susceptibility towards smoking cessation therapies. Therefore this approach will probably fail to fully determine the role of genetic variation in smoking cessation success. In the studies presented in this thesis we provide evidence that indeed combinations of variants can have an effect, even if they do not have significant effects on their own. Future studies should thus focus on multiple functional variants and multiple genes. This will require far larger studies, of hundreds to thousands of participants, to achieve significant statistical power to evaluate these gene-gene interactions.

Secondly, in recent years many new variants or regions have been identified that may 
also contribute to the variance in smoking behaviour, mainly by the use of genome-wideassociation studies (GWAs). The influence of these variants should be further investigated.

Thirdly, the markers identified are often not the causal variants themselves, but rather are in linkage disequilibrium (LD) with them. This may also have contributed to the lack of reproducibility between studies, because the markers may be in LD in some populations but not in others. Therefore it is important to identify the functional genetic variants responsible influencing smoking behaviour and smoking cessation treatments.

Fourthly, until now the pharmacogenetics of only a couple of smoking cessation therapies has been investigated. Newer compounds (e.g. varenicline [Champix ${ }^{\circledR}$ ]) will also require investigation. Furthermore, we were the first to investigate the effect of genetic variants on nortriptyline (Nortrilen ${ }^{\circledR}$ ) treatment for smoking cessation. Therefore, more research on nortriptyline is also needed to confirm our findings and to test whether the effect of variants with a small effect and/or a low frequency, since our study was not powered to detect the effects of these variants.

Fifthly, since several aspects of smoking behaviour and the frequency of genetic variants have been shown to differ per race/ethnicity, pharmacogenetic trials confirming findings in different racial/ethnic groups are required to allow for genotype based selection of pharmacotherapy for ND in practice.

Besides, since some research suggests that smoking cessation treatment might work via different processes and/or are subject to different genetic influences in men and women, the effect of genetic variations will also have to be assessed for men and women separately.

Furthermore, genetic associations with tolerability and side-effects should also be examined. Some individuals might have unusual reactions to drugs or combinations of drugs due to the presence of multiple genetic defects, while certain subgroups of individuals may also exist who respond well to certain medications that are typically not well-tolerated.

Moreover, several practical, policy and ethical considerations have to be addressed to determine if, when, how and under what circumstances such genetically tailored treatment should be incorporated into clinical practice. The amount of improvement in outcomes based on genetic information, the cost-effectiveness, and how the costs of testing will be covered still remains to be determined. Furthermore, the potential psychosocial effects of genetic test disclosure will have to be investigated, because unintended adverse effects could occur (e.g. increased curiosity to try smoking or reduced likelihood of attempting to quit). Moreover, the risk for social stigma, because genotypes used to tailor treatment may also provide information on risk of other (more stigmatised) disorders, and discrimination (e.g. by health or life insurers), will need to be considered. Therefore, additional research should be conducted to examine the benefits, risks, and challenges of conveying genetic information about smoking predisposition to the patient, clinicians, and the public. And appropriate legal and regulatory frameworks should be set up to ensure privacy and to protect against genetic discrimination.

And most importantly, current findings should be validated across independent trials and prospective studies should be set up to fully confirm the effect of the variants on smoking behaviour and cessation. However, a large heterogeneity exists between current (genetic) studies, because smoking cessation therapy is typically given in combination with behavioural support or other therapies. Therefore, future studies should strive for comparability with existing studies. 


\section{CONCLUSION}

We conclude that the use of genetic information has the potential to determine at forehand if a type of medication is effective for an individual smoker, and may also give directions in the development of new types of medication. This will lead to a more efficient use of smoking cessation therapies, increased cessation rates and ultimately, in reduced deaths from smoking. Furthermore, both smokers and health-care providers were found to be interested in a genetic test for smoking. However, before a genetic test for smoking can be developed and implemented in general practice, future studies should investigate the effect of multiple susceptibility genes as well as their mutual interactions on several smoking cessation therapies in large-scale, comparable trials in different ethnic/racial and gender groups. Furthermore, prospective trials should be set up to fully confirm the effect of the variants. Finally, several practical, policy and ethical considerations will have to be addressed.

\section{REFERENCES}

1. The World Bank. Curbing the epidemic: governments and the economics of tobacco control. Tob Control. 1999; 8(2): 196-201.

2. Mackay J, Eriksen M. The tobacco Atlas. Geneva, World Health Organization. 2002.

3. Guindon GE, Boisclair D. Past, current and future trends in tobacco use. HNP discussion paper no.6. Econcomics of tobacco control paper no. 6. 2003.

4. World Health Organization. The world health report 2003 - shaping the future; 2003.

5. Mucha L, Stephenson J, Morandi N, Dirani R. Meta-analysis of disease risk associated with smoking, by gender and intensity of smoking. Gend Med. 2006; 3(4): 279-291.

6. Kenfield SA, Stampfer MJ, Rosner BA, Colditz GA. Smoking and smoking cessation in relation to mortality in women. JAMA 2008; 299(17): 2037-2047.

7. Ezzati M, Lopez AD. Estimates of global mortality attributable to smoking in 2000. Lancet. 2003; 362(9387): 847-852.

8. Mathers CD, Loncar D. Evidence and information for policy: World Health Organization; 2005.

9. Peto R, Lopez AD, Boreham J, Thun M, Heath CJ. Mortality from Smoking in Developed Countries 19502000. Indirect Estimates from National Vital Statistics. New York: Oxford University Press; 1994.

10. The health benefits of smoking cessation. US Department of Health and Human Services, Public Health Service, Centers for Disease Control, Center for Chronic Disease Prevention and Health Promotion, Office on Smoking and Health. 1990; DHHS Publication No. (CDC) 90-8416.

11. Taylor DH, Jr., Hasselblad V, Henley SJ, Thun MJ, Sloan FA. Benefits of smoking cessation for longevity. Am J Public Health. 2002; 92(6): 990-996.

12. Doll R, Peto R, Boreham J, Sutherland I. Mortality from cancer in relation to smoking: 50 years observations on British doctors. Br J Cancer. 2005; 92(3): 426-429.

13. Doll R, Peto R, Wheatley K, Gray R, Sutherland I. Mortality in relation to smoking: 40 years' observations on male British doctors. BMJ. 1994; 309(6959): 901-911.

14. Lancaster T, Stead L, Silagy C, Sowden A. Effectiveness of interventions to help people stop smoking: findings from the Cochrane Library. BMJ. 2000; 321(7257): 355-358.

15. Lancaster T, Stead LF. Individual behavioural counselling for smoking cessation. Cochrane Database Syst Rev. 2002; (3): CD001292. 
16. Stead LF, Lancaster T. Group behaviour therapy programmes for smoking cessation. Cochrane Database Syst Rev. 2005; (2): CD001007.

17. Hughes JR, Stead LF, Lancaster T. Antidepressants for smoking cessation. Cochrane Database Syst Rev. 2007; (1): CD000031.

18. Silagy C, Lancaster T, Stead L, Mant D, Fowler G. Nicotine replacement therapy for smoking cessation. Cochrane Database Syst Rev. 2004; (3): CD000146.

19. Cahill K, Stead LF, Lancaster T. Nicotine receptor partial agonists for smoking cessation. Cochrane Database Syst Rev. 2007; (1): CD006103.

20. David S, Lancaster T, Stead LF, Evins AE. Opioid antagonists for smoking cessation. Cochrane Database Syst Rev. 2006; (4): CD003086.

21. Gourlay SG, Stead LF, Benowitz NL. Clonidine for smoking cessation. Cochrane Database Syst Rev. 2004; (3): CD000058.

22. White AR, Rampes $\mathrm{H}$, Campbell JL. Acupuncture and related interventions for smoking cessation. Cochrane Database Syst Rev. 2006; (1): CD000009.

23. Kaprio J, Hammar N, Koskenvuo M, Floderus-Myrhed B, Langinvainio H, Sarna S. Cigarette smoking and alcohol use in Finland and Sweden: a cross-national twin study. Int J Epidemiol. 1982; 11(4): 378-386.

24. Heath AC, Cates R, Martin NG, Meyer J, Hewitt JK, Neale MC, Eaves L. Genetic contribution to risk of smoking initiation: comparisons across birth cohorts and across cultures. J Subst Abuse. 1993; 5(3): 221-246.

25. Heath AC, Martin NG. Genetic models for the natural history of smoking: evidence for a genetic influence on smoking persistence. Addict Behav. 1993; 18(1): 19-34.

26. True WR, Heath AC, Scherrer JF, Waterman B, Goldberg J, Lin N, Eisen SA, Lyons MJ, Tsuang MT. Genetic and environmental contributions to smoking. Addiction. 1997; 92(10): 1277-1287.

27. Kendler KS, Neale MC, Sullivan P, Corey LA, Gardner CO, Prescott CA. A population-based twin study in women of smoking initiation and nicotine dependence. Psychol Med. 1999; 29(2): 299-308.

28. Sullivan PM, Kendler K. The genetic epidemiology of smoking. . Nicotine and Tobacco Research. 1999; 1(Suppl 2): S51-S57.

29. Batra V, Patkar AA, Berrettini WH, Weinstein SP, Leone FT. The Genetic Determinants of Smoking. Chest. 2003; 123: 1730-1739.

30. Xian H, Scherrer JF, Madden PA, Lyons MJ, Tsuang M, True WR, Eisen SA. The heritability of failed smoking cessation and nicotine withdrawal in twins who smoked and attempted to quit. Nicotine Tob Res. 2003; 5(2): 245-254.

31. Pergadia ML, Heath AC, Martin NG, Madden PA. Genetic analyses of DSM-IV nicotine withdrawal in adult twins. Psychol Med. 2006; 36(7): 963-972.

32. Nakajima M, Yamamoto T, Nunoya K, Yokoi T, Nagashima K, Inoue K, Funae Y, Shimada N, Kamataki T, Kuroiwa Y. Role of human cytochrome P4502A6 in C-oxidation of nicotine. Drug Metab Dispos. 1996; 24(11): 1212-1217.

33. Messina ES, Tyndale RF, Sellers EM. A major role for CYP2A6 in nicotine C-oxidation by human liver microsomes. J Pharmacol Exp Ther. 1997; 282(3): 1608-1614.

34. Dani JÁ, De Biasi M. Cellular mechanisms of nicotine addiction. Pharmacol Biochem Behav. 2001; 70: 439-446.

35. Kenny PJ, Markou A. Neurobiology of the nicotine withdrawal syndrome. Pharmacol Biochem Behav. 2001; 70: 531-549.

36. Benowitz NL. Nicotine addiction. N Engl J Med. 2010; 362(24): 2295-2303.

37. Di Chiara G, Imperato A. Drugs abused by humans preferentially increase synaptic dopamine concentrations in the mesolimbic system of freely moving rats. Proc Natl Acad Sci U S A. 1988; 85(14): 5274-5278. 
38. Pontieri FE, Tanda G, Orzi F, Di Chiara G. Effects of nicotine on the nucleus accumbens and similarity to those of addictive drugs. Nature. 1996; 382(6588): 255-257.

39. Zoli M, Moretti M, Zanardi A, Mclntosh JM, Clementi F, Gotti C. Identification of the nicotinic receptor subtypes expressed on dopaminergic terminals in the rat striatum. J Neurosci. 2002; 22(20): 8785-8789.

40. Balfour DJ. The neurobiology of tobacco dependence: a preclinical perspective on the role of the dopamine projections to the nucleus accumbens [corrected]. Nicotine Tob Res. 2004; 6(6): 899-912.

41. Ribeiro EB, Bettiker RL, Bogdanov M, Wurtman RJ. Effects of systemic nicotine on serotonin release in rat brain. Brain Res. 1993; 621(2): 311-318.

42. Mihailescu S, Palomero-Rivero M, Meade-Huerta P, Maza-Flores A, Drucker-Colin R. Effects of nicotine and mecamylamine on rat dorsal raphe neurons. Eur J Pharmacol. 1998; 360(1): 31-36.

43. Hu S, Brody CL, Fisher C, Gunzerath L, Nelson ML, Sabol SZ, Sirota LA, Marcus SE, Greenberg BD, Murphy $\mathrm{DL}$, Hamer $\mathrm{DH}$. Interaction between the serotonin transporter gene and neuroticism in cigarette smoking behavior. Mol Psychiatry. 2000; 5(2): 181-188.

44. Lerman C, Caporaso NE, Audrain J, Main D, Boyd NR, Shields PG. Interacting effects of the serotonin transporter gene and neuroticism in smoking practices and nicotine dependence. Mol Psychiatry. 2000; 5(2): 189-192.

45. Di Chiara G, North RA. Neurobiology of opiate abuse. Trends Pharmacol Sci. 1992; 13(5): 185-193.

46. Barbier E, Zapata A, Oh E, Liu Q, Zhu F, Undie A, Shippenberg T, Wang JB. Supersensitivity to amphetamine in protein kinase-C interacting protein/HINT1 knockout mice. Neuropsychopharmacology. 2007; 32(8): 1774-1782.

47. Jackson KJ, Chen Q, Chen J, Aggen SH, Kendler KS, Chen X. Association of the histidine-triad nucleotidebinding protein-1 (HINT1) gene variants with nicotine dependence. Pharmacogenomics J. 11(4): 251-257.

48. Payne TJ, Smith PO, McCracken LM, McSherry WC, Antony MM. Assessing nicotine dependence: a comparison of the Fagerstrom Tolerance Questionnaire (FTQ) with the Fagerstrom Test for Nicotine Dependence (FTND) in a clinical sample. Addict Behav. 1994; 19(3): 307-317.

49. Wagena EJ, Knipschild PG, Huibers MJ, Wouters EF, van Schayck CP. Efficacy of bupropion and nortriptyline for smoking cessation among people at risk for or with chronic obstructive pulmonary disease. Arch Intern Med. 2005; 165(19): 2286-2292.

50. Van Schayck CP, Kaper J, Wagena EJ, Wouters EF, Severens JL. The cost-effectiveness of antidepressants for smoking cessation in chronic obstructive pulmonary disease (COPD) patients. Addiction. 2009; 104(12): 2110-2117.

51. Richelson E, Pfenning M. Blockade by antidepressants and related compounds of biogenic amine uptake into rat brain synaptosomes: most antidepressants selectively block norepinephrine uptake. Eur J Pharmacol. 1984; 104(3-4): 277-286.

52. Sanchez C, Hyttel J. Comparison of the effects of antidepressants and their metabolites on reuptake of biogenic amines and on receptor binding. Cell Mol Neurobiol. 1999; 19(4): 467-489.

53. Dwoskin LP, Rauhut AS, King-Pospisil KA, Bardo MT. Review of the pharmacology and clinical profile of bupropion, an antidepressant and tobacco use cessation agent. CNS Drug Rev. 2006; 12(3-4): 178-207.

54. Paterson NE. Behavioural and pharmacological mechanisms of bupropion's anti-smoking effects: recent preclinical and clinical insights. Eur J Pharmacol. 2009; 603(1-3): 1-11.

55. Dong J, Blier P. Modification of norepinephrine and serotonin, but not dopamine, neuron firing by sustained bupropion treatment. Psychopharmacology (Berl). 2001; 155(1): 52-57.

56. El Mansari M, Ghanbari R, Janssen S, Blier P. Sustained administration of bupropion alters the neuronal activity of serotonin, norepinephrine but not dopamine neurons in the rat brain. Neuropharmacology. 2008; 55(7): 1191-1198. 



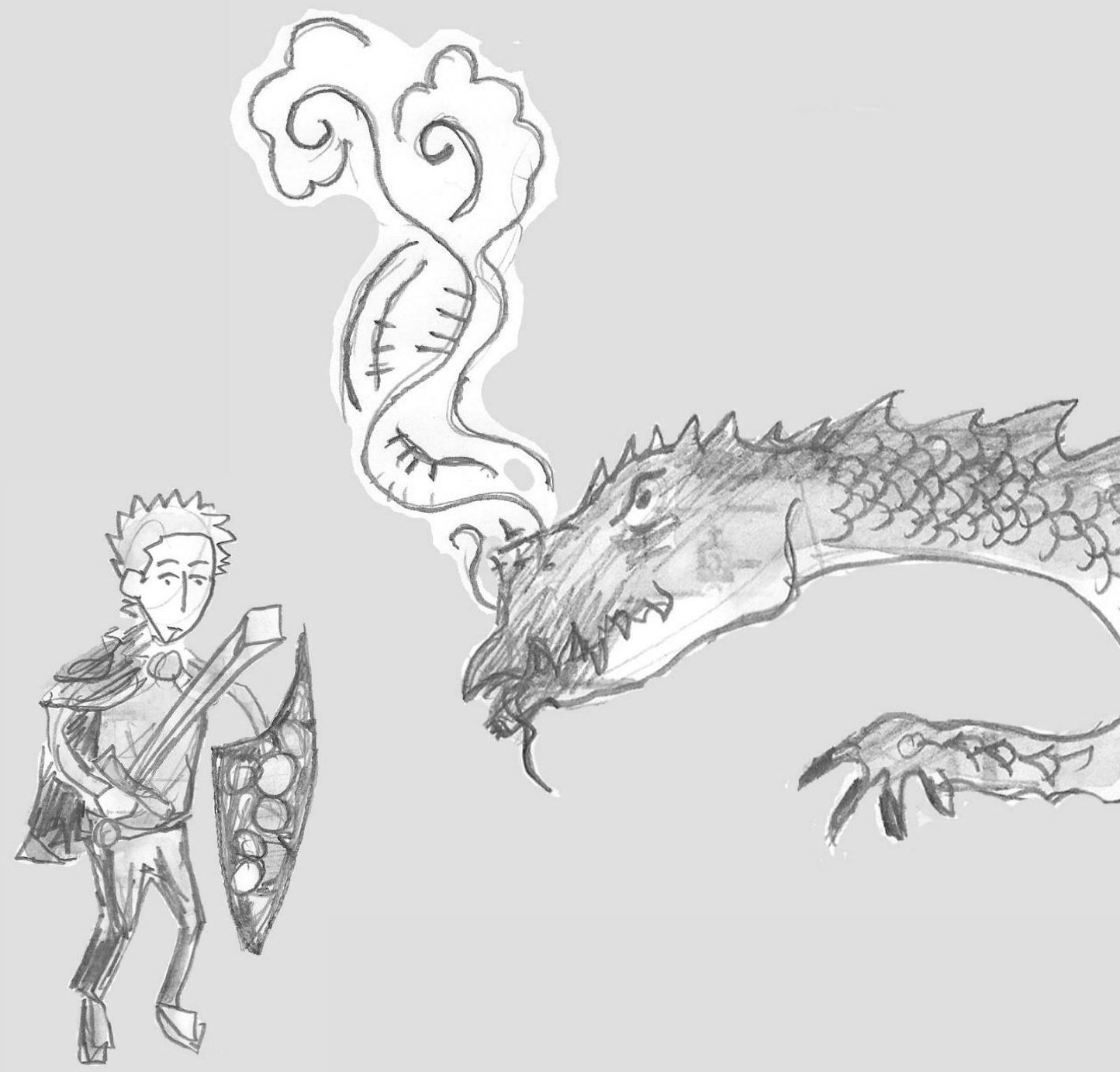

SUMMARY 
Although the risk of cigarette smoking is well documented, smoking continues to be the largest preventable cause of disease and premature death throughout the world. Smoking harms nearly every organ of the body, causing many diseases and compromising health of smokers in general. Even at low levels of intensity, smoking raises the risk of disease to about 3 times that of non-smokers and the risk increases even more with a higher intensity of smoking. Health consequences of smoking include many of the diseases with the highest world-wide prevalence, such as cancer, cardiovascular disease (CVD), and chronic respiratory diseases such as chronic obstructive pulmonary disease (COPD) and asthma. Moreover, about half of all smokers who continue to smoke will eventually die from a smoking-related disease, resulting in over 6 million deaths worldwide per year. Cessation reverses most adverse effects of smoking, therefore smoking cessation as early as possible is important, but cessation at any age results in meaningful life extensions. However, although the majority of smokers are highly motivated to quit, both smokers and healthcare practitioners are confronted with high relapse rates after initial successful smoking cessation attempts. Even with a combination of pharmacological and behavioural therapy, only 5-30\% of the smokers continue to abstain from smoking and therefore often multiple quit attempts are required.

Recent research strongly suggests that smokers vary in their underlying genetic susceptibility to become addicted to smoking. Since pharmacotherapies used for smoking cessation are directed at the pathways involved in ND it is likely that genetic variants in smoking-related pathways will also influence the efficacy of these smoking cessation therapies. Furthermore, genetic variants in genes influencing the metabolism and/or elimination of smoking cessation pharmacotherapy, thereby determining the level and duration of the medication in the body, are also expected to influence the efficacy of smoking cessation treatment. Therefore, cessation rates might be increased by genetic-tailoring of smoking cessation therapy. This is expected to result in a more efficient use of smoking cessation therapies, increased cessation rates and ultimately, in reduced deaths from smoking. To accomplish this, the effect of multiple susceptibility genes as well as their mutual interactions on several smoking cessation therapies will have to be investigated to make genetically based personalized treatments in the near future possible.

In this thesis we therefore investigated the relevance and possibilities of a genetic test determining multiple genetic variants in smoking-related and treatment-related genes to predict the efficacy of different smoking cessation therapies. For this purpose three main research questions were formulated:

1) Which candidate genes influence smoking behaviour, and what are the effects of genetic variants in these smoking-related genes on nicotine dependence (ND) (Chapters 2, 3 and $\mathbf{4})$ ?

2) Which genetic variants influence the efficacy of smoking cessation therapy, in particular antidepressant therapy used for smoking cessation (Chapters 5, 6 and 7)?

3) What is the knowledge, attitudes and preferences of both smokers and GPs regarding a genetic test for smoking to determine possibilities and barriers for the implementation of such a genetic test in daily medical practice (Chapters $\mathbf{8}$ and 9)? 
Chapter 2 comprises a literature review on the influence of genetic variants on smoking behaviour. Research has been focused on two broad classes of genes: 1) genes that may influence the response to nicotine (e.g. nicotine metabolism and nicotinic receptors) and 2) genes that predispose to addictive behaviour due to their effects on key neurotransmitter pathways (mainly dopamine and serotonin). Overall, it seemed that smokers with a reduced nicotine metabolism and increased dopamine levels are less addicted to smoking, smoke fewer cigarettes, have an increased likelihood of quitting and quit for a longer period of time. In contrast, smokers with an increased nicotine metabolism and reduced dopamine levels seemed to be more addicted, had a higher chance of becoming a smoker, a younger age of onset, smoke more cigarettes, and undergo fewer and less succesfull quit attempts. There also seemed to be a relationship with variants in the nicotinic acetylcholinic receptors and the serotonin pathway, but the nature of this relationship was not yet clear.

In Chapter 3 the effect of 35 genetic variants in 19 candidate genes on level of ND, (as measured by the Fagerström Test of Nicotine Dependence [FTND]) and level of addiction (low: FTND-score<6 or high: FTND-score $\geq 6$ ) was assessed among smokers participating in four smoking or smoking cessation trials. Several variants in genes in smokingrelated pathways were found to influence ND (e.g. CHRNA4, CYP2B6, DRD2, COMT, $S L C 6 A 4, O P R M 1, H I N T-1$, and ARRB2). Overall, genetic variants that increase the sensitivity for smoking (e.g. reward deficit, or higher binding capacity) resulted in increased FTND scores, while genetic variants that increase nicotine availability decreased FTND scores. Moreover, combinations of genetic variants were found to be able to have a significant effect, even if the variants did not show an effect on their own. Therefore, it is important to investigate the effect of multiple genetic variants in smoking-related pathways on ND.

Since it has been suggested that the FTND has a multi-factor structure, the effect of the same 35 genetic variants on the different items of the FTND was subsequently investigated among the participants of the four smoking and smoking cessation trials (Chapter 4). In concordance with the results of a principal component analysis (PCA) two groups of items were identified which were influenced by different categories of smoking-related genes: "morning smoking" (especially item 3 ) seemed to be influenced mainly by genes that influence the response to nicotine (CHRNA2, CHRNA4, and CYP2B6), while "smoking pattern" (items 2, 4, and 6) was mainly associated with genes that influence neurotransmitter pathways (DRD2, $D B H$, and OPRM1). This information can help in unravelling the pathways involved in the different aspects of ND, which may guide treatment of smokers wanting to quit and the development of new forms of medication to treat the different aspects of ND.

Chapter 5 reviews the literature on the influence of genetic variants on smoking cessation therapy. Since most research has been directed to the two most widely accepted and licensed forms of smoking cessation therapy, nicotine replacement therapy (NRT) and the antidepressant bupropion $\left(Z_{y b a n}{ }^{\circledR}\right)$, this review focused on these two treatments only. Overall, genotypes associated with increased dopamine availability seemed to predict a better response to bupropion, while smokers with genotypes associated with reduced dopamine levels probably achieve better quit rates with NRT. A decreased metabolism for 
the drug used, resulted in increased cessation rates as well. Furthermore, smokers with reduced dopaminergic and nicotinic receptor activity variants might experience greater benefit from nicotine spray (NS), while smokers with increased activity variants in the $\mu$-opioid receptor (MOR) may have greater success with transdermal nicotine patches (TN). Variants in the serotonin pathway did not seem to have an effect on quit rates using NRT treatment.

Since it was suggested that variants in the serotonin pathway, and especially the serotonin transporter (SERT), are likely to influence the efficacy of antidepressant therapy used for smoking cessation, in Chapter 6 the influence of three functional genetic variants in SERT (5-HTTLPR, STin2, and rs25531) on smoking cessation rates in a randomized placebocontrolled trial of bupropion (sustained release; SR) and nortriptyline for smoking cessation was investigated. Both bupropion and nortriptyline were found to be able to increase smoking cessation rates among carriers of high-activity serotonin transporter variants, probably by blocking the serotonin transporter. Therefore, smoking cessation rates using bupropion and nortriptyline might be increased by selecting at forehand individuals with high-activity serotonin transporter variants (about $15 \%$ of the population), while the use of antidepressant therapy might be less effective in about $10-30 \%$ of the population (e.g. with low serotonin transporter activity).

We subsequently investigated the effect of an extended number of genes and variants in these genes on antidepressant therapy in Chapter 7. The effect of the same 35 genetic variants in 19 genes (Chapter 3) was investigated among the participants of the randomized placebo-controlled trial of bupropion (SR) and nortriptyline for smoking cessation (Chapter 5). Several variants in genes in smoking-related and treatment-related pathways were found to influence cessation rates using bupropion (SR) and nortriptyline treatment (e.g. CHRNA2, CHRNA4, DBH, TPH1, SLC6A4, CHAT, CYP2D6, and CYP2B6). Some of these variants had comparable effects for both bupropion and nortriptyline treatment, but also some genetic variants were identified that had distinct effects depending on the type of antidepressant that was used. Cessation rates using both bupropion and nortriptyline were found to be increased in the presence of genetic variants associated with a dopamine or serotonin deficiency (e.g. decreased synthesis, increased re-uptake, or increased metabolism). Furthermore, antidepressant therapy seemed to attenuate the decreased cessation rates among individuals with a higher nicotine metabolism (CYP2D6), although this was not significant for nortriptyline, possibly because this variant also increases nortriptyline metabolism. Moreover, cessation rates using bupropion were found to be decreased among individuals with a lower bupropion metabolism. On the other hand, a variant in the acetylcholine pathway was found to be associated with nortriptyline only. Finally, variants in nicotinic receptor subunits also seem to play a role, but the nature of this association was not clear.

In Chapter 8 smokers' knowledge, attitudes, and preferences and their intention to undergo genetic testing was assessed using an online cross-sectional questionnaire among 587 Dutch smokers. Overall, smokers were found to be mildly interested in receiving information and participating in genetic testing for smoking cessation, especially when 
offered by their general practitioner (GP). However, knowledge on the influence of genetic factors in smoking addiction and cessation were found to be low. Furthermore, smokers underestimated their chances of having a genetic predisposition and the influence of this on smoking cessation. Participants perceived few disadvantages, some advantages, and showed moderate self-efficacy towards undergoing a genetic test and dealing with the results.

In Chapter 9 the intention of GPs to offer genetic testing for smoking addiction and cessation, and their knowledge, attitudes and preferences about this subject was assessed using data from a cross-sectional survey among 53 Dutch GPs and 18 students was used. Most GPs were found to undertake several smoking cessation activities in their current situation. And although most GPs knew it is important to stop smoking at any age and this will decrease the chance for smoking-related diseases, knowledge on the efficacy of smoking cessation therapy was found to be relatively low. Knowledge on the influence of genetic factors in smoking addiction and cessation was found to be even much lower. Furthermore, most GPs felt they were not able to offer a genetic test and to deal with the results. They perceived some advantages and disadvantages of genetic testing for smoking. However, most GPs did believe that they are the ones who should provide smokers with more information and the genetic test itself. Overall, most GPs were interested in providing a genetic test for smoking addiction, and even more in a genetic test for smoking cessation.

Chapter 10 summarises the main findings of this thesis. Furthermore, the implications of these findings and recommendations for future research are presented. We found that several genetic variants in smoking-related genes seem to influence ND and the different aspects of ND. This information could help to better understand the biological mechanisms that cause ND and the different aspects of ND. This may guide the development of new pharmacotherapies, since these can then be directed at these pathways, and provide more insight in the underlying mechanisms that influence the different aspects of ND in individual smokers, which could be used to better direct treatment (both pharmacological and non-pharmacological) to the individual needs of smokers who want to stop. Furthermore, several genetic variants in smoking-related and treatment-related genes also seem to influence the efficacy of smoking cessation therapies, and these effects are often distinctive for the different forms of pharmacotherapy, especially when they have a different mechanism of action. Therefore, the use of genetic information has the potential to give directions in determining which treatment would be most effective for an individual smoker thereby increasing smoking cessation rates by selecting at forehand individuals with genotypes that have been shown to increase the efficacy of these treatments. Moreover, our research showed that combinations of genetic variants can have a significant effect, even if the variants do not have an effect on their own. Therefore, it is important to investigate the combined effect of multiple genetic variants in smoking-related, and possibly also treatment-related pathways. And finally, we found that both smokers and GPs seem to be mildly interested in a genetic test for smoking cessation and agree that more information on such a genetic test and the genetic test itself should be offered best by GPs. However, for 
successful implementation of genetic testing for smoking in general practice, several issues should be addressed, such as the knowledge on the influence of genetic factors on smoking and smoking cessation, and possibly even genetics in general, and the knowledge on genetic testing, including advantages and disadvantages.

Although much progress has been made in unreaveling the effect of genetic variants on smoking behaviour and smoking cessation treatment, and promising results have been found, much research still remains to be done before genetically tailored smoking cessation therapy can be implemented in standard clinical practice. Therefore, in future studies the effect of multiple susceptibility genes as well as their mutual interactions on several smoking cessation therapies should be studied in large-scale, comparable trials in different ethnic/racial and gender groups. Furthermore, prospective trials should be set up to fully confirm the effect of the variants. Finally, several practical, policy and ethical considerations will have to be addressed. 
\begin{tabular}{l|l} 
SUMMARY & 191
\end{tabular} 



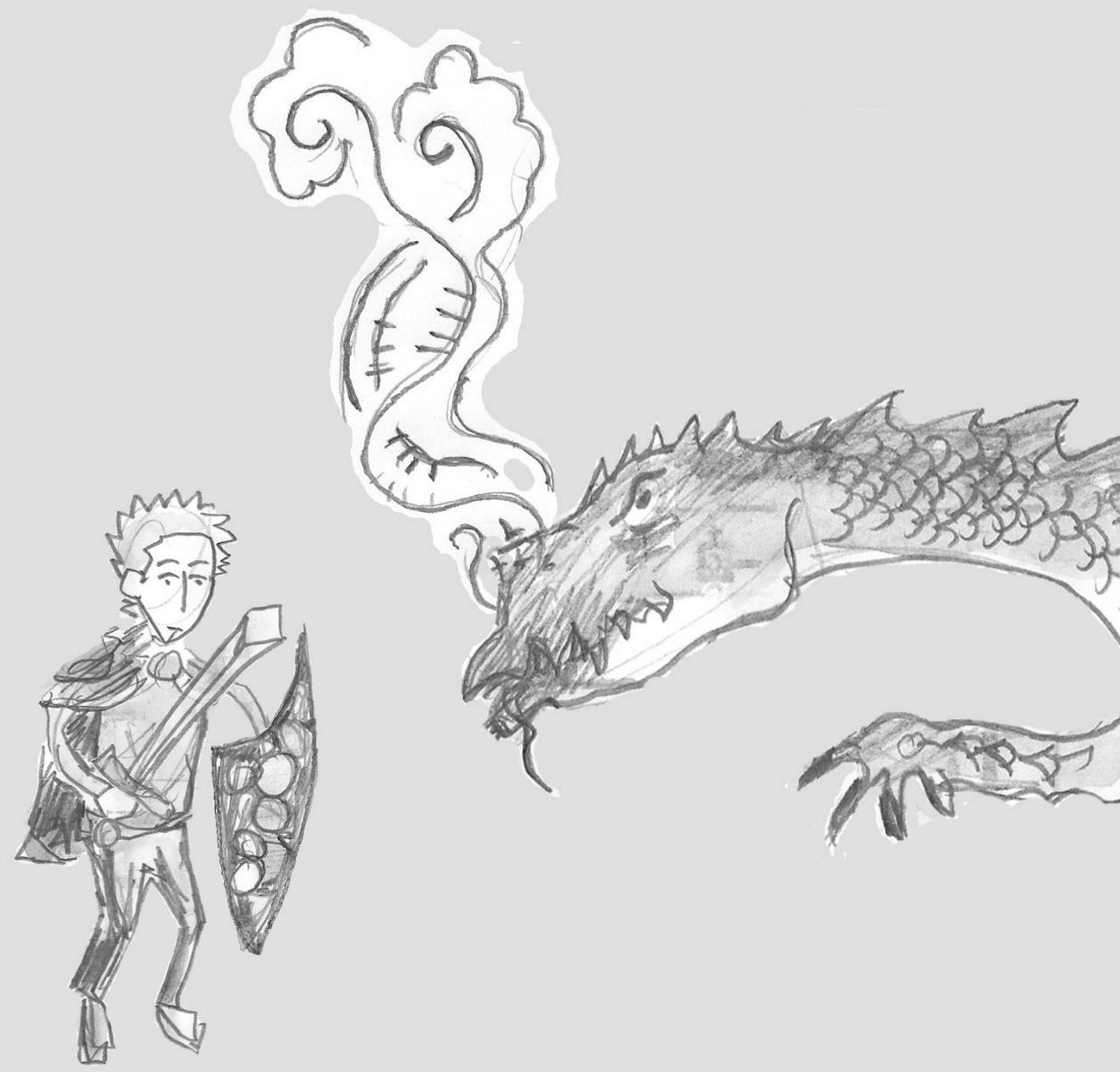

\section{NEDERLANDSE SAMENVATTING}


Hoewel de risico's van sigaretroken welbekend zijn, blijft roken de belangrijkste vermijdbare oorzaak van ziekte en vroegtijdig overlijden over de hele wereld. Roken beschadigt vrijwel alle organen in het lichaam, veroorzaakt vele ziekten en doet afbraak aan de algemene gezondheid van rokers. Zelfs bij een lage intensiteit verhoogd roken het risico op ziekte tot ongeveer 3 keer dat van niet-rokers en het risico neemt nog verder toe bij een hogere intensiteit van roken. Roken veroorzaakt veel van de ziekten met de hoogste wereldwijde prevalentie, zoals kanker, hart-envaatziekten (HVZ), en chronische longaandoeningen, zoals chronisch obstructief longlijden (COPD) en astma. Bovendien zal ongeveer de helft van alle rokers die blijven roken uiteindelijk sterven aan een roken-gerelateerde ziekte, wat neerkomt op meer dan 6 miljoen doden wereldwijd per jaar. Stoppen met roken voorkomt de meeste nadelige effecten van roken. Daarom is het belangrijk om zo vroeg mogelijk te stoppen, maar stoppen op elke leeftijd resulteert in een toename van de levensverwachting. Echter, hoewel de meerderheid van de rokers zeer gemotiveerd is om te stoppen, worden zowel rokers als zorgverleners geconfronteerd met een hoge kans op een terugval na een aanvankelijk succesvolle stoppoging. Zelfs met een combinatie van hulpmiddelen (nicotinevervangers of medicijnen) en gedragstherapie lukt het slechts $5-30 \%$ van de rokers om blijvend te stoppen en daardoor zijn vaak meerdere stoppogingen nodig.

Recent onderzoek wijst er sterk op dat rokers verschillen in hun onderliggende aangeboren gevoeligheid om verslaafd te raken aan roken. En omdat de stoproken behandelingen gericht zijn op de processen die nicotineverslaving veroorzaken is het waarschijnlijk dat aangeboren verschillen in deze roken-gerelateerde genen ook invloed hebben op de werkzaamheid van deze behandelingen. Bovendien, is het waarschijnlijk dat aangeboren verschillen in genen die de afbraak en/of verwijdering uit het lichaam van de stoproken behandelingen beïnvloeden, en dus de hoeveelheid en duur in het lichaam bepalen, ook de effectiviteit van de behandeling beïnvloeden.

Daarom kunnen stoppercentages wellicht worden verhoogd door de stoproken behandeling af te stemmen op deze aangeboren gevoeligheid van individuele rokers. Dit zal naar verwachting resulteren in een efficiënter gebruik van stoproken behandelingen, hogere stoppercentages en uiteindelijk een verminderde sterfte door roken. Om gepersonaliseerde behandelingen op basis van aangeboren verschillen in de nabije toekomst mogelijk te maken zal het effect van meerdere genen, alsmede hun onder-linge interacties op verschillende stoproken behandelingen moeten worden onderzocht.

In dit proefschrift is daarom onderzoek gedaan naar de relevantie en de mogelijkheden van een genetische test die meerdere genetische varianten in rokengerelateerde en behandeling-gerelateerde genen bepaald om de effectiviteit van de verschillende stop-roken behandelingen te voorspellen. Hiervoor werden drie onderzoeksvragen bekeken:

1) Welke kandidaat-genen beïnvloeden het rookgedrag, en wat zijn de effecten van aangeboren verschillen in deze roken-gerelateerde genen op nicotineverslaving (hoofdstukken 2, 3 en 4)? 
2) Welke genetische varianten beïnvloeden de effectiviteit van de stoproken behandelingen, in het bijzonder anti-depressiva (hoofdstukken 5, 6 en 7)?

3) Wat is de kennis, opvattingen en voorkeuren van zowel rokers als huisartsen ten aanzien van een genetische test voor het roken om de mogelijkheden en grenzen te bepalen voor de invoering van een genetische test in de dagelijkse medische praktijk (hoofdstukken 8 en 9 )?

Hoofdstuk 2 bestaat uit een literatuurstudie over de invloed van aangeboren verschillen op rookgedrag. Het onderzoek is gericht op twee algemene klassen van genen: 1) genen die de reactie op nicotine beïnvloeden (bijvoorbeeld afbraak van nicotine en nicotine-receptoren) en 2) genen die de kans op verslavend gedrag verhogen vanwege hun effecten op de belangrijkste neurotransmitters in de hersenen (voornamelijk dopamine en serotonine).

Op basis van de literatuur lijken rokers met een verminderde afbraak van nicotine en verhoogde dopamine niveaus minder verslaafd te zijn aan roken, minder sigaretten roken, een verhoogde kans hebben om te stoppen en voor een langere periode stoppen. Rokers met een verhoogde afbraak en een verminderd dopamine niveau, echter, bleken meer verslaafd te zijn, hadden een hogere kans om een roker te zijn, beginnen op een jongere leeftijd met roken, roken meer sigaretten, en ondergaan minder en minder succesvolle stoppogingen. Er bleek ook een relatie met varianten in de nicotine-receptoren en de serotonine pathway te zijn, maar de aard van deze relatie was nog niet duidelijk.

In hoofdstuk 3 werd het effect van 35 genetische varianten in 19 kandidaatgenen op de mate van nicotineverslaving, (zoals gemeten met de Fagerström Test van de nicotine-afhankelijkheid [FTND]) en het niveau van verslaving (laag: FTND-score<6 of hoog: FTND-score $\geq 6$ ) onderzocht bij de deelnemers van vier roken of stoproken onderzoeken.

Verschillende varianten in de roken-gerelateerde genen (bijv. CHRNA4, CYP2B6, $D R D 2, C O M T, S L C 6 A 4, O P R M 1, H I N T-1$ en $A R R B-2)$ bleken nicotine-verslaving te beïnvloeden. Over het geheel genomen resulteerden genetische varianten die de gevoeligheid voor het roken verhogen (bijvoorbeeld beloningstekort, of hoger bindend vermogen) in verhoogde FTND-scores, terwijl de genetische varianten die nicotine beschikbaarheid verhogen in lagere FTND-scores.

Bovendien werden combinaties van genetische varianten gevonden die een significant effect hadden, zelfs als de varianten geen effect op zichzelf hadden. Het is dus belangrijk om het effect van meerdere genetische varianten in rokengerelateerde genen tegelijkertijd op nicotineverslaving te onderzoeken.

Aangezien eerder is gesuggereerd dat de FTND een multi-factor structuur heeft, werd vervolgens het effect van dezelfde 35 genetische varianten op de verschillende onderdelen (vragen) van de FTND onderzocht onder de deelnemers van de vier (stop)roken onderzoeken (hoofdstuk 4). 
In overeenstemming met de resultaten van de principiële componenten analyse (PCA) werden twee groepen items gevonden die werden beïnvloed door verschillende categorieën van de roken-gerelateerde genen: "'s-ochtends roken" (in het bijzonder vraag 3) leek voornamelijk te worden beïnvloed door genen die de reactie op nicotine beïnvloeden (CHRNA2, CHRNA4, en CYP2B6), terwijl "rook-patroon" (vragen 2, 4 en 6) vooral werden beinvloed door genen in de neurotransmitter pathways (DRD2, $D B H$, en OPRM1).

Deze informatie kan helpen bij het ontrafelen van de processen die betrokken zijn bij de verschillende aspecten van nicotineverslaving. Dit kan helpen bij de keuze voor een behandeling van rokers die willen stoppen, evenals bij de ontwikkeling van nieuwe vormen van medicatie om de verschillende aspecten van nicotineverslaving te behandelen.

Hoofdstuk 5 geeft een overzicht van de literatuur over de invloed van aangeboren verschillen op stoproken behandelingen. Aangezien de meeste onderzoeken gericht zijn op de twee meest geaccepteerde en erkende vormen van stoproken behandelingen, de nicotinevervangers (NRT) en het antidepressivum bupropion (Zyban $\left.{ }^{\circledR}\right)$, was deze studie alleen gericht op deze twee behandelingen.

Over het algemeen leken genetische varianten geassocieerd met een verhoogde dopamine beschikbaarheid een betere reactie op bupropion te voorspellen, terwijl rokers met genetische varianten geassocieerd met een verlaagd dopamine-niveau waarschijnlijk betere stoppercentages bereiken met NRT. Een verlaagde afbraak van het gebruikte stoproken middel, resulteerde ook in verhoogde stoppercentages. Verder hadden rokers met een verminderde activiteit van de dopamine- en nicotine-receptoren meer baat bij nicotine spray (NS), terwijl rokers met verhoogde activiteit varianten in de $\mu$-opioïde receptor (MOR) meer succes hadden met transdermale nicotinepleisters (TN). Varianten in de serotonine pathway leken geen effect te hebben op stoppercentages bij het gebruik van NRT behandeling.

Omdat er eerder is gesuggereerd dat varianten in de serotonine pathway, en vooral de serotonine transporter (SERT), de werkzaamheid van antidepressiva gebruikt om te stoppen met roken beïnvloedt, werd in hoofdstuk 6 de invloed van drie functionele genetische varianten in SERT (5-HTTLPR, STin2, en rs25531) op stoppercentages in een gerandomiseerde placebo-gecontroleerde studie van bupropion (vertraagde afgifte, SR) en nortriptyline voor stoppen met roken onderzocht.

Zowel bupropion als nortriptyline bleken stoppercentages te verhogen onder de dragers van hoge activiteit serotonine transporter varianten, waarschijnlijk doordat ze de serotonine transporter blokkeren. Daarom kunnen stoppercentages met het gebruik van bupropion en nortriptyline verhoogd worden door op voorhand mensen met hoge activiteit serotonine transporter varianten te selecteren (ongeveer $15 \%$ van de bevolking), terwijl het gebruik van antidepressiva minder effectief lijkt te zijn in ongeveer $10-30 \%$ van de bevolking (met een lage serotonine transporter activiteit). 
Vervolgens hebben we het effect van een groter aantal genen en varianten in deze genen op antidepressiva onderzocht in hoofdstuk 7. Het effect van dezelfde 35 genetische varianten in 19 genen (hoofdstuk 3) werd onderzocht bij de deelnemers van de gerandomiseerde placebo-gecontroleerde studie van bupropion (SR) en nortriptyline voor stoppen met roken (hoofdstuk 5).

Verschillende varianten in roken-gerelateerde en behandeling-gerelateerde genen bleken de stoppercentages bij het gebruik van bupropion (SR) en nortriptyline te beïnvloeden (bijvoorbeeld CHRNA2, CHRNA4, DBH, TPH1, SLC6A4, CHAT, CYP2D6, en CYP2B6). Sommige van deze varianten hadden vergelijkbaar effecten voor zowel bupropion als nortriptyline, maar er werden ook een aantal genetische varianten gevonden die verschillende effecten hadden afhankelijk van het type antidepressivum dat werd gebruikt.

Stoppercentages met behulp van zowel bupropion als nortriptyline bleken te worden verhoogd in de aanwezigheid van genetische varianten geassocieerd met een dopamine of serotonine deficiëntie (bijv. verminderde synthese, verhoogde heropname, of verhoogde afbraak). Bovendien, bleken antidepressiva de verlaagde stoppercentages bij personen met een hoger nicotine metabolisme (CYP2D6) tegen te gaan, maar dit was niet significant voor nortriptyline, mogelijk omdat deze variant ook de afbraak van nortriptyline verhoogt. Bovendien bleken stoppercentages met bupropion verlaagd te zijn bij personen met een lagere afbraak van bupropion. Aan de andere kant, werd een variant in de acetylcholine pathway gevonden die alleen een effect had op nortriptyline. Tot slot, lijken varianten in nicotinereceptor sub-units ook een rol te spelen, maar de aard van deze associaties was niet duidelijk.

In hoofdstuk 8 werd de kennis, opvattingen en voorkeuren van rokers en hun intentie om een genetische test voor stoproken te ondergaan onderzocht met behulp van een online cross-sectionele enquête onder 587 Nederlandse rokers.

Over het algemeen bleken rokers enigszins geïnteresseerd te zijn in het ontvangen van informatie en deelname aan een genetische test voor het stoppen met roken, vooral als dit door hun huisarts wordt aangeboden. Echter, de kennis over de invloed van genetische factoren op rookverslaving en stoppen bleek laag te zijn. Bovendien onderschatten de rokers hun kans op een genetische aanleg en de invloed hiervan op stoppen met roken. De deelnemers ervaarden weinig nadelen, een aantal voordelen, en verwachtten enigszins in staat te zijn om een genetische test te ondergaan en het met de resultaten om te gaan (matige self-efficacy).

In hoofdstuk 9 werd de intentie onderzocht van huisartsen om genetische testen voor rookverslaving en stoproken aan te bieden, en hun kennis, opvattingen en voorkeuren over dit onderwerp met behulp van gegevens uit een cross-sectionele enquête onder 53 Nederlandse huisartsen en 18 studenten.

De meeste huisartsen bleken diverse stoproken activiteiten te ondernemen in hun huidige situatie. En hoewel de meeste huisartsen wisten dat het belangrijk is om te stoppen met roken op elke leeftijd en dat dit de kans op roken-gerelateerde ziekten zal verlagen, bleek de kennis over de effectiviteit van de huidige stoproken 
behandelingen relatief laag te zijn. Kennis over de invloed van genetische factoren op rookverslaving en stoppen bleek nog veel lager. Bovendien vonden de meeste huisartsen dat ze niet in staat waren om een genetische test aan te bieden en om te gaan met de resultaten. Ze zagen enkele voordelen en nadelen van een genetische test voor (stop)roken. Echter, de meeste huisartsen waren van mening dat zij degenen zijn die rokers moeten voorzien van meer informatie en de genetische test zelf. Over het geheel genomen waren de meeste huisartsen geïnteresseerd in het aanbieden van een genetische test voor rookverslaving, en zelfs nog meer in een genetische test voor stoproken.

Hoofdstuk 10 vat de belangrijkste bevindingen van dit proefschrift samen. Bovendien worden de implicaties van deze bevindingen en de aanbevelingen voor toekomstig onderzoek gepresenteerd.

We vonden dat verschillende genetische varianten in roken-gerelateerde genen nicotineverslaving en de verschillende aspecten van nicotineverslaving beïnvloeden. Deze informatie kan helpen om een beter inzicht te verkrijgen in de biologische processen die nicotineverslaving en de verschillende aspecten van nicotineverslaving veroorzaken. Dit kan helpen bij de ontwikkeling van nieuwe farmacotherapieën, omdat deze dan kunnen worden gericht op de processen die nicotineverslaving beïnvloeden. Ook kan het meer inzicht bieden in de onderliggende mechanismen die de verschillende aspecten van nicotineverslaving in individuele rokers beïnvloeden, wat kan worden gebruikt om de behandeling (zowel farmacologisch als niet-farmacologisch) beter af te stemmen op de individuele behoeften van rokers die willen stoppen.

Ook bleken verschillende genetische varianten in roken-gerelateerde en behandeling-gerelateerde genen ook de werkzaamheid van de stoproken behandelingen te beïnvloeden, en deze effecten waren vaak kenmerkend voor de verschillende vormen van farmacotherapie, vooral als deze een ander werkingsmechanisme hadden. Daarom heeft het gebruik van genetische informatie de potentie om richting te geven in de keuze welke behandeling het meest effectief zal zijn voor een individuele roker zodat stoppercentages verhoogd kunnen worden door op voorhand personen te selecteren met aangeboren varianten waarvan is aangetoond dat ze de werkzaamheid van deze behandeling verhogen.

Bovendien, bleek uit ons onderzoek dat combinaties van genetische varianten een significant effect kunnen hebben, zelfs als de varianten op zichzelf geen invloed hebben. Daarom is het belangrijk om het gecombineerde effect van meerdere genetische varianten in roken-gerelateerde, en mogelijk ook behandelinggerelateerde, genen te onderzoeken.

Tenslotte vonden we dat zowel rokers als huisartsen enigszins geïnteresseerd zijn in een genetische test voor stoppen met roken. Ook zijn zij het erover eens dat meer informatie over een dergelijke genetische test en de genetische test zelf het beste kan worden aangeboden door huisartsen. Echter, voor een succesvolle invoering van een genetische test voor het roken in de huisartsenpraktijk moeten nog een aantal problemen worden aangepakt, zoals de kennis over de invloed van genetische 
factoren op roken en stoppen met roken, en mogelijk zelfs genetica in het algemeen en de kennis over genetische testen, waaronder de voordelen en nadelen ervan.

Hoewel er veel vooruitgang is geboekt in het ontrafelen van het effect van aangeboren verschillen op rookgedrag en stoproken behandelingen, en veelbelovende resultaten zijn gevonden, moet nog veel onderzoek gedaan worden voordat gerpersonaliseerde stoproken behandelingen op basis van aangeboren gevoeligheid kan worden toegepast in de klinische praktijk. Daarvoor moet in toekomstige studies het effect van meerdere genen en hun onderlinge interacties op verschillende stoproken behandelingen worden onderzocht, in grote, vergelijkbare studies in groepen met verschillende etnische achtergronden en/of geslacht. Bovendien moeten prospectieve studies worden opgezet om het effect van de varianten volledig te bevestigen. Tenslotte, zullen een aantal praktische, beleidsmatige en ethische overwegingen moeten worden aangepakt. 



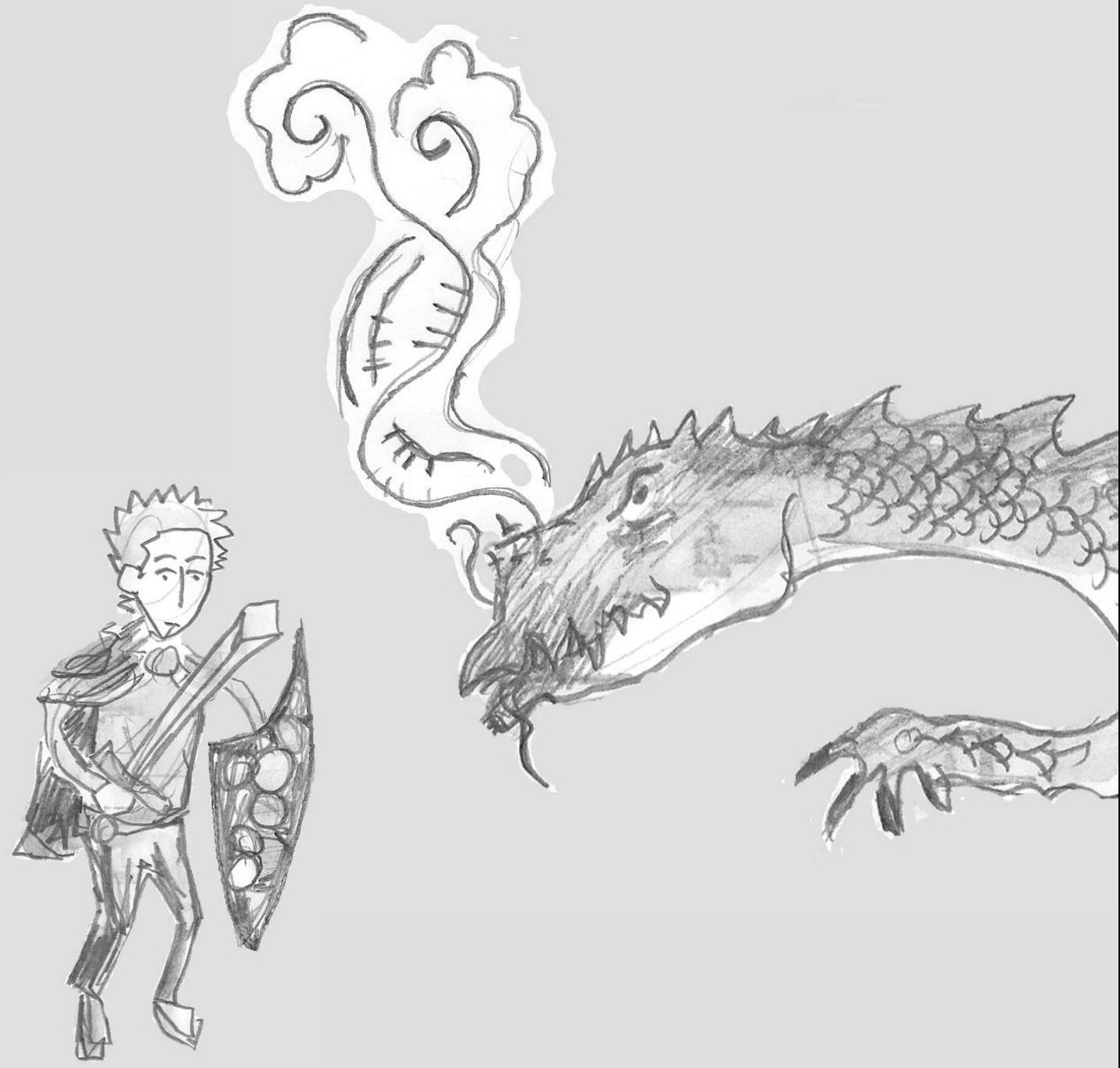

\section{SUPPLEMENTARY DATA}




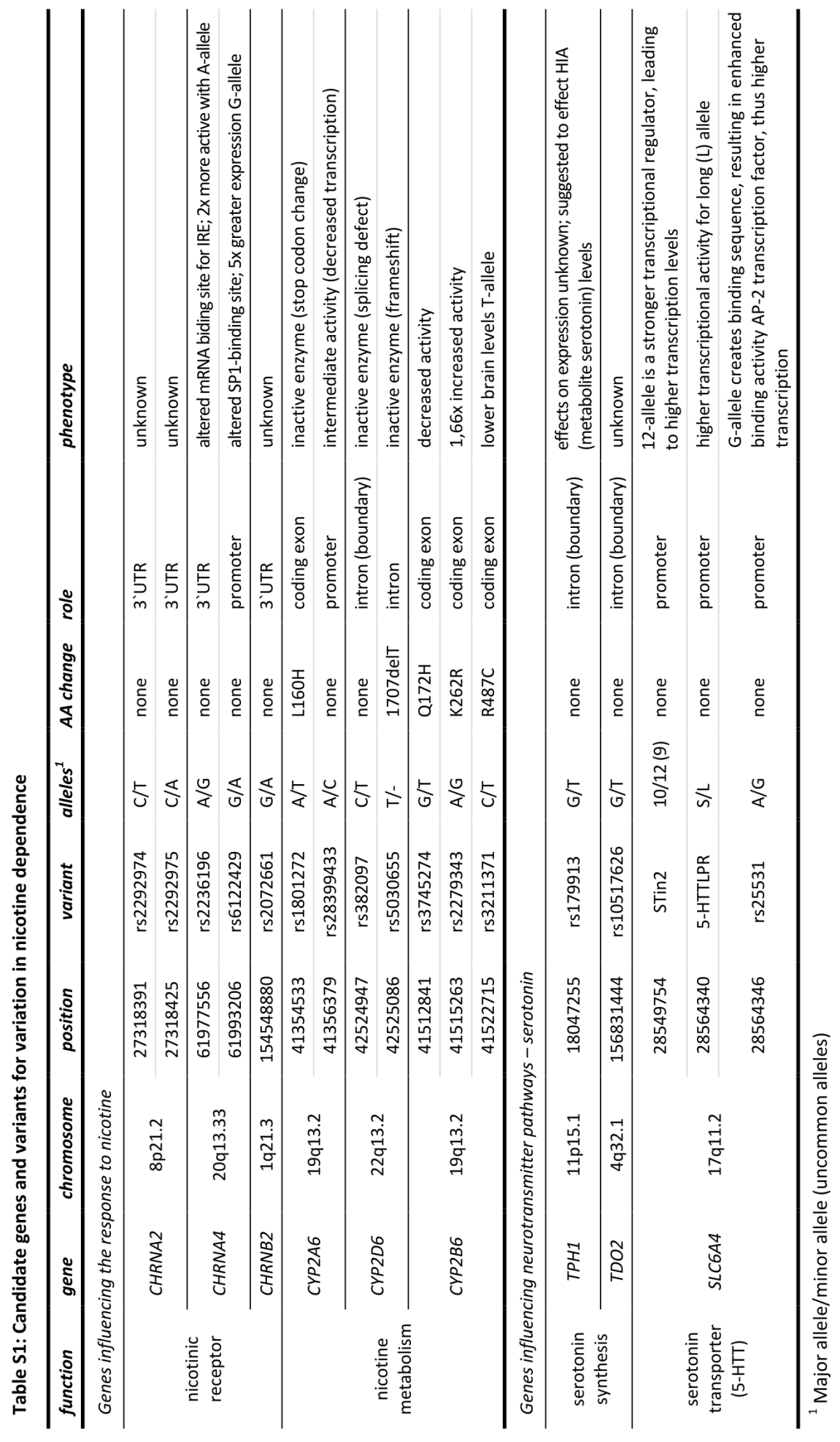




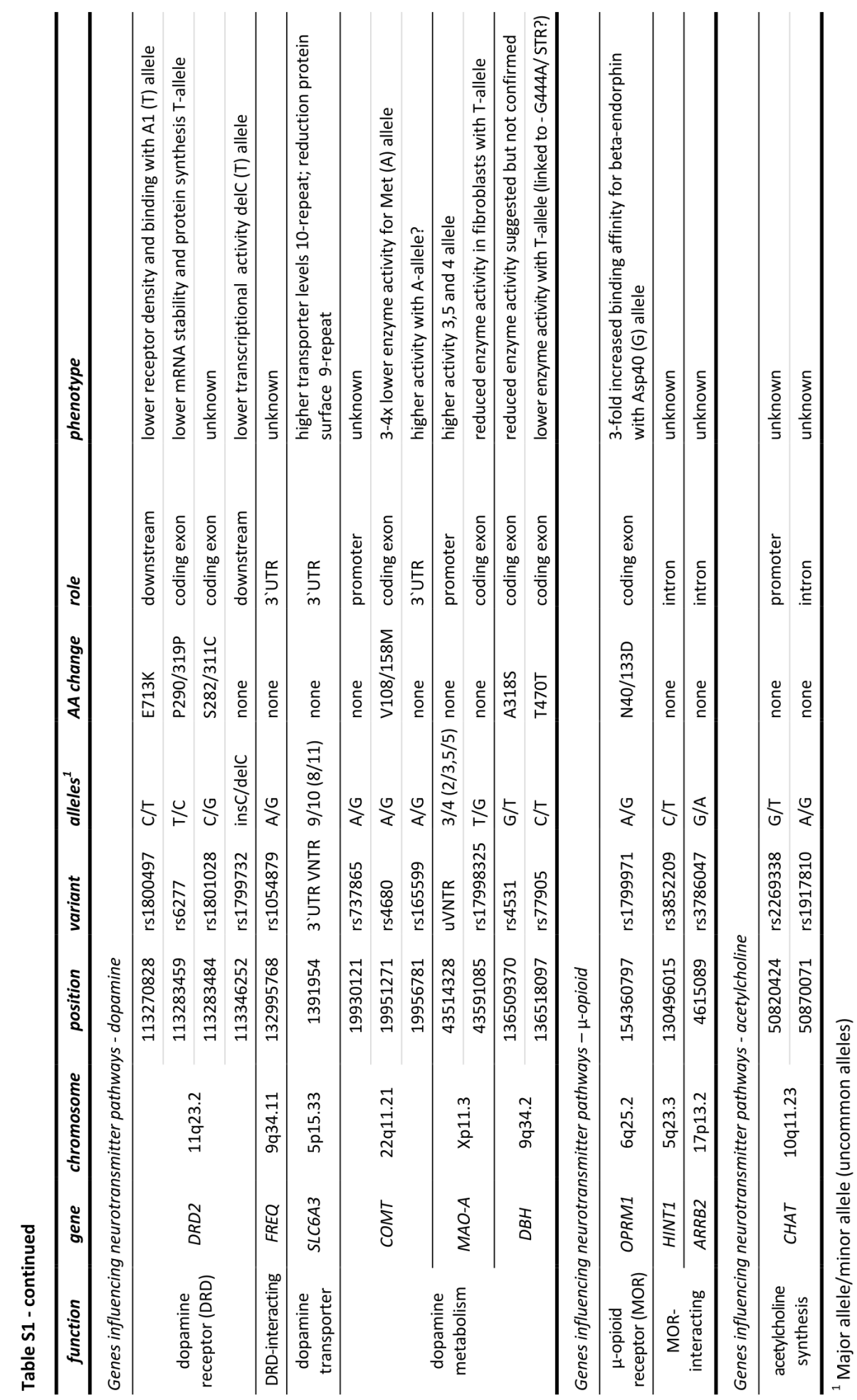




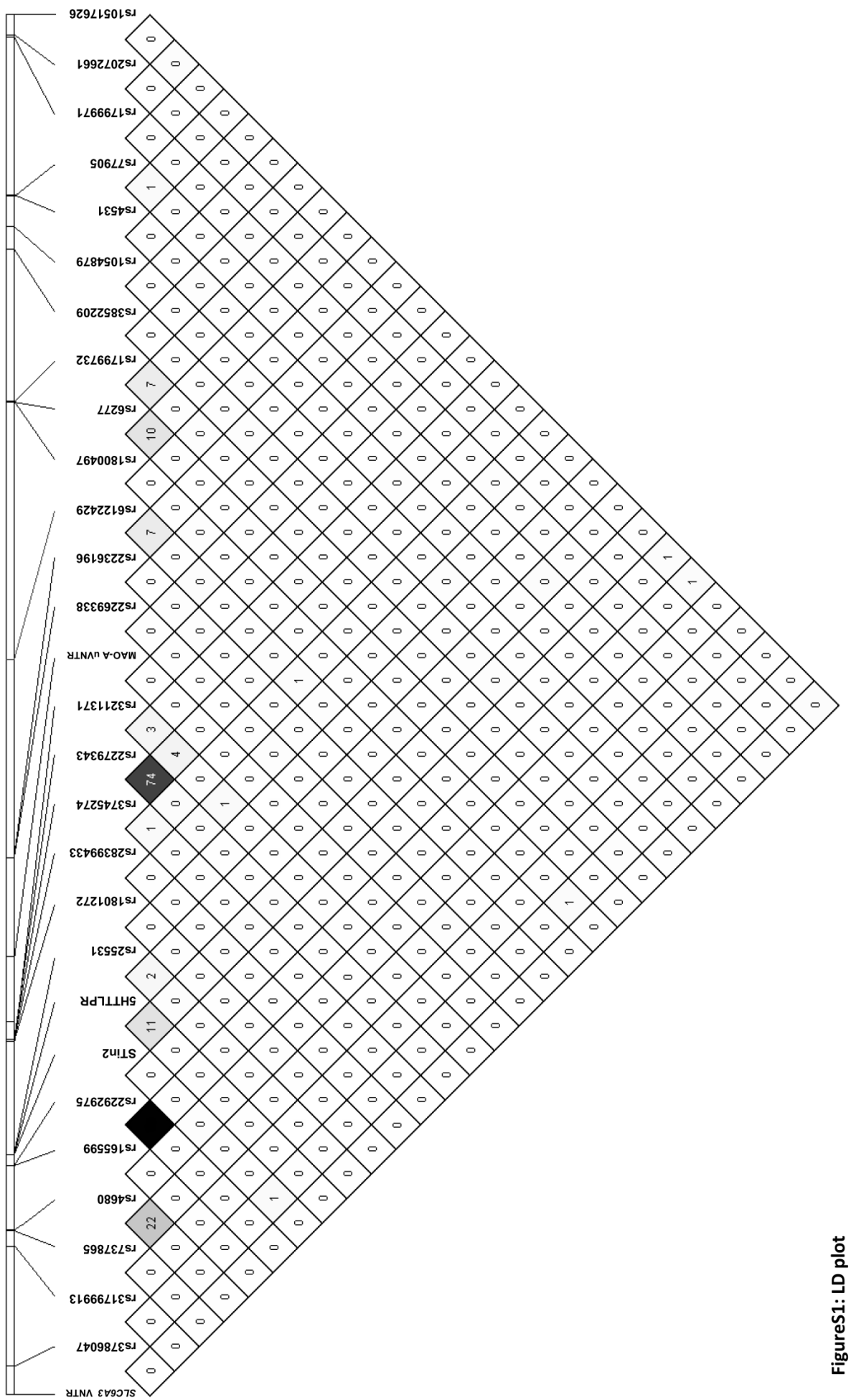




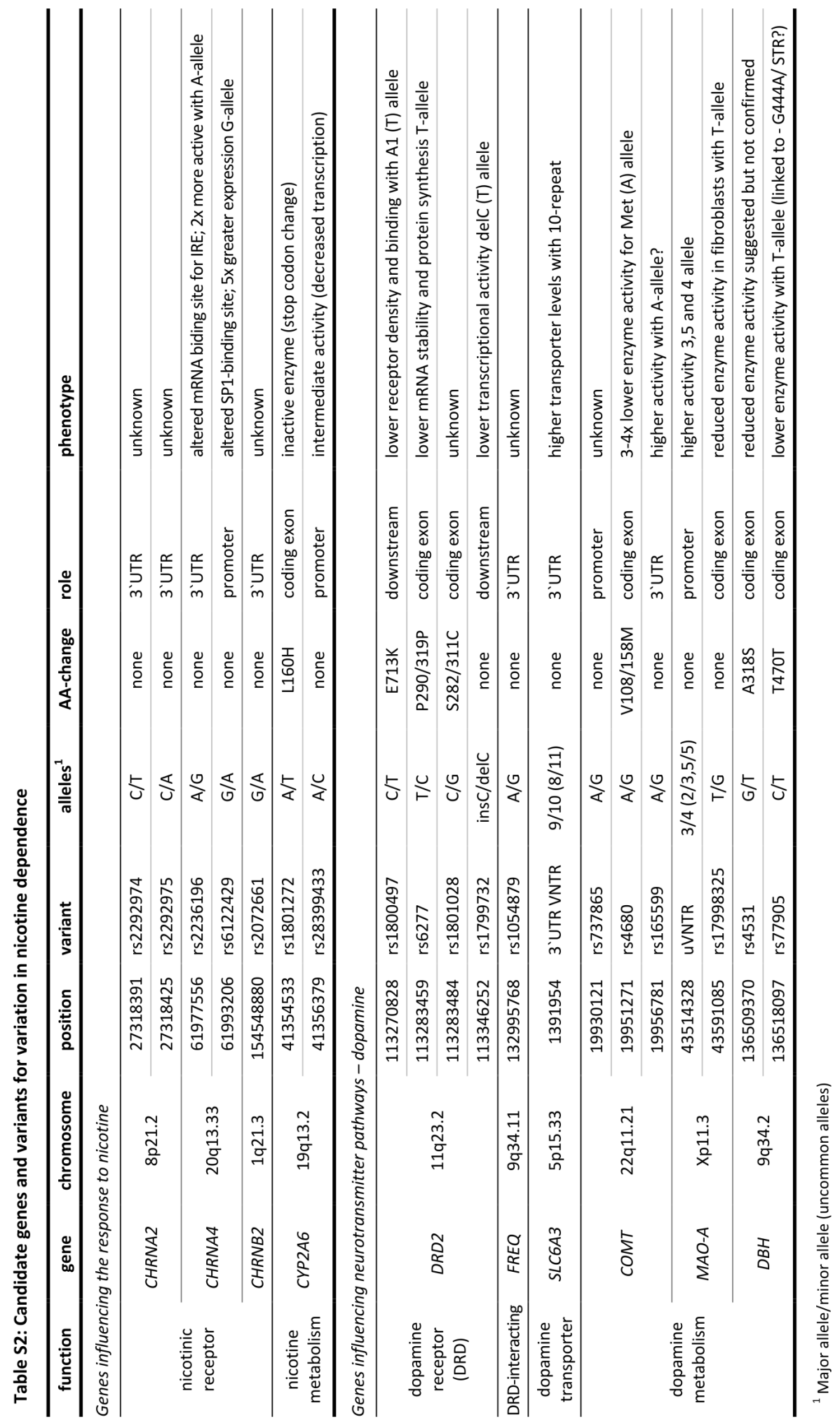




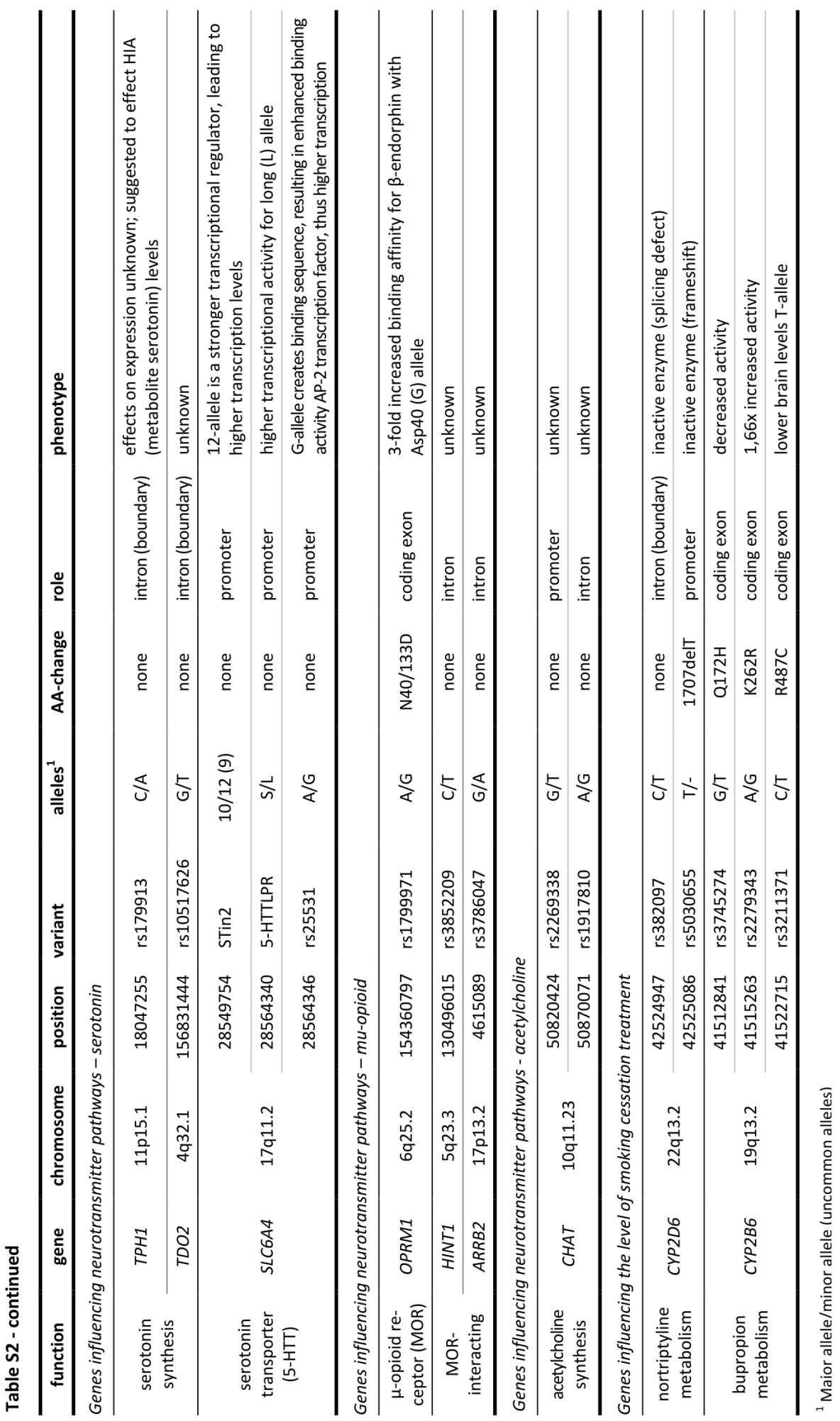




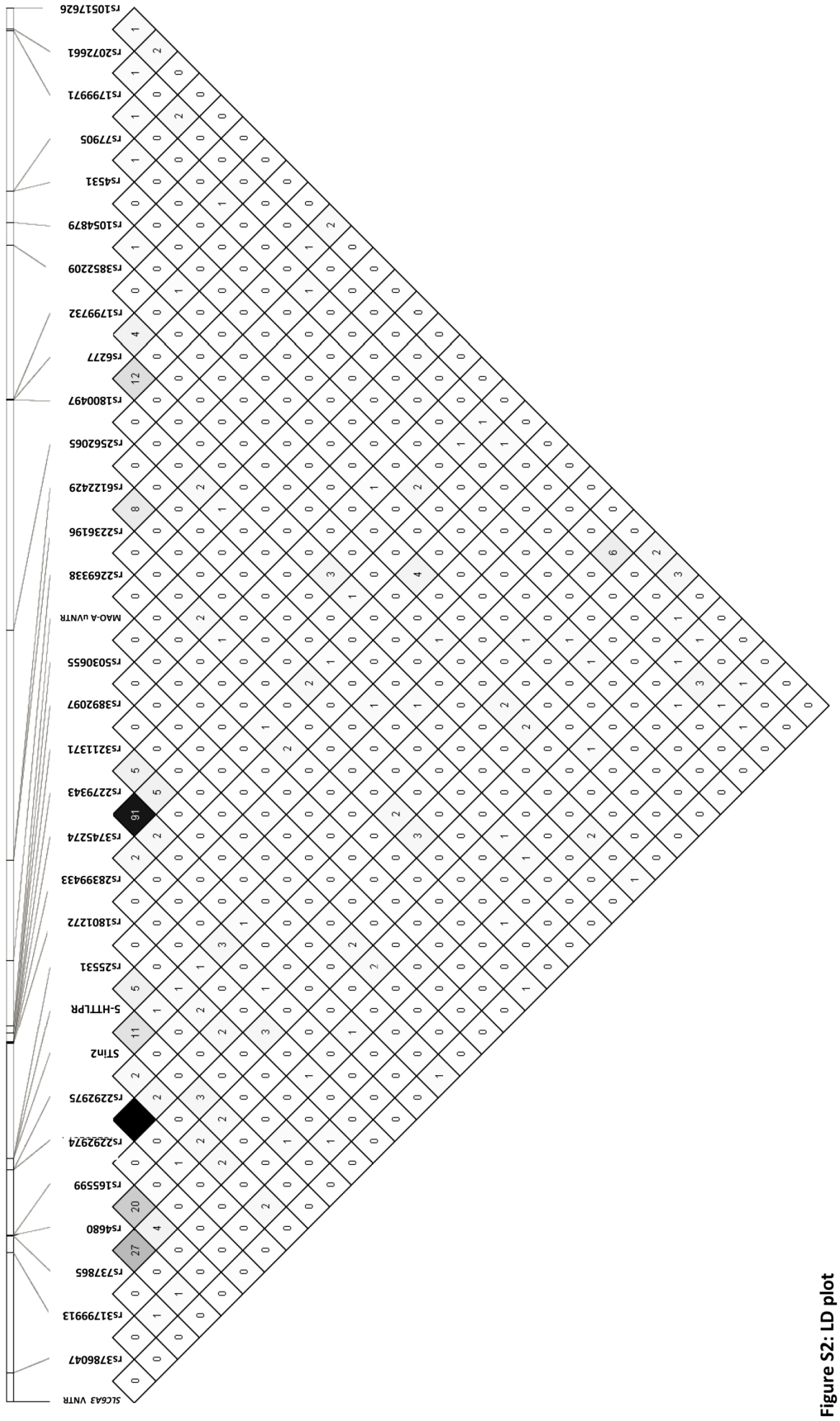





DBH rs4531

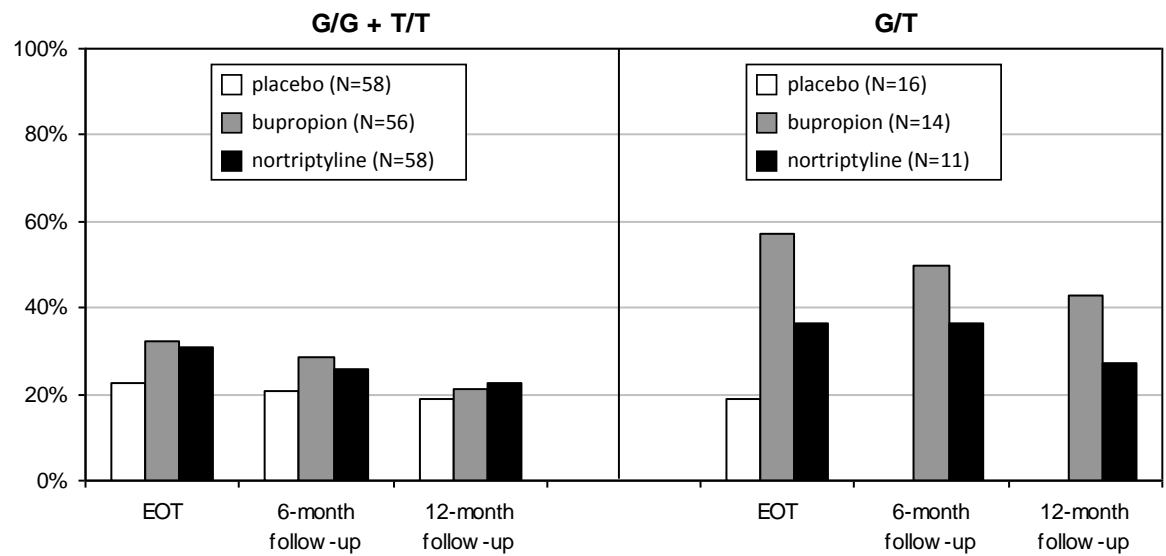

Figure S3: Prolonged abstinence by genotype and treatment group 

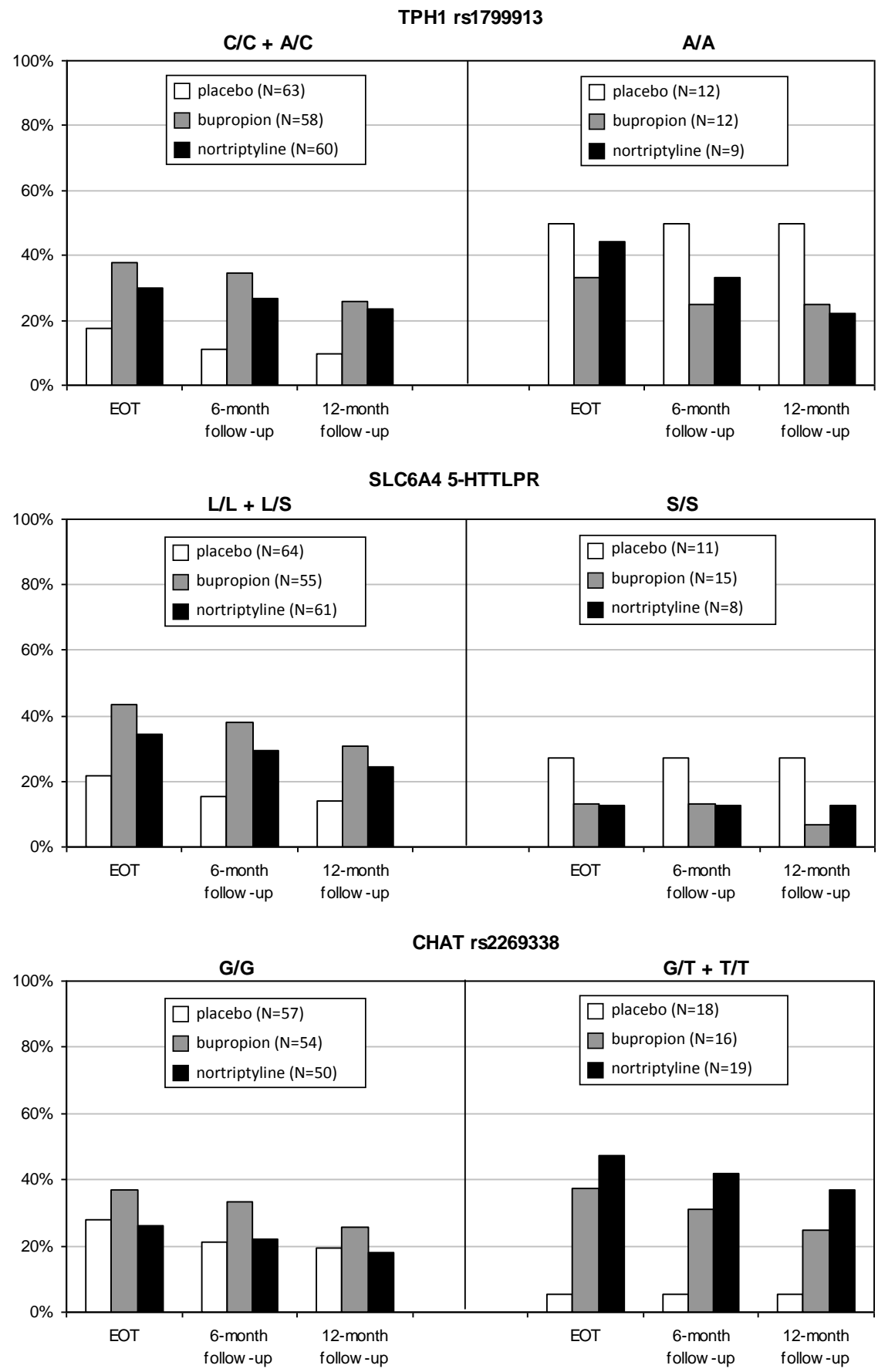

Figure S3-continued: Prolonged abstinence by genotype and treatment group 


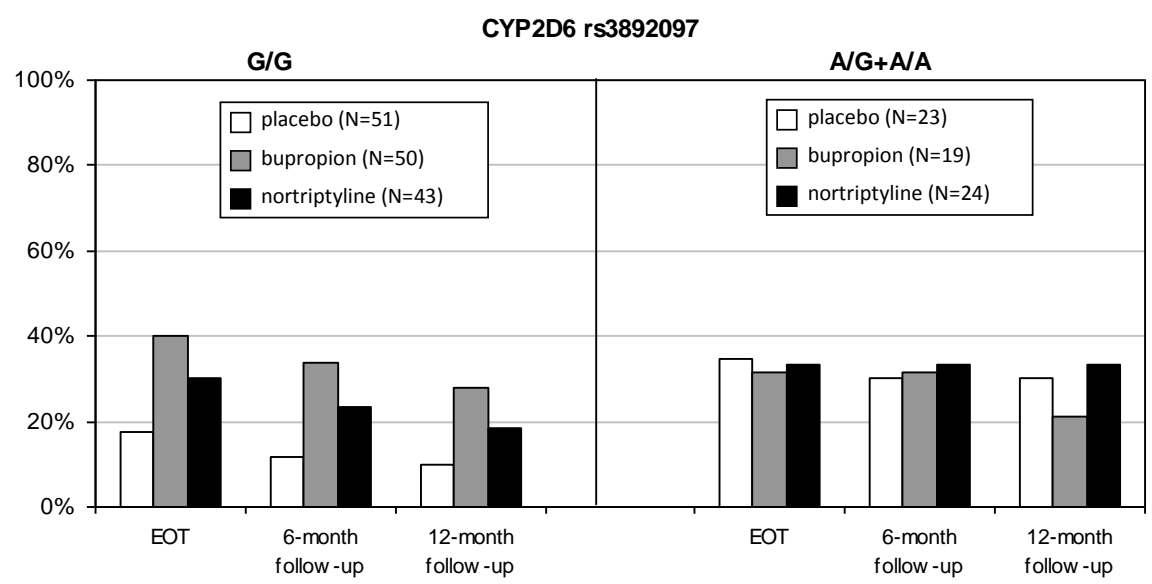

Figure S3-continued: Prolonged abstinence by genotype and treatment group 
Table S3: Perceptions of probability and seriousness of genetic factors influencing smoking addiction and cessation

\begin{tabular}{|c|c|c|c|c|c|c|}
\hline & \multicolumn{3}{|c|}{ probability } & \multicolumn{3}{|c|}{ seriousness } \\
\hline & $\begin{array}{l}\text { (very) } \\
\text { small }\end{array}$ & average & $\begin{array}{c}\text { (very) } \\
\text { big }\end{array}$ & $\begin{array}{c}\text { (completely) } \\
\text { not serious }\end{array}$ & neutral & $\begin{array}{l}\text { (very) } \\
\text { serious }\end{array}$ \\
\hline $\begin{array}{l}\text {...that you have a genetic predisposition } \\
\text { as a result of which you will have } \\
\text { more difficulty to stop smoking. }\end{array}$ & $38.3 \%$ & $44.8 \%$ & $16.8 \%$ & $10.6 \%$ & $35.6 \%$ & $53.9 \%$ \\
\hline $\begin{array}{l}\text {...that you have a genetic predisposition as } \\
\text { a result of which you have more with- } \\
\text { drawal symptoms. }\end{array}$ & $39.4 \%$ & $45.3 \%$ & $15.3 \%$ & $9.4 \%$ & $39.2 \%$ & $51.5 \%$ \\
\hline
\end{tabular}

Table S4: Intention to undergo genetic testing

\begin{tabular}{lccc}
\hline & $\begin{array}{c}\text { (completely) } \\
\text { not interested }\end{array}$ & $\begin{array}{c}\text { undecided } \\
\text { I am planning to undergo a genetic test to determine }\end{array}$ & $\begin{array}{c}\text { (completely) } \\
\text { interested }\end{array}$ \\
$\begin{array}{l}\text { which smoking cessation therapy I could use best. } \\
\text { I am planning to undergo a genetic test if my GP would offer it. }\end{array}$ & $29.5 \%$ & $40.0 \%$ & $16.6 \%$ \\
\hline I am planning to ask my GP to undergo a genetic test. & $50.6 \%$ & $41.6 \%$ & $38.3 \%$ \\
\hline
\end{tabular}
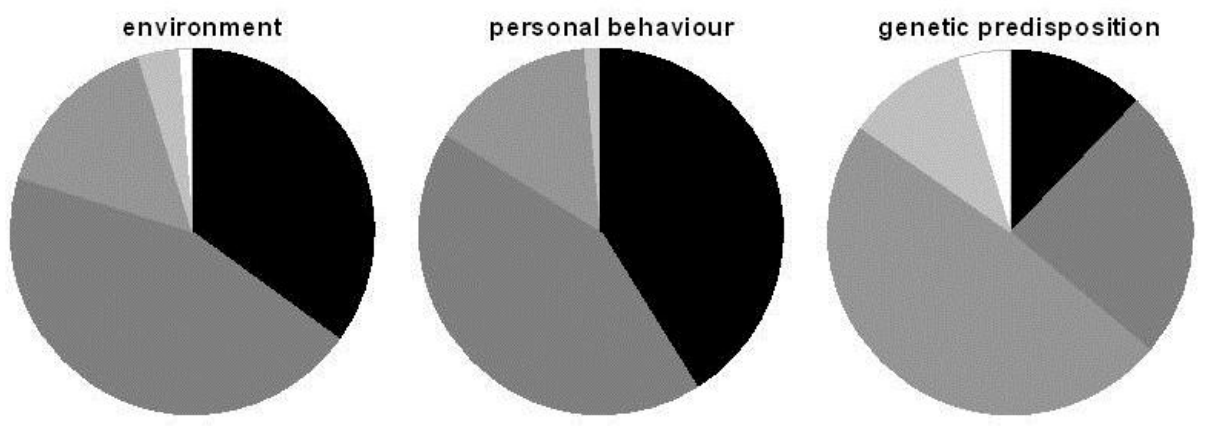

Figure S4: Perceived importance of environment, personal behavior and genetic predisposition as cause of smoking

very unimportant; $\square$ unimportant; $\square$ not unimportant/important; $\square$ important; $\square$ very important 


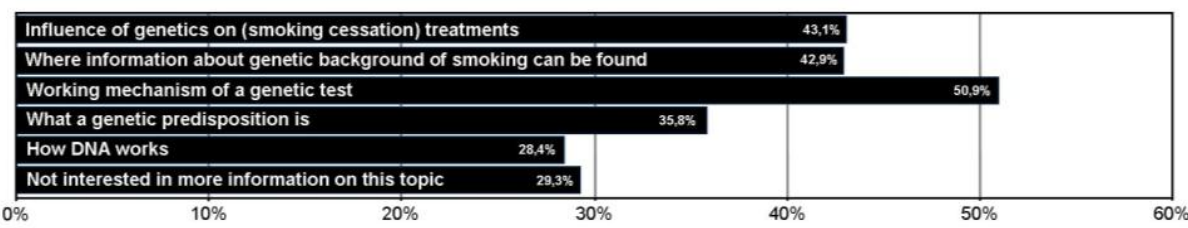

Figure S5-A: Topics of interest



Figure S5-B: Channels of interest for obtaining more information

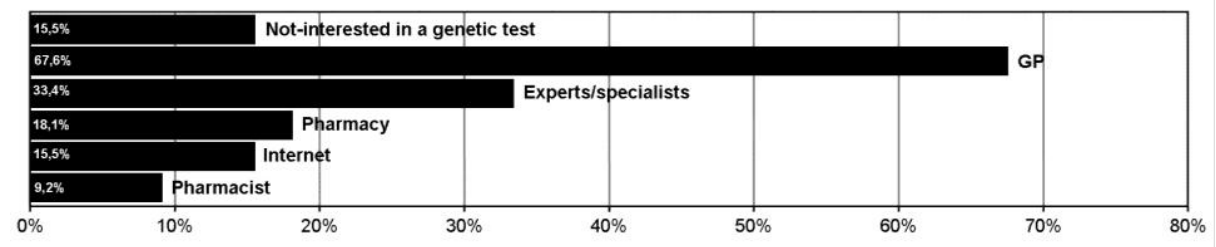

Figure S5-C: Channels of interest for obtaining a genetic test 


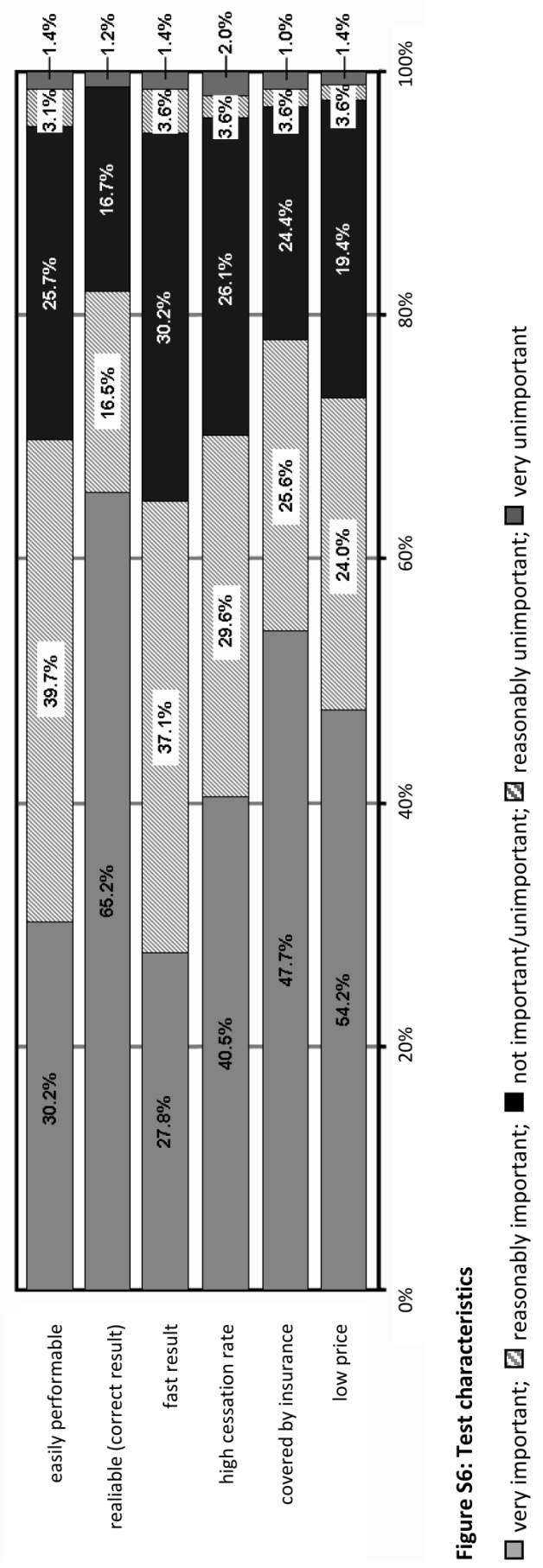


Table S5: Smoking cessation activities by GPs and/or at the practice they work (\%)

\begin{tabular}{lcccc}
\hline & never & sometimes & regularly & always \\
\hline $\begin{array}{l}\text { Do you ask your patients during a consult about their } \\
\text { smoking status? }\end{array}$ & 0.0 & 16.9 & 78.9 & 4.2 \\
\hline $\begin{array}{l}\text { Do you advise your smoking patients during a visit to } \\
\text { quit smoking, even if they do not ask for it? }\end{array}$ & 1.4 & 14.1 & 63.4 & 21.1 \\
\hline $\begin{array}{l}\text { Do you prescribe medication (e.g. Champix, Zyban, } \\
\text { nicotine patch, nicotine gum) to patients who want to } \\
\text { quit smoking? }\end{array}$ & 1.4 & 26.8 & 60.6 & 11.3 \\
$\begin{array}{l}\text { Does the preference of the patient determine which } \\
\text { smoking cessation treatment you will prescribe? }\end{array}$ & 1.4 & 28.2 & 47.9 & 22.5 \\
\hline $\begin{array}{l}\text { Do you refer patients who want to stop smoking to a } \\
\text { smoking cessation program or an expert? }\end{array}$ & 2.8 & 34.3 & 41.4 & 22.4 \\
\hline $\begin{array}{l}\text { Is a trained staff member available at the practice you } \\
\text { work to advise patients who want to quit smoking? }\end{array}$ & 7.2 & 5.8 & 34.8 & 52.2 \\
\hline
\end{tabular}

Table S6: Attitudes towards ability to offer a genetic test (in general) and to deal with the results (\% of total)

\begin{tabular}{lccccc}
\hline & $\begin{array}{c}\text { completely } \\
\text { disagree }\end{array}$ & disagree & neutral & agree & $\begin{array}{c}\text { completely } \\
\text { agree }\end{array}$ \\
\hline $\begin{array}{l}\text { The available treatment time per patient is sufficient } \\
\text { to be able to offer a genetic test. }\end{array}$ & 2.9 & 20.3 & 47.8 & 26.1 & 2.9 \\
\hline $\begin{array}{l}\text { I have sufficient knowledge to be able to offer a } \\
\text { genetic test to my patients. }\end{array}$ & 29.6 & 43.7 & 22.5 & 4.2 & 0.0 \\
$\begin{array}{l}\text { I have sufficient knowledge to be able to understand } \\
\text { the results of a genetic test. }\end{array}$ & 19.7 & 35.2 & 29.6 & 14.1 & 1.4 \\
\hline $\begin{array}{l}\text { I have sufficient knowledge to be able to explain the } \\
\text { results of a genetic test to my patients. }\end{array}$ & 21.1 & 26.8 & 26.8 & 23.9 & 1.4 \\
\hline $\begin{array}{l}\text { I have sufficient knowledge to be able to prescribe the } \\
\text { right treatment based on the results of a genetic test. }\end{array}$ & 23.9 & 33.8 & 29.6 & 11.3 & 1.4 \\
\hline
\end{tabular}
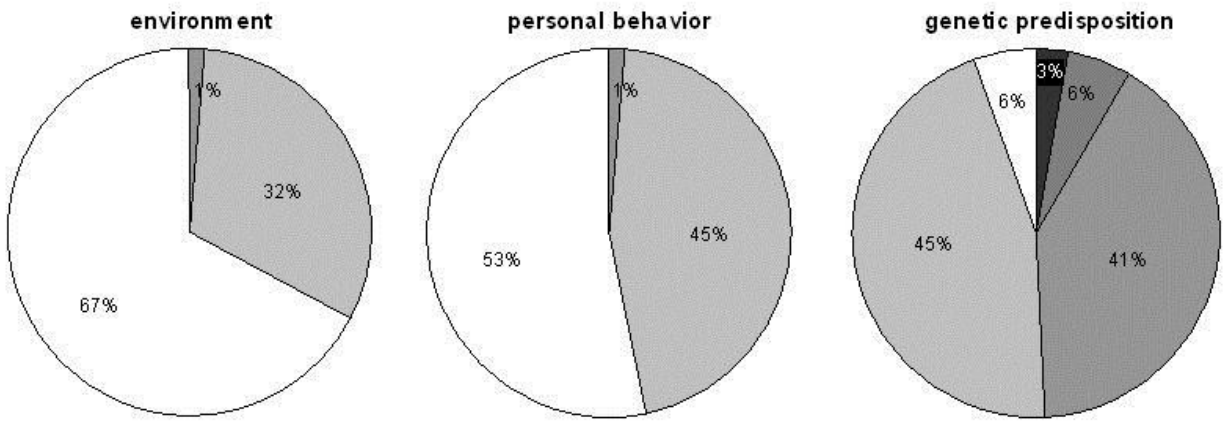

Figure S7: Perceived importance of environment, personal behavior and genetic predisposition as a cause of smoking

very unimportant; $\square$ unimportant; $\square$ not unimportant/important; $\square$ important; $\square$ very important 


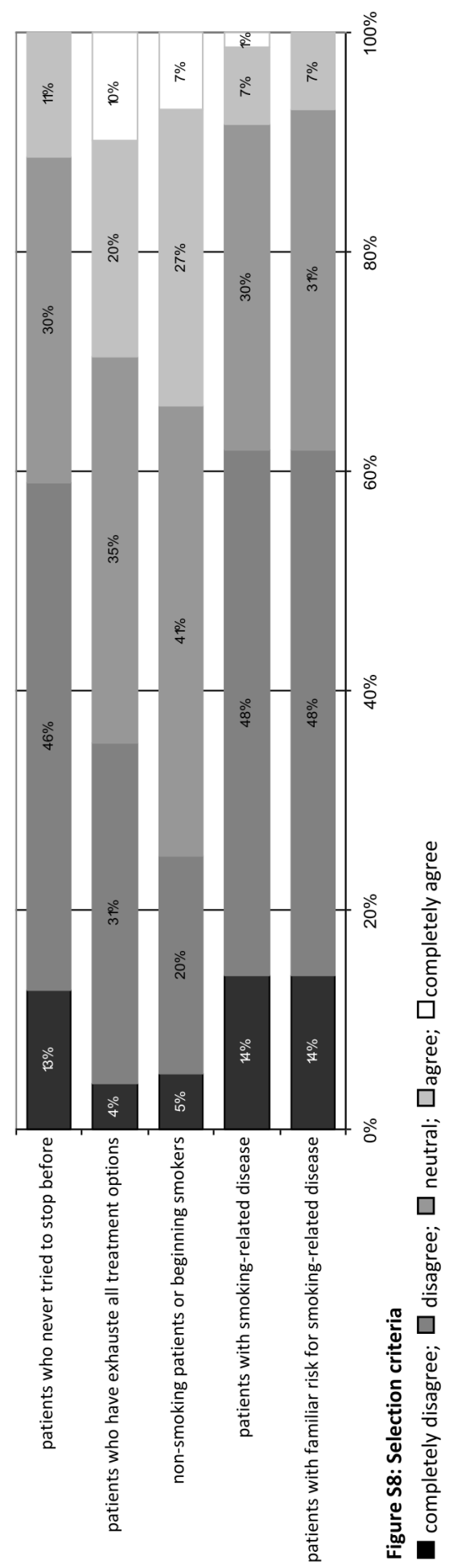


216 | SuPPLEMENTARY DATA - CHAPTER 9

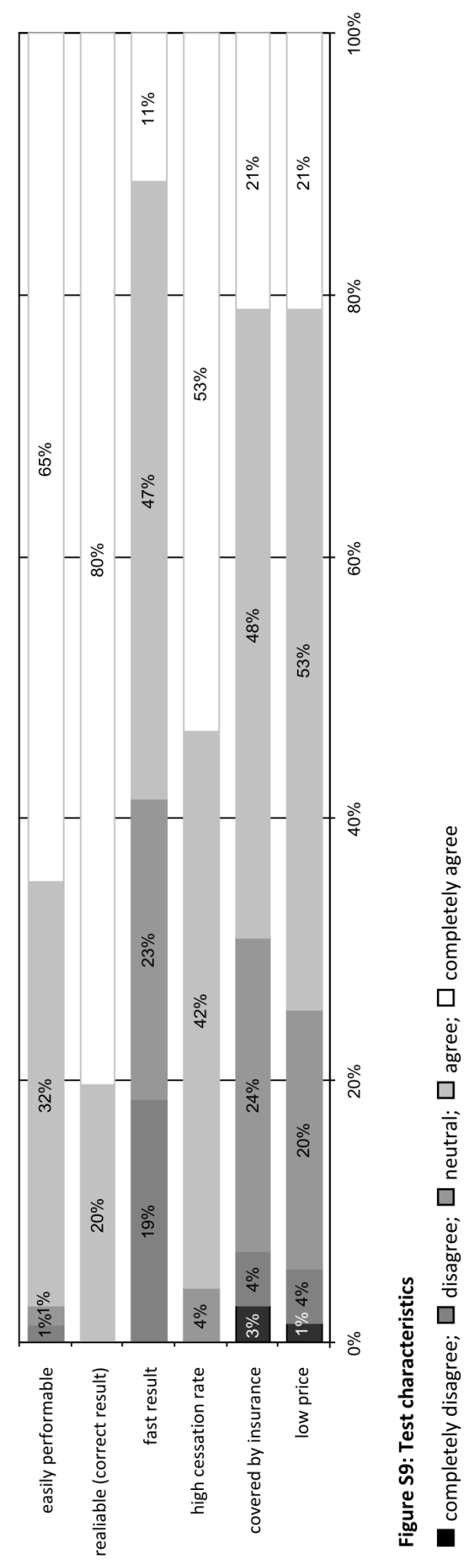




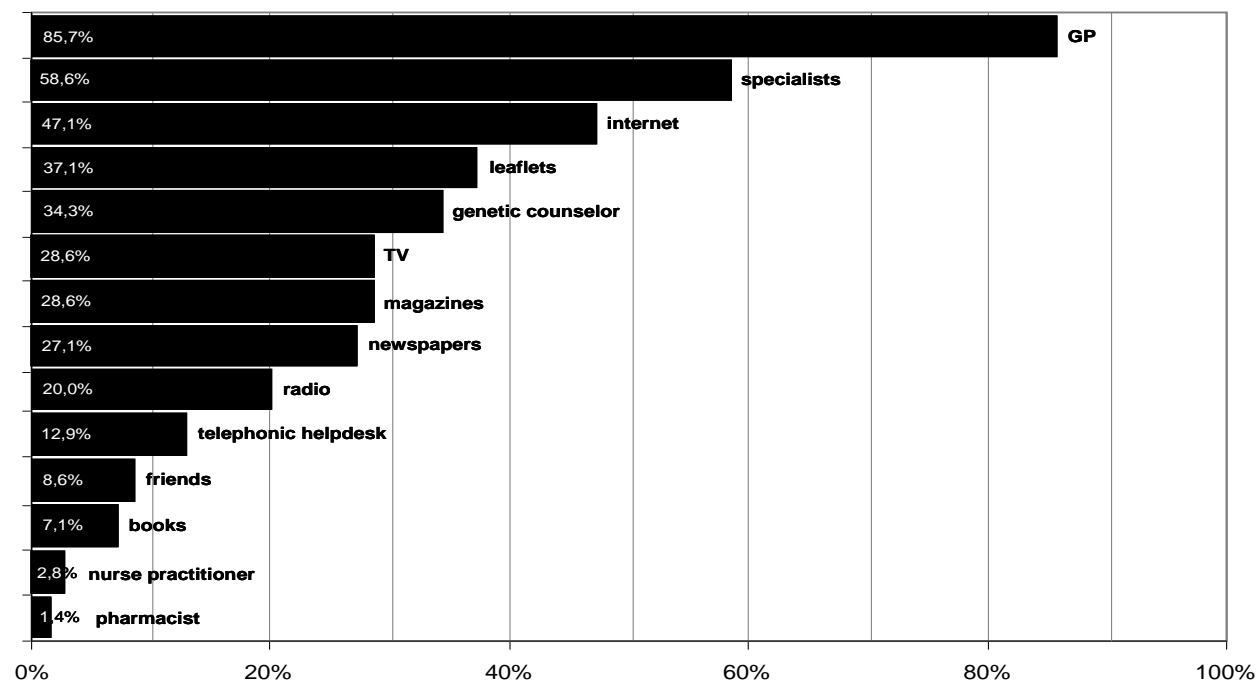

Figure S10-A: Channels of intrest for obtaining more information on a genetic test for smoking

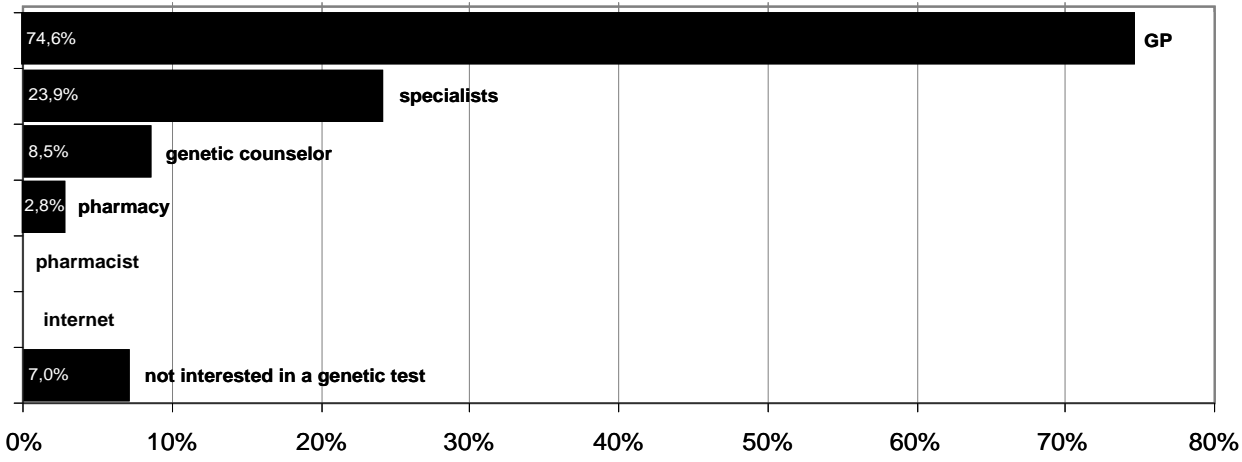

Figure S10-B: Channels of interest for obtaining a genetic test for smoking 



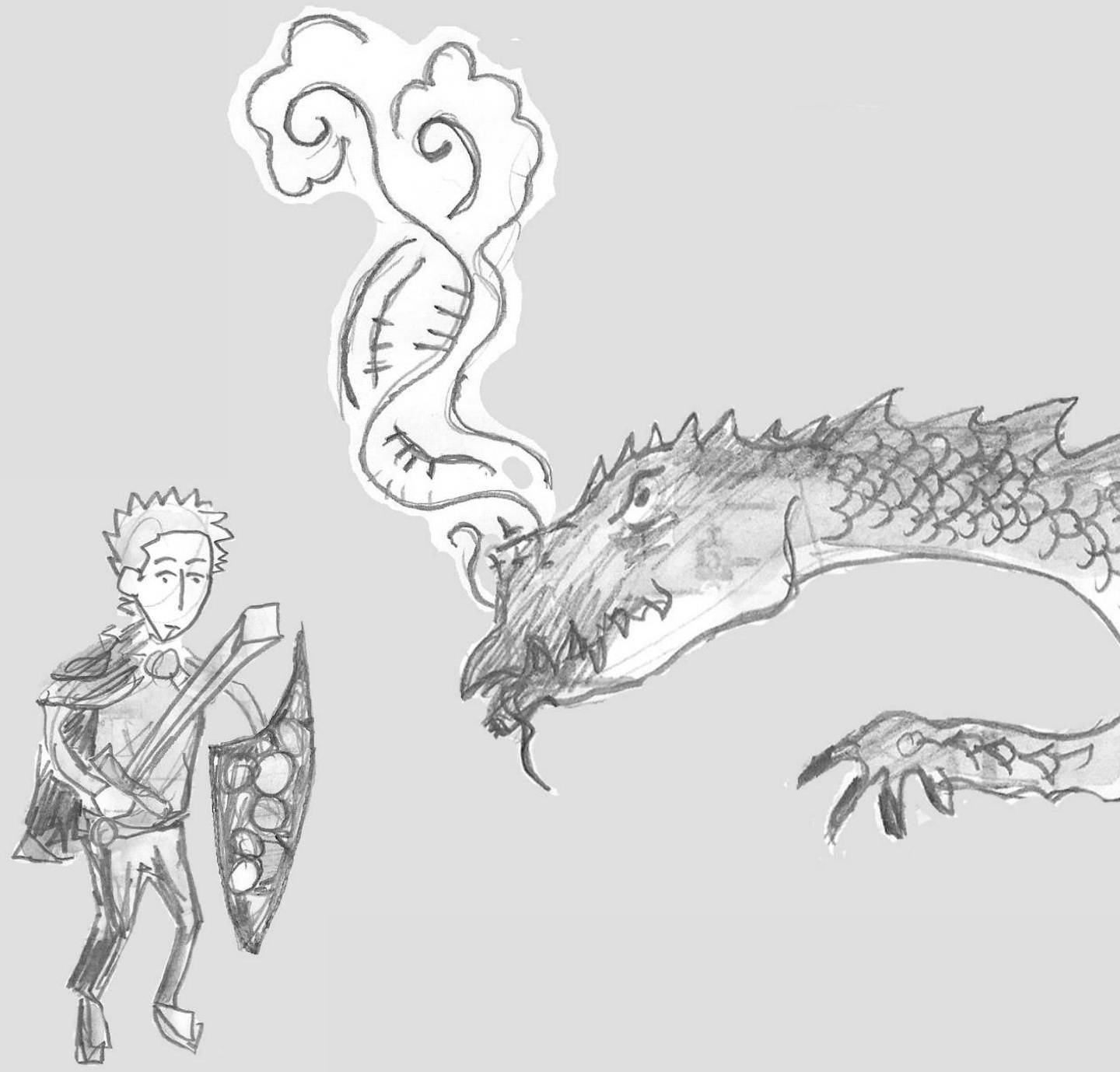

CURRICULUM VITAE

LIST OF PUBLICATIONS 


\section{CURRICULUM VITAE}

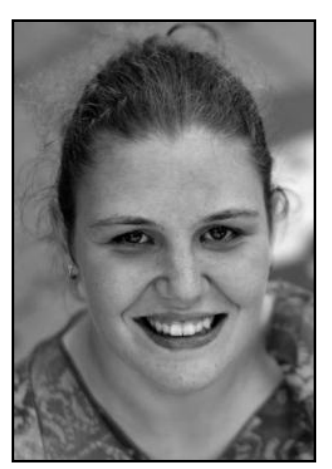

Marieke Quaak was born on February the 15th 1983 in Eindhoven, the Netherlands. After obtaining her gymnasium diploma at "Christiaan Huygens College" in Eindhoven, she started in 2001 her study "Biological Health Sciences" at Maastricht University. She graduated in 2005 on the project "LEU-KO study. Prospective, multi-centre study of infections and immunity in children with acute lymphoblastic leukaemia undergoing treatment according to the DCOG ALL-10 protocol" from the Wilhelmina Children's Hospital, Utrecht in cooperation with the St. Antonius Hospital, Nieuwegein. In this project she investigated the role of pathogen-associated recognition receptors (PPRs) from the innate immune system in the recognition of pathogen-associated molecular patterns (PAMPs) from microbes and tested several techniques for the determination of genetic variants in these PPRs. In September 2005 she started her master "Health Sciences Research Master" at Maastricht University and graduated Cum Laude in 2007. During her masters she wrote a literature review on the influence of genetic variation on smoking behavior and smoking cessation treatment, which was felt to be of outstanding education value by the European Respiratory Journal and selected for continuing medical education (CME) accreditation. Furthermore, during this master she wrote a research proposal entitled "Assessment of genetic variations as a predictor for of smoking cessation success: a promising preventive and intervention tool?" and applied for funding. The project was granted by the Netherlands Organisation for Health Research and Development (ZonMW) and the Care and Public Health Research Institute (CAPHRI), University Maastricht. In September 2007 she started as a PhD student at the Department of General Practice in cooperation with the Department of Toxicology (previously Department of Health Risk Analysis and Toxicology) on a project based on this proposal. In 2008 she was invited by the Royal Netherlands Academy of Arts and Sciences (KNAW) to become a student-member of the judging committee Research-masters (Bio)medical sciences, responsible for the evaluation of the re-accreditation of research masters. In 2008 she was a co-organizer of the "DNA Festival" at the museam Continium (previously Industrion) in Kerkrade, as part of the Oktober Kennismaand (October Knowledge month), comprising of various lab-activities involving DNA. Since 2009 she is the co-organizer of the yearly Kidzcollege "Je DNA maakt je uniek... en ziek" (Your DNA makes you unique... and ill) which is part of the Kids University, an information activity for children from the last grade of primary school organized yearly by the University of Maastricht. In 2009 the obtained a travel grant by the Society of Toxicology (NVT) for attendance of the $10^{\text {th }}$ International Conference on Environmental Mutagens in Florence Italy. In 2010 she obtained a PhD travel grant awarded by CAPHRI for visiting the Finnish Institute of Occupation Health and the University of Helsinki, Finland. In 2011 the attended the 2011 SOT Annual Meeting in Washington D.C., USA, with a travel grant from the NVT and the Society for Reseach on Nicotine and Tobacco (SRNT) $17^{\text {th }}$ Annual Meeting in Toronto, Canada, with a NCI (National Cancer Institute) travel award. In 2012, Marieke acquired a CAPHRI post-doc grant that enables her to continue her research activities in the field of smoking cessation (pharmaco)genetics. 


\section{LIST OF PUBLICATIONS}

Quaak M, van Schayck CP, Knaapen AM, van Schooten FJ. Implications of gene-drug interactions in smoking cessation for improving the prevention of chronic degenerative diseases. Mutat Res. 2009; 667(1-2):44-57. Epub 2008 Nov 5. Review.

Quaak M, van Schayck CP, Knaapen AM, van Schooten FJ. Genetic variation as a predictor of smoking cessation success. A promising preventive and intervention tool for chronic respiratory diseases? Eur Respir J. 2009; 33(3):468-80. Review. (CME accreditation)*

Quaak M, van Schayck CP, Postma DS, Wagena EJ, van Schooten FJ. Genetic variants in the serotonin transporter influence the efficacy of bupropion and nortriptyline in smoking cessation. Addiction. 2012; 107(1):178-187. Epub 2011 Sep 21.

Quaak M, van Schayck CP, Postma DS, Kotz D, Wagena EJ, Hoogsteder P, van Schooten FJ. Multiple genetic variants influence nicotine dependence. [Submitted]

Quaak M, van Schayck CP, Postma DS, Kotz D, Wagena EJ, Hoogsteder P, van Schooten FJ. Different aspects of nicotine dependence are influenced by genetic variants in distinct pathways [Submitted]

Quaak M, van Schayck CP, Postma DS, Wagena EJ, van Schooten FJ. Influence of genetic variants in smoking-related pathways on antidepressant therapy. [in preparation]

Quaak M, Smerecnik C, van Schooten FJ, de Vries H, van Schayck CP. Knowledge, attitudes, and preferences regarding genetic testing for smoking cessation. A cross-sectional survey among Dutch smokers. BMJ Open. 2012; 2: e000321. Print 2012.

Quaak M, Smerecnik C, van Schooten FJ, de Vries H, van Schayck CP. GPs' knowledge, attitudes and preferences regarding genetic testing for smoking. [in preparation]

\section{ADDITIONAL PUBLICATIONS}

Smerecnik C, Quaak M, van Schayck CP, van Schooten FJ, de Vries H. Are smokers interested in genetic testing for smoking addiction? A socio-cognitive approach. Psychol Health. 2011; 26(8): 1099-1112. Epub 2011 Jun 28.

Smerecnik C, Grispen JEJ, Quaak M. Effectiveness of testing for genetic susceptibility to smoking-related diseases on smoking cessation outcomes: A systematic review and meta-analysis. Tob Control. 2011 Sep 26. [Epub ahead of print] 